\title{
Detecção computacional de assimetrias entre mamogramas
}

\author{
Ricardo José Ferrari
}

Tese apresentada à Escola de Engenharia de São Carlos da Universidade de São Paulo, como parte dos requisitos para obtenção do título de Doutor em Engenharia Elétrica

orientadora: Profa. Dra. Annie France Frère 
Aos MEUS PAIS, pelos esforços, compreensão e apoio dados em todas as etapas da minha vida.

À LUCIANA, minha esposa, por ter me ajudado tanto durante todo o meu mestrado e doutorado, pelo seu amor, amizade e principalmente por estar sempre presente. 


\section{Agradecimentos}

À Profa. Dra. Annie France Frère, orientadora desse trabalho de tese. Muito obrigado pela confiança depositada em mim.

Ao Prof. Dr. Rangaraj M. Rangayyan, por ter me recepcionado muitíssimo bem em Calgary, e pelas oportunidades que me deu em seu laboratório.

Ao Dr. J.E. Leo Desautels, radiologista do Alberta Cancer Board, Canadá, e à Profa. Dra. Rejane A. Borges, radiologista da Mogimagem e professora da Universidade de Mogi das Cruzes, pela fundamental participação na elaboração do protocolo de avaliação e análise dos resultados.

Aos Prof. Dr. Nelson D.A. Mascarenhas e Prof. Dr. André C.P.L.F. de Carvalho, por estarem sempre dispostos a ajudar.

À Hilary Alto, Naga Mudigonda e Caroline, por toda a ajuda e atenção durante minha estada em Calgary - Canadá.

Aos colegas do laboratório Aladim e do laboratório de Mogi das Cruzes, por toda a ajuda durante meu doutorado.

Aos colegas do grupo de SVM, pelas discussões e seminários apresentados.

Ao amigo Papão (Arlindo), pelas discussões e questionamentos sempre pertinentes sobre processamento de sinais e imagens, e aos amigos Elvis (Heber) e Pacato (Everaldo), por toda ajuda e também pelos cafés.

Aos amigos Liz e Gerry, pela ajuda que estão me dando, apesar da distância.

Ao Mônaco, pelo arquivo de estilo LTEX usado na elaboração dessa tese.

Meus agradecimentos a todos os funcionários do Departamento de Engenharia Elétrica, em especial a Marisa e a Rosane.

À todos meus familiares, pelo apoio durante todos esses anos.

À FAPESP, por ter me concedido minha bolsa de estudos e reserva técnica durante todo o tempo que estive no Brasil. 
À CAPES, por ter me concedido a bolsa de estudos para a realização do estágio no exterior (doutorado sanduíche). 


\section{Conteúdo}

Lista de Figuras viii

Lista de Tabelas $\quad$ xvi

Lista de Abreviaturas e Siglas $\quad$ xviii

Resumo $\quad$ xx

$\begin{array}{ll}\text { Abstract } & \text { xxii }\end{array}$

1 Introdução 1

1.1 A mamografia como método de diagnóstico do câncer de mama . 2

1.2 Programa de prevenção do câncer de mama . . . . . . . . . . . . 3

1.3 Principais indicadores do câncer de mama . . . . . . . . . . . . . 6

1.3.1 Agrupamento de microcalcificações . . . . . . . . . . . . 6

1.3.2 Nódulos ou massas . . . . . . . . . . . . . . . . . . 7

1.3.3 Distorções do parênquima mamário . . . . . . . . . . . . 8

1.4 Processo de análise dos mamogramas . . . . . . . . . . . . . . . . 9

1.5 Sistemas de diagnóstico auxiliado por computador em mamografia 11

1.6 Organização desta tese . . . . . . . . . . . . . . . . . . . . . 13

2 Objetivos e justificativas desta pesquisa $\quad \mathbf{1 5}$

2.1 Objetivos . . . . . . . . . . . . . . . . . . 15

2.2 Justificativas . . . . . . . . . . . . . . . . . . . . 15

$\begin{array}{llr}3 & \text { Estado da arte } & 17\end{array}$

3.1 Detecção de densidades assimétricas . . . . . . . . . . . . . . . 18

3.2 Detecção de distorções na arquitetura da mama . . . . . . . . . . 26 
3.3 Conclusões da revisão bibliográfica . . . . . . . . . . . . . . . . . 29

4 Base de dados e programas 31

4.1 Base de dados . . . . . . . . . . . . . . . . . . . . . . 31

4.2 Programas utilizados . . . . . . . . . . . . . . . . . . 32

4.3 Validação dos programas desenvolvidos . . . . . . . . . . . . . 32

5 Segmentação anatômica de mamogramas 34

5.1 Identificação da borda da mama . . . . . . . . . . . . . . . . . 34

5.1.1 Correção de contraste da margem da mama . . . . . . . 35

5.1 .2 Limiarização da imagem . . . . . . . . . . . . . . . . . . . 38

5.1.3 Remoção de espúrios através do operador morfológico de abertura .................... 39

5.1.4 Modelo discreto de contorno ativo . . . . . . . . . . . . 40

5.2 Identificação do músculo peitoral . . . . . . . . . . . . . . 47

5.2.1 Método 1: Detecção através da transformada de Hough . 48

5.2.2 Método 2: Detecção através de Gabor wavelets . . . . . . 52

5.3 Detecção do disco fibro-glandular . . . . . . . . . . . . . . . . 59

5.3.1 Modelo de densidades da mama . . . . . . . . . . . 60

5.3.2 Modelo basedo na mistura finita de gaussianas . . . . . 61

5.3 .3 Detecção do disco fibro-glandular . . . . . . . . . . 63

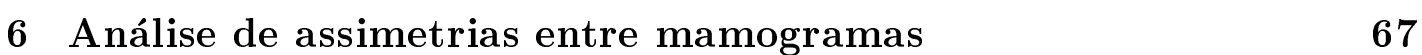

6.1 Análise de assimetrias com base em informações direcionais . . . 68

6.1.1 Região de interesse . . . . . . . . . . . . . . . 68

6.1.2 Procedimento de análise de componentes direcionais . . . 69

6.1.3 Ajuste dos parâmetros da representação . . . . . . . . . . 69

6.1.4 Representação de informações direcionais através de diagramas de Rosa . . . . . . . . . . . . . . . . . 70

6.1.5 Extração de atributos direcionais . . . . . . . . . . . . 71

6.2 Análise de assimetrias com base no modelo de densidades . . . . 73

6.2.1 Extração de atributos de forma e densidade . . . . . . . . 74

6.3 Normalização dos atributos . . . . . . . . . . . . . . . . . 76

6.4 Seleção de atributos . . . . . . . . . . . . . . . . . 76

6.5 Classificação . . . . . . . . . . . . . . . . . . 78 
7 Protocolo usado na avaliação dos resultados $\quad 80$

7.1 Avaliação dos resultados da segmentação dos mamogramas . . 80

7.2 Avaliação dos resultados de análise de assimetrias . . . . . . . . . 82

8 Resultados obtidos e discussões $\quad 83$

8.1 Segmentação de mamogramas . . . . . . . . . . . . . . . 84

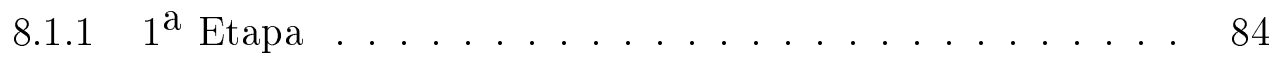

$8.1 .22^{\mathrm{a}}$ Etapa ...................... 85

8.1.3 Conclusões parciais . . . . . . . . . . . . . . . 94

8.2 Detecção de assimetrias entre mamogramas . . . . . . . . . . . . 95

8.2.1 $1^{\mathrm{a}}$ Etapa . . . . . . . . . . . . . . 95

$8.2 .22^{\mathrm{a}}$ Etapa ....................... 104

8.2 .3 Conclusões parciais . . . . . . . . . . . . . 118

9 Conclusões Finais $\quad 120$

9.1 Conclusões . . . . . . . . . . . . . . . . . . . . . 120

9.2 Sumário de contribuições . . . . . . . . . . . . . . . . . . . . . . 122

9.3 Publicações relacionadas a essa tese . . . . . . . . . . . . . . . 122

9.4 Propostas para trabalhos futuros . . . . . . . . . . . . . . 123

A Gabor wavelets

A.1 Estudos neurofisiológicos e o processo de decomposição das imagens 125

A.2 Breve introdução à teoria de Wavelets . . . . . . . . . . . . . 126

A.3 Função de Gabor como wavelet-mãe . . . . . . . . . . . . . . . 128

A.4 Representação Gabor wavelets usada neste trabalho . . . . . . . 129

A.5 Redução de redundâncias através da aplicação da transformada de Karhunen-Loève ． . . . . . . . . . . . . . . . . . . . . . . . . 134

A.6 Eliminação de espúrios através da técnica de limiarização de Otsu 137

A.7 Soma vetorial das imagens filtradas . . . . . . . . . . . . . . . 138

$\begin{array}{ll}\text { B Os algoritmos EM e DAEM } & 140\end{array}$

B.1 Estimativa por máxima-verossimilhança a partir de dados incompletos ........................ 140

B.2 Algoritmo EM . . . . . . . . . . . . . . . . . 141

B.3 Algoritmo DAEM baseado na f.d.p. a posteriori parametrizada . 144 
B.4 Estimativa da densidade da mistura de gaussianas através dos algoritmos EM e DAEM . . . . . . . . . . . . . . . . . 147

\section{Bibliografia}




\section{Lista de Figuras}

FIGURA 1.1 Desenho esquemático indicando como são obtidas as projeções mamográficas CC, ML e MLO. . . . . . . . . . . . . 4

FIGURA 1.2 Regiões contendo agrupamentos de microcalcificações extraídos de diferentes mamogramas. (a) Agrupamento associado a um tumor benigno. (b) Agrupamento associado a um tumor maligno. 7

FIGURA 1.3 Regiões de interesse contendo exemplos de massas. (a) caso benigno - forma arredondada e margens bem definidas. (b) caso maligno - forma e margens irregulares (tumor infiltrante).

FIGURA 1.4 Exemplos de distorções na arquitetura da mama causadas pela presença de massas malignas próximas a pele da mama.

FIGURA 5.1 Diagrama de blocos ilustrando os estágios usados pelo método de identificação da borda da mama. . . . . . . . . . . . . 36

FIGURA 5.2 Resultados de cada um dos estágios do método de identificação da borda da mama. (a) Imagem original (mdb042 da base de dados Mini-MIAS [SUCKLING et al. (1994)]). (b) Imagem original após operação logarítmica. (c)-(d) Imagem binária antes e depois da aplicação do operador morfológico "abertura". (e) Contorno inicial usado pelo modelo de contorno ativo proposto. (f) Borda final. . . . . . . . . . . . . . . . 38 
FIGURA 5.3 Aplicação da direção do gradiente para evitar que o contorno seja atraído para objetos próximos à borda verdadeira. (a) e (c) são as imagens originais mdb006 e mdb042, respectivamente, da base de dados Mini-MIAS [SUCKLING et al. (1994)]. (b) e (d) mostram os detalhes da borda da mama detectada corretamente mesmo estando próxima à marcas de identificações das projeções.

FIGURA 5.4 Exemplo da aplicação da restrição de curvatura usada pelo modelo de contorno ativo para a correção de efeitos de quinas. (a) Imagem original focalizando a região analisada. (b) e (c) mostram os detalhes do contorno da mama com e sem o uso da restrição, respectivamente. . . . . . . . . . . . . . . . . 46

FIGURA 5.5 Pontos de controle determinados automaticamente e utilizados para delimitar a ROI usada na detecção do músculo peitoral. Coincidentemente, neste caso N5=N6. . . . . . . . . . . . 49

FIGURA 5.6 Coordenadas usadas para o cálculo da transformada de Hough. . . . . . . . . . . . . . . . . . . . . 50

FIGURA 5.7 Diagrama de blocos do procedimento de identificação do músculo peitoral através da transformada de Hough. . . . . . . . 51

FIGURA 5.8 (a)-(b) Imagem original mdb028 e a respectiva ROI usada na determinação do músculo peitoral. . . . . . . . . . . . . . 52

FIGURA 5.9 Banco de filtros de Gabor projetado no domínio da freqüência. Cada elipse representa uma faixa de resposta de um determinado filtro, com valores de magnitude ao quadrado no intervalo de 0.5 a 1.0. A amostragem do espectro de freqüências pode ser ajustada através da modificação dos parâmetros $U_{l}, U_{h}, S$, e $K$ da representação. Apenas os filtros em destaque foram usados para realçar estruturas lineares presentes na região de interesse. . . . . 54 
FIGURA 5.10 (a) Pequena região indicada na Figura 5.8(a) contendo uma parte da linha do músculo peitoral. As imagens (b) e (c) mostram o mapa de fluxo de gradientes de bordas antes e depois da propagação do fluxo. . . . . . . . . . . . . . . . . 56

FIGURA 5.11 Resultado de cada estágio do método proposto para a detecção da borda do músculo peitoral. (a) Região de interesse usada para pesquisar a borda do músculo. (b) Imagem de magnitude resultante após a aplicação da representação Gabor wavelets seguida por soma vetorial. (c)-(d) Imagens resultantes antes e depois do estágio de pós-processamento. (e) Borda final indicada na imagem original. . . . . . . . . . . . . . . . . . 57

FIGURA 5.12 Diagrama de blocos do procedimento proposto para a detecção do músculo peitoral. . . . . . . . . . . . . . . 58

FIGURA 5.13 (a) Região efetiva da imagem mamográfica da Figura 5.2(a) usada para exemplificar o modelo de densidades proposto. (b) Histograma da imagem e componentes da mistura. (c) Histograma da imagem e função densidade de probabilidade da mistura. (d) Imagem contendo $K$-níveis, resultante da aplicação do método DAEM. (e) Disco fibro-glandular obtido após limiarização. . . . .

FIGURA 6.1 Imagem original e respectivo diagrama de rosa obtido pelo método descrito no Apêndice A. . . . . . . . . . . . . . 71

FIGURA 6.2 Exemplo de distribuições onde o componente principal não é útil para a classificações dos dados. . . . . . . . . . . . . .

FIGURA 7.1 Imagem mdb042 da base de dados Mini-MIAS indicando os contornos da borda da mama e do músculo peitoral marcados manualmente e verificados pelo radiologista. . . . . . . . . . 
FIGURA 8.1 Resultados obtidos para a imagem mdb003, a qual, de acordo com a base de dados Mini-MIAS é caracterizada essencialmente por tecidos glandulares. (a) Imagem original. (b) Contornos manuais (imagem equalizada). (c) Bordas da mama e do músculo peitoral. (d) Disco fibro-glandular. . . . . . . . . . . . . 86

FIGURA 8.2 Resultados obtidos para a imagem mdb008, a qual, de acordo com a base de dados Mini-MIAS é caracterizada essencialmente por tecidos adiposos. (a) Imagem original. (b) Contornos manuais (imagem equalizada). (c) Bordas da mama e do músculo peitoral. (d) Disco fibro-glandular. . . . . . . . . . . .

FIGURA 8.3 Resultados obtidos para a imagem mdb150, a qual, de acordo com a base de dados Mini-MIAS é caracterizada essencialmente por tecidos adiposos. (a) Imagem original. (b) Contornos manuais. (c) Bordas da mama e do músculo peitoral. (d) Disco fibro-glandular.

FIGURA 8.4 Imagens mdb037 (superior) e mdb068 (inferior) apresentando problemas na segmentação da borda da mama. (a) e (c) são as imagens contendo os contornos demarcados manualmente com a supervisão do radiologista. (b) O contorno não detectou corretamente a borda da mama devido a presença de um espúrio na imagem (linha horizontal na parte superior da imagem). (d) $\mathrm{O}$ contorno inicial não convergiu corretamente para a borda da mama devido a atração exercida pela região glandular densa presente na mama.

FIGURA 8.5 (a) Imagem mdb112 contendo as demarcações manuais dos contornos. (b) Resultado do método de segmentação. Neste caso, o músculo peitoral foi subestimado, gerando uma alta taxa de pixels $\mathrm{FN}$ : $\mathrm{FP}=2.33 \% ; \mathrm{FN}=16.21 \%$. . . . . . . . 
FIGURA 8.6 Imagem mdb110 mostrando o resultado da detecção do músculo peitoral na presença do músculo peitoral menor. (a) Bordas candidatas após o estágio de pós-processamento. (b) Borda final detectada. . . . . . . . . . . . . . . . . . . 92

FIGURA 8.7 Resultados da classificação dos resultados da segmentação do disco fibro-glandular pelo radiologista. Cada categoria apresentada no gráfico é descrita em detalhes no Capítulo 7 - Seção 7.1

FIGURA 8.8 Imagens mdb043 e mdb044 de um caso normal. (a) e (b) imagens originais $(1024 \times 1024$ pixels $)$. (c) e (d) Discos fibroglandulares segmentados e ampliados $(512 \times 512$ pixels $)$. Os discos fibro-glandulares foram equalizados apenas para efeito de visualização. . . . . . . . . . . . . . . . . . 96

FIGURA 8.9 Imagens mdb119 e mdb120 de um caso de distorção de arquitetura. (a) e (b) imagens originais $(1024 \times 1024$ pixels $) . \quad(c)$ e (d) Discos fibro-glandulares segmentados e ampliados $(512 \times$ 512 pixels). Os discos fibro-glandulares foram equalizados apenas para efeito de visualização. . . . . . . . . . . . . . . . . . . 97

FIGURA 8.10 As imagens (a), (b), (c) e (d) indicam, respectivamente, os $1^{\mathrm{O}}, 2^{\mathrm{O}}, 3^{\mathrm{O}}$ e $4^{\mathrm{O}}$ componentes resultantes da aplicação da transformada KL aplicada às respostas dos filtros com orientação de $135^{\circ}$ para a imagem mostrada na Figura $8.9(\mathrm{~d})$. Os autovalores dos quatro componentes indicados acima são: $\lambda_{1}=10.804568$, $\lambda_{2}=0.886360, \lambda_{3}=0.093959$, e $\lambda_{4}=0.013048$. O contraste das imagens foram igualmente corrigidos para melhor visualização. . . 98 
FIGURA 8.11 Resultados obtidos para o caso normal da Figura 8.8. (a) e (b) imagens de magnitude. (c) e (d) imagens de fase. (e) e (f) diagramas de rosa dos resultados em (c) e (d), respectivamente. As imagens de magnitude e fase foram equalizadas para melhor visualização. Os diagramas de rosa foram rotacionados de maneira a coincidirem com a orientação dos mamogramas. . . . . . . . . . 100

FIGURA 8.12 Resultados obtidos par um caso de distorção de arquitetura da Figura 8.9. (a) e (b) imagens de magnitude. (c) e (d) imagens de fase. (e) e (f) diagramas de rosa dos resultados em (c) e (d), respectivamente. As imagens de magnitude e fase foram equalizadas para melhor visualização. Os diagramas de rosa foram rotacionados de maneira a coincidirem com a orientação dos mamogramas. . . . . . . . . . . . . . . . . . . . 101

FIGURA 8.13 Distribuições das combinações entre os atributos $\left(M_{1}\right.$, $M_{2}$, e $H$ ) extraídos dos diagramas de rosa para o processamento de 40 casos. . . . . . . . . . . . . . . . . . . . . 102

FIGURA 8.14 (a)-(b) Imagens mdb003 e mdb004 classificadas como um caso normal. (c)-(d) Imagens mdb081 e mdb082 classificadas como contendo uma densidade assimétrica. . . . . . . . . . . . . 108

FIGURA 8.15 Resultados da segmentação dos discos fibro-glandulares das imagens mdb003 e mdb004 (caso normal) indicadas na Figura 8.14(a)-(b). (a)-(b) Imagens $K$-níveis resultantes do método de segmentação do disco fibro-glandular. (c)-(d) Discos fibroglandulares segmentados. . . . . . . . . . . . . . . . . . 109

FIGURA 8.16 Resultados da segmentação dos discos fibro-glandulares das imagens mdb081 e mdb082 (caso assimétrico) indicadas na Figura 8.14(c)-(d). (a)-(b) Imagens $K$-níveis resultantes do método de segmentação do disco fibro-glandular. (c)-(d) Discos fibroglandulares segmentados. . . . . . . . . . . . . . . . . . 111 
FIGURA 8.17 (a) Distribuição dos dados para os três primeiros componentes principais. (b) Distribuição dos dados para os três melhores componentes principais selecionados pelo classificador linear de Bayes.

FIGURA 8.18 (a) Distribuição dos dados para os três primeiros componentes principais. (b) Distribuição dos dados para os três melhores componentes principais selecionados pelo classificador linear de Bayes.

FIGURA A.1 Exemplos de Gabor wavelets projetadas no domínio espacial com quatro orientações $\left(\theta=0^{\circ}, 45^{\circ}, 90^{\circ}\right.$, e $\left.135^{\circ}\right)$ e quatro escalas $\left(\sigma_{x}=11,5,2,1\right.$ e $\sigma_{y}=32,16,8,4$ pixels) diferentes. O tamanho de cada matriz imagem é de $121 \times 121$ pixels. . . . . . . 130

FIGURA A.2 Exemplos de filtros de Gabor projetados no domínio da freqüência. Cada elipse representa uma faixa de resposta de um filtro específico com magnitude ao quadrado variando de 0.5 a 1.0. Os gráficos (a), (b) e (c) ilustram três maneiras diferentes de amostrar o espectro de freqüências através da alteração dos parâmetros $U_{l}, U_{h}, S$ e $K$ da representação de Gabor. Os gráficos (a) e (b) representam, respectivamente, os bancos de filtros usados na análise de mamogramas e da imagem de teste usada para ilustrar o método propost

FIGURA A.3 Imagem de uma textura natural da base de dados WEBER (1977). . . . . . . . . . . . . . . . . . . 134

FIGURA A.4 Exemplo de um vetor $\bar{x}$ formado a partir de pixels correspondentes entre diferentes escalas, de uma mesma orientação. 
FIGURA A.5 As imagens (a)-(d) indicam, respectivamente, os primeiro, segundo, terceiro e quarto componentes, resultantes da aplicação da transformada KL aplicada às respostas dos filtros com orientação de $90^{\circ}$ para a imagem mostrada na Figura A.3. Os autovalores dos quatro componentes indicados acima são: $\lambda_{1}=$ 85.840935, $\lambda_{2}=36.408596, \lambda_{3}=11.485662$ e $\lambda_{4}=1.204247$. O contraste das imagens foram igualmente corrigidos para melhor visualização. . . . . . . . . . . . . . . . . . . . 136

FIGURA A.6 Exemplo da soma vetorial empregada neste trabalho para compor as imagens de magnitude e fase. Por simplicidade, apenas quatro componentes direcionais são ilustrados na figura. . . . . . . 138

FIGURA A.7 Imagens de magnitude e fase da imagem de teste da Figura A.3. As imagens foram equalizadas para melhor visualização.139 


\section{Lista de Tabelas}

TABELA 5.1 Lista e descrição dos parâmetros usados pelo modelo de contorno ativo. . . . . . . . . . . . . . . . . . 4

TABELA 7.1 Descrição das opções usadas pelo radiologista na avaliação dos resultados da segmentação do disco fibro-glandular.

82

TABELA 8.1 Resultados médios para a classificação dos casos normais e assimétricos através do classificador Bayesiano linear, usando os atributos $M_{1}, M_{2}$, e $H$ em todas as possíveis combinações. . . . . 104

TABELA 8.2 Resultados médios para a classificação dos casos normais e assimétricos através do classificador Bayesiano linear, usando os atributos $M_{1}, M_{2}$, e $H$ em todas as possíveis combinações. . . . . 105

TABELA 8.3 Melhores resultados para a classificação dos casos normais e assimétricos através do classificador Bayesiano linear, analisando todas as possíveis combinações dos atributos $\theta_{R}, s_{\theta}^{2}, M_{1}$, $M_{2}$, e $H . \ldots \ldots \ldots \ldots \ldots \ldots$

TABELA 8.4 Melhores resultados médios para a classificação dos casos normais e assimétricos através do classificador Bayesiano quadrático, analisando todas as possíveis combinações dos atributos $\theta_{R}, s_{\theta}^{2}, M_{1}, M_{2}$, e $H \ldots \ldots \ldots \ldots \ldots$ 
TABELA 8.5 Valores dos atributos de forma e densidade extraídos do caso normal; par de imagens mdb003 e mdb004. . . . . . . . . . . 107

TABELA 8.6 Valores dos atributos de forma e densidade extraídos do caso assimétrico; par de imagens mdb081 e mdb082 . . . . . . . . 110

TABELA 8.7 Melhores resultados médios da classificação dos casos normais e assimétricos através do classificador Bayesiano linear, analisando todas as possíveis combinações dos atributos de forma, área e densidade. . . . . . . . . . . . . . . . . . . . 112

TABELA 8.8 Melhores resultados médios da classificação dos casos normais e assimétricos através do classificador Bayesiano quadrático, analisando todas as possíveis combinações dos atributos de forma, área e densidade. . . . . . . . . . . . . . . . . . . . 112

TABELA 8.9 Relação de autovalores e as respectivas contribuições na formação da matriz de transformação linear da transformada KL. 113

TABELA 8.10 Melhores resultados médios para a classificação dos casos normais e assimétricos através do classificador Bayesiano linear, analisando todos os 7 componentes principais. . . . . . . . . . . 114

TABELA 8.11 Melhores resultados médios para a classificação dos casos normais e assimétricos através do classificador Bayesiano quadrático, analisando todos os 7 componentes principais. . . . . . . 114

TABELA 8.12 Relação de autovalores e as respectivas contribuições na formação da matriz de transformação linear da transformada KL. 116

TABELA 8.13 Melhores resultados da classificação dos casos normais e assimétricos usando 8 componentes principais e o classificador linear Bayesiano. . . . . . . . . . . . . . . . . . 116

TABELA 8.14 Melhores resultados para a classificação dos casos normais e assimétricos usando 8 componentes principais e o classificador quadrático Bayesiano. . . . . . . . . . . . . . 117 


\title{
Lista de Abreviaturas e Siglas
}

\author{
ACR American College of Radiology \\ ACS American Cancer Society \\ BIRADS Breast Imaging Reporting and Data System \\ CAD Computer-Aided Diagnosis \\ CC Crânio Caudal \\ CCD Coupled Charge Device \\ DAEM Deterministic Annealing Expectation Maximization \\ EM Expectation Maximization \\ FFT $\quad$ Fast Fourier Transform \\ FN False Negative \\ FP False Positive \\ FROC Free Response Operating Characteristics \\ IFFT Inverse Fast Fourier Transform \\ INCA Instituto Nacional de Câncer \\ KL Karhunen-Loève \\ MDCA Modelo Discreto de Contorno Ativo
}




$\begin{array}{ll}\text { MDL } & \text { Minimum Description Length } \\ \text { MLAS } & \text { The Mammographic Image Analysis Society } \\ \text { MLO } & \text { Médio Lateral Lateral Oblíqüa } \\ \text { MLP } & \text { Multi-Layer Perceptron } \\ \text { NCI } & \text { Nacional Cancer Institute } \\ \text { PCA } & \text { Principal Components Analysis } \\ \text { RNA } & \text { Rede Neural Artificial } \\ \text { ROI } & \text { Region of Interest } \\ \text { SA } & \text { Simulated Annealing } \\ \text { TP } & \text { True Positive }\end{array}$




\section{Resumo}

Neste trabalho foram propostas técnicas para a segmentação automática de mamogramas, e para a detecção de assimetrias entre mamogramas esquerdo e direito. A segmentação é realizada através de três técnicas computacionais para a identificação de três importantes regiões anatômicas nos mamogramas: borda da mama, músculo peitoral e disco fibro-glandular. O primeiro método focaliza à identificação da borda da mama através do uso de um modelo de contorno ativo especialmente projetado para esse propósito. Neste estágio, a borda da mama é automaticamente demarcada, todos os artefatos fora dessa região são eliminados, e a região de interesse usada para a detecção do músculo peitoral é definida. No próximo estágio, a borda do músculo peitoral é determinada usando uma técnica multiresolução baseada na representação Gabor wavelets. Finalmente, um modelo de densidades da mama, baseado no modelo da mistura finita de Gaussianas, é proposto para a representação de quatro categorias de tecidos mamários com diferentes densidades. O disco fibro-glandular é identificado através da aplicação de um limiar sob as classes de densidades determinadas no modelo. Os métodos propostos foram aplicados à 84 imagens de mamogramas de projeções médiolaterais oblíqüas da base de dados Mini-MIAS ("Mammographic Image Analysis Society", London, UK). A avaliação dos resultados dos procedimentos de segmentação da borda da mama e borda do músculo peitoral foi realizada com base no percentual de pixels falso-positivos (FPs) e falso-negativos (FNs) determinados por comparação entre os contornos verdadeiros e os contornos automaticamente identificados. As taxas médias de FPs e FNs para as bordas da mama e do músculo peitoral foram, respectivamente, de $0.41 \%$ e $0.58 \%$, e $1.78 \%$ e $5.77 \%$. 
A segmentação dos discos fibro-glandulares foi subjetivamente classificada por radiologistas e os resultados indicaram que em mais de $80 \%$ dos casos a segmentação foi considerada aceitável para o uso em sistemas de auxílio ao diagnóstico. A detecção de assimetrias foi realizada usando informações direcionais, obtidas a partir da representação multiresolução Gabor wavelets, e de informações de forma e densidade, extraídas dos discos fibro-glandulares dos mamogramas esquerdo e direito. No procedimento de análise direcional, uma representação wavelet formada por filtros de Gabor bidimensionais com variação em freqüência e orientação, especialmente projetados para reduzir a redundância na representação, é aplicada para uma dada imagem. As respostas dos filtros para diferentes escalas e orientações são analisadas através da transformada de Karhunen-Loève (KL) e pelo método de limiarização de Otsu. A transformada KL é aplicada para selecionar os componentes principais das respostas dos filtros, preservando apenas os elementos direcionais mais relevantes que aparecem em todas as escalas. Os componentes principais selecionados e limiarizados pela técnica de Otsu são usados para obter as imagens de magnitude e fase dos componentes direcionais da imagem. Medidas estatísticas extraídas dos diagramas de rosa calculados a partir das imagens de fase são usadas para a análise quantitativa e qualitativa dos padrões orientados. Um total de 11 atributos são também extraídos dos discos fibro-glandulares segmentados dos mamogramas esquerdo e direito, e a diferença calculada para cada par de atributos é usada como uma medida para a detecção de assimetrias. Um total de 88 imagens (22 casos normais, 14 casos de densidades assimétricas e 8 casos de distorção de arquitetura) da base de dados Mini-MIAS foram usadas para avaliar o método proposto. A combinação exaustiva dos atributos juntamente com a análise de componentes principais foram usadas para selecionar o melhor subgrupo de atributos. A classificação foi realizada através de classificadores de Bayes (linear e quadrático) e usando o método "leave-one-out". Uma taxa de classificação correta de $84.44 \%$ foi alcançada. 


\section{Abstract}

In this work, techniques are proposed for the automatic segmentation of mammograms and detection of asymmetries between left and right mammograms. The segmentation is performed by using three computational techniques for the identification of three important anatomical regions of mammograms: the skin - air boundary, the pectoral muscle, and the fibro-glandular disc. The first method focuses on the identification of the skin - air boundary by using an active contour model algorithm specially tailored for this purpose. In this stage, the skin - air boundary is demarcated, all artifacts outside the breast region are eliminated, and the region of interest for detection of the pectoral muscle is defined. In the next stage, the edge of the pectoral muscle is determined by using a multiresolution technique based upon a Gabor wavelets representation. Finally, a density breast model based upon a Gaussian mixture model is proposed for the representation of four categories of different density tissues in the breast. The fibro-glandular disc is identified by thresholding the density categories of the model. The methods proposed were applied to 84 images of medio-lateral oblique mammograms from the Mini-MIAS (Mammographic Image Analysis Society, London, U.K.) database. The evaluation of the skin - air boundary and the pectoral muscle edge were performed based upon the percentage of false-positive (FP) and false-negative (FN) pixels determined by comparison between the true contours and the contours automatically identified. The FP and FN average rates for the skin - air boundary and the pectoral muscle edge were, respectively, $0.41 \%$ and $0.58 \%$, and $1.78 \%$ and $5.77 \%$. The segmentation of the fibro-glandular disc was subjectively rated by two radiologists and the results indicate that in more than $80 \%$ of the cases, the seg- 
mentation was considered acceptable for a Computer Aided Diagnosis purposes. Detection of asymmetries is performed by using directional information, obtained from a multiresolution Gabor wavelets representation, and shape and density information, extracted from the fibro-glandular discs of left and right mammograms. In the directional procedure, a particular wavelet scheme with 2-D Gabor filters as elementary functions with varying tuning frequency and orientation, specifically designed in order to reduce the redundancy in the wavelet-based representation, is applied to the given image. The filter responses for different scales and orientation are analyzed by using the Karhunen-Loève (KL) transform and Otsu's method of thresholding. The KL transform is applied to select the principal components of the filter responses, preserving only the most relevant directional elements appearing at all scales. The selected principal components, thresholded by using Otsu's method, are used to obtain the magnitude and phase of the image directional components. Rose diagrams computed from the phase images and statistical measures computed thereof are used for quantitative and qualitative analysis of the oriented patterns. A total of 11 features are also extracted from the segmented fibro-glandular discs of left-right mammograms, and the difference of each feature pair is used as a measure for detecting asymmetries. A total of 88 images from 22 normal cases, 14 asymmetric cases, and 8 architectural distortion cases from the Mini-MIAS database were used to evaluate the scheme. An exaustive combination of the features along with the principal components analysis were used to select the best feature set. The classification was performed by using two Bayes' classifiers (linear and quadratic) and the leave-one-out methodology. Average classification accuracy up to $84.44 \%$ was achieved. 


\section{Capítulo 1}

\section{Introdução}

De acordo com o órgão americano "Nacional Cancer Institute" (NCI), o câncer de mama é a causa líder de morte em mulheres com idade entre 35 e 54 anos em muitos países no mundo. Outro órgão americano, o "American Cancer Society" (ACS), afirma que uma em cada 10 mulheres tem a probabilidade de desenvolver um câncer de mama durante a sua vida. Em 1999, segundo o mesmo órgão, 215.000 novos casos de câncer de mama foram diagnosticados nos Estados Unidos, e aproximadamente 43.000 mulheres morreram dessa doença.

No Brasil, de acordo com o Instituto Nacional de Câncer (INCA), o câncer de mama é a principal causa de mortes entre as mulheres na faixa etária de 35 a 54 anos. Em 1998, foram registrados 8.044 mortes decorrentes deste tipo de patologia. Dos 305.330 novos casos com previsão de serem diagnosticados em 2001, o câncer de mama será o principal a atingir a população feminina, sendo responsável por 31.590 novos casos.

Infelizmente até o momento, suas causas não foram ainda determinadas. Dessa forma, a deteç̧ão precoce e a remoção do tumor na fase inicial continua a ser, ainda hoje, a estratégia mais eficiente na redução da taxa de mortalidade dos pacientes [SCHNEIDER (2000)]. A falha na detecção precoce de sinais ou indicadores do câncer de mama pode resultar na progressão da doença desde estágios iniciais, nos quais o câncer está confinado à mama, até estágios mais avançados, 
em que houve metástase para outras partes do corpo. Em estágios avançados, o tratamento se torna mais caro e as chances de sobrevida da paciente são drasticamente diminuídas. Estatísticas efetuadas a partir de mulheres americanas diagnosticadas com câncer de mama mostram que as taxas de sobrevida em 5 anos estão geralmente em torno de $93 \%$ para os casos detectados em estágios iniciais, caindo para $72 \%$ em estágios intermediários e apenas $18 \%$ para estágios finais da doença [HOMER (1997)].

De acordo com SCHNEIDER (2000), a taxa de mortalidade de mulheres canadenses com câncer de mama têm diminuído desde 1986. Tal diminuição está associada a dois fatores principais: ao bom programa de rastreamento aplicado naquele país e na melhoria dos tratamentos disponíveis. Similares reduções têm sido relatadas também nos Estados Unidos, Inglaterra e Austrália, [GAUDETTE et al. (1997)]. Vários estudos apresentados na literatura indicam que programas de rastreamento podem alcançar reduções de até $30 \%$ na taxa de mortalidade de mulheres, [KARSSEMEIJER et al. (1998) - Seção "Clinical Impact of Digital Mammography].

\subsection{A mamografia como método de diagnóstico do câncer de mama}

Dentre os métodos de diagnósticos atualmente disponíveis (Ressonância Magnética, Tomografia Computadorizada, Ultra-sonografia, Mamografia, etc.), a mamografia continua sendo o método mais eficaz para a detecção precoce do câncer de mama. Isso porque ela ainda é o único método com os requisitos necessários à localização de lesões pequenas [DANCE (1996)]. O seu sistema tela-filme apresenta altas resoluções espaciais (grão do filme $\sim 0.003 \mathrm{~mm}$ ) e de contraste $(0 \mathrm{a}$ 4.0 OD - "optical density"), fundamentais no registro de microcalcificações, pequenos nódulos e variações de densidades. Cabe ressaltar que nos últimos anos têm havido também um avanço crescente no número de pesquisas na área de mamografia digital [DOI et al. (1996), KARSSEMEIJER et al. (1998), YAFFE 
(2000)]. Nesse tipo de técnica, o sistema de registro (tela-filme) é substituído por detectores digitais (tal como CCD - "charge coupled device") que, segundo os pesquisadores, são capazes de suprimir grande parte dos ruídos e de eliminar a resposta não-linear do filme.

No entanto, para que o uso de mamógrafos totalmente digitais possam ser usados na prática como método diagnóstico, muitos problemas precisam ainda ser solucionados. Alguns desses problemas envolvem o armazenamento da imagem digital, o tempo de carregamento e de "zoom" das imagens, a adequação de acessórios voltados à manipulação e visualização das imagens (mouse, track-ball, monitores de alta resolução). Outro fator polêmico envolvendo tais sistemas é a resolução espacial fornecida pelas atuais câmeras CCDs $(\sim 0.050 \mathrm{~mm})$ em comparação com filmes convencionais (grão do filme 0.003mm) [YAFFE (2000)].

Embora seja comprovado que a mamografia é a técnica atual mais eficaz para a detecção precoce do câncer de mama, 10 a 30\%, incluindo casos com tumores palpáveis, não são detectados na rotina mamográfica. Dois terços desses falsonegativos (FNs) são evidenciados através de uma revisão detalhada dos mamogramas anteriores. Esses falso-negativos são atribuídos a vários fatores, incluindo: baixa qualidade da imagem, complexidade do tipo de imagem, fadiga do radiologista e descuido humano [DOI et al. (1999)].

\subsection{Programa de prevenção do câncer de mama}

Em um programa de prevenção do câncer de mama ou rastreamento mamográfico ("Mammography Screening"), uma das primeiras etapas é a triagem dos mamogramas, separando os que não apresentam nenhum sinal de anormalidade dos que possuem algum tipo de sinal suspeito. Este último grupo é posteriormente analisado por 2 radiologistas e se necessário a paciente é submetida a um exame de biópsia para a confirmação da doença. Um exame mamográfico normal consiste de 4 mamogramas, sendo duas projeções para cada mama: a projeção crânio-caudal (CC) e a médio-lateral (ML) (ou médio-lateral oblíqua (MLO)). 


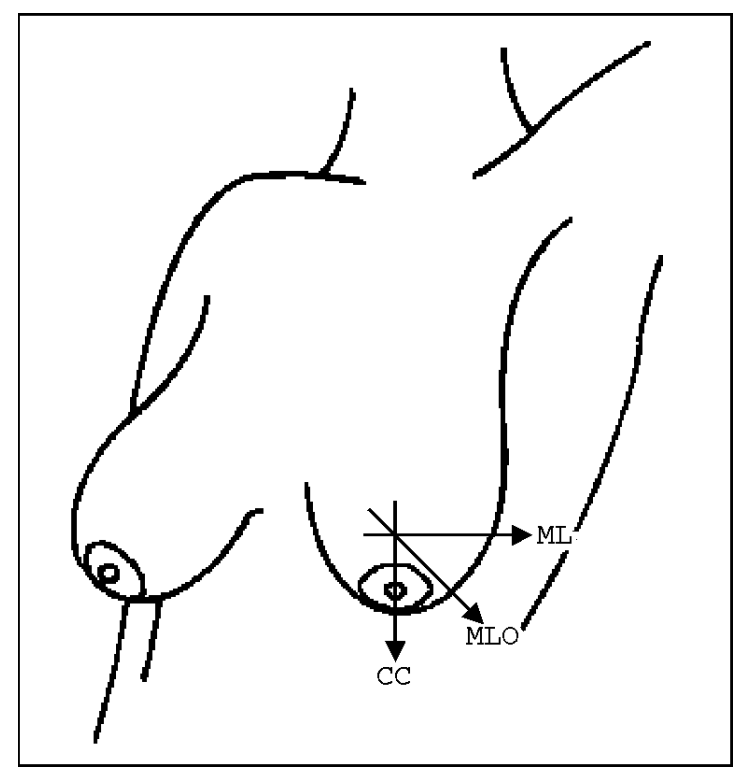

Figura 1.1: Desenho esquemático indicando como são obtidas as projeções mamográficas CC, ML e MLO.

A projeção MLO é uma projeção realizada a $45^{\circ}$ e em alguns programas têm efeito apenas de diagnóstico e não de prevenção. Entretanto, em algumas rotinas mamográficas, a projeção MLO é preferida ao invés da ML. A Figura 1.1 ilustra como são obtidas tais projeções mamográficas.

O sucesso de um programa de rastreamento de câncer de mama é bastante dependente do padrão de qualidade do processo. Um dos aspectos mais importantes é a realização da leitura do mamograma por radiologistas altamente especializados [SCHMIDT et al. (1998)]. A interpretação dos mamogramas é uma tarefa difícil devido a grande variabilidade da aparência dos tecidos normais e cancerosos, e também por causa da sutileza dos sinais indicadores de malignidade. Além disso, na rotina diária de um programa de rastreamento, os radiologistas normalmente analisam um número muito grande de mamogramas, sendo em sua maioria relativos a casos normais. O trabalho de interpretação é ainda maior devido ao desafio em aumentar a taxa de detecção precoce desse tipo de doença, mantendo-se um número mínimo de biópsias.

Considerando as altas taxas de incidência do câncer de mama e o prognóstico favorável associado à sua detecção precoce, é surpreendente que apenas 15 a $30 \%$ das mulheres em idade para participar de um programa de prevenção do câncer 
de mama tenham realizado apenas um único exame mamográfico [CARDENOSA (1997)]. Entre as razões para esse fato estão: o ceticismo sobre a confiabilidade do exame e o desconforto físico do processo de obtenção da imagem e diagnóstico.

Um dos principais problemas na implantação de um sistema de rastreamento do câncer de mama é o alto custo financeiro. Grande parte deste custo está relacionado à honorários médicos, uma vez que a interpretação dos mamogramas é difícil e por isso exige a presença de radiologistas experientes.

Dos mamogramas gerados, apenas $10 \%$ apresentam algum tipo de anormalidade. Devido ao grande número de casos analisados e da existência de uma enorme variação das estruturas de tecidos nas mamas, a inconsistência na leitura entre diferentes radiologistas ou mesmo por um único radiologista em diferentes épocas contribui significativamente para elevar os custos desse sistema. O baixo valor preditivo positivo ${ }^{1}$ desses programas, gerando um alto número de biópsias desnecessárias, é outro fator agravante [KOPANS (1992)].

Programas de rastreamento típicos têm registrado taxas de sensibilidade entre 30 e 95\% [KARSSEMEIJER et al. (1998), YAFFE (2000)], o que representa uma variação muito grande. A qualidade do sistema de obtenção da imagem e o posicionamento da mama no mamógrafo são fatores que podem afetar a detecção precoce do câncer. Entretanto, de acordo com DOI et al. (1999), aproximadamente $30 \%$ das lesões visíveis no mamograma não serão identificadas por alguma razão. Outros 30\% apresentarão sinais sutis de malignidade de difícil detecção.

A eficácia na interpretação dos mamogramas pode aumentar de 5 a $15 \%$ pela análise de um segundo radiologista ou pela releitura dos mesmos após um certo período de tempo [VYBORNY (1994), NISHIKAWA et al. (1996b)]. Experimentos têm mostrado que a dupla leitura dos mamogramas pode diminuir a taxa de falso-negativos. Entretanto, como mencionado anteriormente, esse procedimento aumenta significativamente os custos financeiros. Outro problema relatado por

\footnotetext{
${ }^{1} \mathrm{O}$ valor preditivo positivo é a razão entre o número de verdadeiro-positivos (TP) (ou canceres corretamente diagnosticados) pela soma do número de verdadeiro-positivos (TP) e falsopositivos $(\mathrm{FP})(\mathrm{TP}+\mathrm{FP}=$ número de biópsias realizadas $)$.
} 
algumas pesquisas é a alta variabilidade entre os diagnósticos realizados por radiologistas para um mesmo grupo de casos. SCHMIDT et al. (1998) mostraram que radiologistas experientes são capazes de detectar aproximadamente $16 \%$ a mais de casos de câncer em comparação a um novato ou residente.

\subsection{Principais indicadores do câncer de mama}

Durante a análise dos mamogramas, os radiologistas buscam detectar sinais sutis que possam indicar o desenvolvimento de uma lesão. Dentre esses sinais, os mais importantes são: agrupamentos de microcalcificações, nódulos ou massas com formatos irregulares e distorções na arquitetura da mama. De acordo MCKENNA (1994), 80 a 85\% dos casos de câncer de mama apresentam uma massa (ou nódulo) ou um agrupamento de microcalcificações, ou a combinação de ambos nos mamogramas. Os principais indicadores são definidos a seguir.

\subsubsection{Agrupamento de microcalcificações}

De acordo com TUCKER (1993), uma microcalcificação é um pequeno depósito de cálcio que se acumula no tecido da mama e aparece em forma de pontos brilhantes nos mamogramas. Um agrupamento é tipicamente definido como um conjunto de 3 ou mais microcalcificações contidas em uma região de $1 \mathrm{~cm}^{2}$. Aproximadamente $50 \%$ das massas malignas estão associadas a agrupamentos de microcalcificações, sendo estas, em alguns casos, os únicos sinais de malignidade. As microcalcificações variam de 0.1 a $5 \mathrm{~mm}$ em diâmetro. Informações de forma, tamanho e densidade radiográfica são os fatores mais importantes para a análise individual de microcalcificações. O número e a maneira como as microcalcificações estão agrupadas também são fatores importantes.

Nas Figuras 1.2(a) e (b) são apresentados dois agrupamentos de microcalcificações associados, respectivamente, a um caso benigno e a um caso de câncer. 


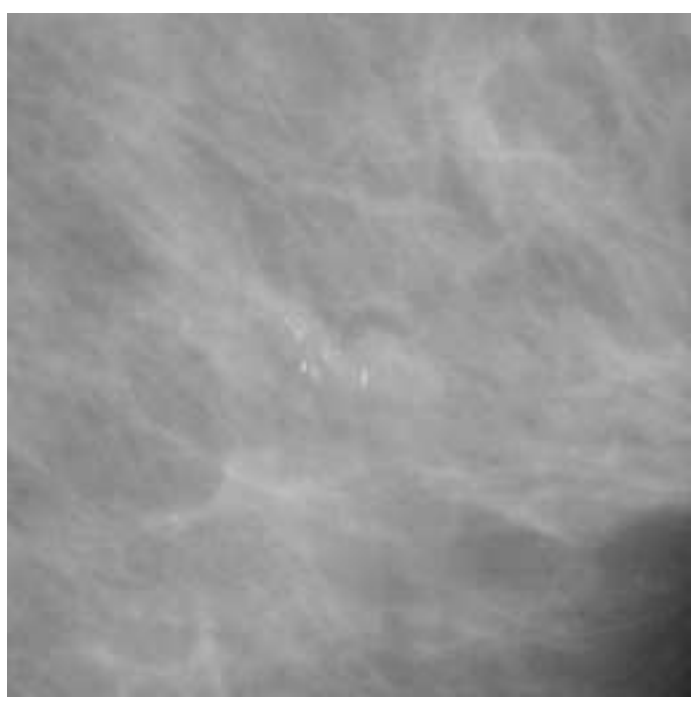

(a)

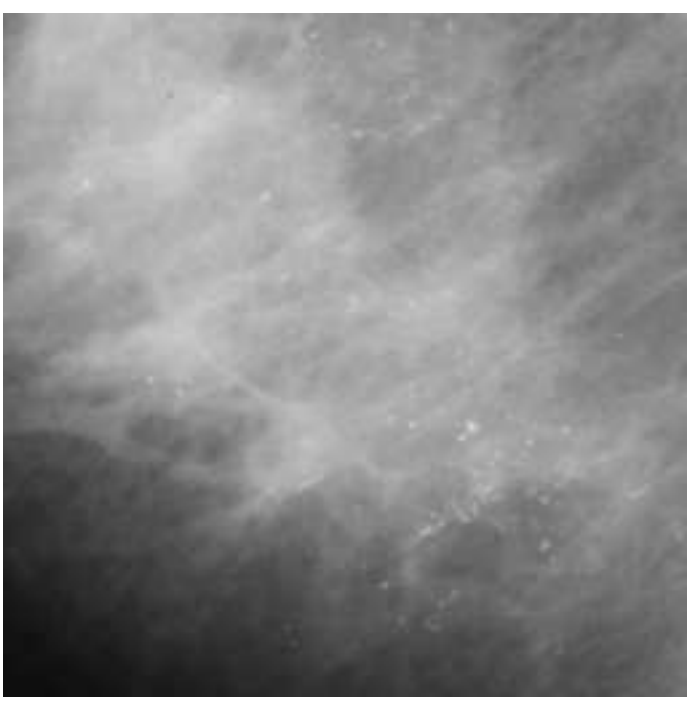

(b)

Figura 1.2: Regiões contendo agrupamentos de microcalcificações extraídos de diferentes mamogramas. (a) Agrupamento associado a um tumor benigno. (b) Agrupamento associado a um tumor maligno.

\subsubsection{Nódulos ou massas}

De acordo com a normalização internacional aplicada à área de mamografia ("Breast Imaging Reporting and Data System" - BIRADS), criada pelo "American College of Radiology" (ACR), uma massa é definida como uma lesão que é vista ocupando um espaço determinado em duas projeções diferentes (vistas CC e ML ou MLO). Quando uma região aparente é localizada em apenas uma projeção, ela é referenciada por "densidade mamográfica" ou simplesmente "densidade". Embora uma densidade possa ser uma massa, talvez obscurecida por tecidos glandulares, ela pode também representar apenas a sobreposição de vários tecidos normais.

Após a localização de uma massa, os radiologistas utilizam determinadas características extraídas dos mamogramas a fim de determinar se ela está ou não associada a um tumor maligno. As características mais importantes nesse caso são: forma, margem e densidade.

Em geral, as formas arredondadas ou em formato de ovo são associadas a 
processos benignos porque elas implicam na presença de uma boa margem circunscrita, a qual é considerada como um sinal benigno (observar Figura 1.3(a)).

A análise da margem de uma massa é a caracterização de sua forma ou da transição entre ela e os tecidos normais de sua vizinhança. Sua importância se dá na indicação da tendência invasiva do câncer para os tecidos adjacentes. Para casos malignos, ela geralmente possui uma aparência em forma de espículas (linhas radiando a partir de um centro), (observar Figura 1.3(b)).

A densidade mamográfica ou grau de atenuação aos raios $\mathrm{X}$ é definida como a atenuação esperada para um dado volume, igual ao volume de tecido glandular normal de mama. Ela é importante porque muitos canceres que formam uma massa apresentam atenuação maior que a dos tecidos fibro-glandulares vizinhos. A região contendo um tumor possui alta densidade por causa de sua firmeza e resistência. A análise de densidades pode ser muito útil na detecção de uma lesão de mama, mas ela pode causar confusões quando uma grande quantidade de tecido adiposo está presente no mamograma. Nesse caso, uma região normal no mamograma pode ser confundida com uma massa devido ao alto contraste desta em relação aos tecidos adiposos que a circunscreve. A medida de densidade deve ser usada com cuidado e em combinação com a análise de margem.

\subsubsection{Distorções do parênquima mamário}

A distorção da arquitetura da mama (ou parênquima mamário) é outro sinal analisado pelos radiologistas no mamograma. Esse tipo de sinal algumas vezes não possui uma massa associada. Em sua análise inclui-se a determinação de regiões com espículas, alterações no fluxo normal de tecidos mamários que convergem para o mamilo e retrações das linhas de tecidos conectivos. Tais informações são importantes para a determinação de um possível câncer infiltrante, o qual ocorre freqüentemente ao longo de planos de tecidos normais, causando um endurecimento ou contração anormal, como indicado pelas Figuras 1.4(a) e (b). Esse fato algumas vezes pode ser visto antes mesmo da presença de uma massa. 


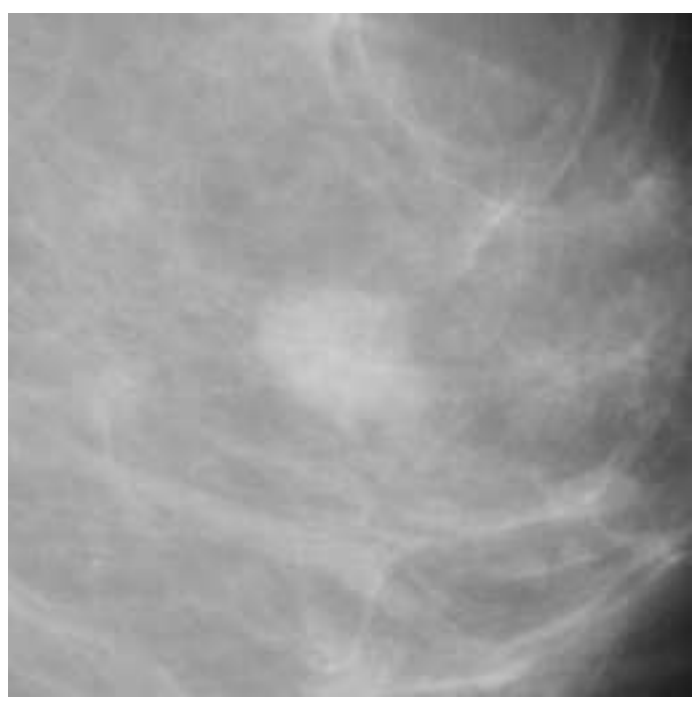

(a)

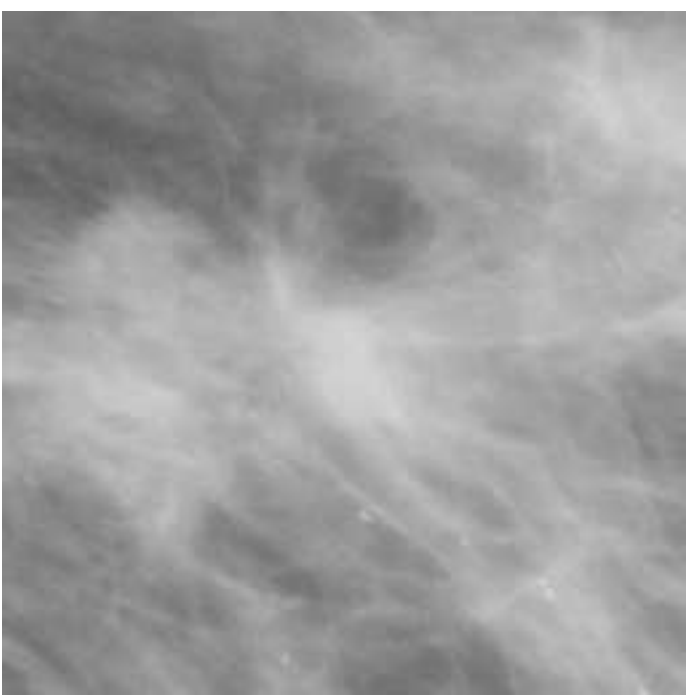

(b)

Figura 1.3: Regiões de interesse contendo exemplos de massas. (a) caso benigno forma arredondada e margens bem definidas. (b) caso maligno - forma e margens irregulares (tumor infiltrante).

Caso seja constatada uma distorção suspeita no parênquima mamário, recomenda-se a realização de projeções especiais para o estabelecimento exato da localização do sinal investigado. Se tal distorção não estiver associada a nenhuma explicação plausível, geralmente é recomendada uma análise de biópsia, mesmo na ausência de uma massa evidente. Um cuidado especial deve ser tomado em relação a possíveis cicatrizes que a mama possa apresentar. Algumas características benignas de distorção da arquitetura, tal como um ferimento, tendem a se manter inalteradas ou mesmo desaparecer após algum tempo. Portanto, se existirem mamogramas anteriores, uma boa recomendação é a comparação dos mesmos para determinar possíveis mudanças.

\subsection{Processo de análise dos mamogramas}

O processo de análise dos mamogramas pelo radiologista é executado através de duas abordagens distintas.

A primeira abordagem consiste na pesquisa sistemática de padrões visuais 


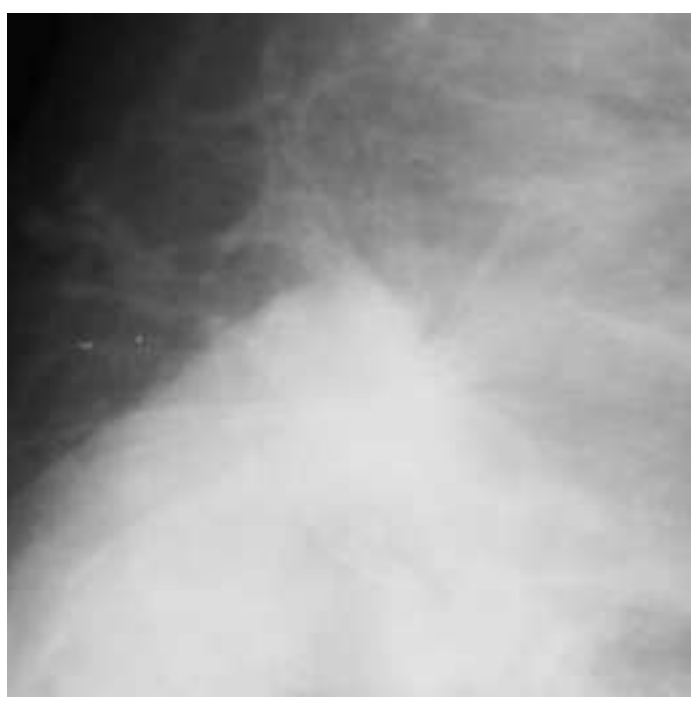

(a)

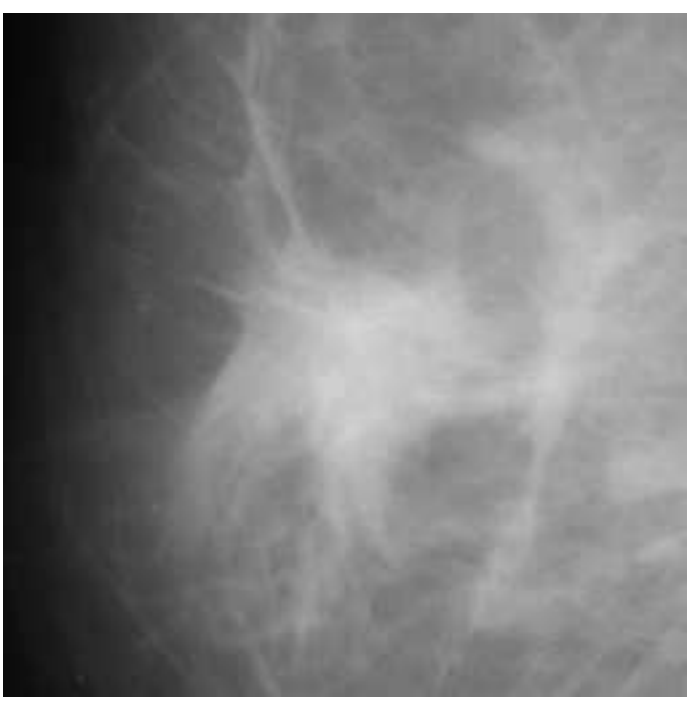

(b)

Figura 1.4: Exemplos de distorções na arquitetura da mama causadas pela presença de massas malignas próximas a pele da mama.

patológicos em cada um dos mamogramas de forma isolada. Por exemplo, a procura por agrupamentos de microcalcificações ou densidades suspeitas.

A segunda abordagem, - análise de assimetrias - usada na realização desta pesquisa, consiste da comparação bilateral sistemática de regiões correspondentes entre os mamogramas de uma mesma projeção (CC e ML ou MLO). Assimetrias estruturais significantes entre duas regiões podem indicar uma possível presença de um tumor.

O processo de análise com base no grau de assimetria entre os mamogramas, embora seja de extrema importância na detecção precoce de um câncer de mama, possui alguns elementos que tornam esse procedimento bastante difícil, dentre os quais pode-se citar:

1. a assimetria natural entre as mamas e as assimetrias decorrentes do processo de aquisição das imagens (posicionamento da paciente).

2. a não existência de uma correspondência perfeita entre os mamogramas esquerdo e direito implica na dificuldade de obtenção de pontos correspondentes entre eles. 
3. o processo de análise pelo radiologista envolve alto grau de subjetividade.

De acordo com MILLER \& ASTLEY (1993), os radiologistas realizam a avaliação de assimetria através de bases regionais, sendo o disco glandular a região de maior interesse durante a análise diagnóstica, devido a grande ocorrência de nódulos nessa área.

\subsection{Sistemas de diagnóstico auxiliado por com- putador em mamografia}

Sistemas de diagnóstico auxiliados por computador ("Computer-Aided Diagnosis" - CAD) e sistemas de pré-rastreamento automáticos são duas formas potenciais de análise que podem ajudar a solucionar alguns dos problemas encontrados em programas de rastreamento de câncer de mama, tais como: grande volume de exames para análise, alto custo financeiro referente a honorários médicos, erros de prescrição devido a fadiga humana, diferentes níveis de conhecimento entre residentes e radiologistas experientes, etc..

No cenário de um sistema CAD, o resultado da análise da imagem, realizada pelo computador, é usado para sugerir possíveis regiões suspeitas, as quais terão maior atenção por parte dos médicos durante a interpretação dos mamogramas. Adicionalmente, operações computacionais como realce de contraste e deteç̧ão de bordas podem ser aplicadas às imagens antes mesmo da análise do radiologista, como uma forma de isolar determinadas regiões ou tecidos mamários específicos.

Outra característica importante de um sistema CAD é a uniformidade em relação ao padrão de análise e repetibilidade do processo. Nesse tipo de sistema, o computador age essencialmente como um segundo leitor, sem incorrer em custos adicionais referentes à contratação de um segundo radiologista. Cabe ressaltar que a leitura de um mesmo mamograma por dois radiologistas diferentes é uma prática comum numa rotina hospitalar, devido a dificuldade deste tipo de diagnóstico. Sendo assim, a substituição de um deles por um sistema CAD de alta 
sensibilidade pode fazer com que os médicos tenham mais tempo efetivo para a realização de outras tarefas, ou mesmo para a análise dos casos mais difíceis.

Com o uso de sistemas CAD, espera-se um aumento na sensibilidade de detecção (maior número casos de câncer detectados) para uma determinada taxa fixa de sinais falso-positivos. Os casos sutis, detectados como resultado do aumento da sensibilidade, serão tratados precocemente, diminuindo os custos psicológicos e financeiros, além de aumentar as chances de sobrevida da paciente, como é mostrado em alguns trabalhos de pesquisa nesta área [KARSSEMEIJER et al. (1998) - seção "Clinical Impact of Digital Mammography", MOBERG et al. (2001)].

No entanto, o principal objetivo das pesquisas atualmente é o desenvolvimento de técnicas para a redução da taxa de falso-positivos, considerando a sensibilidade em patamares aceitáveis. Isso têm sido uma preocupação unânime nesta área visto o baixo valor preditivo positivo dos sistemas (alto número de biópsias desnecessárias). De acordo com NISHIKAWA et al. (2000), 80\% das lesões identificadas por um radiologista em mamogramas normais (casos falso-positivos) são também identificadas pelo computador como uma lesão em potencial.

Numa situação de pré-rastreamento, a análise da imagem pelo computador é usada para separar com extremo grau de confiança algumas frações dos mamogramas normais. Apenas os mamogramas restantes, aqueles com máxima suspeita, serão examinados pelos radiologistas. Visto que aproximadamente $90 \%$ dos mamogramas analisados num programa típico de rastreamento são normais, a separação de qualquer fração substancial desse grupo através de técnicas automáticas reduziria expressivamente os custos financeiros relacionados a honorários médicos, viabilizando a implementação de um programa nacional de rastreamento de câncer de mama.

Consistência e repetibilidade são dois aspectos importantes da análise de imagens pelo computador, dos quais os sistemas CAD para mamografia devem se beneficiar. De acordo com KOPANS (1991), existe um fenômeno psicovisual ine- 
rente ao processo de interpretação mamográfica que faz com que o radiologista as vezes falhe na percepção de sinais malignos significantes. Esse fato é comprovado por estudos que mostram que a análise retrospectiva dos mamogramas pode identificar casos suspeitos que não tinham sido recomendados para a biópsia [BIRD et al. (1992), HARLEY et al. (1993)].

Também, é sabido que existem níveis significantes de variabilidade nas opiniões dos próprios observadores em mamografia [SCHMIDT et al. (1998)]. Ao contrário, um sistema de deteç̧ão não estocástico, realizado por computador, sempre produzirá a mesma saída para uma dada imagem, uma vez que a pesquisa por anomalias numa imagem será sistemática e completa. De acordo com SHTERN (1992) e DOI et al. (1999), a análise do câncer de mama através do processamento de imagens é identificada como uma tecnologia inovadora e com grande potencial de impacto sobre o gerenciamento do câncer de mama. De fato, existe um número muito grande de grupos de pesquisa, tanto em institutos universitários quanto em agências particulares, ao redor do mundo que estão ativamente pesquisando sobre esse assunto.

\subsection{Organização desta tese}

Essa tese é dividida em 8 capítulos e 2 apêndices, além desta introdução. A seguir é apresentada uma breve descrição de cada um deles.

- Capítulo 2: Apresenta os objetivos e justificativas de desta pesquisa.

- Capítulo 3: Apresenta uma revisão bibliográfica sobre métodos computacionais para a detecção e análise de assimetrias entre mamogramas.

- Capítulo 4: Base de dados e programas utilizados neste trabalho.

- Capítulo 5: Métodos desenvolvidos para a segmentação anatômica dos mamogramas. 
- Capítulo 6: Métodos desenvolvidos para a detecção automática de assimetrias entre os mamogramas.

- Capítulo 7: Protocolo de avaliação utilizado para avaliar os resultados obtidos neste trabalho.

- Capítulo 8: Resultados obtidos e discussões.

- Capítulo 9: Conclusões finais, sumário de conclusões, publicações relacionadas à tese e propostas para trabalhos futuros.

- Apêndice 1: Apresenta a descrição da representação Gabor wavelets utilizada para a análise de componentes direcionais em mamogramas.

- Apêndice 2: Descrição das técnica EM e DAEM utilizadas para o desenvolvimento do modelo de densidades da mama. 


\section{Capítulo 2}

\section{Objetivos e justificativas desta pesquisa}

\subsection{Objetivos}

Os objetivos desta pesquisa foram:

1. Segmentar os mamogramas em regiões anatômicas ("segmentação anatômica") a fim de delimitar a região efetiva da mama e possibilitar a análise comparativa entre os discos glandulares.

2. Desenvolver métodos computacionais automáticos capazes de classificar pares de mamogramas (esquerdo e direito de uma mesma paciente) como normais ou assimétricos a partir de medidas mensuráveis extraídas de imagens digitalizadas dos mamogramas.

\subsection{Justificativas}

Em um sistema automático de auxílio ao diagnóstico do câncer de mama, a etapa de segmentação dos mamogramas é de fundamental importância para eliminar as informações desnecessárias presentes na imagem, e também para prepará-la 
para os estágios posteriores de processamento. Nos programas de rastreamento do câncer de mama, esse processo deve ser automático, rápido e robusto, uma vez que o volume de imagens a ser analisado é muito grande. A segmentação dos mamogramas é também necessária, neste trabalho, para a determinação da região do disco fibro-glandular da mama, a qual serve como base para a análise de informações direcionais e de densidades assimétricas entre os mamogramas.

A razão por considerar a análise de assimetrias entre mamogramas não está no fato de que essa possa alcançar resultados superiores (em termos de sensibilidade e especificidade) aos métodos convencionais de análise. Métodos convencionais que buscam detectar sinais primários específicos (como microcalcificações e nódulos) terão provavelmente melhor desempenho. Entretanto, esta abordagem pode trazer novas pistas a respeito da presença do câncer de mama em estágios iniciais, antes mesmo da formação de um nódulo ou da presença de agrupamentos de microcalcificações. Esse tipo de análise visa principalmente detectar modificações globais entre os mamogramas (distorções no parênquima mamário, densidades assimétricas, distorções do fluxo dos tecidos, etc.), as quais não são analisadas pelos demais métodos.

Cabe ressaltar que não existe uma relação direta entre assimetrias entre mamogramas e a presença do câncer de mama, ou seja, um par de mamogramas pode apresentar assimetrias e mesmo assim ser um caso benigno. Entretanto, a presença de um tumor quase sempre implica em distorções diferencias entre os mamogramas.

Apesar de sua relevância, a investigação de novas técnicas para a análise de assimetrias entre mamogramas foi objeto de um número reduzido de trabalhos, sendo estes não conclusivos. Portanto, a investigação de novas abordagens de análise, como a apresentada nesta tese, é justificada. 


\section{Capítulo 3}

\section{Métodos computacionais para a análise de assimetrias entre}

mamogramas

Como descrito no Capítulo 1 - Seção 1.4, um procedimento comum entre os radiologistas, e que tem sido explorado por pesquisadores na área de CAD para mamografia, é o uso da comparação bilateral e/ou temporal entre os mamogramas de uma mesma paciente com o objetivo de identificar sinais assimétricos suspeitos.

Para ser definido, o cálculo de uma medida local de assimetria requer um mapeamento prévio (de maneira direta ou indireta) entre os mamogramas esquerdo e direito (análise bilateral) e/ou de projeções iguais de uma mesma mama obtidas em períodos diferentes (análise temporal).

Infelizmente, na maioria dos casos esse mapeamento é comprometido por fatores inerentes ao processo de aquisição da imagem ou mesmo devido à natureza física desse órgão anatômico. Na análise bilateral, por exemplo, o primeiro problema decorre da assimetria natural existente entre as mamas esquerda e direita. Também, as variações no processo de obtenção da imagem podem gerar distribuições diferentes na intensidade de cinza dos mamogramas. Mas, o fator mais agravante é devido ao procedimento de compressão das mamas, necessário pa- 
ra minimizar o efeito de espalhamento de raios $\mathrm{X}$ e reduzir a dose aplicada à paciente. Esse procedimento acarreta distorções diferenciais nas imagens.

Entretanto, apesar das dificuldades relatadas acima, alguns métodos abordando esse tema têm sido propostos na literatura. Alguns desses trabalhos têm demonstrado que o uso combinado entre esse tipo de abordagem e de técnicas que avaliam de forma isolada cada uma das projeções mamográficas pode aumentar significativamente o desempenho de sistemas CAD voltados à detecção de lesões de mama, [YIN et al. (1993), KARSSEMEIJER \& te Brake (1998), MOBERG et al. (2001)].

Neste capítulo serão descritos os principais trabalhos encontrados na literatura para a detecção computadorizada de sinais assimétricos entre pares de mamogramas. Embora a detecção de densidades assimétricas e a análise de distorções da arquitetura da mama sejam muitas vezes características correlacionadas, nesta tese optou-se pela divisão dos trabalhos nesses dois grupos citados simplesmente para facilitar a leitura e compreensão.

\subsection{Detecção de densidades assimétricas}

Uma densidade assimétrica não é um sinal muito específico, uma vez que a maioria das densidades assimétricas são resultantes de variações normais do padrão de parênquima da mama [WOLFE (1976), BYNG et al. (1994)]. Entretanto, quando uma densidade assimétrica possui algumas das características típicas de uma massa maligna ou aparece numa região da mama que deveria estar livre de qualquer sinal, tal como entre o disco glandular e o músculo peitoral, ela se torna altamente suspeita [MILLER \& ASTLEY (1993)].

Um dos primeiros métodos usando a abordagem de análise de assimetrias para a localização de regiões suspeitas na mama foi apresentado por SEMMLOW et al. (1980). A correspondência entre as imagens nesse trabalho foi realizada através do alinhamento dos mamilos e da direção ortogonal a eles. A técnica 
do mínimo erro quadrático foi utilizada para o ajuste das imagens. Os autores também utilizaram características relacionadas à região suspeita para estabelecer a probabilidade daquela região conter uma lesão maligna.

Em 1991, Yin e seus colegas da Universidade de Chicago [YIN et al. (1991)] apresentaram um trabalho para a detecção de nódulos mamários baseado na determinação de densidades assimétricas entre mamogramas. Nos trabalhos apresentados até 1993 [YIN et al. (1991), YIN et al. (1993)] o alinhamento das imagens era realizado de forma manual durante o processo de digitalização dos mamogramas. Em 1994, YIN et al. (1994) acrescentaram técnicas de análise de atributos para caracterizar as aparências radiográficas das regiões suspeitas. Isso envolveu a seleção automática de regiões retangulares da imagem original ajustadas com base no tamanho das regiões suspeitas na imagem processada. Uma técnica de crescimento de região foi aplicada a cada região marcada na imagem original para extrair com exatidão as bordas do sinal suspeito. A seguir os sinais suspeitos foram analisados a partir de medidas de área, circularidade e contraste.

Também, a partir de 1994 [YIN et al. (1994b)] o alinhamento das imagens passou a ser realizado de maneira automática, usando os mamilos e alguns pontos sobre as bordas das mamas contra-laterais como pontos de referência. O co-registro entre as imagens foi alcançado através de movimentos de rotação e translação, buscando maximizar a correspondência entre duas matrizes de pontos de referência (uma matriz para cada mamograma). A menor área comum entre as imagens ajustadas foi utilizada para realizar o processamento.

Após o alinhamento das mamas, um método de subtração bilateral não-linear é aplicado, seguido pela comparação entre as múltiplas imagens resultantes da aplicação de um limiar de nível de cinza. A análise "run-length" é usada para unir os dados das várias imagens subtraídas, acumulando as informações das diversas subtrações em apenas duas imagens (projeções ML e CC) contendo as localizações das massas suspeitas. Como forma de caracterizar as regiões suspeitas, os autores usaram um filtro morfológico, um teste de tamanho e um teste de bor- 
da, todos aplicados sobre as imagens "run-length". O pré-processamento usando filtro morfológico (operações de abertura e fechamento) foi aplicado para eliminar pequenos sinais isolados na imagem. O teste de borda serviu para eliminar artefatos resultantes nas bordas das imagens devido a perda de alinhamento.

ZOURAS et al. (1996) apresentaram um método para a detecção de câncer de intervalo a partir da análise temporal de mamogramas. Esse trabalho foi adicionado ao sistema de subtração bilateral descrito anteriormente. O método proposto foi baseado na técnica descrita em YIN et al. (1991), com a única diferença que, no novo método os autores incluíram uma Rede Neural Artificial (RNA) com o objetivo de aumentar a especificidade do sistema. O novo método, combinando as técnicas de subtração bilateral e temporal, detectou $85 \%$ das massas contidas numa base de dados com 79 casos. Segundo os autores isso representou um aumento de $8 \%$ na detecção em relação ao desempenho isolado da técnica de subtração bilateral.

SALLAM \& BOWYER (1996), apresentaram um método para a determinação de alterações na simetria de uma mesma mama ao longo do tempo, o qual é um aperfeiçoamento do trabalho publicado pelos mesmos autores em [SALLAM \& BOWYER (1994)]. O método proposto consiste de dois estágios principais: o primeiro estágio produz uma imagem diferencial através do co-registro e subtração das imagens, e o segundo estágio, realiza a análise da imagem resultante da subtração.

Para o co-registro das imagens, os autores utilizaram uma técnica bidimensional de "warping" aplicada sob pontos de controle determinados na região interna à mama. A fim de capturar informações locais invariantes, os autores utilizaram a transformada Wavelet para decompor a imagem em diferentes escalas de representação. A determinação dos pontos de controle foi realizada através da associação de um vetor de atributos à cada pixel da imagem. Cada vetor foi formado pelos coeficientes da transformada Wavelet nas direções horizontal, vertical e diagonal. Uma medida de correlação local entre os vetores de atributos 
foi calculada e os pixels apresentando valores máximos foram selecionados como pontos de controle.

Após o co-registro e a subtração entre as imagens, a imagem resultante foi analisada com base na distribuição gerada da diferença entre os histogramas das duas imagens. Um grupo de oito casos (seis normais, e dois assimétricos) foram usados para a avaliação do método. De acordo com os autores, o algoritmo foi capaz de encontrar as anomalias nos dois casos com uma taxa de falso-positivos de 0.87 por imagem.

Em 1996 e 1997, Vujovic e seus colegas [VUJOVIC et al. (1996), VUJOVIC \& BRZAKOVIC (1997)] apresentaram um método para a detecção de sinais característicos de câncer de mama através da análise temporal de mamogramas.

Para a correspondência entre as imagens os autores usaram as intersecções entre estruturas alongadas (tais como ductos e vasos) como pontos de referência. Segundo Vujovic, o uso desses pontos são mais confiáveis e menos variantes do que outros tipos de marcas propostas na literatura.

A correspondência entre dois pontos, em dois mamogramas consecutivos, é estabelecida com base em suas localizações e similaridades de assinaturas. A assinatura de cada ponto, calculada para capturar os padrões das estruturas alongadas, é formada pelas seguintes características: (a) ângulo de referência indicando a direção da estrutura alongada analisada e (b) molde da assinatura calculado através da contagem de todos os pixels diferentes de zero em direções espaçadas de $10^{\circ}$ a partir do ângulo de referência da estrutura.

A correspondência entre todos os pares de pontos é realizada pela técnica descrita em [SKEA et al. (1993)], que usa uma matriz acumuladora gerada da análise entre todas as possíveis combinações dos pares de pontos. Após a construção da matriz, um limiar é aplicado para eliminar pontos inconsistentes e determinar os melhores pontos para a correspondência. As regiões suspeitas, correspondentes no par de imagens, são determinadas pela localização de pontos de alta densidade nos mamogramas com distâncias equivalentes entre os subgrupos de pontos de 
controle.

A aplicação dos rótulos benigno e maligno às regiões é realizada através da comparação de seus histogramas de níveis de cinza, obtidos após a aplicação da transformada Wavelet e filtragem B-Spline, e análise de textura.

Os autores utilizaram 29 mamogramas para a determinação do desempenho do método. Em média, 70 pontos de controle foram determinados por mamograma, sendo utilizados efetivamente 5 pontos em média para a correspondência. $\mathrm{O}$ grau de correspondência entre os mamogramas foi medido através da validação realizada por radiologistas. O nível de concordância alcançado variou de 75 a 91\%. De acordo com os autores o método proposto também é bastante robusto em relação à variação dos tipos de tecidos da mama.

KARSSEMEIJER \& te Brake (1998), apresentaram um trabalho para a detecção de massas combinando atributos extraídos de projeções mamográficas isoladas e atributos de assimetria extraídos de pares de imagens mamográficas.

O trabalho usando características extraídas de projeções isoladas foi previamente apresentado pelos autores em [KARSSEMEIJER \& te Brake (1996), te Brake \& KARSSEMEIJER (1996)], e usava análises estatísticas de linhas e padrões de orientação dos gradiente da imagem para a detecção de massas circunscritas e espiculadas.

No trabalho apresentado em 1998, os autores utilizaram um algoritmo para determinar os pontos de máxima curvatura gerados sobre os contornos de regiões densas do mamograma e dentro da área de tecido denso num segundo estágio. A correspondência entre os mamogramas foi estabelecida através da minimização de uma função de custo, usando o método "Thin-Plate Spline", descrito em [BOOKSTEIN (1989)].

A seguir, uma medida local simples de assimetria é calculada através da subtração bilateral entre os mamogramas. Para resolver o problema da perda dos limites das bordas dos mamogramas, causada pela variação das condições de 
compressão da mama, ou autores implementaram uma correção fina na região periférica do mamograma. Além disso, as imagens foram segmentadas em fundo, tecidos mamários e músculo peitoral, sendo esse último determinado nas projeções oblíquas através da aplicação da transformada de Hough [KARSSEMEIJER \& te Brake (1998)].

De acordo com Karssemeijer, os algoritmos para a detecção de massas podem gerar facilmente falsos alarmes ou encobrir tumores devido à presença do forte valor de gradiente de intensidade na região da borda do peitoral. Apesar da afirmação estar correta, isso pode levar a falsa idéia de que a subtração da região do peitoral seria um fator positivo nesse tipo de análise. Entretanto, tumores de mama são freqüentemente projetados em áreas logo abaixo do peitoral, o que faz dessa idéia uma abordagem pouco atrativa.

Para evitar a implementação de técnicas diferentes para a detecção de massas nas proximidades do músculo peitoral, os autores desenvolveram um método de pré-processamento para remover o alto contraste da área do peitoral através da subtração do valor estimado da contribuição do peitoral no padrão de intensidade da imagem. Após a subtração das imagens, a imagem resultante é suavizada por um grande núcleo gaussiano.

O método proposto foi testado em um grupo de 71 casos de câncer, detectados no programa bi-anual de rastreamento mamográfico da cidade de Nijmegen Holanda, no período de 1993 a 1996. Os mamogramas contendo apenas microcalcificações foram excluídos. Um total de 132 mamogramas com pelo menos uma lesão maligna e 132 mamogramas contra-laterais normais foram utilizados. Todas as anormalidades foram previamente confirmadas por um radiologista usando os mamogramas contendo as lesões. Nesse trabalho, o diâmetro médio das lesões foi de $15.4 \mathrm{~mm}$, e $72 \%$ das lesões foram menores que $2 \mathrm{~cm}$.

Uma RNA-MLP ("Multi-Layer Perceptron") foi usada para classificar os pixels de acordo com a probabilidade de suspeita. O treinamento da rede foi realizado separadamente através de 39 mamogramas de lesões malignas obtidos da base de dados de domínio público MIAS [SUCKLING et al. (1994)]. Segundo 
os autores, apesar dos mamogramas terem sido digitalizados com características diferentes, os atributos utilizados para a classificação das lesões foram definidos de maneira a não afetar os resultados.

Para a análise dos resultados utilizou-se curvas FROC ("Free Response Operating Characteristics"), sendo o acerto na detecção definido como a concordância entre o centro da massa detectada pelo programa e a região marcada pelo radiologista. Os resultados mostraram que a adição de atributos de assimetria ao método de detecção usando apenas projeções isoladas melhora o desempenho em massas circunscritas e assimétricas, mas não afeta o desempenho em massas espiculadas. No entanto, o desempenho diminuiu quando as distorções de arquitetura foram analisadas.

KOK-WILES et al. (1998) apresentaram um trabalho para a detecção de massas usando mapeamentos temporal e bilateral dos pares de mamogramas. Essa abordagem foi usada para a representação de estruturas densas agrupadas nos mamogramas.

No caso de pares temporais, as regiões densas foram extraídas independentemente nos dois mamogramas da mesma mama, nominalmente a mesma projeção em duas datas diferentes. No caso da comparação bilateral, os autores investigaram apenas regiões densas aparecendo em uma das projeções, sem correspondência no mamograma contra-lateral.

Na abordagem descrita por KOK-WILES et al. (1998), as regiões de brilho salientes de tamanhos variados foram determinadas e representadas por um atributo específico. O grupo de regiões determinado em cada imagem foi então representado por uma estrutura em árvore. Segundo os autores, esse tipo de representação é invariante a mudanças pequenas e localizadas da estrutura do tecido do parênquima, o que é uma vantagem em relação às técnicas de subtração de imagens.

Para a análise do método, primeiro os autores utilizaram um mamograma assintomático no qual uma massa simulada foi introduzida. Para a verificação da 
invariância do método foram feitas rotações e translações na massa. O método mostrou-se invariante à translação, mas para movimentos de rotação surgiram alguns sinais falso-positivos, embora a massa tenha ainda sido detectada. O algoritmo foi também testado sobre 26 pares bilaterais de mamogramas, 14 da base de dados do MIAS [SUCKLING et al. (1994)] e 12 obtidos da Philips. De acordo com os autores, o método foi capaz de detectar com sucesso as densidades em todos os 26 mamogramas.

Em 2000, WOO et al. (2000) apresentaram um trabalho para a avaliação de similaridade entre as arquiteturas das mamas esquerda e direita. Entretanto, apesar do título do trabalho, apenas densidades assimétricas foram analisadas. O método possui duas abordagens de análise distintas.

Na primeira, o procedimento inicia-se pela determinação do contorno da mama através de um método simples de limiarização. A seguir os mamogramas são alinhados através de uma técnica de "warping" (co-registro não rígido) e subtraídos. Para o co-registro entre as imagens, os autores utilizaram pontos igualmente espaçados sob os contornos das mamas. Após a subtração das imagens, o histograma da imagem resultante é comparado aos histogramas das imagens originais a fim de determinar prováveis regiões assimétricas.

Na segunda abordagem, as regiões efetivas das mamas foram usadas para a determinação de dois grupos de atributos de textura, cada grupo correspondendo a um mamograma. Os atributos de textura foram obtidos a partir das imagens filtradas usando a transformada de Gabor wavelets proposta por MANJUNATH \& MA (1996). Neste caso, um par de mamogramas é considerado assimétrico se a distância Euclidiana entre os dois vetores de atributos for maior que um determinado limiar.

Um total de 100 imagens (50 casos: 18 assimétricos e 32 normais) da base de dados MIAS [SUCKLING et al. (1994)] foi utilizado para a avaliação dos métodos. Para a primeira abordagem utilizada, envolvendo a subtração dos mamogramas, os autores relataram uma taxa de $83 \%$ de sensibilidade com $81 \%$ de 
especificidade. Para a segunda abordagem, envolvendo análise de textura, os autores não conseguiram diferenciar os casos normais dos assimétricos.

\subsection{Detecção de distorções na arquitetura da mama}

Uma distorção na arquitetura normal da mama é em geral caracterizada por espículas radiando a partir de um ponto no mamograma, por retrações focais ou distorções do fluxo normal de tecidos fibro-glandulares que convergem em direção ao mamilo [MILLER \& ASTLEY (1993)].

A dificuldade na análise desse tipo de sinal é ocasionada principalmente pela falta de um padrão de normalidade bem definido e pelo procedimento de compressão da mama, que muitas vezes causa distorções diferencias entre os mamogramas. Por esse fato, os radiologistas utilizam de forma subjetiva uma combinação de informações (radiológicas, anatômicas e patológicas) para a realização do diagnóstico.

Nesta seção iremos descrever dois trabalhos encontrados na literatura que além da análise de densidades assimétricas realizaram também uma análise global dos mamogramas, incluindo distorções da arquitetura na mama.

LAU \& BISCHOF (1991) apresentaram um trabalho para a detecção automática de tumores de mama usando a análise de assimetrias entre as mamas esquerda e direita. A detecção das assimetrias foi realizada através do alinhamento prévio das imagens e posterior extração de características.

De acordo com os autores, os mamogramas foram alinhados para compensar as possíveis diferenças em tamanho e forma entre as duas mamas. Tal procedimento foi realizado em 4 estágios:

1. segmentação da mama separando sua área efetiva através da aplicação de 
uma técnica de limiarização simples realizada a partir do histograma da imagem.

2. aplicação de um filtro da média para eliminar os ruídos gerados na segmentação.

3. determinação automática de 3 pontos de referência sobre os contornos da mama. Um deles é definido sobre o mamilo e os outros dois sobre os pontos extremos da parede do tórax.

4. alinhamento das imagens através de movimentos de rotação e translação (co-registro rígido) usando os pontos de referências determinados no ítem 3.

Após a etapa de alinhamento, quatro atributos foram extraídos dos pares de imagens: brilho, rugosidade, razão entre brilho e rugosidade e uma medida de direção. Todos os atributos foram combinados em uma única medida.

Para a determinação de regiões de brilho saliente, os autores realizaram a suavização do par de imagens, seguido pela subtração das mesmas. Atributos de variância local foram utilizados para determinar a rugosidade das regiões obtidas no estágio anterior. De acordo com os autores, tanto o atributo de brilho quanto o de rugosidade não foram suficientes para detectar tumores grandes em regiões homogêneas da imagem. No entanto, eles observaram que a razão entre os atributos foi capaz de separar esses tumores.

Segundo os autores, a análise do padrão de resposta gerado pelos atributos de assimetria mencionados acima revelaram que eles respondem para outros tipos de estruturas além de tumores. Respostas positivas são também geradas em regiões contendo vasos sanguíneos ou tecidos glandulares. Como essas regiões aparecem tipicamente como padrões altamente orientados na direção ortogonal à parede do tórax, os autores criaram uma nova medida, chamada direcionalidade, para descriminar esses casos. Essa medida é baseada no espectro de potência da transformada de Fourier. Por fim, todos os atributos descritos acima foram com- 
binados em um único valor, o qual os autores definiram como sendo a "assimetria estrutural" do sistema. Ele é uma composição não-linear das demais medidas.

O método proposto foi testado em um conjunto de 10 pares de mamogramas. Esses mamogramas apresentavam um total de 13 áreas contendo um tumor ou uma área altamente suspeita. Os resultados gerados pela técnica proposta foram medidos através da comparação com as regiões contendo os tumores, demarcadas por um radiologista. O critério utilizado para a determinação do verdadeiropositivo (TP - "True Positive") foi: o sinal é considerado TP se a sobreposição entre a área indicada pelo radiologista e aquela indicada pelo sistema automático é maior que 50\%, caso contrário o sinal será considerado como um FP ("False Positive" - FP).

Os resultados finais mostraram que para o grupo de mamogramas analisados, 12 das 13 áreas suspeitas foram detectadas com uma média de 4.9 FPs. De acordo com os autores, apesar do pequeno número de casos analisados, o método baseado na assimetria entre as mamas é bastante promissor. No entanto, os autores concluíram que ele não é suficientemente confiável para ser usado isoladamente em um CAD.

MILLER \& ASTLEY (1993) mostraram que a comparação de regiões anatomicamente correspondentes é mais apropriada para a detecção de assimetrias do que a análise de correspondência espacial. Seus estudos demonstraram que os radiologistas são capazes de alcançar um nível de desempenho relativamente alto na detecção de lesões (sensibilidade de aproximadamente 70\%) mesmo removendo todas as informações diagnósticas, exceto a forma das regiões de tecidos glandulares (tecidos densos e fibrosos) da imagem.

O sistema que eles desenvolveram opera através da segmentação semi-automática das regiões glandulares de cada mamograma usando medidas de textura. Um grupo de atributos é calculado para cada região e comparado para determinar se as correspondentes regiões são assimétricas. Com exceção de uma medida chamada "transportation", todas as outras medidas da imagem são globais, não 
havendo necessidade de nenhum tipo de alinhamento prévio entre as regiões. Três tipos de medidas de assimetria foram usados: forma (solidez, circularidade, excentricidade e descritores de Fourier), distribuição dos níveis de cinza (momentos e "transportation") e topologia (área e momento binário). Desses atributos, seis se revelaram mais eficazes para a discriminação das classes.

O sistema foi testado em um conjunto de 104 pares de mamogramas, cada um contendo um sinal assimétrico simples tal como uma massa, uma distorção de arquitetura ou uma densidade focal. Uma taxa de $67 \%$ de TPs foi relatada para $17 \%$ de FPs. O acerto global na classificação dos pares de mamogramas foi de $74 \%$.

\subsection{Conclusões da revisão bibliográfica}

Em geral, os esquemas computadorizados de análise de densidades assimétricas apresentam 3 etapas principais: alinhamento das imagens dos mamogramas, correlação entre as imagens e técnicas de extração de características. Métodos de detecção de assimetrias variam muito em relação ao grau de complexidade, mas de maneira geral eles podem ser classificados em dois grupos principais: métodos que realizam subtração bilateral entre as imagens e métodos que utilizam mapeamentos de atributos de cada imagem.

Técnicas do primeiro grupo aplicam a subtração bilateral entre as imagens de forma direta ou após certas transformações, [YIN et al. (1991), YIN et al. (1993), YIN et al. (1994), YIN et al. (1994b), GIGER (1996), KARSSEMEIJER \& te Brake (1998), SALLAM \& BOWYER (1994), SALLAM \& BOWYER (1996), WOO et al. (2000)]. Esses métodos têm a vantagem de eliminar rapidamente uma grande quantidade de informações desnecessárias à análise. Entretanto, são extremamente vulneráveis a pequenas assimetrias normais da mama. Além disso, muitas vezes eles envolvem técnicas sofisticadas de "warping", com a aplicação de transformações não rígidas bastante questionáveis, e muitas vezes envolvem um alto custo computacional. Outra dificuldade apresentada por esse tipo de técnica 
é a falta de pontos de referências confiáveis para o co-registro das imagens. Uma análise comparativa detalhada entre métodos que realizam correspondência direta entre os mamogramas é encontrada em MARTI et al. (2000).

O segundo grupo abrange as técnicas que utilizam atributos extraídos das duas imagens, tais como textura, regiões de alta densidade, etc., para realizar a análise de assimetria entre as imagens, [MILLER \& ASTLEY (1993), KOKWILES et al. (1998), VUJOVIC et al. (1996), VUJOVIC \& BRZAKOVIC (1997), WOO et al. (2000)]. Nesse caso, a análise é realizada com base na comparação de mapas de atributos determinados de forma isolada para cada uma das projeções. Esses métodos são em geral menos vulneráveis às variações normais de assimetria entre as imagens, no entanto envolvem todos os problemas associados à extração, análise e seleção de atributos.

Devido a diversidade de bases de dados usadas para a avaliação dos métodos propostos na literatura, torna-se muito difícil uma comparação direta entre eles. Apesar do esforço de vários grupos de pesquisa em buscar uma solução para esse problema [NISHIKAWA et al. (1996), BOWYER et al. (1996), MASCIO et al. (1996), SUCKLING et al. (1994), BISOGNI et al. (2000)], ainda não existe um consenso na comunidade científica em relação a qual base de dados deveria servir como padrão. As bases de dados usadas com maior freqüência tem sido a base de dados de domínio público Mini-MIAS [SUCKLING et al. (1994)], e a base de dados LLNL/UCSF [MASCIO et al. (1996)].

Outra constatação, com base na revisão bibliográfica realizada, é que a maioria dos trabalhos utilizaram essa abordagem de análise com o objetivo de detectar nódulos. Apenas dois trabalhos apresentados na literatura [LAU \& BISCHOF (1991), MILLER \& ASTLEY (1993)] realizaram uma análise mais ampla a respeito desse assunto. Esse fato se deve principalmente a dificuldade em se definir o termo "assimetria" ou em caracterizar um padrão normal de mama. 


\section{Capítulo 4}

\section{Base de dados e programas}

\subsection{Base de dados}

Para a realização deste trabalho foi utilizada a base de dados de domínio público Mini-MIAS (Mammographic Image Analysis Society, London, U.K. SUCKLING et al. (1994)), a qual contém um total de 322 imagens, distribuídas de acordo com o tipo de anormalidade presente na imagem.

Um total de 84 imagens, selecionadas de forma aleatória da base de dados Mini-MIAS, foram utilizadas na avaliação dos resultados dos métodos de segmentação dos mamogramas.

Os métodos propostos para a detecção de assimetrias foram avaliados usando um total de 44 casos: um grupo de 8 casos referentes a distorções da arquitetura da mama, um grupo de 14 casos referentes a densidades assimétricas e um grupo de 22 casos escolhidos de forma aleatória dentre os casos normais presentes na base de dados. Cada caso é representado por duas imagens (mamogramas esquerdo e direito).

Todas as imagens dessa base de dados são de projeções MLO digitalizadas com resolução espacial de $200 \mu \mathrm{m}$ e resolução de contraste de 256 níveis de cinza (8 bits de quantização). Todas as imagens fornecidas são centralizadas em uma matriz de $1024 \times 1024$ pixels. 
Essa base de dados possui documentação indicando a localização dos sinais de interesse, o tipo de tecido mamário predominante, e o rótulo "benigno" ou "maligno" determinado através da análise de biópsia.

O uso desta base de dados para a avaliação dos métodos tem sido sugerido pela comunidade científica para permitir futuras comparações entre os resultados das técnicas. Entretanto, cabe ressaltar que algumas das imagens nela contida apresentam problemas quanto a aquisição e posicionamento da mama.

\subsection{Programas utilizados}

Os programas utilizados nessa tese de doutorado foram desenvolvidos, em sua maioria, em linguagem $\mathrm{C}++$. Rotinas em $\mathrm{C}$ e MatLab também foram utilizadas. A biblioteca de domínio público FFTW [MATTEO \& JOHNSON (2001)] foi usada para o cálculo das transformadas rápidas de Fourier utilizadas na implementação do método de detecção de informações direcionais usando filtros de Gabor.

O sistema operacional utilizado foi o GNU/Linux - distribuição Debian, que é um sistema operacional de domínio público sob a licença "GNU-General Public License".

\subsection{Validação dos programas desenvolvidos}

Os programas desenvolvidos foram testados através de padrões (imagens) conhecidos, muitos dos quais criados a partir do programa GIMP [MATTIS \& KIMBALL (1997)].

As equações usadas para o projeto do banco de filtros de Gabor foram validadas através da visualização e análise de diversas representações dos filtros, projetados no domínio da freqüência e plotados em gráficos 2-D usando o programa Matlab. 
Os atributos de forma, implementados e utilizados para a análise do disco fibro-glandular, foram validados através de imagens em tons de cinza e binárias, de círculos, triângulos e quadrados, escalonadas, rotacionadas e transladadas de diversas maneiras. 


\section{Capítulo 5}

\section{Segmentação anatômica de}

\section{mamogramas}

Visto que as imagens mamográficas são complexas e difíceis de analisar devido a enorme variação em densidade dos tecidos [WOLFE (1976)], e também com base no fato de que os radiologistas usam "bases regionais" para a interpretação dos mamogramas [MILLER \& ASTLEY (1993)], métodos para segmentar os mamogramas em três importantes regiões anatômicas: borda da mama (determinação da área efetiva da mama), músculo peitoral e região de tecido glandular foram desenvolvidos.

\subsection{Identificação da borda da mama}

A identificação da borda da mama é um procedimento importante para a determinação da região efetiva da mama no mamograma. A inserção deste procedimento em sistemas CAD para a detecção do câncer de mama pode reduzir o tempo necessário para o processamento das imagens e também o volume de dados a ser armazenado e transmitido (no caso de mamografia digital ou telemedicina).

Através da determinação da borda da mama é possível remover quaisquer artefatos ou informações desnecessárias presentes na imagem, tal como a iden- 
tificação do paciente (região altamente densa) e demais ruídos, os quais podem afetar o desempenho de técnicas automáticas de análise e reconhecimento de padrões. O perfil da mama tem sido utilizado também como informação adicional em diferentes tarefas de processamento de mamogramas tais como: correção da densidade de tecidos periféricos da mama [BICK et al. (1996), BYNG et al. (1997)], referência para a localização do mamilo no mamograma [CHANDRASEKHAR \& ATTIKIOUZEL (1997)] e co-registro de mamogramas em análise de assimetrias [LAU \& BISCHOF (1991), MILLER \& ASTLEY (1993)].

A maioria dos trabalhos apresentados na literatura para a identificação automática da borda da mama é baseado na análise do histograma de níveis de cinza da imagem [LAU \& BISCHOF (1991), MILLER \& ASTLEY (1993), MÉNDEZ et al. (1996), BYNG et al. (1997), LOU et al. (2000)]. De acordo com BICK et al. (1995), tais técnicas são criticamente dependentes do método usado na determinação do valor do limiar a ser aplicado à imagem, e em geral não são suficientemente robustas para a aplicação em sistemas CAD.

Mais recentemente, um método similar ao proposto nesta tese para a identificação da borda da mama foi apresentado por OJALA et al. (2001).

\subsubsection{Correção de contraste da margem da mama}

O método proposto para identificar a borda da mama, indicado pelo diagrama de blocos da Figura 5.1, inicia-se através de uma operação logarítmica simples definida como $G(x, y)=\log [1.0+I(x, y)]$, onde $I(x, y)$ é a imagem original e $G(x, y)$ é a imagem transformada. Esta operação de compressão da faixa dinâmica de níveis de cinza, embora seja aplicada de forma global à imagem, é suficiente para realçar o contraste de regiões próximas à borda da mama, as quais são caracterizadas pelo baixo contraste e pobreza de definição de detalhes devido ao processo de compressão da mama [BICK et al. (1996), BYNG et al. (1997)]. O resultado desse processo de correção de contraste pode ser observado através da comparação entre a imagem original e a imagem realçada indicadas, respectivamente, pelas Figuras 5.2(a) e 5.2(b). 


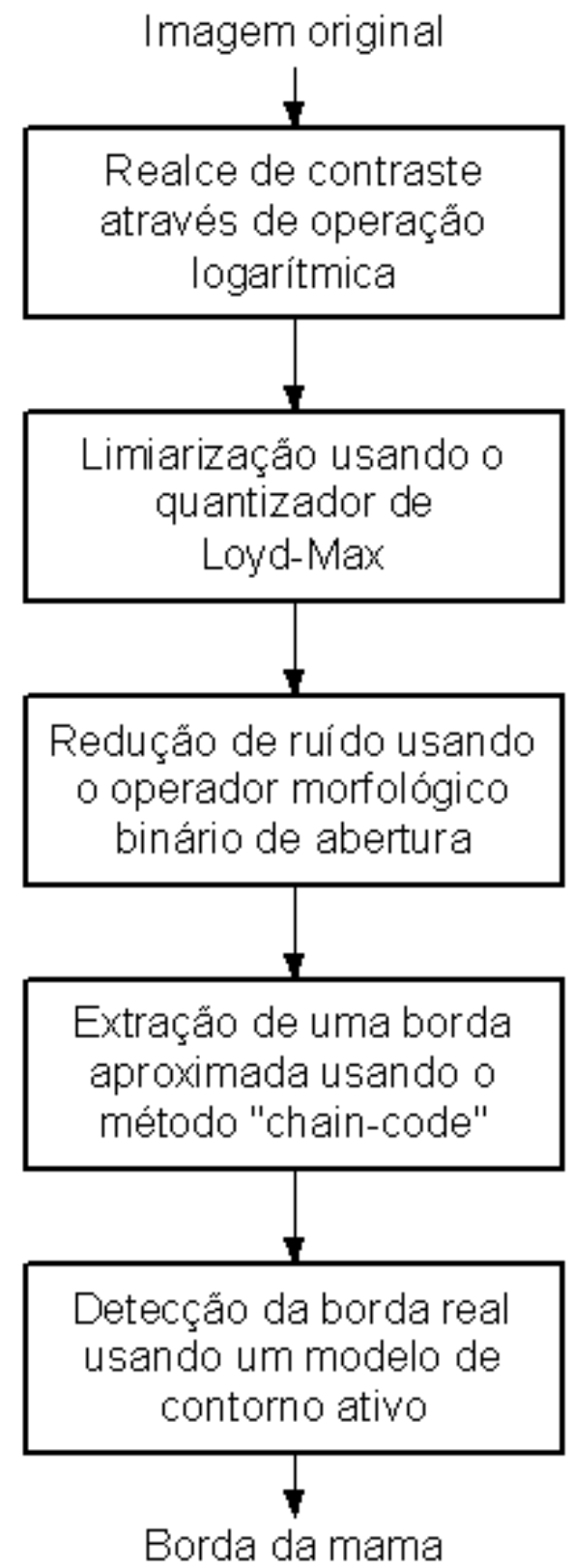

Figura 5.1: Diagrama de blocos ilustrando os estágios usados pelo método de identificação da borda da mama. 


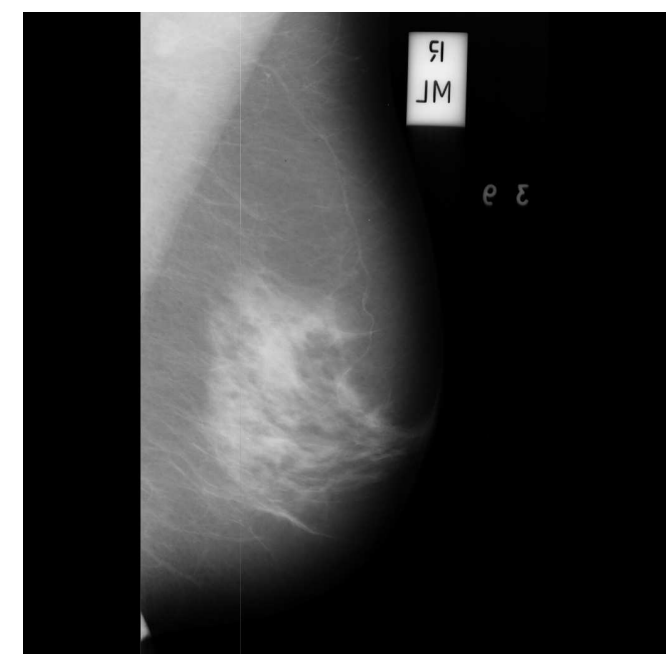

(a)

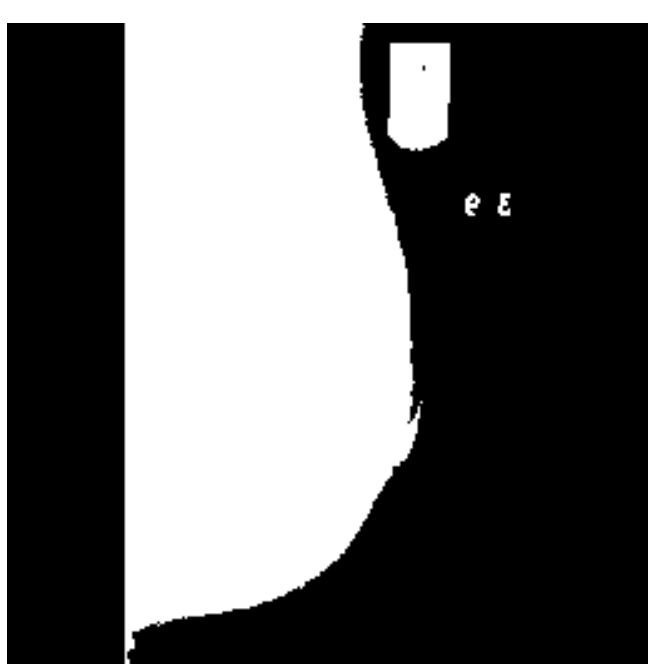

(c)

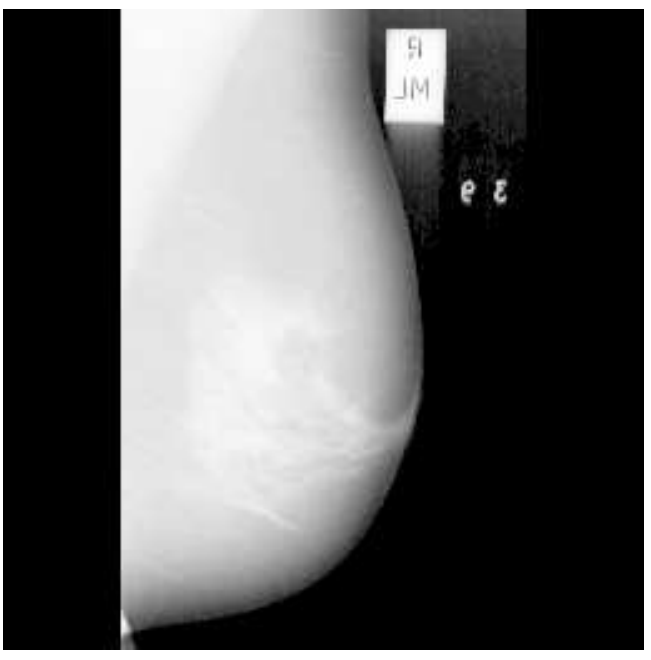

(b)

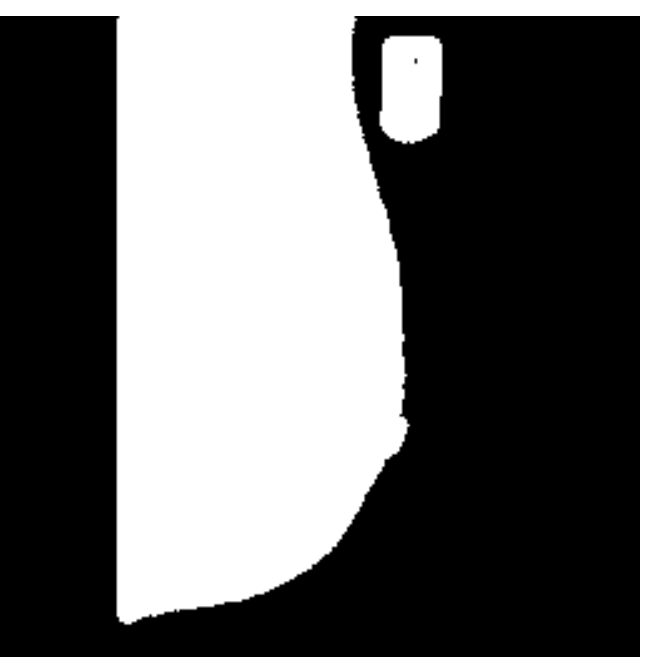

(d) 


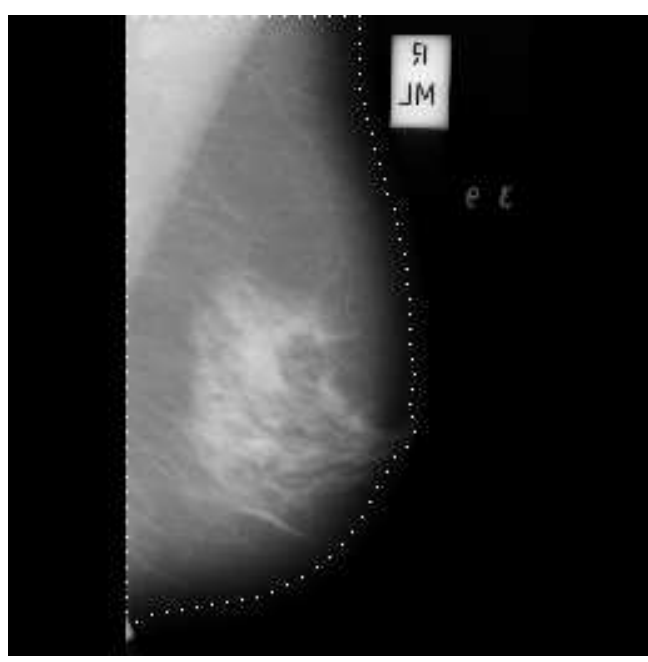

(e)

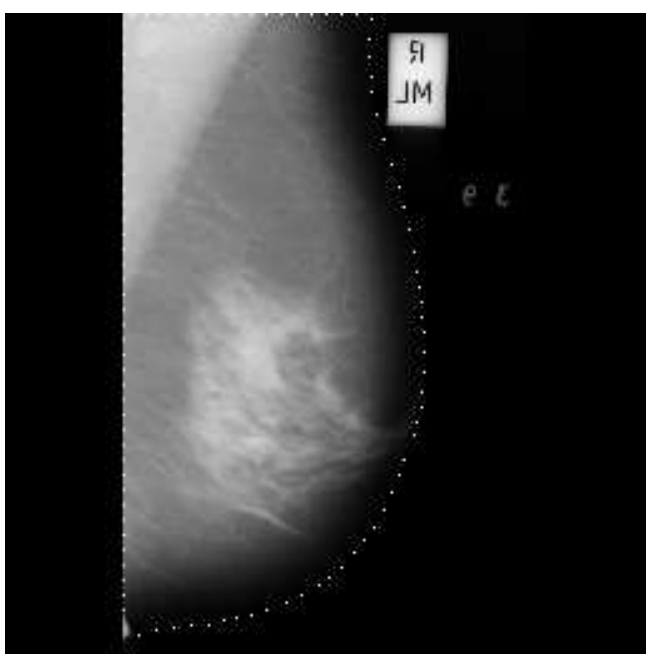

(f)

Figura 5.2: Resultados de cada um dos estágios do método de identificação da borda da mama. (a) Imagem original (mdb042 da base de dados Mini-MIAS [SUCKLING et al. (1994)]). (b) Imagem original após operação logarítmica. (c)(d) Imagem binária antes e depois da aplicação do operador morfológico "abertura". (e) Contorno inicial usado pelo modelo de contorno ativo proposto. (f) Borda final.

\subsubsection{Limiarização da imagem}

Após o realce de contraste, a imagem é limiarizada através do algoritmo "Lloyd - Max least-squares" [LLOYD (1982)], que é uma técnica iterativa e rápida (a convergência é alcançada em três ou quatro ciclos nesse trabalho) usada para o projeto de quantizadores com baixa distorção. Essa técnica usa o histograma da imagem para otimizar, em relação ao critério do erro médio quadrático, o procedimento de quantização aplicado à imagem, analisando cada um dos possíveis quantizadores de $N$-níveis $(N=2$ neste trabalho para propósito de binarização da imagem) para determinar qual deles fornece a menor distorção. A medida de distorção nesse caso é dada por

$$
\varepsilon=\min \sigma_{j}^{2}=\min \sum_{j=1}^{N} \sum_{x=a_{j}}^{b_{j}}(x-y)^{2} f(x),
$$

onde $y=\frac{1}{2}\left(L_{1}+L_{2}\right)$ é o valor de limiar para os níveis de quantização $L_{1}<L_{2}, f(x)$ 
é a função densidade de probabilidade representada neste caso pela distribuição dos níveis de cinza na imagem (histograma da imagem). A variável $x$ representa os valores dos níveis de cinza no intervalo $\left[a_{j}, b_{j}\right]$. Os valores $a_{j}, b_{j}$, e $\sigma_{j}^{2}$ indicam, respectivamente, os valores de níveis de cinza mínimo e máximo, e a variância do ruído para o nível de quantização $j$. Os níveis de quantização são calculados como o centróide do intervalo de quantização, que é definido como

$$
L_{j}=\frac{\sum_{x=a_{j}}^{b_{j}} x f(x)}{\sum_{x=a_{j}}^{b_{j}} f(x)}, j=1,2 .
$$

Nesse trabalho, o procedimento iterativo inicia-se com $L_{1}$ e $L_{2}$ iguais aos valores mínimo e máximo dos níveis cinza, respectivamente, determinados a partir do histograma da imagem. O procedimento é interrompido quando o valor do limiar y, calculado entre duas iterações consecutivas, não mais se altera.

A Figura 5.2(c) mostra um exemplo do resultado obtido da aplicação do processo de limiarização descrito acima.

\subsubsection{Remoção de espúrios através do operador morfoló- gico de abertura}

O processo de limiarização da imagem gera pequenos espúrios (grupos de pixels não conectados) próximos à borda da mama na imagem binária (ver Figura 5.2(c)), dificultando a determinação automática de uma borda inicial (ou aproximada) da mama. Nesse trabalho, o operador morfológico binário de abertura [GONZALEZ \& WOODS (1992)], com um elemento estruturante circular de diâmetro igual a 3 pixels, foi utilizado para eliminar os pequenos espúrios resultantes do processo de limiarização da imagem.

A operação de abertura, indicada pelo símbolo (o), é realizada a partir da aplicação combinada de duas operações morfológicas simples, erosão $(\ominus)$ e dilatação $(\oplus)$, de acordo com a seguinte fórmula 


$$
I \circ B=(I \ominus B) \oplus B
$$

onde $I$ representa a imagem e $B$ é o elemento estruturante.

Um exemplo da aplicação da operação morfológica de abertura é apresentado na Figura 5.2(d).

\subsubsection{Modelo discreto de contorno ativo}

Após a etapa de limiarização da imagem, um contorno aproximado $C_{\text {appr }}$ representando a borda da mama é obtido através do método "chain code" [GONZALEZ \& WOODS (1992)]. O ponto inicial do contorno $C_{a p p r}$ é obtido seguindo a linha horizontal que se inicia no centro de gravidade da imagem e vai em direção a parede do tórax até que um pixel de valor de cinza igual a zero (fundo da imagem) seja encontrado. Este procedimento é usado para evitar que o contorno $C_{a p p r}$ seja representado a partir de uma borda pertencente a um possível artefato ou rótulo de paciente, os quais podem estar presentes na image.

Finalmente, o contorno fechado $V=\left\{v_{1}, \cdots, v_{N}\right\}$, formado pela coleção ordenada de $N$ pontos $v_{i}=\left(x_{i}, y_{i}\right), i=\{1, \cdots, N\}$, é obtido através da amostragem, igualmente espaçada, do contorno aproximado $C_{a p p r}$. Esse contorno é então usado como contorno inicial para o modelo discreto de contorno ativo (MDCA), como ilustrado na Figura 5.2(e). Apenas 10\% do total de pontos presentes em $C_{a p p r}$ é usado no contorno amostrado. O MDCA, que combina importantes características de outros modelos de contorno ativo apresentados na literatura [MACKIEWICH (1995), LOBREGT \& VIERGEVER (1995), WILLIAMS \& SHAH (1992)], o contorno é movido no domínio espacial de maneira a minimizar o seguinte funcional de energia:

$$
E_{\text {total }}=\sum_{i=1}^{N}\left[\alpha E_{\text {interna }}\left(v_{i}\right)+\beta E_{\text {externa }}\left(v_{i}\right)\right],
$$


onde $\alpha$, e $\beta$ são os coeficientes que controlam, respectivamente, a contribuição das energias interna e externa em cada ponto $v_{i}$.

\subsubsection{Energia interna}

A energia interna usada neste trabalho é composta de dois termos como

$$
E_{\text {interna }}\left(v_{i}\right)=a E_{\text {continuidade }}\left(v_{i}\right)+b E_{\text {bala } a}\left(v_{i}\right) .
$$

Este componente de energia assegura uma forma estável ao contorno e tenta manter os pontos igualmente espaçados. Os parâmetros $a$ e $b$ controlam as contribuições dos dois termos que compõem a energia interna, e neste trabalho foram ajustados para $a=b=1$ visto que em geral os contornos iniciais apresentam uma forma suave e estão suficientemente próximos às bordas verdadeiras.

Termo continuidade: $\quad$ Para cada elemento $e_{j k}\left(v_{i}\right)$ numa vizinhança de $7 \times 7$ pixels, a energia de continuidade é calculada como:

$$
e_{j k}\left(v_{i}\right)=\frac{1}{l(V)}\left\|p_{j k}\left(v_{i}\right)-\rho\left(v_{i-1}+v_{i+1}\right)\right\|^{2}
$$

onde $l(V)=\frac{1}{N} \sum_{i=1}^{N}\left\|v_{i+1}-v_{i}\right\|^{2}$ é o fator de normalização que faz com que a energia seja independente do tamanho, localização e orientação do contorno $V$. $p_{j k}\left(v_{i}\right)$ é o ponto da imagem localizado na posição $(j, k)$ da vizinhança de $v_{i}$, e $\rho=\frac{1}{2 \cos \left(\frac{2 \pi}{N}\right)}$ é um valor constante que força com que a posição $v_{i}$ do contorno $V$ permaneça sobre o círculo que passa sobre os pontos $v_{i-1}$ e $v_{i+1}$, no caso de $V$ ser um contorno fechado.

\section{Força de Balão:}

A força de balão é usada para expandir o contorno inicial em direção à borda da mama. Neste trabalho, essa força é calculada de forma adaptativa à magnitude do gradiente da imagem, fazendo com que o contorno se expanda rapidamente em regiões homogêneas e lentamente em regiões 
próximas a borda da mama.

A energia de balão $e_{j k}\left(v_{i}\right)$ é definida como

$$
e_{j k}\left(v_{i}\right)=\vec{n}_{i} \bullet\left\{v_{i}-p_{j k}\left(v_{i}\right)\right\}
$$

onde $n_{i}$ é o vetor unitário normal localizado no ponto $v_{i}$ e aponta para a região externa de $V$. O símbolo $\bullet$ indica o produto interno. $n_{i}$ é calculado através da rotação do vetor $t_{i}=\frac{v_{i}-v_{i-1}}{\left\|v_{i}-v_{i-1}\right\|}+\frac{v_{i+1}-v_{i}}{\left\|v_{i+1}-v_{i}\right\|}$, que é o vetor unitário tangente ao contorno $V$ no ponto $v_{i}$.

\subsubsection{Energia externa}

A energia externa usada na formulação do MDCA utiliza informações de magnitude e direção do gradiente da imagem e visa atrair o contorno para a borda da mama. Ela é definida como

$$
e_{j k}\left(v_{i}\right)=-\vec{n}_{i} \bullet \nabla \vec{I}\left\{p_{j k}\left(v_{i}\right)\right\}
$$

onde $\vec{n}_{i}$ e $\nabla \vec{I}\left\{p_{j k}\left(v_{i}\right)\right\}$ indicam, respectivamente, o vetor unitário perpendicular ao contorno em $v_{i}$ e o vetor gradiente (magnitude e direção) da imagem na posição $(j, k)$ da vizinhança de $v_{i}$. A direção do gradiente é usada para evitar com que o contorno seja atraído para formas ou estruturas que possam estar próximas à borda verdadeira da mama, tais como: a identificação do tipo projeção, informações do paciente, ou pequenos artefatos - veja Figuras 5.3(a)-(d). Nesta situação, a direção do gradiente numa posição $(j, k)$, localizada na borda de uma estrutura externa à borda da mama, e a direção do vetor unitário normal ao contorno ativo terão sinais opostos, fazendo com que o termo de energia $e_{j k}\left(v_{i}\right)$ apresente um valor positivo, aumentando o valor total da energia do contorno. 


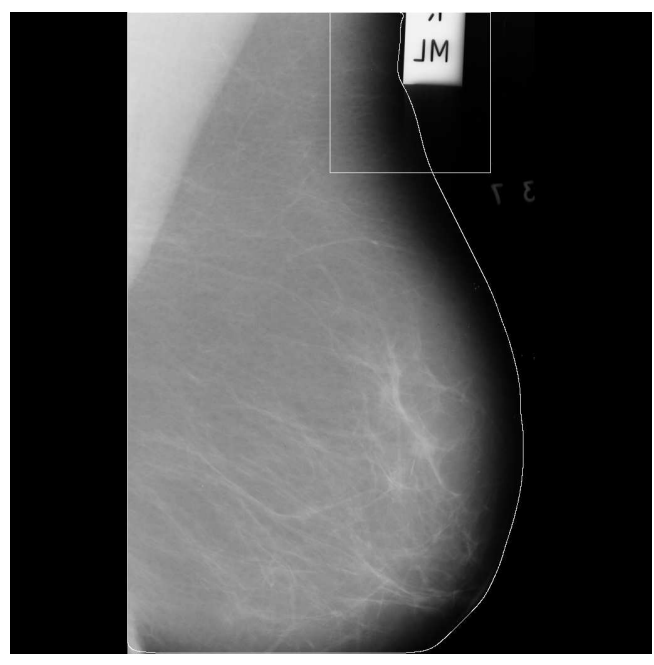

(a)

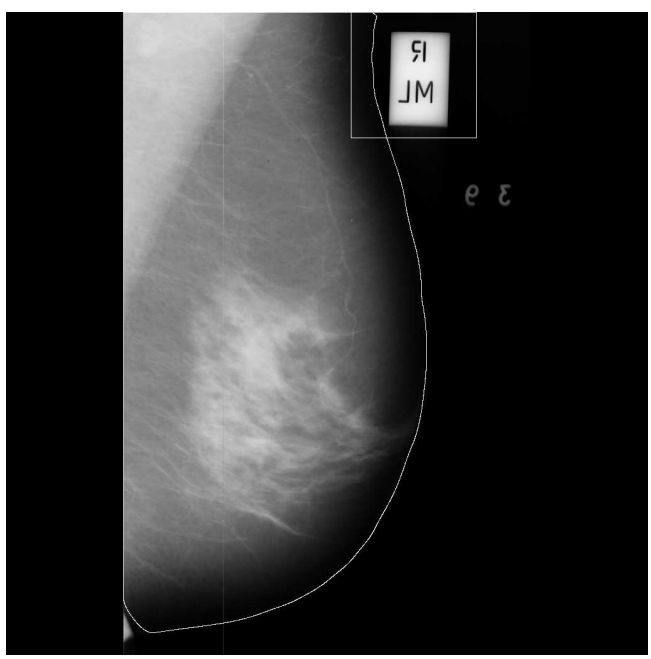

(c)

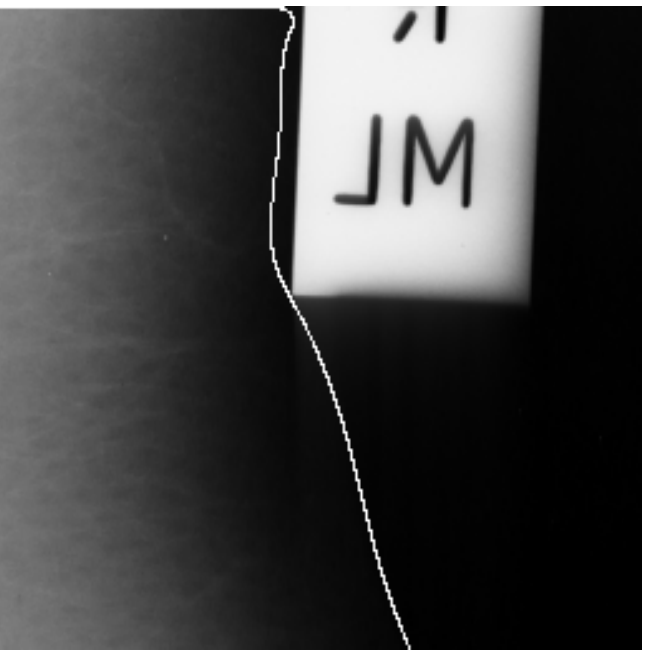

(b)

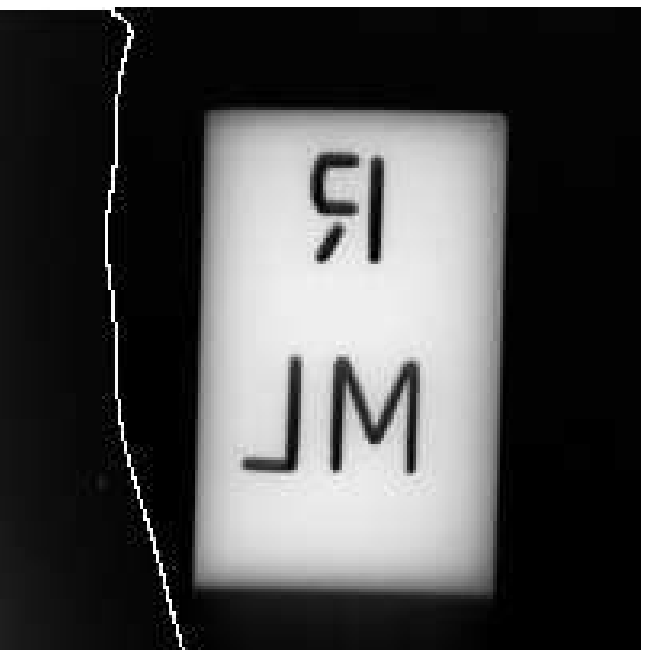

(d)

Figura 5.3: Aplicação da direção do gradiente para evitar que o contorno seja atraído para objetos próximos à borda verdadeira. (a) e (c) são as imagens originais mdb006 e mdb042, respectivamente, da base de dados Mini-MIAS [SUCKLING et al. (1994)]. (b) e (d) mostram os detalhes da borda da mama detectada corretamente mesmo estando próxima à marcas de identificações das projeções. 


\subsubsection{Regularização e ajuste dos parâmetros do modelo}

Para possibilitar a comparação direta entre os valores dos termos de energia $e_{j k}\left(v_{i}\right)$, calculados na posição $(j, k)$ da vizinhança de $v_{i}$, conforme as Equações $5.5,5.6$ e 5.7 , os valores $e_{j k}\left(v_{i}\right)$ são escalonados para o intervalo [0, 1] através das seguintes alterações aplicadas às equações de energia:

- Energia de continuidade: $e_{j k}^{\prime}\left(v_{i}\right)=\frac{e_{j k}\left(v_{i}\right)-e_{\min }\left(v_{i}\right)}{e_{\max }\left(v_{i}\right)-e_{\min }\left(v_{i}\right)}$,

- Energia de balão: $e_{j k}^{\prime}\left(v_{i}\right)=\frac{e_{j k}\left(v_{i}\right)-e_{\min }\left(v_{i}\right)}{e_{\max }\left(v_{i}\right)-e_{\min }\left(v_{i}\right)} \cdot\left(1-\frac{\left|\nabla I\left(v_{i}\right)\right|}{|\nabla I|_{\max }}\right)$,

- Energia externa: $e_{j k}^{\prime}\left(v_{i}\right)=\frac{e_{j k}\left(v_{i}\right)-e_{\min }\left(v_{i}\right)}{\max \left[e_{\max }\left(v_{i}\right)-e_{\min }\left(v_{i}\right),|\nabla I|_{\max }\right]}$,

onde $e_{\min }\left(v_{i}\right)$ e $e_{\max }\left(v_{i}\right)$ representam, respectivamente, os valores máximo e mínimo de cada um dos termos de energia calculados na vizinhança de $v_{i}$ definida por $7 \times 7$ pixels. $|\nabla I|_{\max }$ é o valor máximo do gradiente calculado na imagem.

Nesse trabalho, a minimização do funcional de energia indicado pela Equação 5.3, é realizada através do algoritmo Greedy proposto por WILLIAMS \& SHAH (1992). Embora esse algoritmo apresente a desvantagem de não garantir uma solução mínima global, ele é mais rápido que outros métodos propostos na literatura, tais como programação dinâmica [AMINI et al. (1990)], cálculo variacional [XU \& PRINCE (1998)] e elementos finitos [COHEN \& COHEN (1993)]. Ele permite também a inserção de restrições ao modelo como, por exemplo, a avaliação de curvatura em cada ponto do contorno discutida a seguir.

Para melhorar a estabilidade do movimento do contorno ativo, a propagação do contorno foi realizada através de dois estágios, numa abordagem "multiescala". Dessa forma, a imagem original foi suavizada através da convolução com dois núcleos gaussianos de variâncias iguais a $\sigma_{x}=\sigma_{y}=3$ e $\sigma_{x}=\sigma_{y}=1.5$ pixels. Em cada estágio, o processo de iteração é interrompido quando a energia total do MDCA aumenta entre duas iterações consecutivas.

Para permitir o ajuste do contorno ativo à regiões de quina, tal como a região superior da borda da mama (região demarcada pela pele da mama), uma restrição 
foi inserida no final de cada iteração. Essa restrição permite o relaxamento da energia de continuidade do modelo, definida pela Equação 5.5, dependendo do valor local de curvatura. O valor da curvatura $C\left(v_{i}\right)$ em cada ponto $v_{i}$ do contorno foi calculado como

$$
C\left(v_{i}\right)=2 \sin (\theta / 2)=\left|\frac{u_{i}}{\left|u_{i}\right|}+\frac{u_{i-1}}{\left|u_{i-1}\right|}\right|,
$$

onde $u_{i}=\left(v_{i+1}-v_{i}\right)$ é o vetor unindo dois elementos vizinhos do contorno, e $\theta$ é o ângulo externo definido pelos vetores $u_{i}$ e $u_{i-1}$ que compartilham um mesmo elemento comum.

Essa equação de curvatura, como discutido em WILLIAMS \& SHAH (1992), possui três importantes vantagens em relação a outras medidas de curvatura: ela é fácil e rápida de ser calculada, fornece valores coerentes, e depende apenas da posição relativa dos elementos do contorno.

Então, para cada posição $v_{i}$ do contorno, os fatores de peso para os termos de energia de continuidade $(a)$ e energia externa $(\beta)$, são ajustados, respectivamente, para zero $(a=0)$ e para duas vezes o seu valor inicial $(\beta=2 \beta)$ no caso da seguinte expressão ser satisfeita

$$
\left(C\left(v_{i}\right)>C\left(v_{i-1}\right)\right) \text { e }\left(C\left(v_{i}\right)>C\left(v_{i+1}\right)\right) \text { e }\left(C\left(v_{i}\right)>\text { Thresh }\right) .
$$

O valor do limiar Thresh foi ajustado para 0.25 nesse trabalho, o que corresponde a um ângulo externo de aproximadamente $29^{\circ}$. De acordo com WILLIAMS \& SHAH (1992), esse valor de limiar é suficiente para a diferenciação entre quinas e demais linhas curvas. As Figuras 5.4(b) and (c) ilustram um exemplo com e sem o uso da restrição de curvatura para a correção de problemas de quina.

Os fatores de peso $\alpha$ e $\beta$ na Equação 5.3 foram ajustados para cada elemento do contorno como 0.2 e 1.0, respectivamente. Esses dois parâmetros foram determinados experimentalmente através de um grupo de 20 imagens aleatoriamente escolhidas da base de dados Mini-MIAS [SUCKLING et al. (1994)] e não estão 


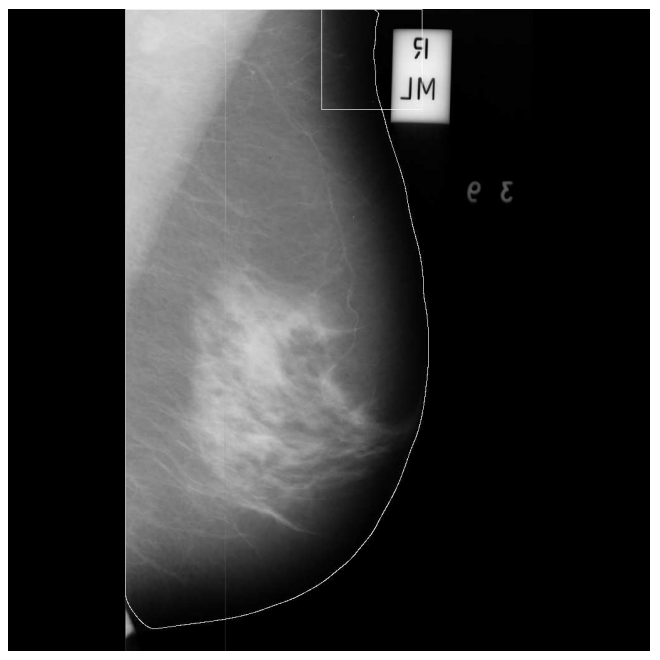

(a)

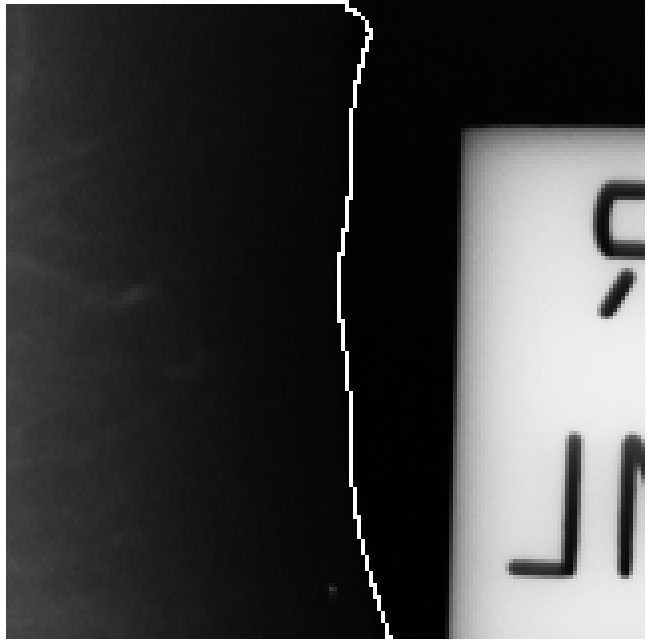

(b)

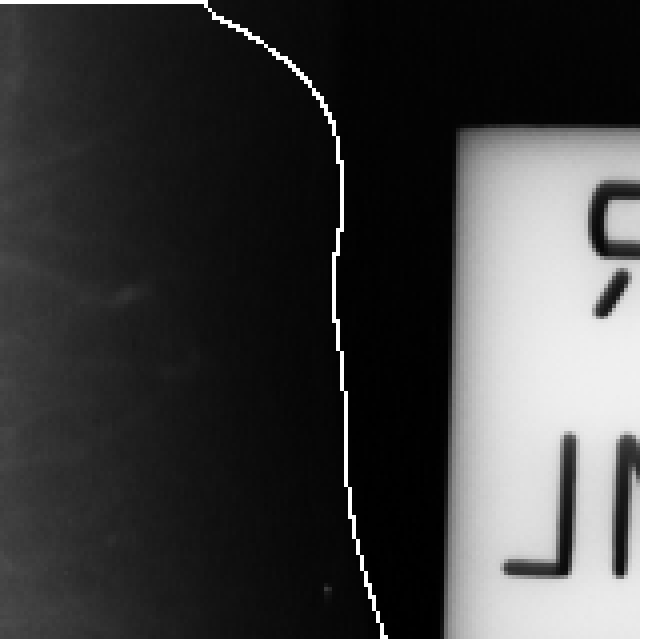

(c)

Figura 5.4: Exemplo da aplicação da restrição de curvatura usada pelo modelo de contorno ativo para a correção de efeitos de quinas. (a) Imagem original focalizando a região analisada. (b) e (c) mostram os detalhes do contorno da mama com e sem o uso da restrição, respectivamente. 
presentes no grupo de teste usado para a avaliação dos resultados dos métodos propostos. Um valor maior foi dado ao fator de peso da energia externa $(\beta) \mathrm{em}$ comparação à energia interna $(\alpha)$, favorecendo assim a deformação do contorno em direção à borda da mama. A Tabela 5.1 apresenta os valores dos parâmetros usados no método de detecção da borda da mama.

Tabela 5.1: Lista e descrição dos parâmetros usados pelo modelo de contorno ativo.

\begin{tabular}{c|l|c} 
Parâmetro & Descrição & Valor \\
\hline $\mathrm{a}$ & peso associado a energia de continuidade & 1.0 \\
\hline $\mathrm{b}$ & peso associado a energia de balão & 1.0 \\
\hline$\alpha$ & peso associado a energia interna & 0.2 \\
\hline$\beta$ & peso associado a energia externa & 1.0 \\
\hline
\end{tabular}

Embora esses parâmetros tenham sido determinados de maneira experimental, eles mostraram ser bastante robustos quando aplicados às imagens do grupo de teste.

\subsection{Identificação do músculo peitoral}

O músculo peitoral representa uma região densa predominante na maioria dos mamogramas de projeções MLO, e pode afetar os resultados de métodos de processamento de imagens. Métodos que se utilizam da intensidade de níveis de cinza, por exemplo, podem apresentar baixo desempenho quando aplicados para diferenciar estruturas densas tais como o disco glandular ou pequenas densidades suspeitas.

A análise isolada da região do músculo peitoral pode ajudar a identificar possíveis nódulos linfáticos anormais, os quais em alguns casos são as únicas manifestações de um carcinoma de mama oculto [HOMER (1997)]. Apenas alguns poucos trabalhos são encontrados na literatura discutindo esse problema. KARSSEMEIJER (1998) usou a transformada de Hough e um grupo de limiares aplicados ao arranjo acumulador a fim de detectar o músculo peitoral. AYLWARD et al. (1998) desenvolveram um algoritmo chamado "ridge traversal" para realçar 
estruturas lineares nos mamogramas. A seguir, os autores usaram um esquema de votação para determinar o segmento linear representando o músculo peitoral.

Nesse trabalho, duas novas técnicas são propostas para a determinação do músculo peitoral; a primeira [FERRARI et al. (2000b), FERRARI et al. (2000)] é baseada na transformada de Hough e é uma modificação do método proposto por KARSSEMEIJER (1998). A segunda técnica [FERRARI et al. (2001b)], a qual elimina a limitação imposta pela hipótese de representação do músculo peitoral por uma reta, utiliza uma representação Gabor wavelets [MANJUNATH \& MA (1996)], modificada especialmente para a solução do problema em questão.

\subsubsection{Método 1: Detecção através da transformada de Hough}

O método proposto para detectar o músculo peitoral com base na transformada de Hough é uma modificação do método proposto por KARSSEMEIJER (1998). O músculo peitoral é considerado como uma linha reta, e para efeito de filtragem é utilizado o fato de que esta linha sempre intercepta o segmento de reta N1-N2 ilustrado na Figura 5.5.

\subsubsection{Determinação da região de interesse contento o músculo pei- toral}

A região de interesse ("Region of Interest" - ROI) usada para detectar o músculo é a região retangular definida pelos pontos N1, N2, N3 e N4. Os pontos N1, N3 e N5 são determinados a partir da parede do tórax no mamograma, enquanto que os pontos N2 e N6, indicando os limites da borda "pele-ar", são determinados como os pontos mais distantes à N5 e N1, respectivamente. 


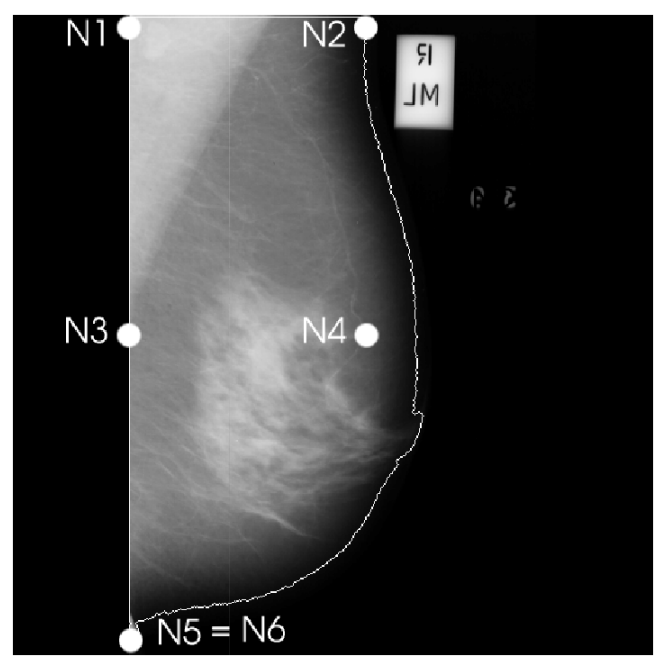

Figura 5.5: Pontos de controle determinados automaticamente e utilizados para delimitar a ROI usada na detecção do músculo peitoral. Coincidentemente, neste caso $\mathrm{N} 5=\mathrm{N} 6$.

\subsubsection{Construção do arranjo acumulador}

Após a determinação automática da ROI, um núcleo gaussiano com desvios padrão iguais a $\sigma_{x}=\sigma_{y}=4$ pixels é convoluído com a ROI para remover ruídos de alta freqüência da imagem. A seguir, a transformada de Hough é aplicada na imagem gradiente (gradiente de Sobel) da ROI para a detecção do músculo peitoral.

A linha reta, representando o músculo, é especificada no sistema polar como

$$
\rho=\left(x-x_{0}\right) \cos \theta+\left(y-y_{0}\right) \sin \theta
$$

onde $\left(x_{0}, y_{0}\right)$ é o centro do sistema de coordenadas da imagem, e $\rho$ e $\theta$ representam, respectivamente, a distância e o ângulo entre $\left(x_{0}, y_{0}\right)$ e a coordenada $(x, y)$ do pixel analisado, conforme indicado na Figura 5.6. O arranjo acumulador da transformada de Hough é quantizado em 45 faixas de $4^{\circ}$ cada uma a partir da seguinte restrição $\left|\phi_{x, y}-\theta\right|<2^{\circ}$, onde $\phi_{x, y}$ é a orientação do pixel localizado na posição $(x, y)$ da imagem gradiente. 


\subsubsection{Filtragem do arranjo acumulador para remoção de improváveis retas}

Após a aplicação da transformada de Hough, um procedimento de filtragem é usado para eliminar as retas improváveis (pares de parâmetros $\rho$ e $\theta$ ). Neste procedimento, todas as linhas interceptando o topo da imagem fora da região definida pelo segmento de reta N1-N2 são removidas ajustando-se as respectivas células do arranjo acumulador para zero. Além disso, linhas com inclinações angulares fora do limite $\left[\frac{\pi}{6} ; \frac{\pi}{2}\right.$ [ são também desconsideradas (neste trabalho, o eixo $x$ corresponde a $0^{\circ}$ e a parede do tórax é sempre posicionada ao lado esquerdo, como indicado na Figura 5.6).

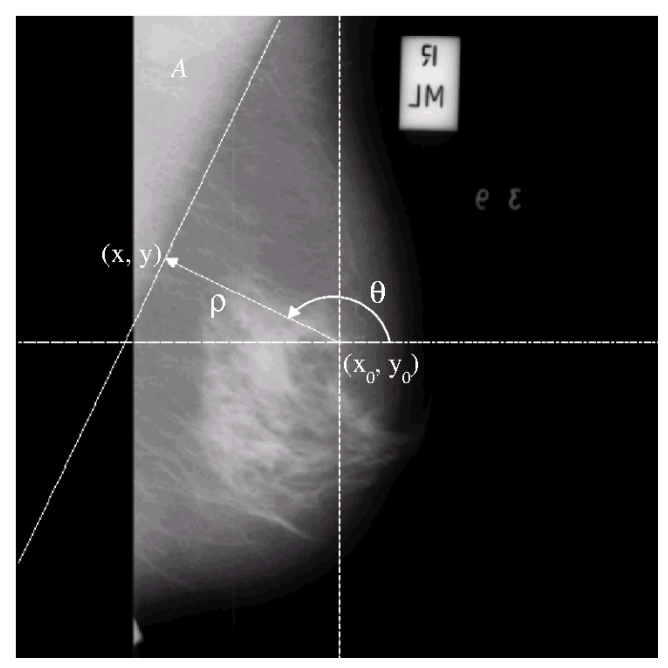

(a)

Figura 5.6: Coordenadas usadas para o cálculo da transformada de Hough.

\subsubsection{Realce de células do arranjo acumulador}

Depois do procedimento de filtragem, cada célula no acumulador é multiplicada pelo seu respectivo fator $\alpha=\left.\frac{\mu}{\sigma^{2}} A\right|_{\theta, \rho}$, onde $\mu$ e $\sigma^{2}$ representam, respectivamente, a média e a variância dos valores de níveis de cinza na área $A$ definida pela linha reta especificada pelos parâmetros $\rho$ e $\theta$ e pela parede do tórax. 


\subsubsection{Definição da reta representando o músculo peitoral}

Finalmente, o par de parâmetros $\rho$ e $\theta$, correspondendo a célula de maior valor no arranjo acumulador, é usado para representar a linha do músculo peitoral. A Figura 5.7 apresenta um diagrama de blocos do método descrito acima para a detecção do músculo peitoral.

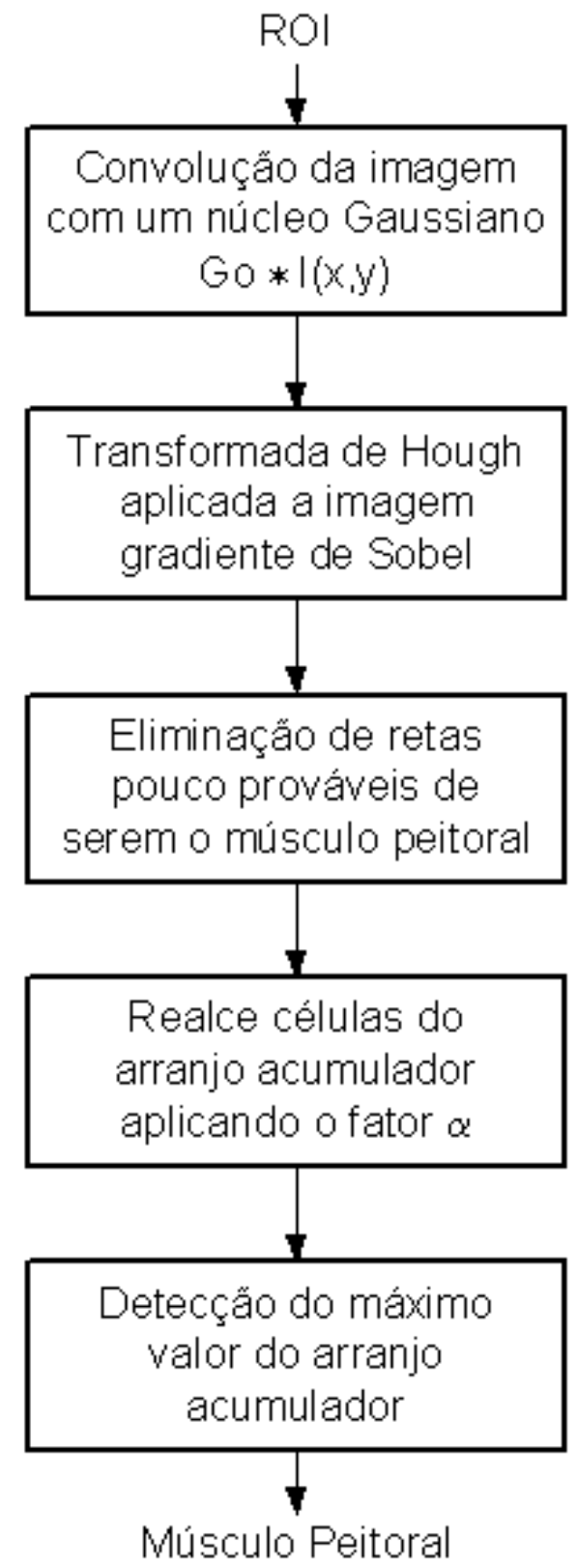

Figura 5.7: Diagrama de blocos do procedimento de identificação do músculo peitoral através da transformada de Hough. 


\subsubsection{Método 2: Deteç̧ão através de Gabor wavelets}

Na representação Gabor wavelets proposta por MANJUNATH \& MA (1996), descrita no Apêndice A - Seção A.4, um banco de filtros de Gabor é projetado de maneira apropriada a fim de maximizar as respostas dos filtros com o mínimo de redundância na representação. Neste trabalho, tal representação foi utilizada para realçar estruturas lineares, em um intervalo específico de direções da ROI contendo o músculo peitoral.

\subsubsection{Determinação da região de interesse contento o músculo pei- toral}

A região de interesse contendo o músculo peitoral usada nesta técnica é definida automaticamente a partir da parede do tórax e do limite superior da borda pele-ar da mama, conforme indicado na Figura 5.8(b).

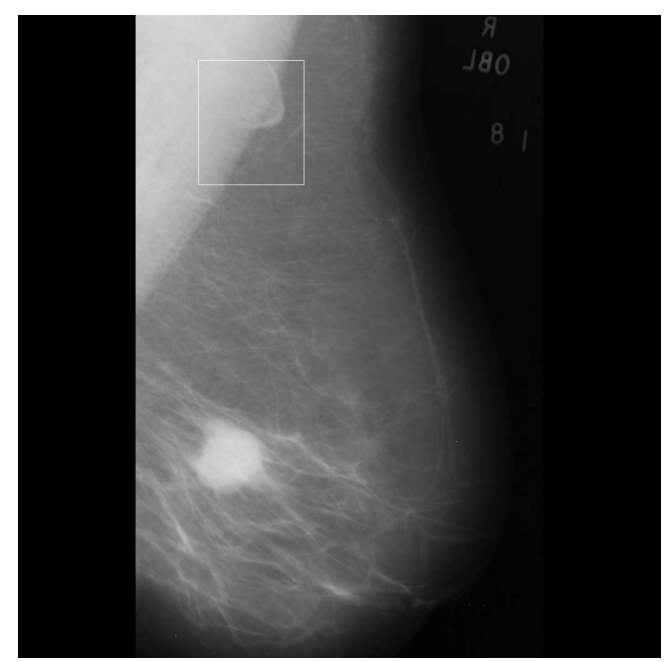

(a)

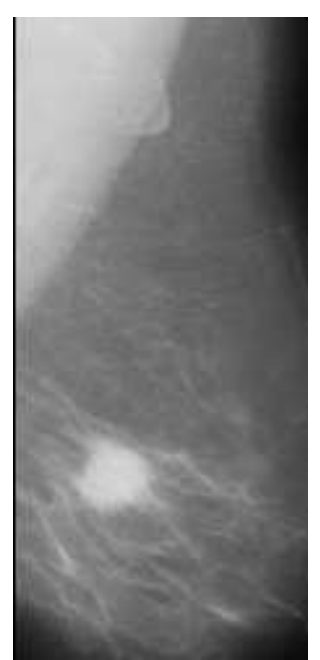

(b)

Figura 5.8: (a)-(b) Imagem original mdb028 e a respectiva ROI usada na determinação do músculo peitoral. 


\subsubsection{Decomposição da ROI em componentes direcionais}

A decomposição da ROI em componentes com diferentes escalas e orientações é executada através da convolução da imagem da ROI com os filtros de Gabor indicados em destaque na Figura 5.9.

Os parâmetros da representação de Gabor foram ajustados neste trabalho como $U_{l}=0.05, U_{h}=0.45, S=4$, e $K=12$ para imitar os modelos visuais propostos por pesquisadores na área de neurofisiologia (ver Apêndice A). Através desses valores de parâmetros assegura-se uma largura de banda em freqüência de uma oitava e uma largura de banda angular de $15^{\circ}$ entre os filtros.

Visto que neste trabalho todas as imagens são orientadas de forma que a parede toráx fique posicionada à esquerda, então, para projeções MLO adquiridas adequadamente, o músculo peitoral estará localizado sempre acima de $45^{\circ}$ e abaixo de 90², [TUCKER (1993) (Capítulo 3 - página 34)] (o ângulo de orientação do músculo peitoral é definido como indicado na Figura 5.6.). Por esse motivo, apenas filtros de Gabor com orientações de $45^{\circ}, 60^{\circ}$ e $75^{\circ}$ (no domínio espacial) foram utilizados, conforme indicado em destaque na Figura 5.9.

\subsubsection{Pós-processamento e detecção do músculo peitoral}

As imagens filtradas, resultantes da convolução da ROI com os filtros de Gabor, são utilizadas para compor as imagens de magnitude e de fase. Esse procedimento é realizado através da aplicação da transformada KL entre as escalas, seguido de uma soma vetorial, conforme descrito no Apêndice A, Seção A.7.

A partir das imagens de magnitude e fase, formas relevantes são detectadas na ROI utilizando um algoritmo proposto por MA \& MANJUNATH (2000) (ver algoritmo 1) para a propagação do "fluxo de gradientes de bordas" ("EdgeFlow").

Entretanto, diferente do algoritmo original, que usa um modelo preditivo com elevado custo computacional para a determinação do vetor de fluxo de gradientes, neste trabalho esse vetor é representado pelas informações de magnitude, $A(s)$, e a fase, $\phi(s)$, obtidas em cada localização $s$ da imagem. 


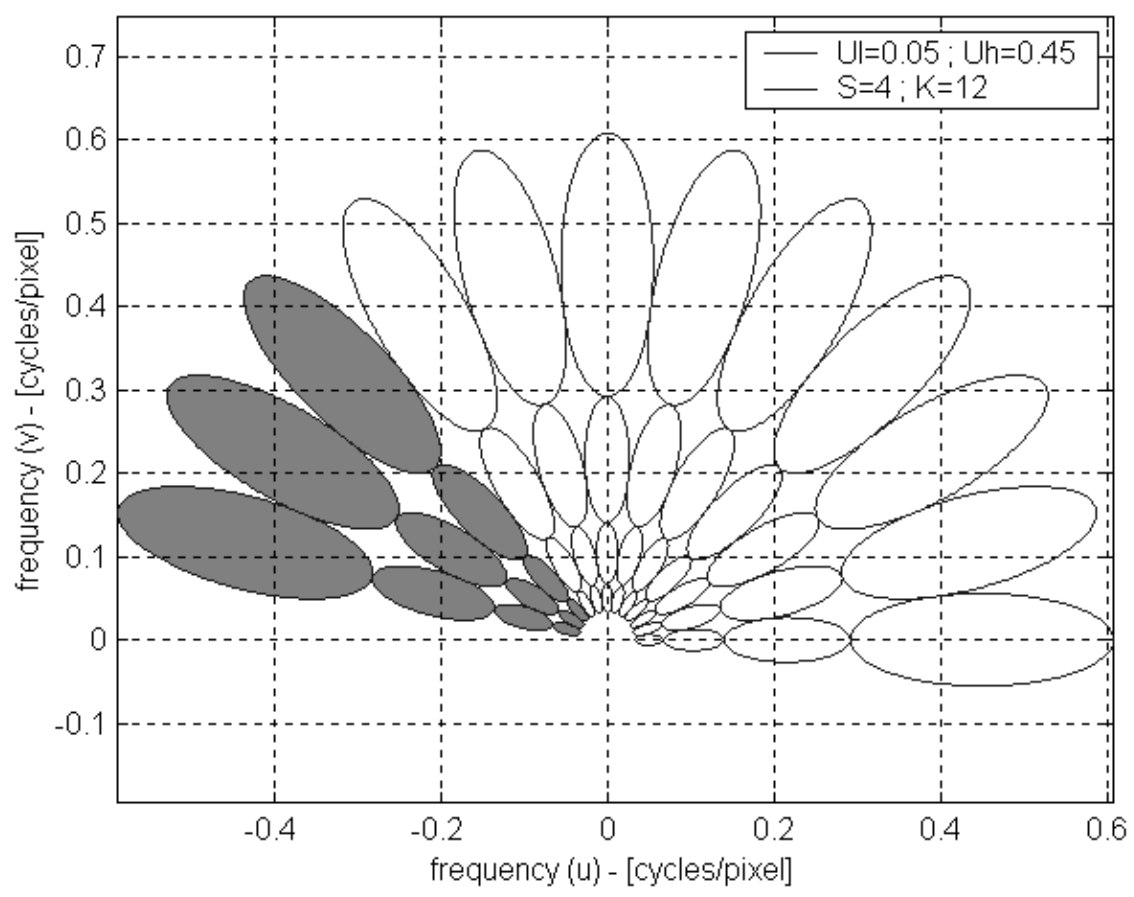

Figura 5.9: Banco de filtros de Gabor projetado no domínio da freqüência. Cada elipse representa uma faixa de resposta de um determinado filtro, com valores de magnitude ao quadrado no intervalo de 0.5 a 1.0. A amostragem do espectro de freqüências pode ser ajustada através da modificação dos parâmetros $U_{l}, U_{h}, S$, e $K$ da representação. Apenas os filtros em destaque foram usados para realçar estruturas lineares presentes na região de interesse.

$\overline{\text { Algorithm } 1 \text { Algoritmo para a propagação do fluxo de gradientes de bordas }}$ proposto por MA \& MANJUNATH (2000) e usado aqui para a propagação dos vetores resultantes da soma vetorial entre as imagens filtradas.

1. Ajuste $n=0$ e $\vec{F}_{0}(s)=[A(s) \cdot \cos \phi(s), A(s) \cdot \sin \phi(s)]$

2. Ajuste o vetor $\vec{F}_{n+1}(s)$ para zero na iteração $n+1$.

3. Para cada localização $s$ na imagem, identifique o pixel vizinho $s^{\prime}=\left(x^{\prime}, y^{\prime}\right)$ cuja direção coincide com a orientação $\theta$ do vetor de formas $\vec{F}_{n}(s)$. A direção $\theta$ é calculada como $\theta=\arctan ((y,-y) /(x,-x))$.

4. Se $\left(\vec{F}_{n}\left(s^{\prime}\right) \bullet \vec{F}_{n}(s)>0\right)$ - (o símbolo • representa o produto escalar) então $\vec{F}_{n+1}\left(s^{\prime}\right)=\vec{F}_{n+1}\left(s^{\prime}\right)+\vec{F}_{n}(s)$

caso contrário $\vec{F}_{n+1}(s)=\vec{F}_{n+1}(s)+\vec{F}_{n}(s)$.

5. Se não houver nenhuma mudança

então pare o processo iterativo,

caso contrário, vá para o estágio 2 e repita o procedimento novamente. 
A direção do vetor de bordas em cada ponto na imagem é propagada até que seja alcançada uma posição onde o fluxo se oponha à direção de propagação. As Figuras 5.10(b) e (c) ilustram um exemplo do mapa de orientações antes e depois da aplicação do algoritmo 1.

Depois da propagação dos vetores, as bordas candidatas para representar o músculo peitoral são obtidas através da identificação das localizações apresentando valores de fluxo diferentes de zero vindos de duas direções opostas.

Bordas fracas (pouco prováveis) são eliminadas através de um limiar aplicado à ROI. O valor do limiar é fixado em $10 \%$ do valor máximo dos tons de cinza encontrados na ROI.

Com a finalidade de unir segmentos de borda desconectados, geralmente presentes na imagem após a propagação do fluxo de gradientes de bordas, uma vizinhança em forma de meia-elipse, com seu centro localizado no pixel de início ou de fim da borda analisada, foi definida. Essa meia-elipse é posicionada com seu eixo principal na mesma direção da borda e seu tamanho é ajustado de maneira proporcional ao comprimento da borda $\left(R_{1}=0.2 \times C_{\text {len }} \text {, e } R_{2}=5 \text { pixels }\right)^{1}$. Se um pixel de fim ou início de uma linha desconectada é encontrado na vizinhança definida acima, este é conectado à borda através de uma técnica linear simples de interpolação.

O método descrito acima é iterativo e termina após todos os segmentos de borda serem analisados, o que normalmente é realizado em algumas poucas iterações (cinco a vinte iterações neste trabalho). Falsas bordas, resultantes da resposta dos filtros às estruturas orientadas dentro do disco fibro-glandular ou do próprio processo de filtragem (ver Figuras 5.11(c)-(d)), são removidas se seus limites se encontram distantes do topo ou do lado esquerdo da imagem da ROI, ou se a linha reta com ângulo de inclinação formado pelos pontos limites dessa borda candidata interceptar o topo e o lado esquerdo da ROI fora de seus limites. Finalmente, a linha resultante de maior comprimento é definida como o músculo

\footnotetext{
${ }^{1} R_{1}$ e $R_{2}$ indicam, respectivamente, os raios maiores e menores da meia-elipse. $C_{l e n}$ é o comprimento do segmento de borda sendo analisado.
} 


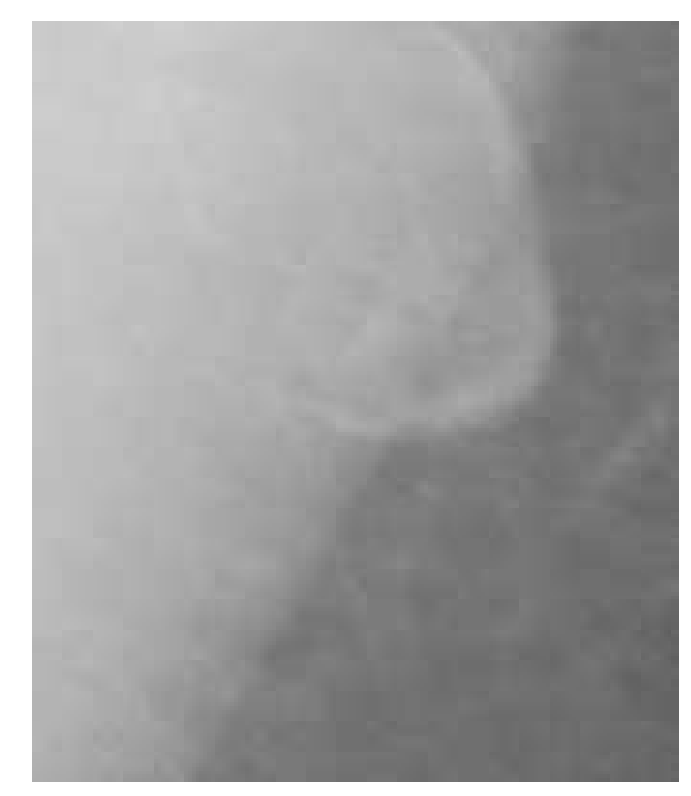

(a)

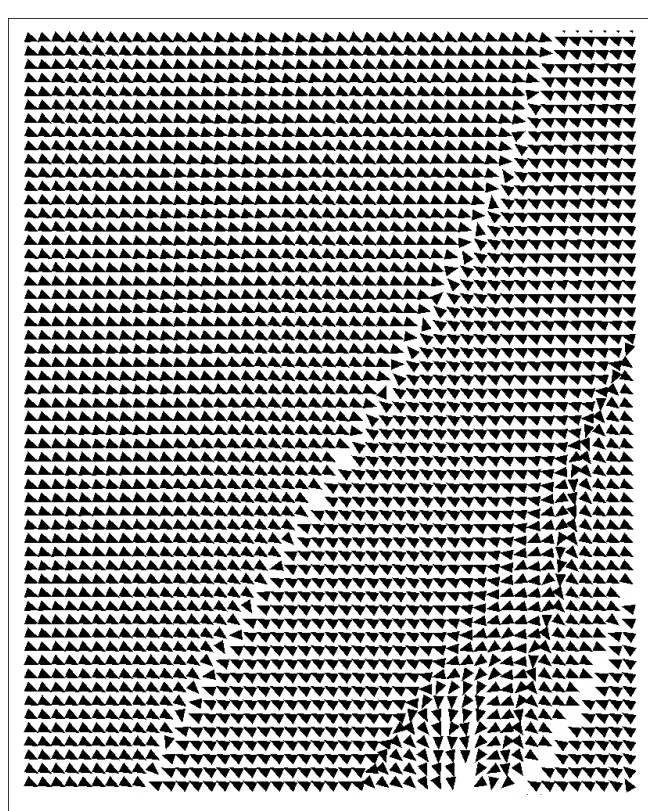

(b)

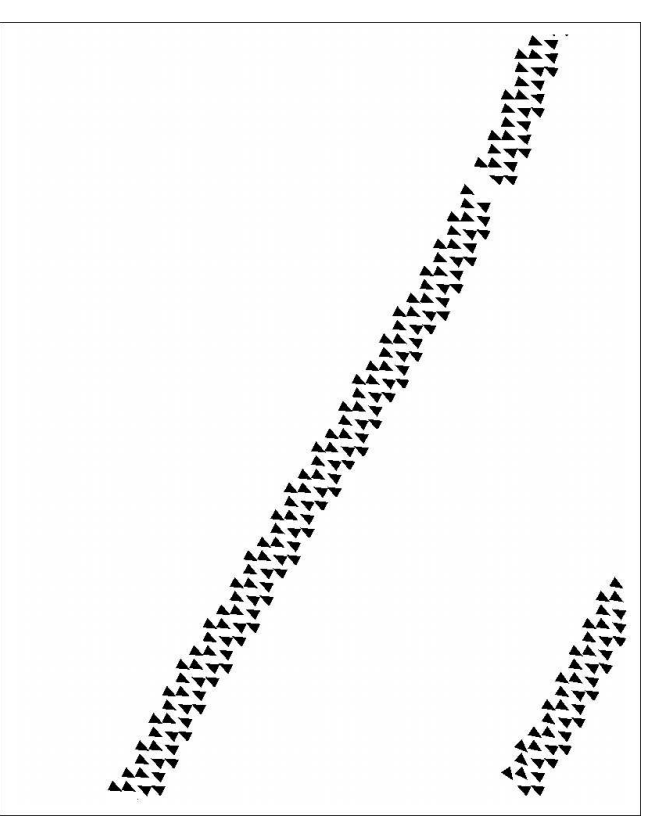

(c)

Figura 5.10: (a) Pequena região indicada na Figura 5.8(a) contendo uma parte da linha do músculo peitoral. As imagens (b) e (c) mostram o mapa de fluxo de gradientes de bordas antes e depois da propagação do fluxo. 


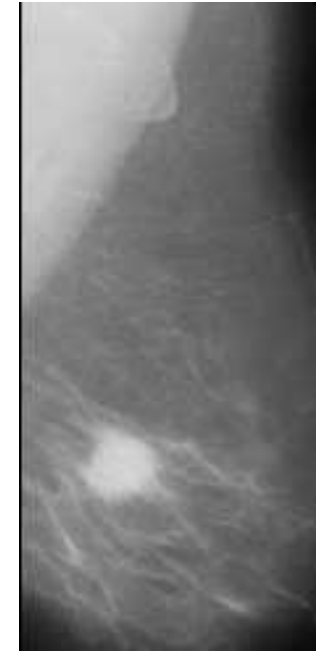

(a)

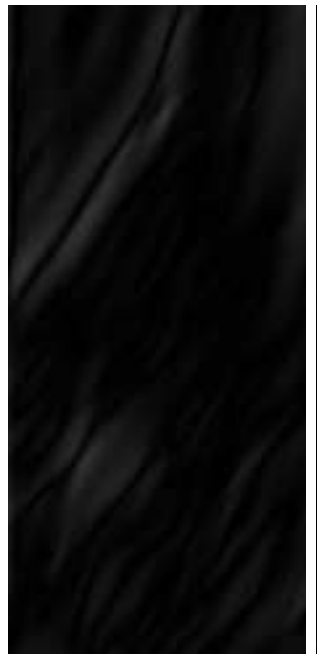

(b)

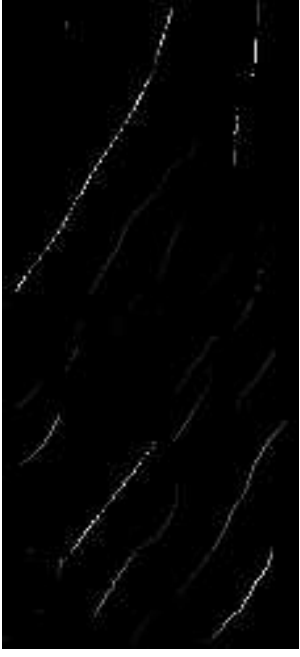

(c)

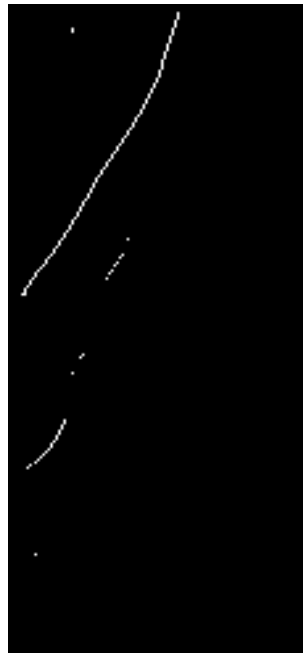

(d)

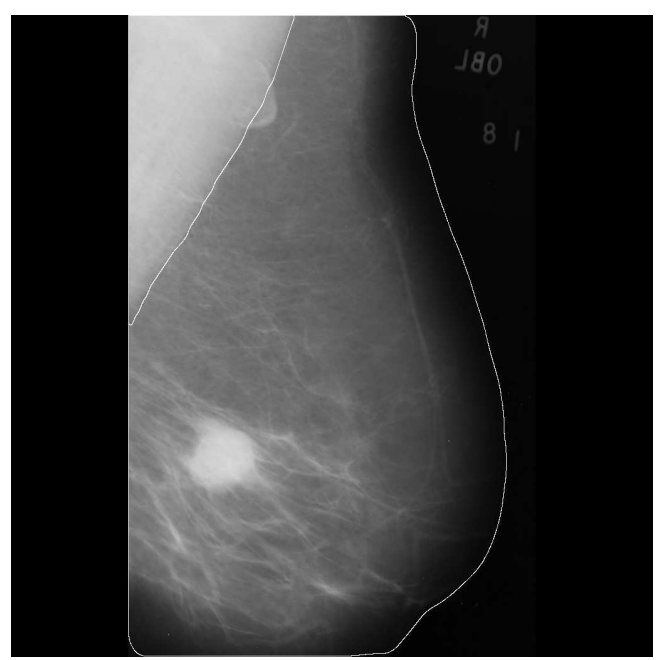

(e)

Figura 5.11: Resultado de cada estágio do método proposto para a detecção da borda do músculo peitoral. (a) Região de interesse usada para pesquisar a borda do músculo. (b) Imagem de magnitude resultante após a aplicação da representação Gabor wavelets seguida por soma vetorial. (c)-(d) Imagens resultantes antes e depois do estágio de pós-processamento. (e) Borda final indicada na imagem original. 
peitoral.

As Figuras 5.11 e 5.12 apresentam, respectivamente, as imagens resultantes e o diagrama de blocos dos principais estágios do método descrito anteriormente.

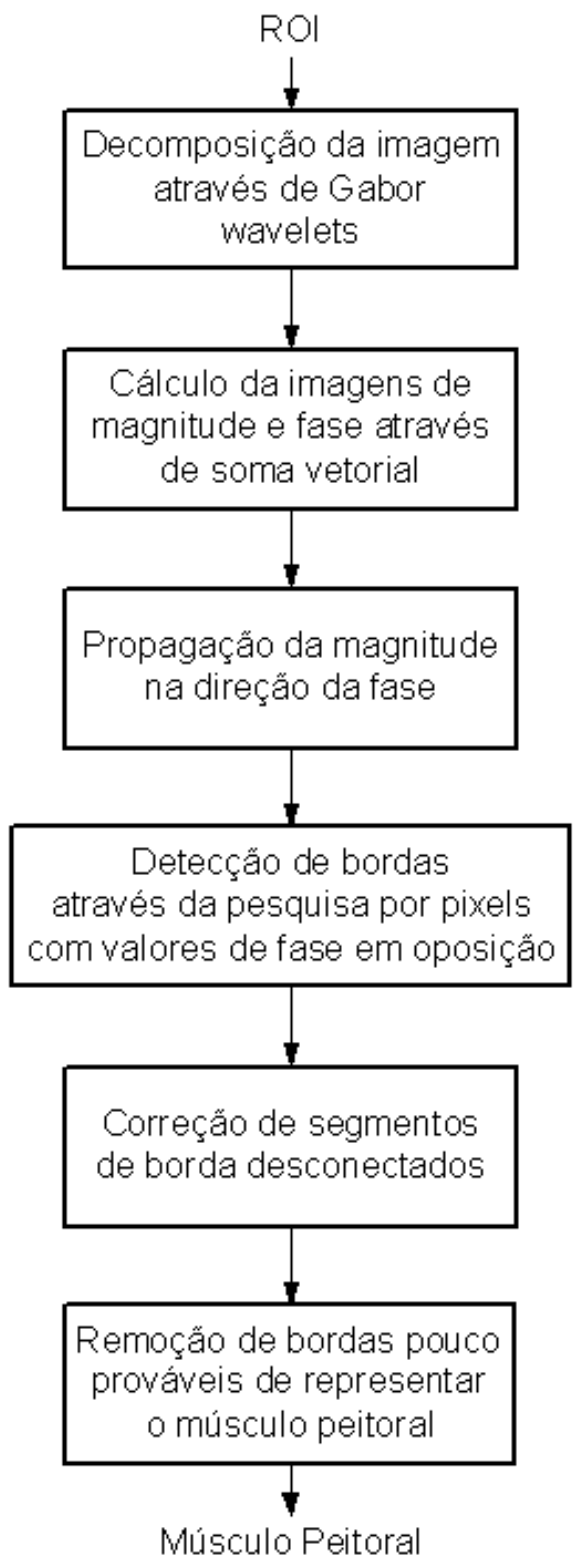

Figura 5.12: Diagrama de blocos do procedimento proposto para a detecção do músculo peitoral. 


\subsection{Detecção do disco fibro-glandular}

O disco fibro-glandular é uma região anatômica da mama caracterizada por tecidos densos, ligamentos e ductos de leite. Normalmente, ele se apresenta na forma de um disco ou cone no mamograma e se estende desde a parede do tórax até o mamilo [BASSETT \& GOLD (1987) - Seção "Anatomy of the breast"]. De acordo com CAULKIN et al. (1998), é observado clinicamente que os canceres de mama ocorrem com maior freqüência no quadrante superior lateral da mama e em sua maioria estão associados a tecidos glandulares.

Um procedimento comum usado pelos radiologistas em programas de rastreamento é a comparação entre os disco glandulares esquerdo e direito de uma mesma paciente. Este tipo de análise é baseado principalmente em informações de forma e densidade dos discos fibro-glandulares. Portanto, a identificação automática e subseqüente análise das regiões dos discos glandulares são de muita importância para os sistemas CAD.

Vários trabalhos tem sido apresentados na literatura para a quantificação automática dos tecidos densos da mama e análise de sua associação com o risco do câncer de mama [WOLFE (1976b), BYNG et al. (1994), BYNG et al. (1996), TAHOCES et al. (1995), KARSSEMEIJER (1998), HUO et al. (2000), SIVARAMAKRISHNA et al. (2001)]. Muitos desses trabalhos propõem um índice ou grupo de valores para a quantificação dos tecidos densos. Entretanto, apenas algumas pesquisas [AYLWARD et al. (1998), MATSUBARA et al. (2000), FERRARI et al. (2000b), ZHOU et al. (2001)], tem investigado métodos para a segmentação automática da região do disco glandular, visando análises posteriores.

Nesse trabalho, o disco fibro-glandular de um mamograma é detectado através de um modelo de densidades proposto e projetado através de uma mistura finita de gaussianas [BISHOP (1995)]. A partir desse modelo e da informação de intensidade do músculo peitoral, o disco fibro-glandular é determinado. 


\subsubsection{Modelo de densidades da mama}

O modelo de densidades da mama é baseado na mistura finita de gaussianas [BISHOP (1995)] e é estimado através da distribuição da intensidade dos níveis de cinza da imagem e representa categorias ou classes de densidades dentro da imagem.

Diferente do modelo proposto por AYLWARD et al. (1998), que fixa em cinco o número de classes de densidades presentes no mamograma, o modelo proposto neste trabalho usa a hipótese de que o número de classes de densidades, dentro da região efetiva da mama, pode variar entre dois e quatro, dentre as seguintes possibilidades:

1. Classe 1 - (tecidos adiposos não-comprimidos): esta classe é representada por tecidos adiposos localizados na periferia da mama.

2. Classe 2 - (tecidos adiposos): composta por tecidos adiposos localizados logo após a periferia da mama e faz fronteira com áreas de tecidos densos do disco fibro-glandular.

3. Classe 3 - (tecidos densos não uniformes): regiões densas próximas a porções muito densas do disco fibro-glandular e se extendem até próximo a parede do tórax.

4. Classe 4 - (tecidos altamente densos): esta classe é representada por porções altamente densas de tecido glandular - disco fibro-glandular.

Com exceção da primeira categoria, as categorias descritas a seguir estão relacionadas aos tipos de tecidos presentes na mama.

A hipótese formulada acima baseia-se no fato de que os tecidos que compõem a mama podem naturalmente mudar de uma paciente para a outra ou mesmo na mesma paciente durante seu período de vida [WOLFE (1976)]. Além disso, atualmente essas modificações na densidade da mama tem se acentuado devido ao uso 
de terapias de reposição hormonal [RUTTER et al. (2001)]. Portanto, mamogramas de mamas muito densas ou muito adiposas, provavelmente apresentarão apenas duas das categorias descritas acima.

\subsubsection{Modelo basedo na mistura finita de gaussianas}

A função densidade de probabilidade do modelo proposto na Seção 5.3.1 é representada pela superposição linear de múltiplos núcleos gaussianos, cada um com um peso específico associado, como

$$
f(x \mid \Theta)=\sum_{i=1}^{K} W_{i} f\left(x \mid \theta_{i}\right)
$$

onde os valores de $x$ representam os valores dos níveis de cinza da imagem, $W_{i}$ são os parâmetros normalizados da mistura $\left(\sum_{i=1}^{K} W_{i}=1\right.$ e $\left.0 \leq W_{i} \leq 1\right)$, e $f\left(x \mid \theta_{i}\right)$ é a função densidade de probabilidade aussiana parametrizada por $\theta_{i}=\left[\mu_{i}, \sigma_{i}\right]$ (i.e., o valor da média e da variância do núcleo gaussiano $i$ ). O vetor $\Theta$ representa a coleção de parâmetros do modelo da mistura $\left(W_{1}, \ldots, W_{K}, \theta_{1}, \ldots, \theta_{K}\right)$, e $K$ é o número de núcleos gaussianos. Cada núcleo gaussiano nesse trabalho é representado por

$$
f\left(x \mid \theta_{i}\right)=\frac{1}{2 \pi \sigma_{i}^{2}} \exp \left[-\frac{\left(x-\mu_{i}\right)^{2}}{2 \sigma_{i}^{2}}\right]
$$

A restrição imposta sob a forma dos núcleos gaussianos no modelo descrito acima, faz com que o processo de estimação de seus parâmetros se torne mais simples, diminuindo assim o tempo para o processamento dos mamogramas.

Para a estimação dos parâmetros do modelo da mistura foi utilizado o algoritmo "Deterministic Annealing Expectation Maximization" (DAEM) [ROSE (1998), UEDA \& NAKANO (1998)], que é um algoritmo iterativo usado para o cálculo do estimador de máxima-verossimilhança num contexto de "dados incompletos". Uma descrição dos algoritmos "Expectation Maximization" (EM) e DAEM é apresentada no Apêndice B desta tese. 


\subsubsection{Inicialização dos parâmetros do modelo}

O processo de iteração usado pelo método DAEM requer uma inicialização prévia ("chute inicial") dos parâmetros do modelo. Neste trabalho, os parâmetros foram inicializados através do ajuste do centro e do fator de peso de cada gaussiana como $\mu_{i}=\eta$, e $W_{i}=\frac{1}{K}$, onde $i=1, \cdots, K$ é o índice do núcleo gaussiano, $\eta$ é um valor aleatório contido dentro da faixa de valores mínimo e máximo dos tons de cinza da imagem. $\mathrm{O}$ valor da variância de cada núcleo gaussiano foi inicializado como o valor da menor distância entre os demais núcleos.

Se o valor da variância $\sigma_{i}^{2}$ de cada gaussiana se torna menor que a unidade durante o estágio de maximização (estágio "M") do algoritmo DAEM, esse é reinicializado através de um valor aleatório maior que a unidade. Esse procedimento é usado para evitar que a variância se fixe em algum valor muito pequeno. $\mathrm{O}$ procedimento de estimação usando o algoritmo DAEM é inicializado e repetido três vezes, com o intuito de minimizar as chances de convergência do algoritmo para um mínimo local.

O valor de $\beta$ no algoritmo DAEM variou neste trabalho entre 0.2 a $1.0 \mathrm{com}$ incrementos de $20 \%$ a cada iteração, e para cada valor de $\beta$, os estágios "E" e "M" foram executados até que o erro de estimação entre dois estágios consecutivos fosse menor que $1 \%$.

\subsubsection{Seleção do melhor modelo}

Além da inicialização dos parâmetros, uma outra dificuldade com os modelos de mistura de gaussianas está no fato da escolha do número de componentes que melhor se ajusta aos agrupamentos (categorias de densidades neste trabalho) presentes na imagem.

Como discutido na seção 5.3.1, o número de categorias de densidades do modelo proposto pode variar entre 2 e 4 . Visto não haver nenhuma informação confiável a respeito do número de categorias presentes num dado mamograma, a técnica "Minimum Description Length" (MDL) [RISSANEN (1978)] foi utilizada 
para selecionar o número $K$ de núcleos gaussianos mais adequado ao modelo. $\mathrm{O}$ princípio por trás da técnica MDL relaciona o compromisso entre o critério de máxima-verossimilhança (ou mínimo erro) usado para ajustar o modelo a partir de um grupo de dados e a complexidade do modelo sendo projetado [CARSON et al. (1999)]. Dessa maneira, se os modelos projetados usando dois valores diferentes de $K$ se ajustarem aos dados igualmente bem (no sentido do mínimo erro), então o modelo mais simples é usado. A técnica MDL age essencialmente como uma função de custo na escolha do melhor modelo.

Neste trabalho, o valor de $K$ é escolhido de forma a maximizar a quantidade

$$
\log L(\bar{\Theta} \mid x)-\frac{N(k)}{2} \log K
$$

onde $N(k)=K \cdot(2 \cdot d+1)$ é o número de parâmetros livres do modelo da mistura com $K$ núcleos gaussianos. O valor de $K$ varia entre 2 e 4 , e $d=1$ representa a dimensão do espaço de atributos. O valor de $\log L(\bar{\Theta} \mid x)$ representa a função de verossimilhança dos dados observáveis.

Após a estimação dos parâmetros do modelo da mistura de gaussianas, o classificador por máxima-verossimilhança é aplicado à imagem original para produzir uma imagem contendo $K$-níveis. Essa imagem codifica em cada pixel um valor inteiro relacionando o pixel ao agrupamento mais provável. As Figuras 5.13(a)(c) mostram, respectivamente, a região efetiva da imagem mamográfica mdb042 usada para a estimação do modelo e as funções densidades de probabilidade para todos os componentes da mistura.

\subsubsection{Detecção do disco fibro-glandular}

De acordo com KARSSEMEIJER (1998), a densidade do músculo peitoral é uma importante informação e pode ser usada como referência para a interpretação de densidades no mamograma, visto que regiões de brilho similar têm alta probabilidade de corresponder à tecidos fibro-glandulares. Com base na observação acima e no modelo de densidades proposto na Seção 5.3.1, um estágio 


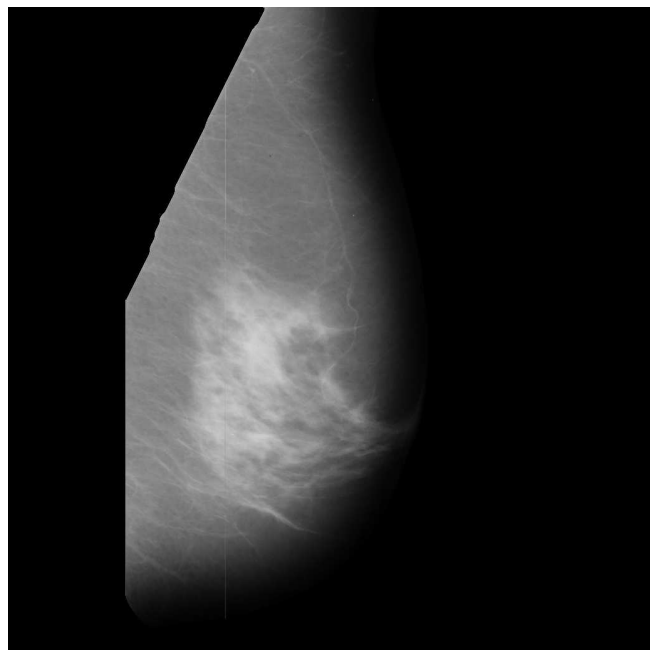

(a)

Histograma da imagem e Componentes da Mistura

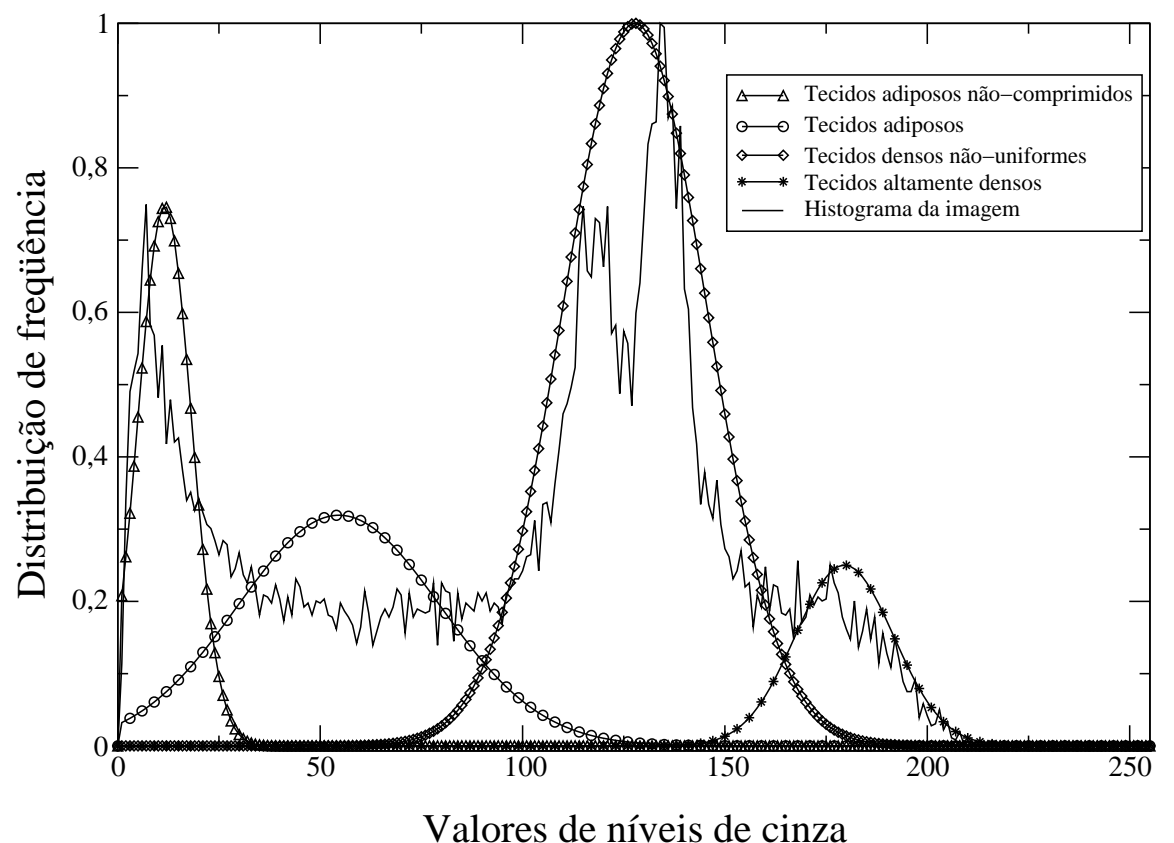

(b) 
Histograma da imagem e f.d.p da mistura resultante

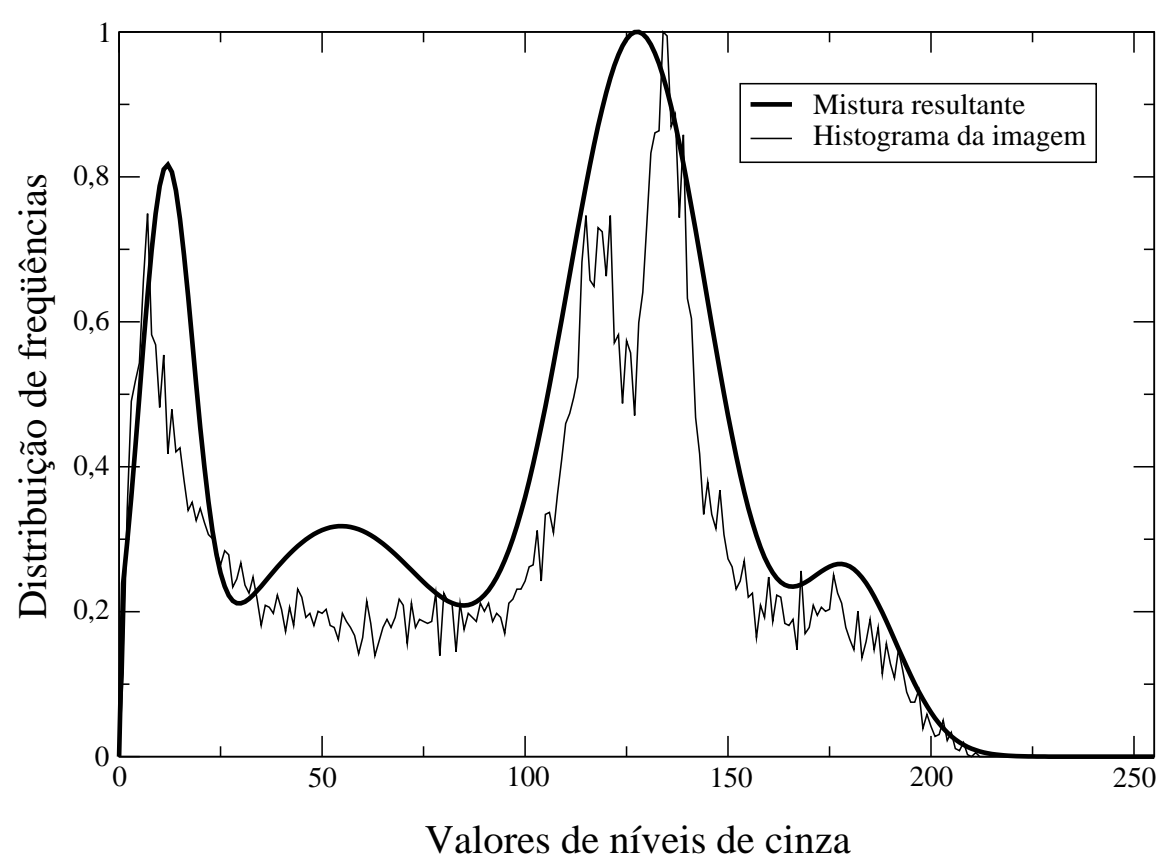

(c)

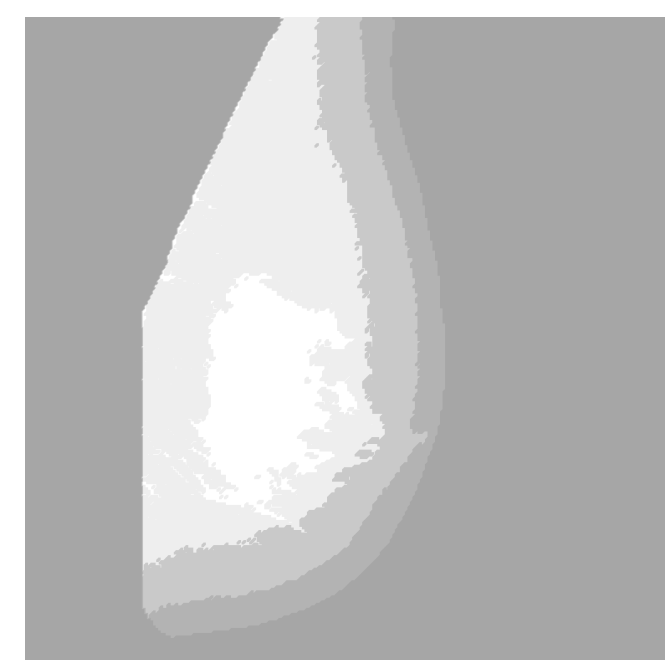

(d)

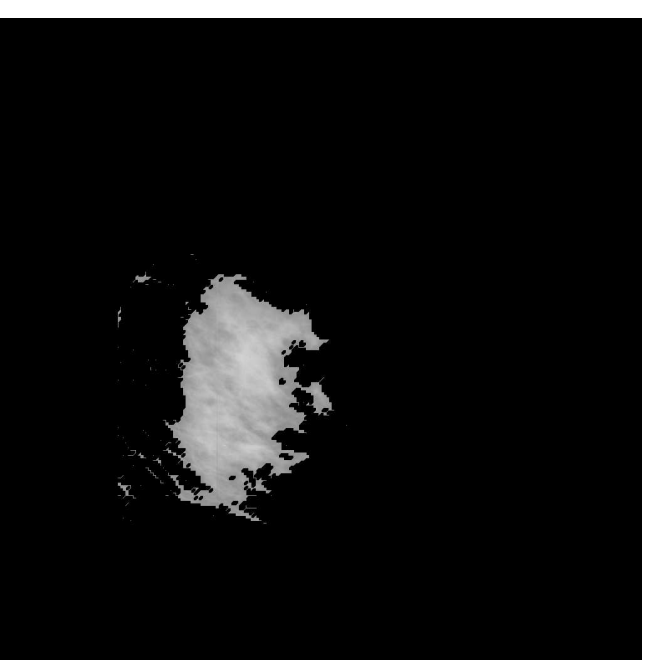

(e)

Figura 5.13: (a) Região efetiva da imagem mamográfica da Figura 5.2(a) usada para exemplificar o modelo de densidades proposto. (b) Histograma da imagem e componentes da mistura. (c) Histograma da imagem e função densidade de probabilidade da mistura. (d) Imagem contendo $K$-níveis, resultante da aplicação do método DAEM. (e) Disco fibro-glandular obtido após limiarização. 
simples de pós-processamento foi desenvolvido para determinar quais agrupamentos da imagem de $K$-níveis pertencem ao disco fibro-glandular. Neste estágio, o agrupamento $K$ é classificado como região fibro-glandular se

$$
\mu_{K} \geq \mu_{P}-\sigma_{P}
$$

onde $\mu_{P}$ e $\sigma_{P}$ são, respectivamente, a média e o desvio padrão dos níveis de cinza da região do músculo peitoral, e $\mu_{K}$ é o valor médio dos níveis de cinza calculado para o agrupamento $K$ a partir da imagem original. $\mathrm{O}$ valor de limiar $\left(\mu_{P}-\sigma_{P}\right)$ usado para determinar o disco glandular foi ajustado com base em experimentos, visto que uma comparação entre as densidades do músculo peitoral e dos tecidos fibro-glandulares, relacionando parâmetros físicos, seria difícil devido a influência de vários fatores do sistema de aquisição da imagem [DANCE (1996)].

A Figura 5.13(d) e (e) ilustram, respectivamente, a imagem $K$-níveis ( $K=$ 4 por sugestão da técnica MDL) e o disco fibro-glandular identificado para o mamograma da Figura 5.2(a). 


\section{Capítulo 6}

\section{Análise de assimetrias entre mamogramas}

O grau de assimetria entre mamogramas esquerdo e direito de uma mesma paciente é um importante sinal usado pelos radiologistas para o diagnóstico do câncer de mama [HOMER (1997)]. A análise de assimetria pode trazer novas informações a respeito da presença de tumores (distorção do parênquima mamário, pequenas densidades assimétricas, etc.) que não são analisados pelos demais métodos [MILLER \& ASTLEY (1993)].

Neste trabalho, a análise de assimetrias foi realizada com base em medidas de forma, área e densidade, extraídas das regiões dos discos glandulares determinados na etapa de segmentação dos mamogramas, e também com base em medidas direcionais obtidas através da transformada de Gabor wavelets. A análise comparativa entre os discos glandulares teve por objetivo determinar mudanças na topologia entre os mamogramas, enquanto a análise direcional visou retratar possíveis distorções globais do parênquima mamário.

A estratégia de detecção de assimetrias utilizada neste trabalho pode ser resumida da seguinte maneira: dado um par de mamogramas esquerdo e direito de uma mesma paciente, segmenta-se os mamogramas em suas regiões anatômicas mais importantes ("Segmentação Anatômica") e então cria-se um mapa de atri- 
butos para cada região, em cada um dos mamogramas. Esses mapas são a seguir comparados para a detecção de sinais assimétricos.

\subsection{Análise de assimetrias com base em infor- mações direcionais}

A quantificação de estruturas direcionais no mamograma é importante para a localização de distorções globais do parênquima mamário. Tais estruturas podem aparecer em diferentes escalas e, em geral, possuem uma direção preferencial dada pela linha imaginária perpendicular a borda do músculo peitoral. $\mathrm{O}$ desenvolvimento de um tumor quase sempre implica na distorção localizada dessas estruturas, mudando a orientação natural do fluxo de tecidos.

Com base no fato mencionado acima, a técnica multiresolução Gabor wavelets foi utilizada para filtrar os componentes direcionais mais relevantes presentes nos mamogramas esquerdo e direito de uma mesma paciente e a seguir a orientação dessas estruturas foi analisada em relação a suas distribuições angulares.

\subsubsection{Região de interesse}

Neste trabalho, apenas a região do disco fibro-glandular foi selecionada para a análise dos componentes direcionais. Esse procedimento foi realizado porque essa região possui a maior parte das estruturas densas nos mamogramas e porque que a maior parte dos tumores de mama ocorrem nesta região. Também, a aplicação da técnica direcional sobre a imagem completa do mamograma poderia fazer com que informações direcionais como as transições das bordas da mama e do músculo peitoral interferissem nas distribuições dos diagramas de rosa. 


\subsubsection{Procedimento de análise de componentes direcionais}

A análise de componentes direcionais nos mamogramas foi realizada através do procedimento descrito no Apêndice A. De maneira resumida, esse procedimento inicia-se pelo projeto de um banco de filtros de Gabor wavelets com quatro (4) escalas de resolução e doze (12) orientações. A ROI é então convoluída com cada um dos filtros e a seguir as imagens filtradas, para cada uma das orientações, nas 4 escalas, são analisadas através da transformada KL [GONZALEZ \& WOODS (1992)], a qual é usada para selecionar apenas os componentes principais das saídas dos filtros. O resultado da aplicação da transformada KL para todas as orientações é um conjunto de $K$ imagens, onde $K$ é o número de orientações utilizado no projeto do banco de filtros.

Visto que as Gabor wavelets são funções não-ortogonais, elas não permitem uma reconstrução perfeita. Esse fato resulta em uma quantidade pequena de energia fora da banda da freqüência analisada, gerando alguns artefatos na imagem reconstruída. Para eliminar tais artefatos, as imagens resultantes da transformada KL são limiarizadas através do método proposto por Otsu [OTSU (1979)]. Finalmente, as informações de fase e magnitude de cada imagem são obtidas através da soma vetorial de cada imagem filtrada [JÄHNE (1997)].

\subsubsection{Ajuste dos parâmetros da representação}

A escolha do número de escalas e orientações usadas neste trabalho, assim como a maioria dos trabalhos apresentados na literatura, é baseada em modelos neurofisiológicos sobre sistemas visuais de mamíferos [De Valois et al. (1982), DAUGMAN (1985)]. Tais modelos indicam que as larguras de banda de freqüência de células simples e complexas do sistema visual de mamíferos se encontram na faixa de 0.5 a 2.5 oitavas, se agrupando em torno de 1.2 e 1.5 oitavas. Eles também sugerem que as larguras de banda angulares devem ser menores do que $30^{\circ}$ [DAUGMAN (1985), JONES \& PALMER (1987)].

Dessa forma, selecionando os parâmetros como $U_{l}=0.05, U_{h}=0.45, S=4$ 
e $K=12$, a representação de Gabor é ajustada com uma largura de banda de freqüência de uma oitava e largura de banda angular de $15^{\circ}$. Além do suporte obtido dos modelos neurofisiológicos, a escolha de $U_{l}=0.05$ e $U_{h}=0.45$ implica na análise de quase todas as freqüências contidas na imagem, uma vez que não há nenhuma informação a priori a respeito das estruturas nela presentes.

\subsubsection{Representação de informações direcionais através de diagramas de Rosa}

O diagrama de rosa ou histograma polar de distribuições é uma representação gráfica de informações direcionais [MARDIA (1972)]. Nesta representação, a área de cada faixa é normalizada para que se torne proporcional a quantidade de informações direcionais presentes numa específica direção.

Neste trabalho, os diagramas de rosa foram construídos para representar informações direcionais na faixa de 0 a $180^{\circ}$, conforme exemplo indicado na Figura 6.1. A área do diagrama foi normalizada para a unidade e cada faixa possui uma largura angular de $15^{\circ}$, visto que a análise direcional neste trabalho foi realizada utilizando 12 orientações diferentes. A partir do diagrama de rosa, diversas informações direcionais quantitativas podem ser calculadas.

Em resultados preliminares [RANGAYYAN et al. (2000), FERRARI et al. (2001)], a diferença entre os diagramas foi realizada de forma direta, sem nenhum alinhamento prévio. No entanto, nas últimas análises do método os diagramas esquerdo e direito passaram a ser alinhados a partir do ângulo perpendicular a borda do músculo peitoral, como sugerido em [FERRARI et al. (2001), Seção "Discussion and Conclusions"]. Essa direção corresponde a direção natural do fluxo de tecidos que convergem desde as regiões do músculo peitoral e da parede do tórax até o mamilo. 


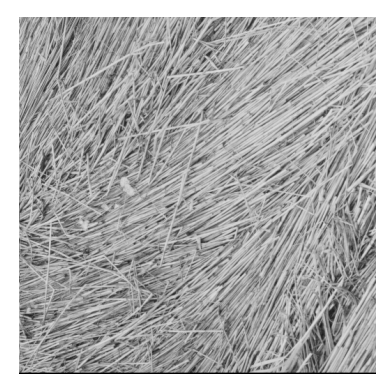

(a)

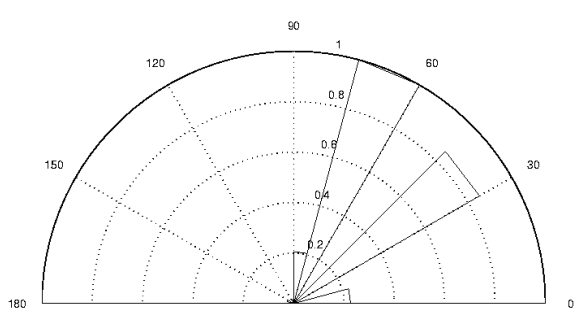

(b)

Figura 6.1: Imagem original e respectivo diagrama de rosa obtido pelo método descrito no Apêndice A.

\subsubsection{Extração de atributos direcionais}

Para a caracterização do grau de assimetria entre os pares de mamogramas, foram utilizados três atributos de distribuição direcional obtidos do diagrama de rosa resultante da diferença entre os diagramas de rosa calculados para os mamogramas esquerdo e direito. Embora a transformada KL use a informação de magnitude das imagens filtradas, os atributos descritos a seguir são baseados apenas na informação de fase.

\subsubsection{Entropia}

O atributo entropia $(H)$ é usado neste trabalho para representar o espalhamento dos componentes direcionais na imagem. Se a imagem é composta de componentes direcionais com uma distribuição uniforme, então a entropia será máxima; caso contrário, se a imagem é composta de componentes direcionais orientados apenas numa faixa angular estreita, a entropia terá valores pequenos. A 
medida de entropia é calculada como

$$
H=-\sum_{i=1}^{N} x_{i} \log _{2} x_{i}
$$

onde $N$ é o número de faixas angulares do diagrama de rosa $(N=12$ neste trabalho) e $x_{i}$ é a razão entre a área de uma faixa angular na direção $i$ pela área total do diagrama de rosa.

\subsubsection{Momento angular de primeira ordem}

O momento angular de primeira ordem $\left(M_{1}\right)$ ou orientação média $(\bar{\theta})$ de uma distribuição angular é definida como

$$
M_{1}=\bar{\theta}=\sum_{i=1}^{N} \theta_{i} x_{i}
$$

onde $\theta_{i}$ é o ângulo central da $i^{\text {th }}$ faixa angular.

\subsubsection{Momento angular central de segunda ordem}

O momento angular central de segunda ordem $\left(M_{2}\right)$ é uma medida de dispersão ou variância angular em relação a orientação média e é definida como

$$
M_{2}=\sum_{i=1}^{N}\left(\theta_{i}-\bar{\theta}\right)^{2} x_{i}
$$

\subsubsection{Orientação dominante}

Para a obtenção da orientação dominante do diagrama de rosa $\left(\theta_{R}\right)$, são considerados o raio $\left(R_{i}\right)$ e o ângulo médio $\left(\theta_{i}\right)$ de cada faixa angular para formar um conjunto de vetores ordenados. A seguir a orientação dominante ou vetor resultante é obtida através da soma vetorial desses vetores, como: 


$$
\begin{gathered}
\theta_{R}=\arctan \left(\frac{Y_{r}}{X_{r}}\right), \quad \text { onde } \\
X_{r}=\sum_{i=1}^{K} R_{i} \cos \theta_{i}, \\
Y_{r}=\sum_{i=1}^{K} R_{i} \sin \theta_{i} .
\end{gathered}
$$

$K$ representa o número de faixas do diagrama de rosa.

\subsubsection{Variância circular}

A variância circular $\left(s_{\theta}^{2}\right)$ é uma medida de dispersão análoga a variância. Seu valor esta contido no intervalo [0,1] e é calculado como:

$$
s_{\theta}^{2}=1-\frac{R}{K}=(K-R) / K
$$

onde $K$ é o número de faixas angulares e

$$
R=\sqrt{X_{r}^{2}+Y_{r}^{2}}
$$

\subsection{Análise de assimetrias com base no modelo de densidades}

A análise de assimetrias com base no modelo de densidades foi realizada levando-se em consideração a diferença entre as regiões dos discos glandulares, determinadas através do procedimento de segmentação das imagens.

Para cada disco glandular, um grupo de onze (11) medidas, conforme descrito a seguir, foram extraídas com a finalidade de caracterizar diferenças de densidade e forma entre as regiões dos mamogramas esquerdo e direito. Tais medidas visam avaliar diferenças globais entre os mamogramas. 


\subsubsection{Extração de atributos de forma e densidade}

\subsubsection{Momentos de $\mathrm{Hu}$}

O conceito de momento usado em distribuições estatíticas pode também ser usado para representar uma distribuição espacial de valores em uma imagem. Dada uma imagem $I(x, y)$ de tamanho $M \times N$, o momento geométrico de ordem $(p+q)$ é definido por:

$$
m_{p q}=\sum_{x=1}^{M} x^{p} y^{q} I(x, y) \text { para } p, q=0,1,2, \ldots
$$

A equação de momento acima pode ser aplicada tanto à imagens binárias quanto à imagens em tons de cinza. No caso de imagens binárias, os momentos quantificam apenas informações de forma da região segmentada; por outro lado, no caso de imagens em tons de cinza, os momentos incluem informações de intensidade e distribuição em adição à forma.

A principal desvantagem dos momentos invariantes é que eles constituem um conjunto infinito, e portanto não são capazes de representar com exatidão todas as informações de uma imagem. Entretanto, para muitas aplicações práticas, um número reduzido de momentos pode fornecer um conjunto bastante efetivo de descritores de forma [BANKMAN (2000), KULKARNI (1994)].

Para que os momentos se tornem invariantes a translação e rotação, a seguinte normalização deve ser realizada:

$$
m_{p q}=\sum_{x=1}^{M} \sum_{y=1}^{N}\left(x-x^{\prime}\right)^{p}\left(y-y^{\prime}\right)^{q} I(x, y),
$$

onde $x^{\prime}=\frac{m_{10}}{m_{00}}$ e $y^{\prime}=\frac{m_{01}}{m_{00}}$, indicam as coordenadas do centro de massa da imagem.

Em 1962, M.K. Hu [HU (1962)] desenvolveu um conjunto de sete descritores, como descrito a seguir, derivados a partir de momentos geométricos e que foram usados neste trabalho para quantificar as diferenças em forma e distribuição de 
intensidade entre os discos fibro-glandulares esquerdo e direito. Visto que a escala é um fator importante neste caso, nenhuma normalização foi realizada em relação a essa dimensão.

$$
\begin{aligned}
\phi_{1}= & m_{20}+m_{02} \\
\phi_{2}= & \left(m_{20}-m_{02}\right)^{2}+4 m_{11}^{2} \\
\phi_{3}= & \left(m_{30}-3 m_{12}\right)^{2}+\left(3 m_{21}-m_{03}\right)^{2} \\
\phi_{4}= & \left(m_{30}+m_{12}\right)^{2}+\left(m_{21}+m_{03}\right)^{2} \\
\phi_{5}= & \left(m_{30}-3 m_{12}\right)\left(m_{12}+m_{30}\right)\left[\left(m_{12}+m_{30}\right)^{2}-3\left(m_{21}+m_{03}\right)^{2}\right] \\
& +\left(3 m_{21}-m_{03}\right)\left(m_{21}+m_{03}\right)\left[3\left(m_{12}+m_{30}\right)^{2}-\left(m_{21}+m_{03}\right)^{2}\right] \\
\phi_{6}= & \left(m_{20}-m_{02}\right)\left[\left(m_{12}+m_{30}\right)^{2}-\left(m_{21}+m_{03}\right)^{2}\right] \\
& +4 m_{11}\left(m_{12}+m_{30}\right)\left(m_{21}+m_{03}\right) \\
\phi_{7}= & \left(3 m_{21}-m_{03}\right)\left(m_{12}+m_{30}\right)\left[\left(m_{12}+m_{30}\right)^{2}-3\left(m_{21}+m_{03}\right)^{2}\right] \\
& +\left(3 m_{12}-m_{30}\right)\left(m_{21}+m_{03}\right)\left[3\left(m_{12}+m_{30}\right)^{2}-\left(m_{21}+m_{03}\right)^{2}\right]
\end{aligned}
$$

De acordo com KULKARNI (1994), os valores dos descritores relacionados acima são muito pequenos e portanto muito sensíveis a erros de arredondamento. Um procedimento útil, o qual foi aplicado neste trabalho, é a utilização do logaritmo dos valores originais.

\subsubsection{2 Área, densidade, excentricidade e alongamento}

Outros atributos extraídos dos discos glandulares e utilizados para a caracterização da assimetria foram: a área, a densidade média, a medida de excentricidade calculada como

$$
\varepsilon_{i}=\frac{\left(m_{20}-m_{02}\right)^{2}+4 m_{11}^{2}}{\left(m_{20}+m_{02}\right)^{2}}
$$

e a medida de alongamento 


$$
\text { along }=\frac{x_{\max }-x_{\min }}{y_{\max }-y_{\min }} .
$$

No caso da medida de alongamento ser menor que a unidade, então

$$
\text { along }=\frac{1.0}{\text { along }} \text {. }
$$

A classificação das imagens em assimétricas e normais foi realizada utilizando o valor da diferença entre cada par de atributos calculados para os discos glandulares esquerdo e direito.

\subsection{Normalização dos atributos}

Para a normalização dos atributos, os valores da média $(\mu)$ e do desvio padrão $(\sigma)$ de cada um dos atributos foram estimados através das amostras de treinamento. A seguir eles foram normalizados para ter média zero e desvio padrão igual a unidade, através da seguinte transformação:

$$
\widehat{x}=\frac{x-\mu}{\sigma},
$$

onde $\widehat{x}$ indica o valor normalizado do atributo $x$.

A vantagem em se utilizar esse tipo de normalização dos dados é prevenir que um determinado atributo se torne dominante em relação aos outros na classificação.

\subsection{Seleção de atributos}

A alta dimensionalidade do espaço de dados de entrada, em comparação ao número de amostras de treinamento, pode degradar o desempenho de classificadores [HOFFBECK \& LANDGREBE (1996)]. Esse efeito, ocorre porque quando a dimensão do espaço de atributos cresce, a estimativa das funções densidades se 
torna mais difícil de ser realizada.

Por essa razão, foi utilizada a transformada de Karhunen-Loève (KL) [GONZALEZ \& WOODS (1992), WEBB (1999)] ou análise de principais componentes ("Principal Components Analysis" - PCA) para reduzir a dimensionalidade do espaço de atributos. Essa transformação utiliza os autovetores mais significantes da matriz de covariância dos atributos para construir uma matriz de transformação linear. Visto que os autovetores são ortonormais, eles transformarão os dados originais em um novo grupo de atributos não-correlacionados e possuindo a máxima variância. Neste trabalho, os autovetores referentes a autovalores contribuindo com menos que $2 \%$ da variância total dos dados foram eliminados.

Embora a transformada KL tenha sido bastante explorada na literatura para a redução de dimensionalidade, não existe nenhuma garantia que os componentes principais correspondentes aos maiores autovalores definem a base ótima para o problema de classificação [WEBB (1999)]. Um exemplo simples desse fato pode ser visto nos gráficos de distribuição dos atributos A, B e C da Figura 6.2.
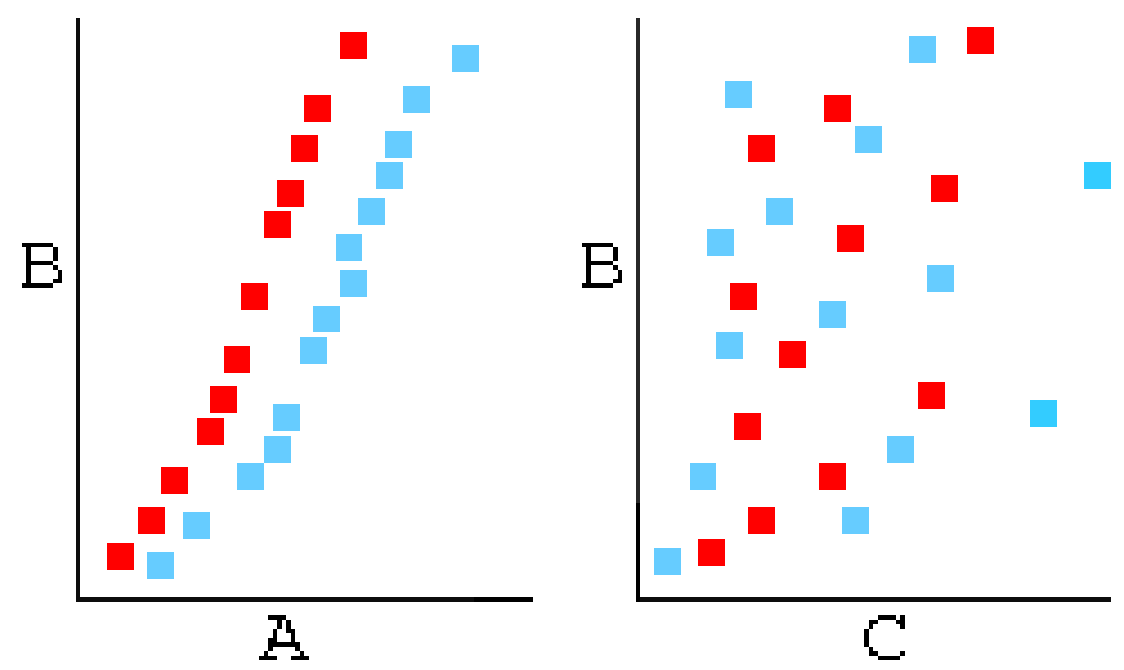

Figura 6.2: Exemplo de distribuições onde o componente principal não é útil para a classificações dos dados.

Como pode ser visto por inspeção dos gráficos, os atributos B e C, apesar de apresentarem altos valores de variância, não permitem uma boa separação entre as classes. Também, a direção ao longo da diagonal a $45^{\circ}$ no painel AB à esquerda, contém a maior variância e mesmo assim é inútil para efeito de 
classificação. Por outro lado, a direção com a menor variância (diagonal a 135) no painel A-B, contém toda a informação necessária para a separação das classes.

Com base no exposto acima, após a determinação dos $N$ componentes principais, uma combinação exaustiva entre eles foi realizada para determinar qual o melhor grupo, no sentido de fornecer a maior taxa média de classificação das amostras.

O método "leave-one-out" [PRECHELT (1994)] foi aplicado na classificação dos dados para minimizar possíveis efeitos causados pelo número limitado de amostras usadas neste trabalho.

\subsection{Classificação}

A classificação dos pares de mamogramas em assimétricos e normais foi realizada através de classificadores de Bayes (linear e quadrático) [DUDA \& HART (1973)]. Neste trabalho, a distribuição gaussiana foi assumida para modelar as f.d.p.s dos atributos. Os parâmetros do modelo (vetor de médias $\bar{\mu}$, e matriz de covariância $\bar{\Sigma}$ ) foram estimados por "máxima-verossimilhança" como

$$
\begin{gathered}
\bar{\mu}_{i}=\frac{1}{N_{i}} \sum_{j=1}^{N_{i}} \bar{x}_{j}, \\
\bar{\Sigma}_{i}=\frac{1}{N_{i}} \sum_{j=1}^{N_{i}}\left(\bar{x}-\bar{\mu}_{i}\right)\left(\bar{x}-\bar{\mu}_{i}\right)^{T},
\end{gathered}
$$

onde $i=\{n, a\}$ indica o rótulo da classe ( $n$ - normal; $a$ - assimétrico).

As probabilidades a priori foram assumidas como sendo iguais $\left(P_{n}=P_{a}=0.5\right)$ e no caso do classificador linear, a matriz de covariância foi calculada através da média das matrizes de covariância das duas classes $\left(\bar{\Sigma}=\left(\bar{\Sigma}_{n}+\bar{\Sigma}_{a}\right) / 2\right)$.

Portanto, a regra de decisão estatística foi realizada como 


$$
\begin{gathered}
f\left(\bar{x} \mid w_{n}\right) \stackrel{\gtrless_{w_{a}}}{w_{n}} f\left(\bar{x} \mid w_{a}\right), \\
f\left(\bar{x} \mid w_{i=n, a}\right)=\frac{1}{(2 \pi)^{d / 2}\left|\Sigma_{i}\right|^{1 / 2}} \exp \left[-\frac{1}{2}\left(\bar{x}-\overline{\mu_{i}}\right)^{T} \Sigma_{i}^{-1}\left(\bar{x}-\overline{\mu_{i}}\right)\right],
\end{gathered}
$$

onde $f\left(\bar{x} \mid w_{i=n, a}\right)$ representam as f.d.p.s do vetor de atributos $\bar{x}$ nas classes normal $\left(w_{i=n}\right)$ e assimétrica $\left(w_{i=a}\right)$, respectivamente. 


\section{Capítulo 7}

\section{Protocolo usado na avaliação dos resultados}

\subsection{Avaliação dos resultados da segmentação dos mamogramas}

Os resultados dos métodos de segmentação dos mamogramas propostos nesta tese foram avaliados em duas etapas do desenvolvimento dos métodos por dois médicos radiologistas (Dr. J.E. Leo Desautels (JELD) e a Dra. R.A. Borges $(\mathrm{RAB}))$.

O primeiro radiologista (JELD) realizou a análise preliminar dos resultados de forma subjetiva através da visualização dos resultados num monitor de computador de 20" de tamanho diagonal e pontos de $0.26 \mathrm{~mm}$.

O segundo radiologista (RAB) realizou a avaliação dos resultados de maneira sistemática através do protocolo descrito a seguir.

As imagens de teste foram visualizadas num monitor de computador com 19" de tamanho diagonal e pontos de $0.27 \mathrm{~mm}$. Através do programa Gimp [MATTIS \& KIMBALL (1997)], o contraste e o brilho de cada imagem foram realçados para permitir uma boa visualização dos contornos da mama. Então, as bordas da 
mama e do músculo peitoral foram manualmente marcadas e os resultados foram impressos em papel sulfite especial usando uma impressora HP-Laserjet $1100 \mathrm{com}$ resolução de 600 dpi. A opção de "zoom" do programa Gimp foi utilizada para auxiliar no desenho dos contornos. As bordas marcadas em todas as imagens foram verificadas pelo radiologista usando as cópias impressas juntamente com a imagem visualizada na tela do computador. A avaliação do radiologista para cada imagem foi registrada para posterior análise.

Os resultados da segmentação relacionados aos dois contornos detectados por processamento automático das imagens foram avaliados com base no número de pixels FPs e FNs identificados e normalizados em relação as áreas correspondentes, demarcadas pelos contornos manuais.

A área de referência para o músculo peitoral foi definida como a área contida entre a parede do tórax e a linha do músculo marcada manualmente. A referência para a área da mama foi definida como a área completa da mama - incluindo o músculo peitoral - delimitada pelo contorno manual.

A Figura 7.1 ilustra um exemplo de imagem onde os contornos foram marcados manualmente.

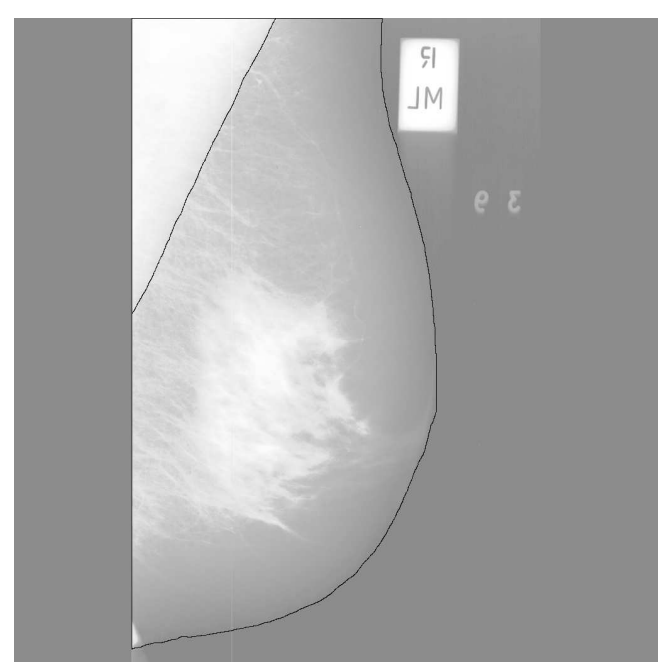

Figura 7.1: Imagem mdb042 da base de dados Mini-MIAS indicando os contornos da borda da mama e do músculo peitoral marcados manualmente e verificados pelo radiologista. 
Os resultados da segmentação do discos fibro-glandulares foram avaliados através de um critério subjetivo, pois a demarcação exata desta região seria uma tarefa difícil e consumiria muito tempo do radiologista. Outro fato é que o método proposto para a detecção do disco fibro-glandular pode gerar regiões desconectadas na imagem.

Portanto, as imagens original e segmentada foram simultaneamente apresentadas ao radiologista no monitor do computador. O radiologista visualmente comparou as duas imagens e associou uma das cinco categorias, descritas na Tabela 7.1, para o resultado da segmentação.

Tabela 7.1: Descrição das opções usadas pelo radiologista na avaliação dos resultados da segmentação do disco fibro-glandular.

\begin{tabular}{l|l} 
Nível de concordância & Descrição \\
\hline \hline (1) - Excelente & Concordância entre o DFGO e o DFGD é maior que $80 \%$. \\
\hline (2) - Bom & Concordância entre o DFGO e o DFGD está entre 60 e $80 \%$. \\
\hline (3) - Regular & Concordância entre o DFGO e o DFGD está entre 40 e $60 \%$. \\
\hline (4) - Ruim & Concordância entre o DFGO e o DFGD está entre 20 e $40 \%$. \\
\hline (5) - Falha completa & Concordância entre o DFGO e o DFGD é menor que $20 \%$. \\
\hline DFGO - disco fibro-glandular observado pelo radiologista na imagem original. \\
\hline DFGD - disco fibro-glandular detectado pela técnica proposta. \\
\hline
\end{tabular}

\subsection{Avaliação dos resultados de análise de assi- metrias}

A avaliação dos resultados obtidos pelos métodos de análise de assimetrias foi realizada mediante a comparação entre os resultados fornecidos pelos classificadores Bayesianos (linear e quadrático) e os rótulos (assimétrico ou normal) presentes na documentação da base de dados Mini-MIAS [SUCKLING et al. (1994)]. 


\section{Capítulo 8}

\section{Resultados obtidos e discussões}

Os resultados obtidos pelos métodos propostos tanto para a segmentação dos mamogramas quanto para a detecção de assimetrias foram desenvolvidos e avaliados em duas etapas distintas, e por dois radiologistas diferentes: Dr. J.E.L. Desaultes (JELD) da Universidade de Calgary, Canadá e a Dra. R.A. Borges (RAB) da Universidade de Mogi das Cruzes.

Na primeira etapa, realizada junto a Universidade de Calgary - Canadá sob a supervisão do Prof. Dr. Rangaraj M. Rangayyan, foram desenvolvidos métodos para a segmentação dos mamogramas e para a análise de assimetrias com base em informações direcionais obtidas através da técnica Gabor wavelets. Após a avaliação dos resultados obtidos nesta etapa, concluiu-se que algumas modificações nos métodos propostos e a implementação de uma nova abordagem de análise poderiam melhorar ainda mais os resultados obtidos.

Na segunda etapa, realizada junto a Universidade de São Paulo - USP - São Carlos, um novo método para a detecção do músculo peitoral foi desenvolvido, eliminando a restrição imposta da representação do músculo peitoral por uma linha reta. Um novo método foi proposto para a detecção de assimetrias através da análise de forma e densidade dos discos fibro-glandulares. Com isso, dois tipos de informações foram integradas em nossa abordagem: informações direcionais, obtidas através da técnica Gabor wavelets, e informações topológicas, obtidas 
através de atributos extraídos dos discos fibro-glandulares. Também nesta segunda epata, os resultados fornecidos pelos algoritmos foram avaliados de forma quantitativa através de um protocolo de avaliação.

\subsection{Segmentação de mamogramas}

\subsection{1 $1^{\mathrm{a}}$ Etapa}

$\mathrm{Na}$ primeira etapa, os resultados fornecidos pelos algoritmos de segmentação foram analisados pelo radiologista JELD de maneira subjetiva através da comparação visual dos resultados apresentados num monitor de computador.

$\mathrm{Na}$ opinião do radiologista, o método de detecção da borda da mama teve sucesso em 61 imagens. Apenas 5 das 66 imagens analisadas apresentaram pequenas distorções, causadas principalmente pelo alto nível de ruído no fundo da imagem. O algoritmo foi capaz de detectar o contorno do mamilo na maioria das imagens.

O músculo peitoral foi identificado com exatidão em 58 imagens, com uma diferença aproximada de 1 a $3 \mathrm{~mm}$ entre a borda identificada visualmente e a borda detectada automaticamente através do método proposto. Em 7 imagens, o método teve sucesso parcial, identificando aproximadamente $90 \%$ da região do músculo peitoral, devido a não concordância com hipótese de representação do músculo peitoral por um segmento de reta. Para uma imagem o método falhou totalmente, identificando apenas $30 \%$ da região do músculo peitoral. Nesse caso, o algoritmo identificou o músculo peitoral menor.

O procedimento para a segmentação do disco fibro-glandular, de acordo com o radiologista, foi capaz de segmentar com sucesso 56 das 66 imagens analisadas.

Em 7 casos, pequenas partes da região do músculo peitoral, não eliminadas na estágio de segmentação anterior, foram detectadas juntamente com o disco fibro-glandular. O método falhou em 3 casos, onde o método subestimou ou superestimou o tamanho real do disco glandular. 


\subsection{2 $2^{\mathrm{a}}$ Etapa}

Na segunda etapa de desenvolvimento dos métodos, os resultados do processo de segmentação das imagens foram analisados de forma qualitativa pela radiologista RAB de acordo com o protocolo descrito no Capítulo 7. Um total de 84 imagens foram analisadas e os resultados obtidos são discutidos nos parágrafos seguintes. Alguns resultados são ilustrados nas Figuras 8.1, 8.2, e 8.3.

\subsubsection{Resultados da identificação da borda da mama}

Os métodos para a detecção da borda da mama e do músculo peitoral foram avaliados com base no número de pixels FPs e FNs determinados através da comparação entre os contornos reais indicados pela radiologista RAB e os contornos automaticamente identificados.

Os percentuais médios de FPs e FNs juntamente com os desvios padrão obtidos para a detecção da borda da mama foram $0.41 \pm 0.25 \%$ e $0.58 \pm 0.67 \%$, respectivamente. A distribuição do número de imagens em relação aos percentuais de FP e FN foram:

1. menores que $0.5 \%$ para 33 imagens.

2. entre $0.5 \%$ e $1 \%$ para 38 imagens.

3. maiores que $1 \%$ para 13 imagens.

A causa mais comum de pixels FNs está relacionada a não detecção da região do mamilo (ver Figuras 8.1(b) e (c)), que na maioria dos casos possui um contraste muito baixo o qual não foi suficiente para atrair o contorno deformável. Um processamento local poderia ser realizado a fim de solucionar tal problema. No entanto, no caso específico de reconhecimento de assimetrias, a não detecção dessa região não interfere nos resultados.

A principal causa dos pixels FPs está associada com a suavização do contorno nos limites da borda da mama. Apesar da introdução de uma restrição que 


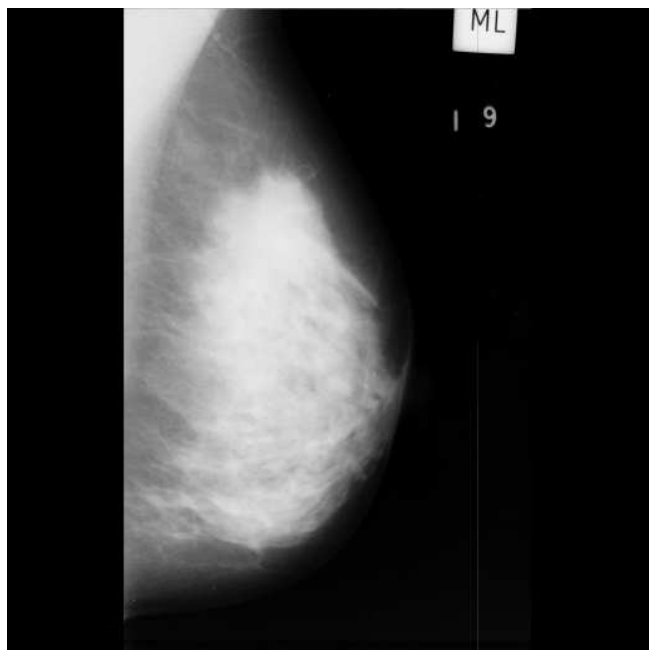

(a)

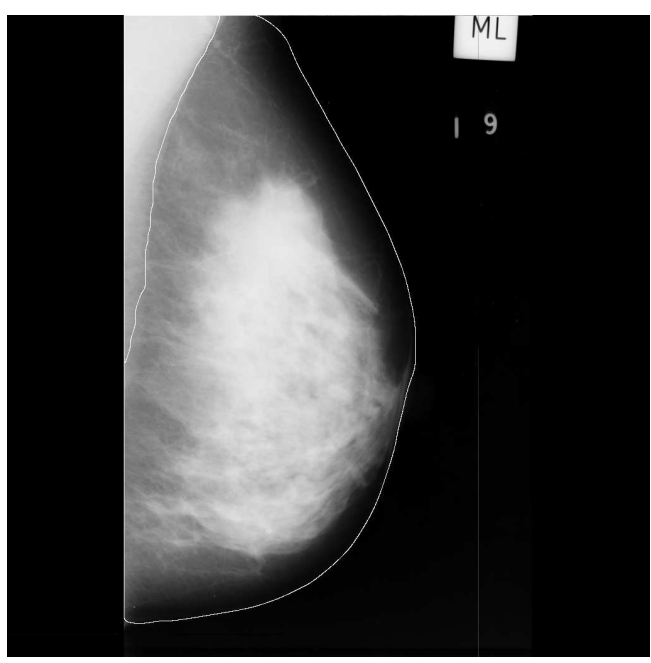

(c)

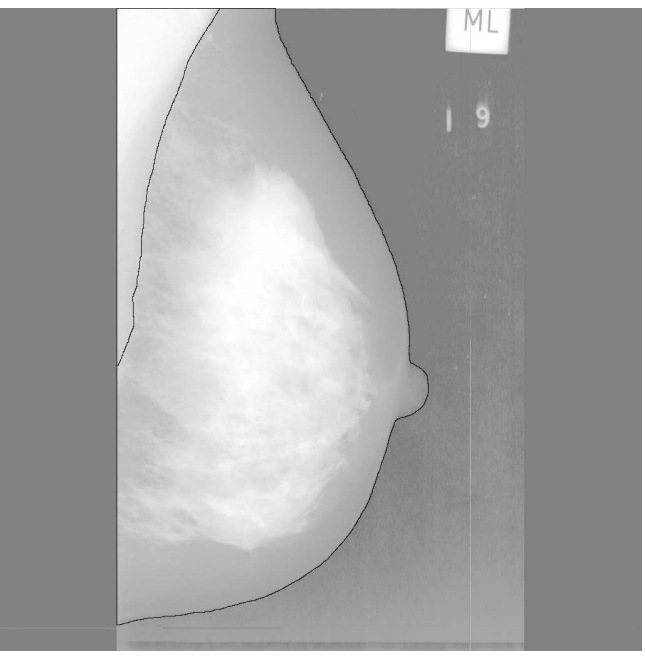

(b)

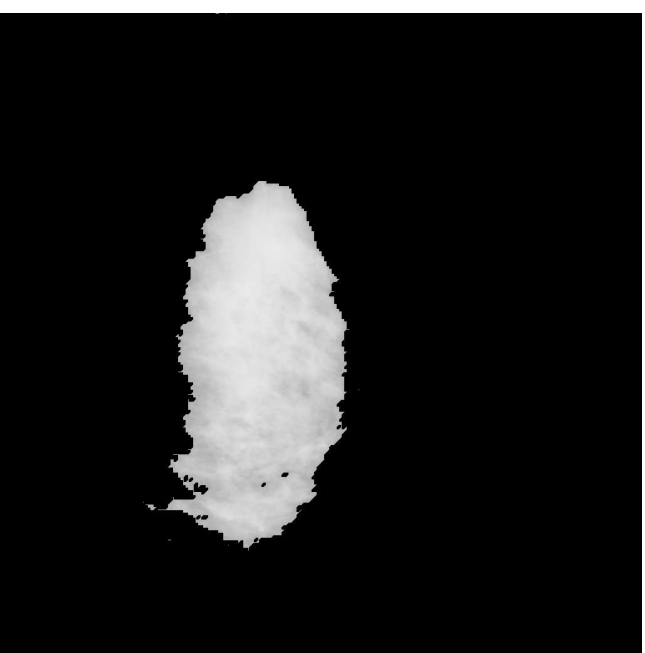

(d)

Figura 8.1: Resultados obtidos para a imagem mdb003, a qual, de acordo com a base de dados Mini-MIAS é caracterizada essencialmente por tecidos glandulares. (a) Imagem original. (b) Contornos manuais (imagem equalizada). (c) Bordas da mama e do músculo peitoral. (d) Disco fibro-glandular. 


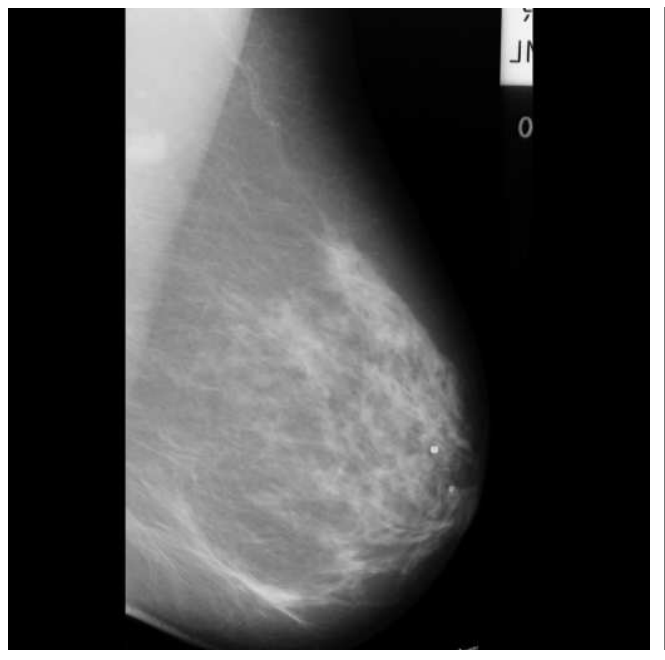

(a)

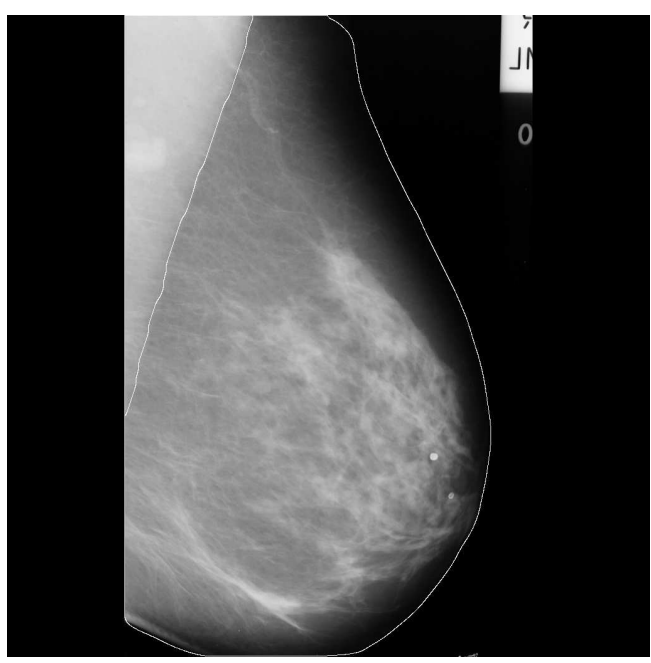

(c)

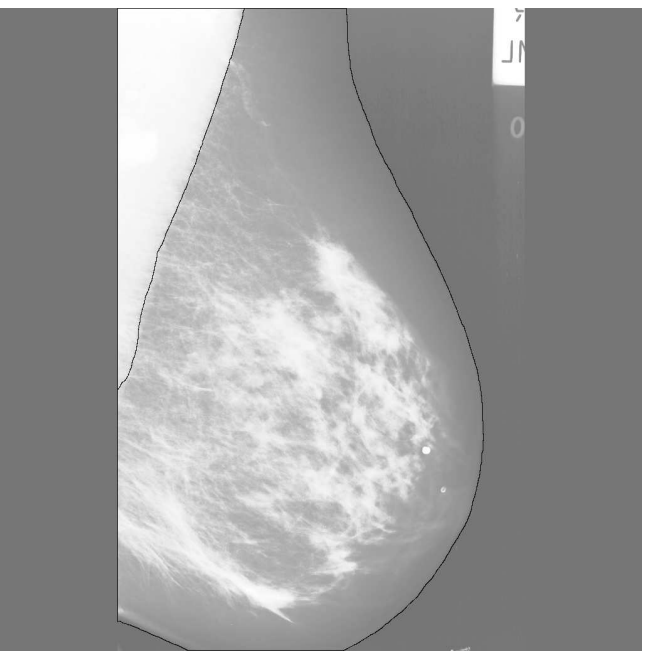

(b)

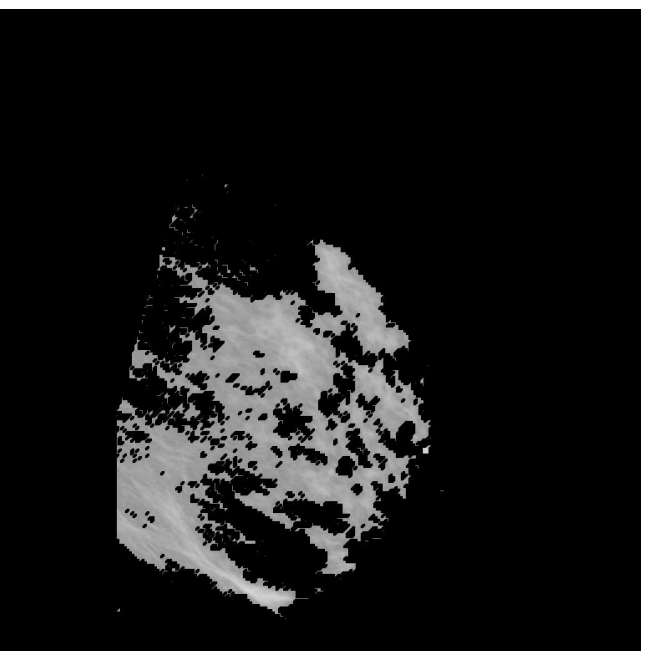

(d)

Figura 8.2: Resultados obtidos para a imagem mdb008, a qual, de acordo com a base de dados Mini-MIAS é caracterizada essencialmente por tecidos adiposos. (a) Imagem original. (b) Contornos manuais (imagem equalizada). (c) Bordas da mama e do músculo peitoral. (d) Disco fibro-glandular. 


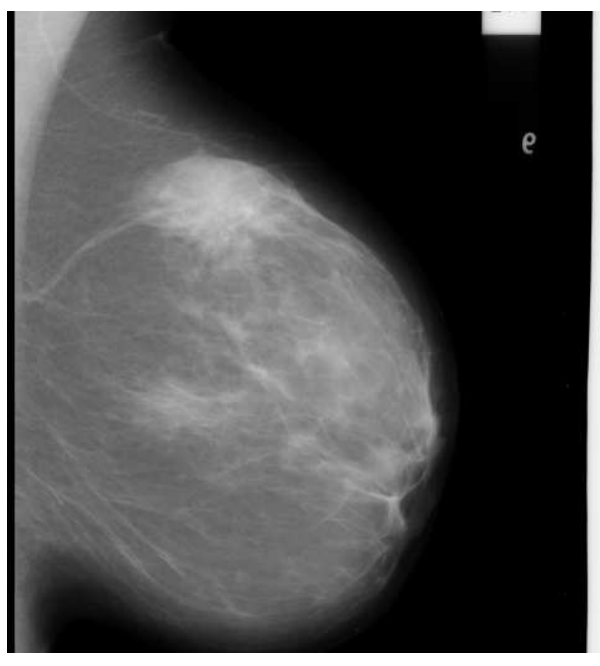

(a)

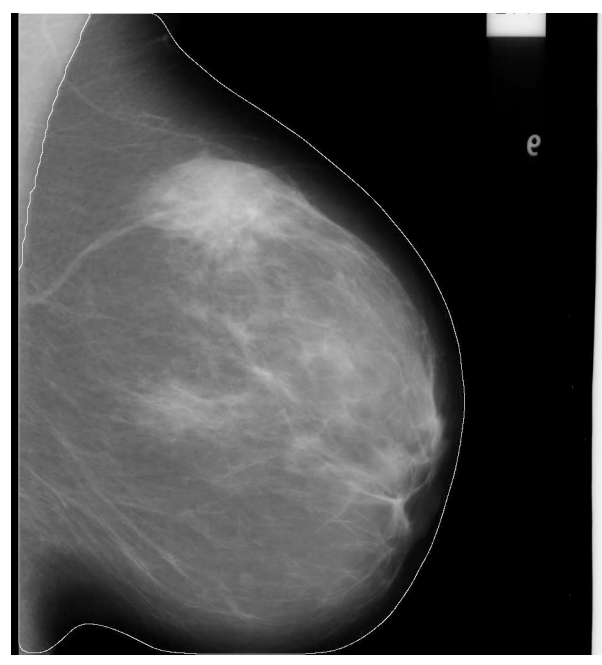

(c)

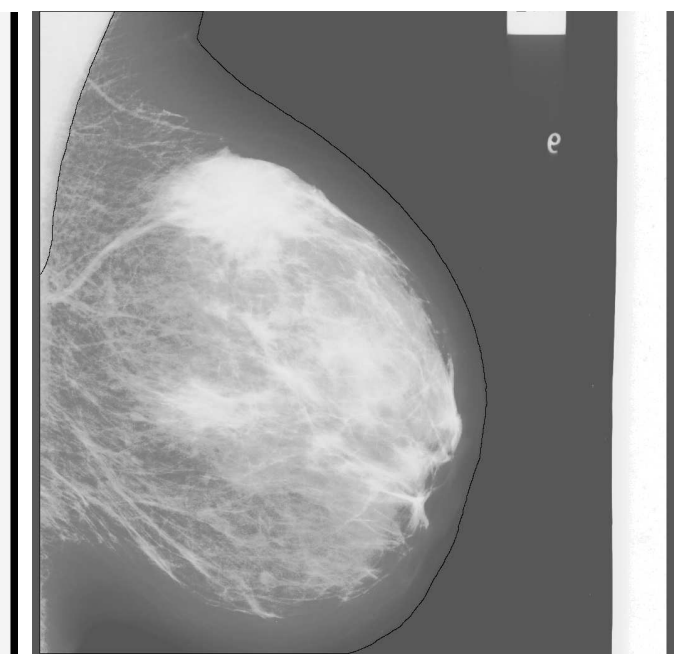

(b)

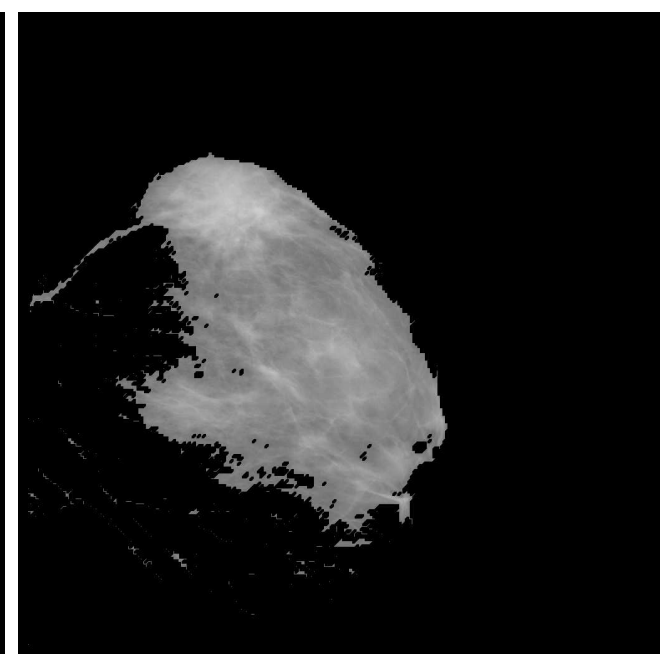

(d)

Figura 8.3: Resultados obtidos para a imagem mdb150, a qual, de acordo com a base de dados Mini-MIAS é caracterizada essencialmente por tecidos adiposos. (a) Imagem original. (b) Contornos manuais. (c) Bordas da mama e do músculo peitoral. (d) Disco fibro-glandular. 
modifica a energia de curvatura dessa região, em algumas imagens o contorno deformável não conseguiu se ajustar totalmente (ver Figuras 8.2(b)-(c) e 8.3(b)(c)). Entretanto, cabe ressaltar que em mamogramas adquiridos corretamente, os contornos da mama serão sempre suaves, inclusive em projeções crânio-caudal.

As Figuras 8.4(a) e (b) apresentam dois casos onde ambos os percentuais FPs e FNs são maiores que 1\%. No primeiro caso, a imagem mdb037 possui um artefato (linha horizontal) dividindo a imagem em duas partes o qual foi responsável pela falha na detecção correta da borda da mama. Na imagem mdb068, o contorno inicial (automaticamente obtido) não se moveu devido a atração exercida pela região altamente densa (borda com alto valor de gradiente) observada na mama. Nesse caso, talvez a determinação do contorno inicial tenha que ser realizada após algum pré-processamento da imagem, para que regiões altamente densas, como a indicada na imagem, possam ser previamente corrigidas.

Devido ao uso da orientação do gradiente no MDCA, neste trabalho o método mostrou bons resultados para os casos onde pequenos artefatos estavam presentes próximos a borda real da mama.

Os parâmetros $\alpha$ e $\beta$ usados no MDCA, embora tenham sido ajustados de forma experimental, provaram ser bastante robustos com base nos resultados obtidos. No entanto, acreditamos que a técnica minmax proposta por LAI (1994), e que é usada para determinar localmente os parâmetros $\alpha$ e $\beta$ através da minimização da energia máxima do modelo, possa otimizar o problema da generalização do método para imagens de outras bases de dados.

\subsubsection{Resultados da identificação do músculo peitoral}

Os percentuais médios FPs e FNs juntamente com os valores de desvio padrão obtidos para a detecção da borda do músculo peitoral foram $1.78 \pm 4.11 \%$ e $5.77 \pm$ $4.83 \%$, respectivamente. A distribuição da imagens de acordo com o percentuais de FPs e FNs foram:

1. menores que $5 \%$ para 45 imagens. 


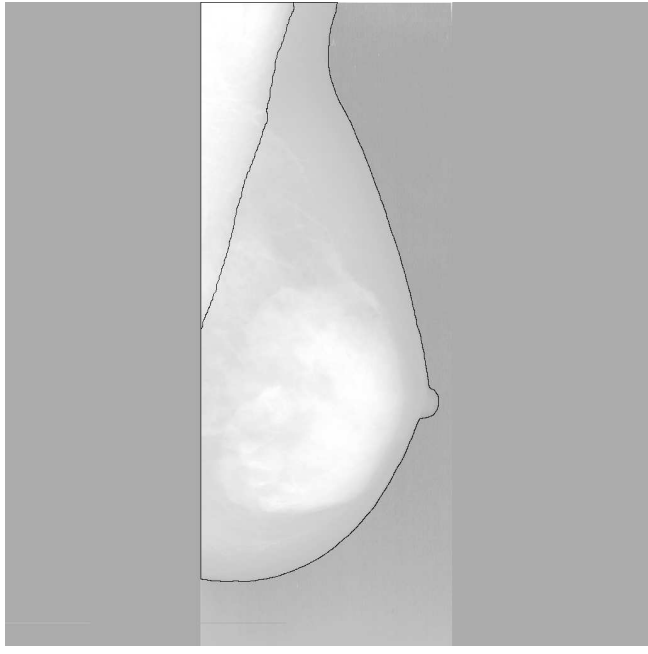

(a)

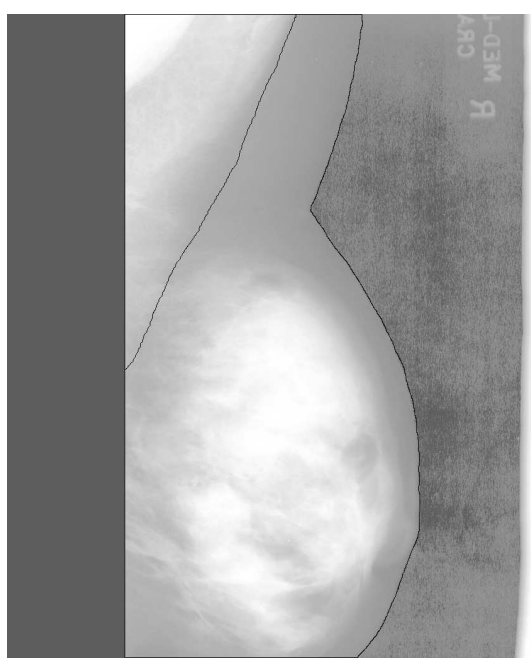

(c)

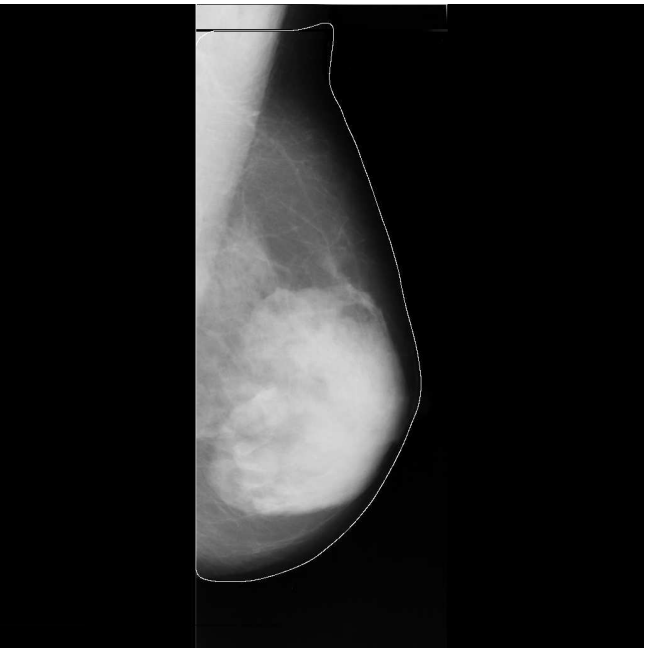

(b)

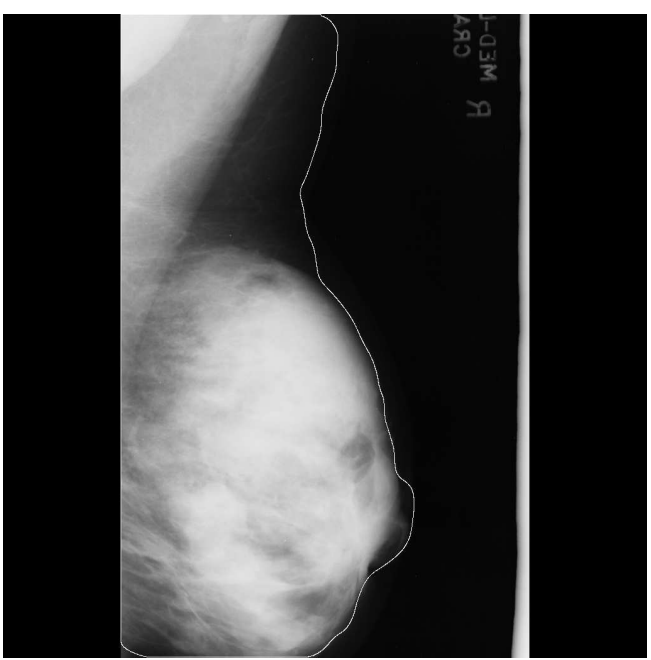

(d)

Figura 8.4: Imagens mdb037 (superior) e mdb068 (inferior) apresentando problemas na segmentação da borda da mama. (a) e (c) são as imagens contendo os contornos demarcados manualmente com a supervisão do radiologista. (b) $\mathrm{O}$ contorno não detectou corretamente a borda da mama devido a presença de um espúrio na imagem (linha horizontal na parte superior da imagem). (d) O contorno inicial não convergiu corretamente para a borda da mama devido a atração exercida pela região glandular densa presente na mama. 
2. entre $5 \%$ e $10 \%$ para 22 imagens.

3. maiores que $10 \%$ para 17 imagens.

A Figura 8.5(b) ilustra um exemplo onde a região do músculo peitoral foi subestimada e conseqüentemente apresentou uma alta taxa de pixels FNs. Neste caso, a parte do músculo peitoral, mais próxima da parede do tórax, não foi corretamente detectada devido ao baixo contraste apresentado naquela região.

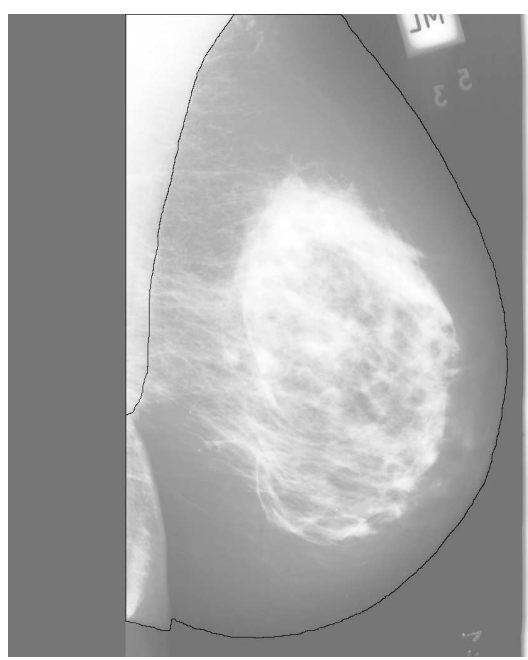

(a)
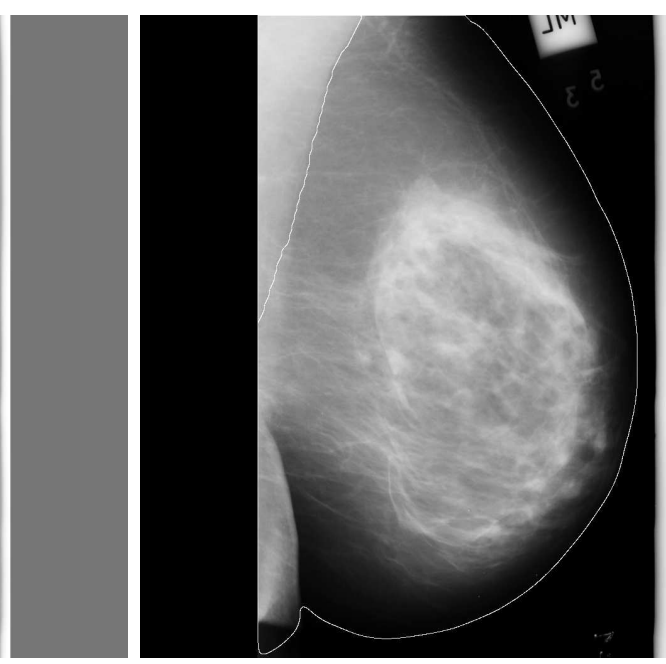

(b)

Figura 8.5: (a) Imagem mdb112 contendo as demarcações manuais dos contornos. (b) Resultado do método de segmentação. Neste caso, o músculo peitoral foi subestimado, gerando uma alta taxa de pixels $\mathrm{FN}$ : $\mathrm{FP}=2.33 \%$; $\mathrm{FN}=16.21 \%$.

Ao contrário da borda da mama, a demarcação exata da borda do músculo peitoral foi mais difícil pois a região mais próxima à parede do tórax, se apresentou em várias imagens misturada a porções de tecido fibro-glandular.

O novo método, baseado na representação Gabor wavelets e na propagação do fluxo de gradientes de bordas, removeu a hipótese de representação do músculo por um segmento de reta formulada anteriormente [FERRARI et al. (2000b)], como pode ser visto nas Figuras 8.1(b) e 8.3(b). O método mostrou bons resultados mesmo na presença do músculo peitoral menor (ver Figura 8.6). 


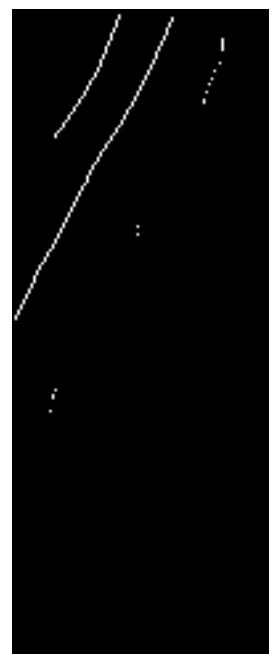

(a)

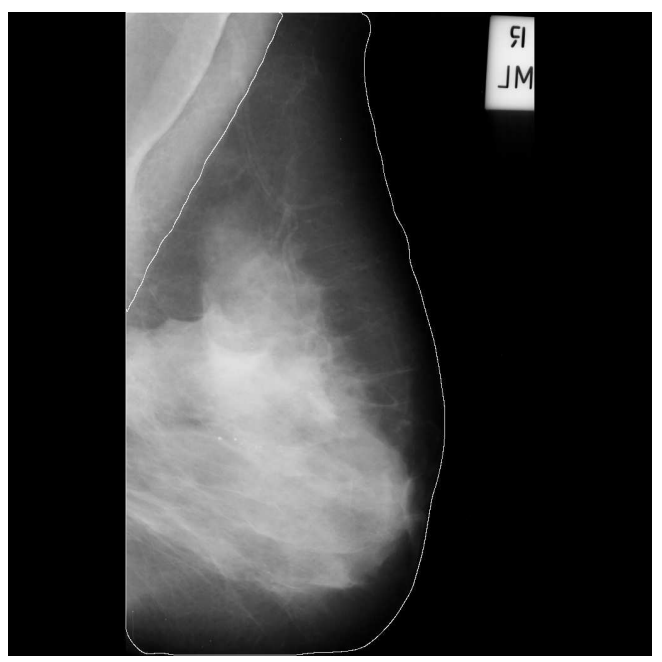

(b)

Figura 8.6: Imagem mdb110 mostrando o resultado da deteç̧ão do músculo peitoral na presença do músculo peitoral menor. (a) Bordas candidatas após o estágio de pós-processamento. (b) Borda final detectada.

\subsubsection{Resultados da identificação do disco fibro-glandular}

Os resultados da identificação do disco fibro-glandular, indicados no gráfico de barras na Figura 8.7, mostraram-se promissores (ver Figuras 8.1(c), 8.2(c), e 8.3(c)). Aproximadamente 81\% (68 imagens) (categorias 1 e 2) dos casos foram classificados como aceitáveis para o uso em sistemas CAD. Na categoria 1, 10 imagens resultantes foram consideradas pelo radiologista como subestimadas e 11 como superestimadas. A Figura 8.1(c), por exemplo, foi considerada como um caso subestimado, mesmo sendo rotulado como categoria 1. Na categoria 2, uma imagem resultante foi considerada como subestimada, e duas como superestimada. Em aproximadamente 19\% dos casos (16 imagens; das categorias 3, 4, e 5) a segmentação foi considerada insatisfatória.

A causa mais comum de problemas na identificação do disco fibro-glandular esteve relacionada ao custo introduzido pela técnica MDL usada para a seleção do modelo mais apropriado para a segmentação. Nesses casos, a técnica MDL superestimou o número de classes de tecidos. A utilização de outras técnicas de "clustering", como por exemplo a técnica K-médias, talvez possa auxiliar na 


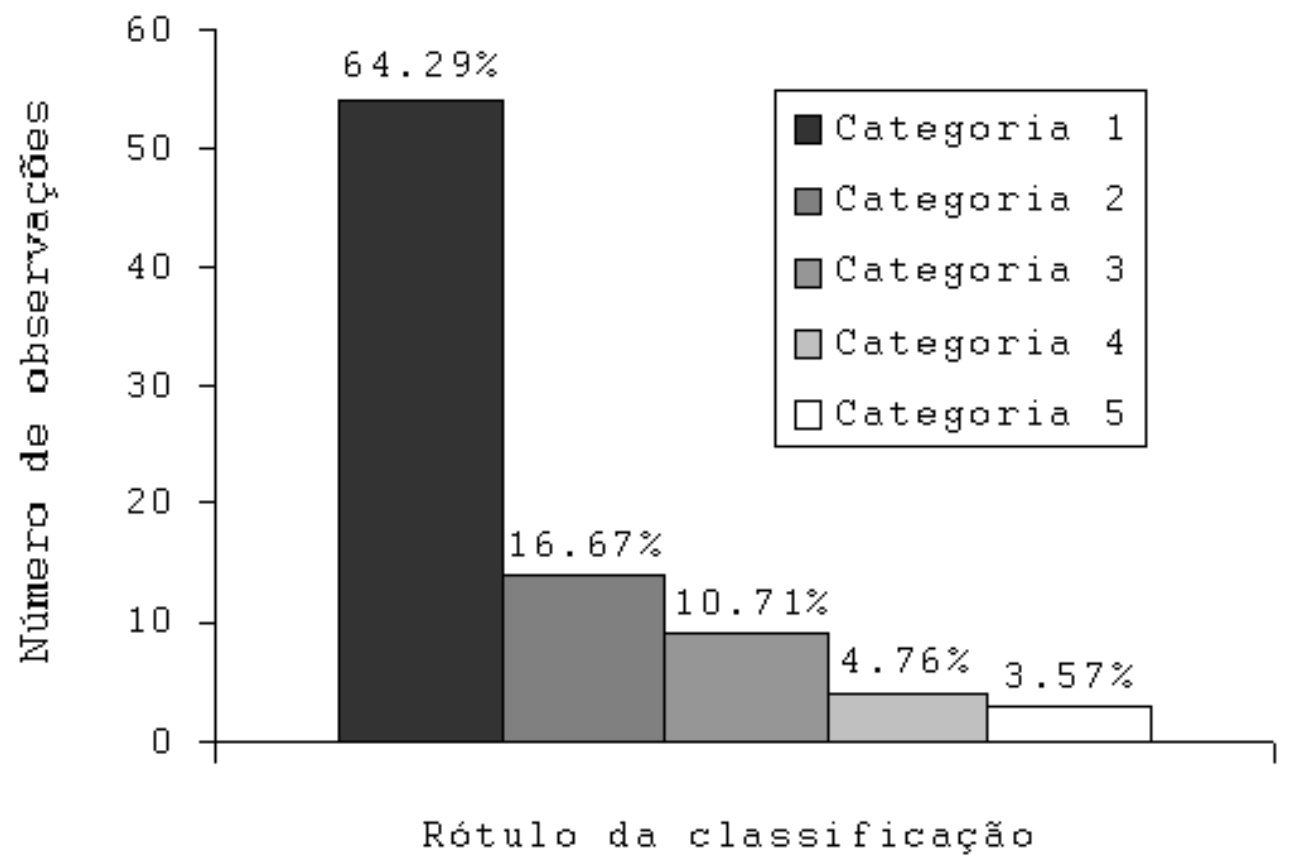

Figura 8.7: Resultados da classificação dos resultados da segmentação do disco fibro-glandular pelo radiologista. Cada categoria apresentada no gráfico é descrita em detalhes no Capítulo 7 - Seção 7.1. 
determinação mais apropriada do número de classes.

A técnica DAEM mostrou-se bastante robusta em relação à inicialização dos parâmetros do modelo de mistura de gaussianas.

O tempo de processamento para a identificação das três regiões anatômicas do mamograma, após as modificações efetuadas nos métodos propostos inicialmente [FERRARI et al. (2000b)], é de 0.7 min em média, usando um microcomputador de 850 MHz com 512 MB de memória RAM.

\subsubsection{Conclusões parciais}

De acordo com as opiniões dos dois radiologistas (JELD e RAB), os resultados gerais dos métodos propostos, aplicados inicialmente a 66 imagens e posteriormente a outras 84 imagens da base de dados Mini-MIAS [SUCKLING et al. (1994)], mostraram-se bastante adequados para o uso em estágios de pré-processamento de sistemas CAD.

De acordo com os radiologistas e também com base na análise quantitativa, os métodos para a deteç̧ão da borda da mama e do músculo peitoral mostraram resultados bastante satisfatórios para a grande maioria das imagens. O método para a identificação do disco fibro-glandular poderá ser aperfeiçoado, através da substituição ou modificação da função de custo MDL usada atualmente para selecionar o melhor modelo de densidades.

A elaboração de um padrão de comparação (base de dados com os contornos demarcados) possibilitou uma análise quantitativa dos resultados, tornando-os mais confiáveis.

Os métodos propostos para a segmentação anatômica dos mamogramas podem ser eventualmente utilizados para diferentes aplicações em mamografia, tal como compressão da imagem do mamograma (usando apenas a região efetiva da mama), análise de assimetrias [RANGAYYAN et al. (2000), FERRARI et al. (2001)], co-registro de imagens, quantificação e classificação de padrões de parênquima da mama e estimação da densidade das mamas. 


\subsection{Detecção de assimetrias entre mamogramas}

A avaliação dos resultados do procedimento de análise de assimetrias entre pares de mamogramas foi também realizada em duas etapas distintas devido a modificações realizadas nos procedimentos de análise.

\subsection{1 $1^{\mathrm{a}}$ Etapa}

Nesta etapa, um total de 80 imagens foram analisadas (20 casos normais, 14 casos de assimetria e 6 casos de distorção de arquitetura). Os valores dos atributos foram normalizados para a unidade através da divisão de seus valores pelo valor máximo calculado entre os vetores de atributos. A classificação das 80 imagens foi realizada apenas com base nos atributos extraídos dos diagramas de rosa (análise direcional), e usando o classificador linear de Bayes.

\subsubsection{Análise direcional}

As Figuras 8.8 e 8.9 mostram dois pares de imagens que serão usados para ilustrar os resultados do procedimento de análise direcional aplicado aos mamogramas. O par de imagens mdb043 e mdb044 da Figura 8.8 é classificado na base de dados Mini-MIAS como um caso normal, e o par mdb119 e mdb120 da Figura 8.9 como um caso de distorção de arquitetura.

A Figura 8.10 mostra os componentes principais obtidos após a aplicação da transformada KL sobre as imagens filtradas pela transformada Gabor wavelets com orientação de $135^{\circ}$ e quatro escalas para o mamograma da Figura $8.9($ d). Como pode ser observado, as informações mais relevantes estão concentradas nos primeiros dois componentes principais. Este fato é evidente analisando-se os autovalores indicados na legenda da Figura 8.10. Neste exemplo, apenas os dois primeiros componentes principais foram usados para representar as informações orientadas a $135^{\circ}$, visto que seus autovalores somam $99.34 \%$ (> 95\% ) da variância 


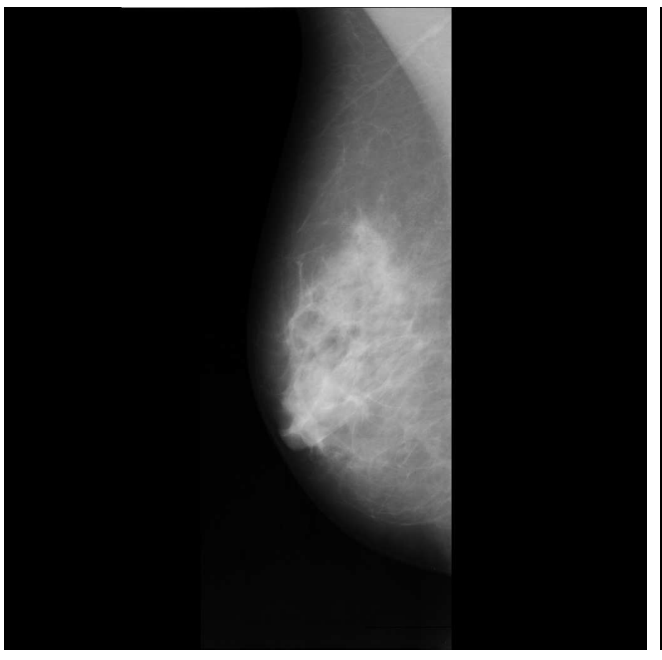

(a)

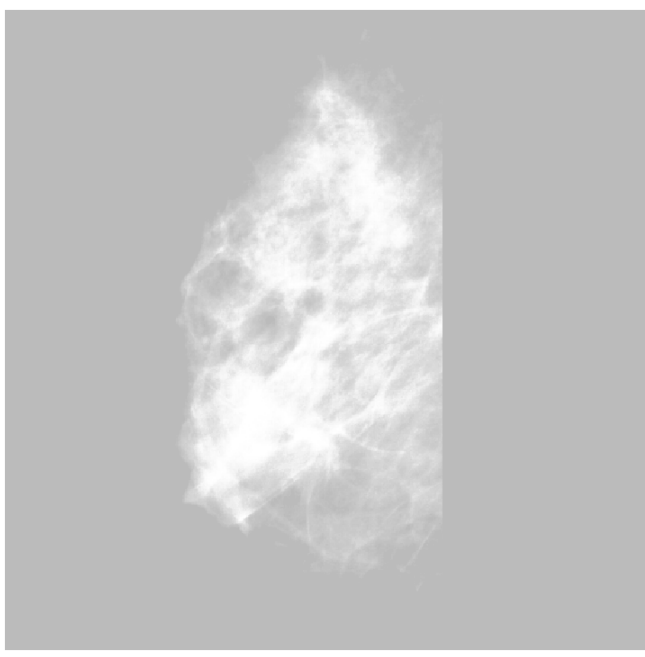

(c)

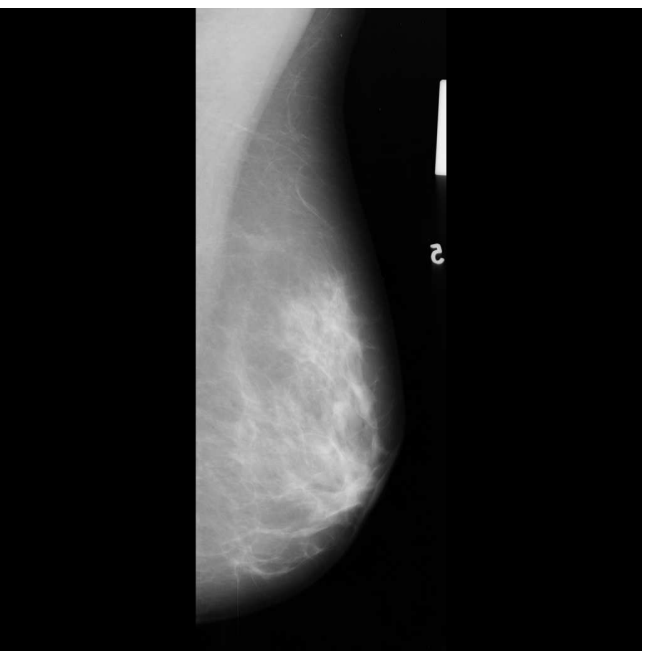

(b)

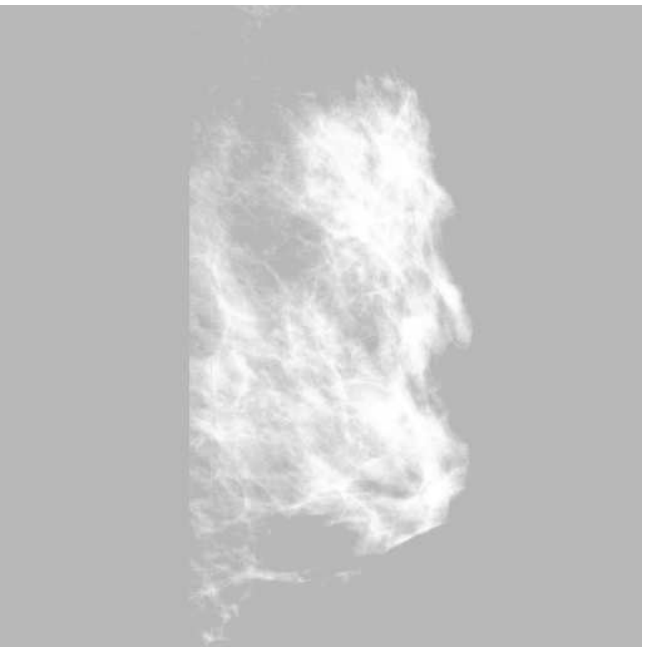

(d)

Figura 8.8: Imagens mdb043 e mdb044 de um caso normal. (a) e (b) imagens originais $(1024 \times 1024$ pixels $)$. (c) e (d) Discos fibro-glandulares segmentados e ampliados $(512 \times 512$ pixels $)$. Os discos fibro-glandulares foram equalizados apenas para efeito de visualização. 


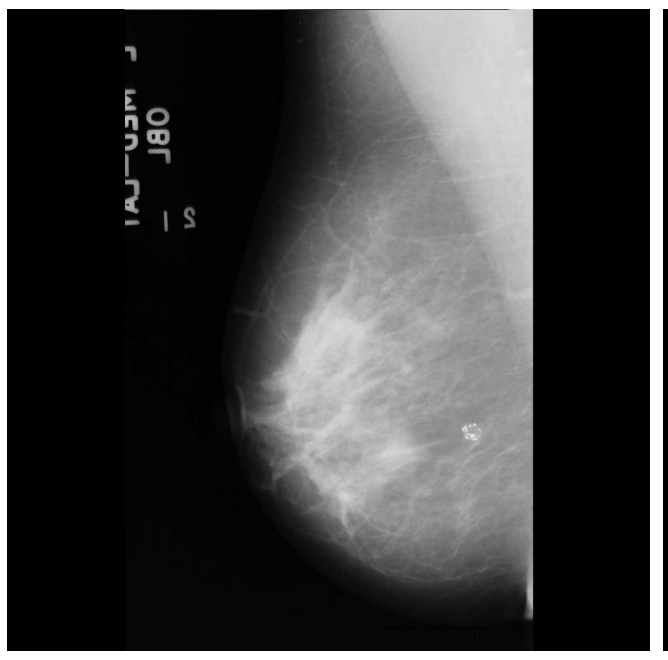

(a)

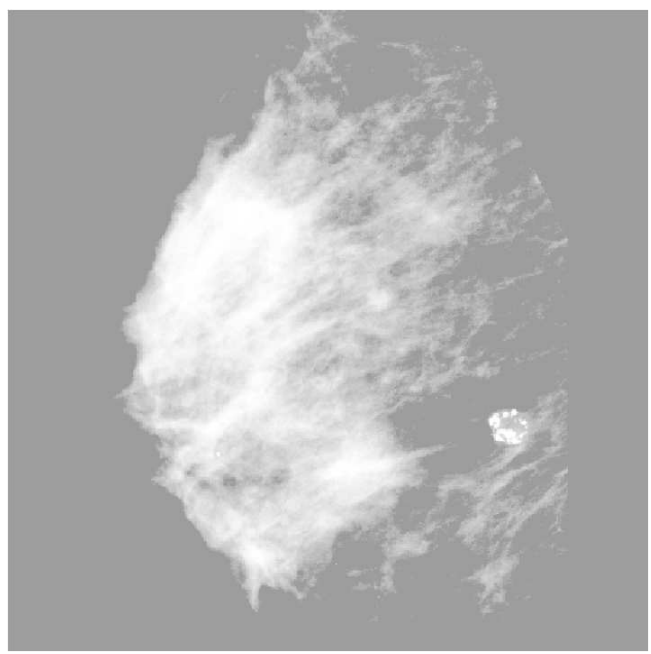

(c)

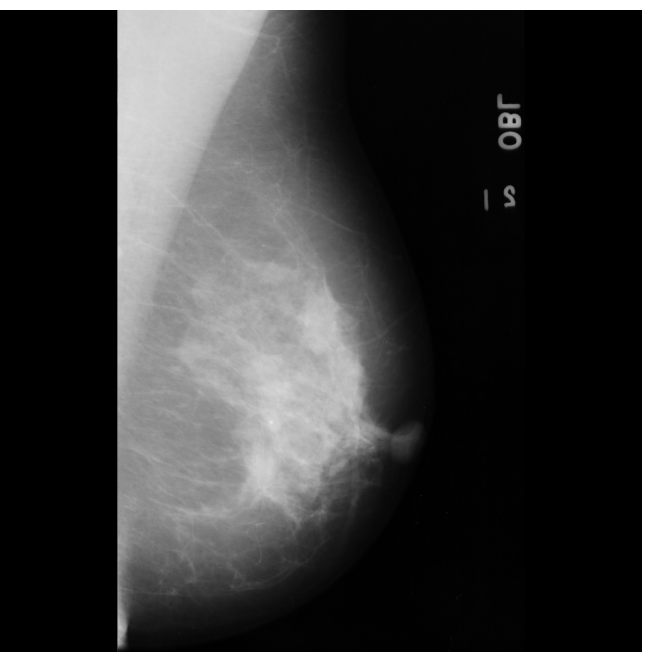

(b)

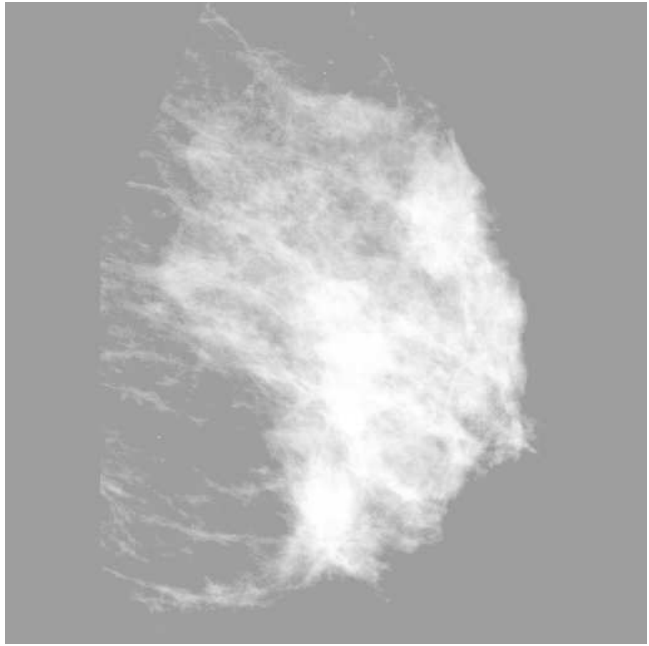

(d)

Figura 8.9: Imagens mdb119 e mdb120 de um caso de distorção de arquitetura. (a) e (b) imagens originais $(1024 \times 1024$ pixels $)$. (c) e (d) Discos fibro-glandulares segmentados e ampliados $(512 \times 512$ pixels $)$. Os discos fibro-glandulares foram equalizados apenas para efeito de visualização. 
total.

Após a limiarização das imagens filtradas com o método de Otsu, as imagens de magnitude e fase foram compostas através de uma soma vetorial, como ilustradas nas Figuras 8.11 e 8.12 .

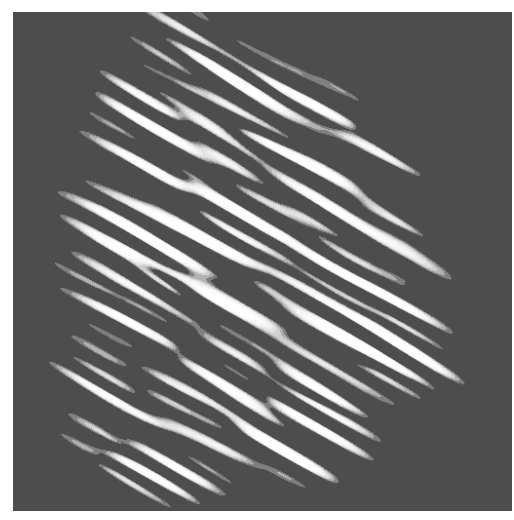

(a)

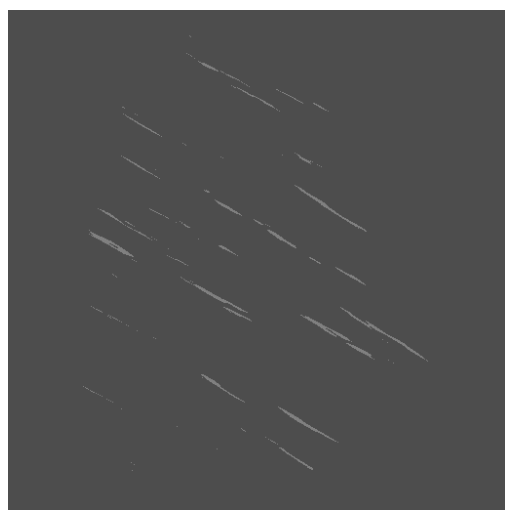

(c)

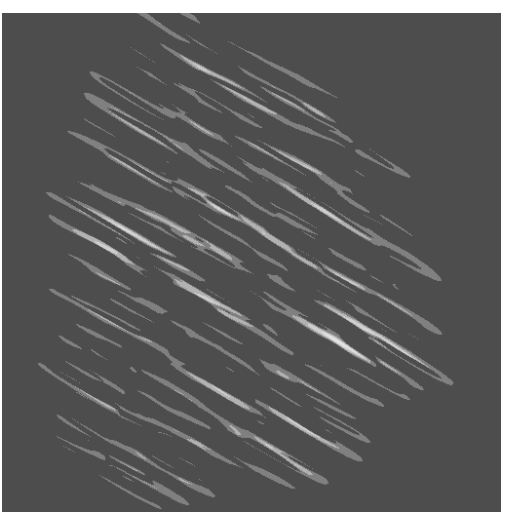

(b)

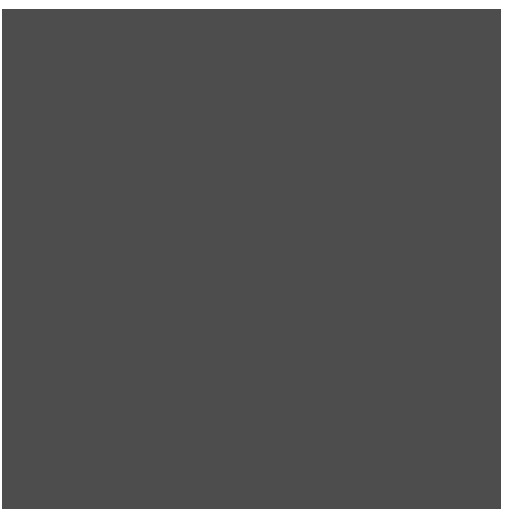

(d)

Figura 8.10: As imagens (a), (b), (c) e (d) indicam, respectivamente, os $1^{\mathrm{O}}, 2^{\mathrm{O}}, 3^{\mathrm{O}}$ e $4^{\mathrm{O}}$ componentes resultantes da aplicação da transformada KL aplicada às respostas dos filtros com orientação de $135^{\circ}$ para a imagem mostrada na Figura 8.9(d). Os autovalores dos quatro componentes indicados acima são: $\lambda_{1}=10.804568, \lambda_{2}=0.886360, \lambda_{3}=0.093959$, e $\lambda_{4}=0.013048$. O contraste das imagens foram igualmente corrigidos para melhor visualização.

As Figuras 8.11(a)-(d) mostram as imagens de magnitude e fase para o caso normal da Figura 8.8. Analisando as imagens de fase é possível visualizar que as projeções esquerda e direita possuem praticamente a mesma orientação dominante. Alguns artefatos podem ser observados na direção da parede do tórax, 
causados pelas transições dos níveis de cinza (ver Figuras 8.8(c) e (d)).

Os diagramas de rosa nas Figuras 8.11(e) e (f) mostram a distribuição dos tecidos fibro-glandulares de ambas as projeções, esquerda e direita. Através de uma inspeção dos diagramas de rosa é possível verificar que os resultados obtidos estão em boa concordância em relação a análise visual das Figuras 8.11(c) e (d), e as correspondentes ROIs das Figuras 8.8(c) e (d). As informações angulares mais relevantes indicadas nos diagramas de rosa são muito similares.

Os resultados do processo de filtragem para o caso de distorção de arquitetura (ver Figura 8.9) juntamente com os respectivos diagramas de rosa são mostrados na Figura 8.12. Analisando as imagens de magnitude e fase é possível observar uma modificação no padrão do fluxo de tecidos, causada pela presença de uma região altamente densa. Uma característica importante dos filtros de Gabor pode ser observada nesse resultado: os filtros não respondem as regiões com intensidade praticamente uniformes, isto é, as regiões sem informações direcionais (ver Figuras 8.9(c) e 8.12(c)). Neste exemplo, uma distorção global do fluxo normal de tecidos pode ser observada através da comparação entre os diagramas de rosa.

Os diagramas de rosa das Figuras 8.11 e 8.12 apresentam uma forte associação visual com os componentes direcionais das imagens de fase obtidas através do método proposto, e poderiam ser utilizados de acordo com o radiologista JELD como um auxílio na interpretação dos mamogramas.

As Figuras 8.13(a)-(d) mostram as distribuições dos atributos $M_{1}, M_{2}$, e $H$ definidos no Capítulo 6 - Seção 6.1.5 para a caracterização de informações direcionais.

Visto o pequeno número de atributos usados nesta avaliação, uma combinação exaustiva foi aplicada para selecionar o melhor subconjunto de atributos. A seleção foi realizada com base nos resultados do classificador linear de Bayes e usando o método "leave-one-out".

Resultados preliminares do procedimento de análise direcional, aplicados aos 40 casos mencionados anteriormente, são apresentados de forma resumida na 


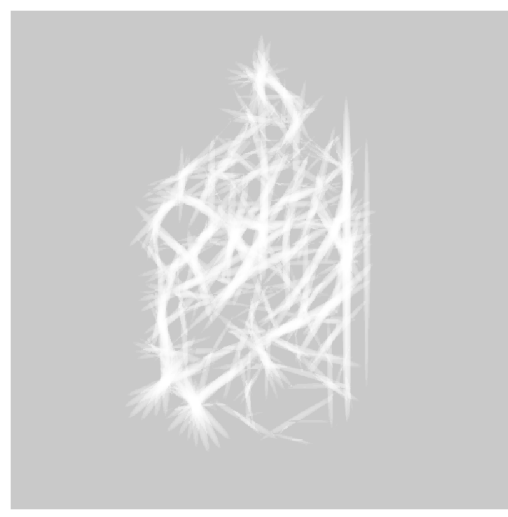

(a)

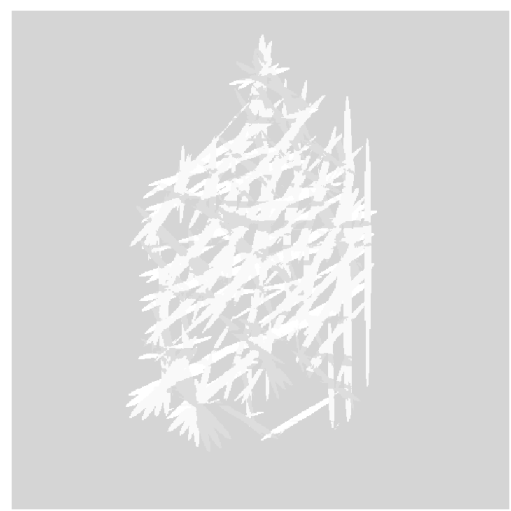

(c)

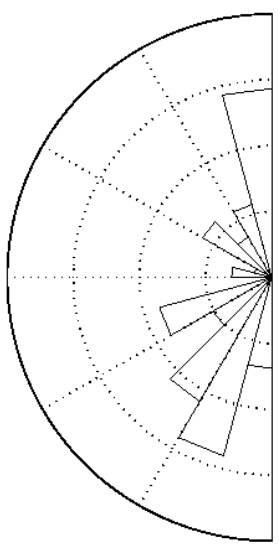

(e)

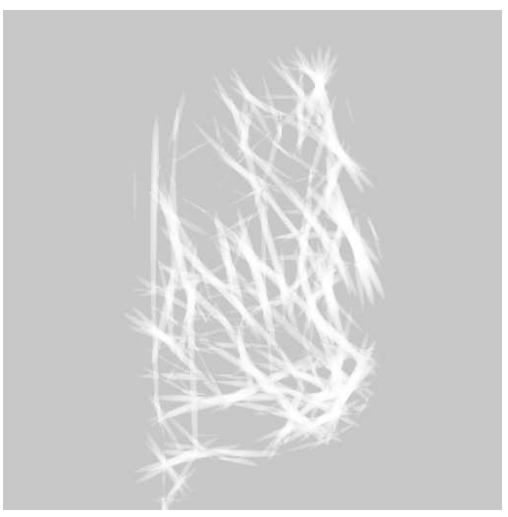

(b)

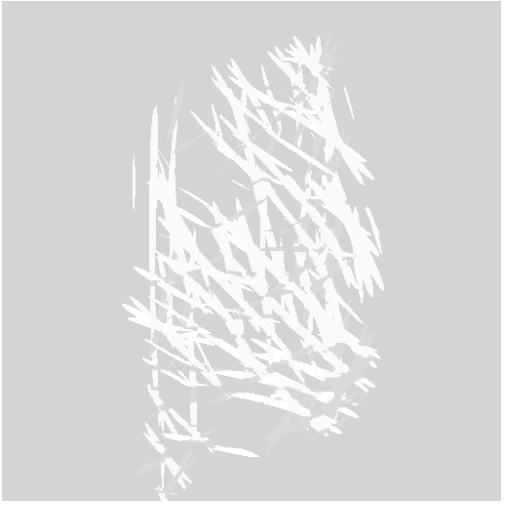

(d)

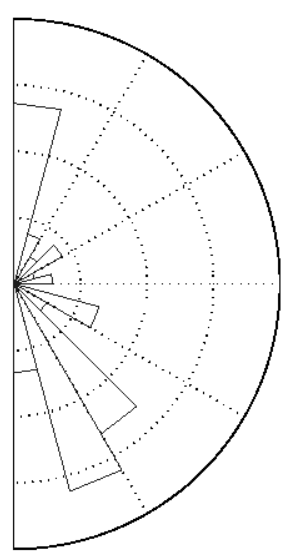

(f)

Figura 8.11: Resultados obtidos para o caso normal da Figura 8.8. (a) e (b) imagens de magnitude. (c) e (d) imagens de fase. (e) e (f) diagramas de rosa dos resultados em (c) e (d), respectivamente. As imagens de magnitude e fase foram equalizadas para melhor visualização. Os diagramas de rosa foram rotacionados de maneira a coincidirem com a orientação dos mamogramas. 


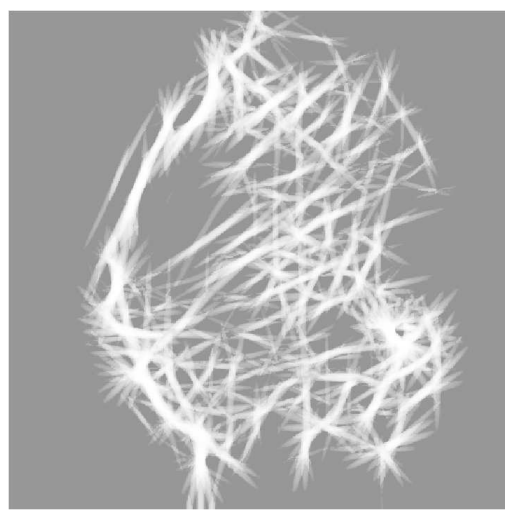

(a)

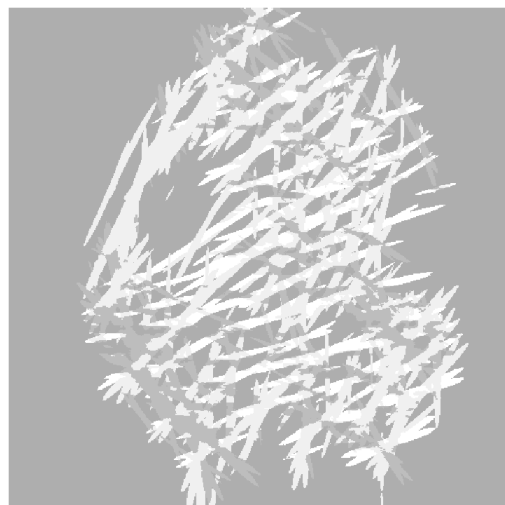

(c)

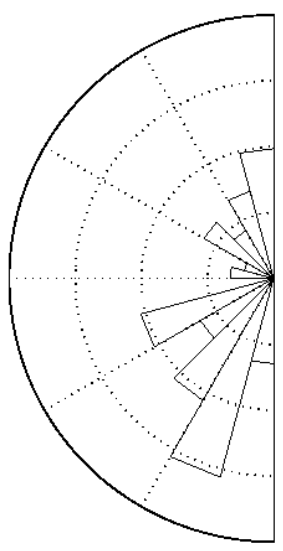

(e)

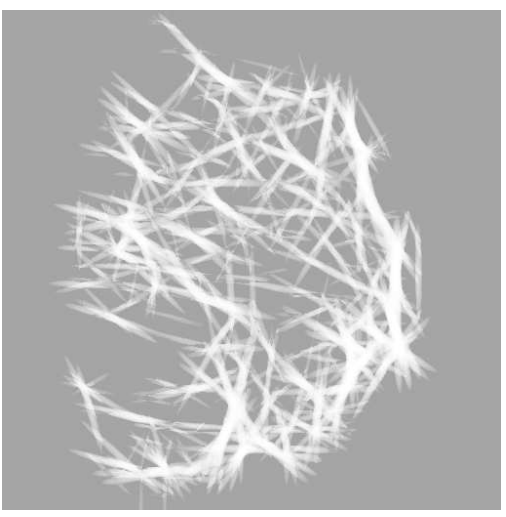

(b)

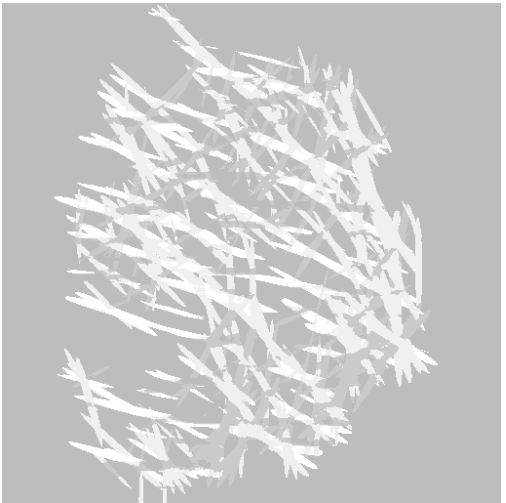

(d)

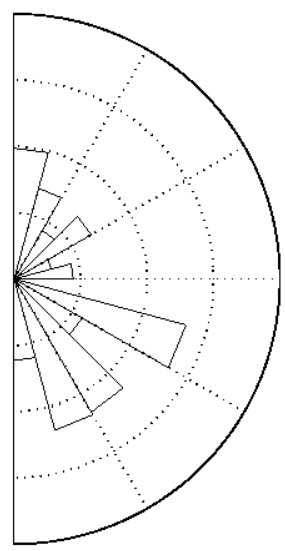

(f)

Figura 8.12: Resultados obtidos par um caso de distorção de arquitetura da Figura 8.9. (a) e (b) imagens de magnitude. (c) e (d) imagens de fase. (e) e (f) diagramas de rosa dos resultados em (c) e (d), respectivamente. As imagens de magnitude e fase foram equalizadas para melhor visualização. Os diagramas de rosa foram rotacionados de maneira a coincidirem com a orientação dos mamogramas. 


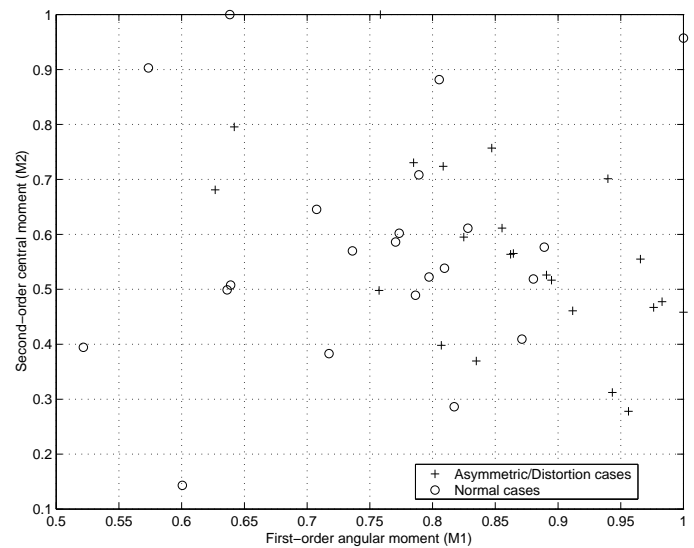

(a)

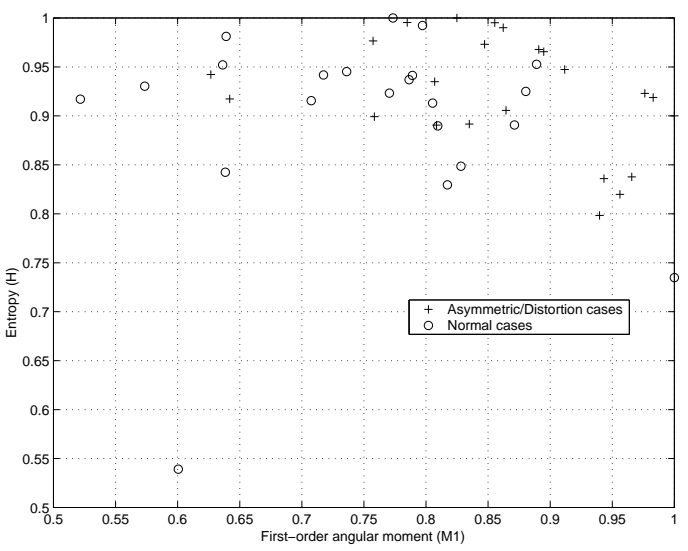

(b)

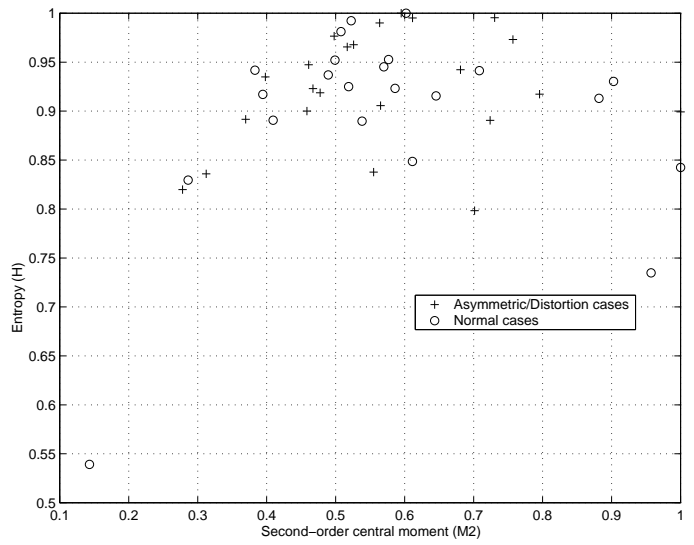

(c)

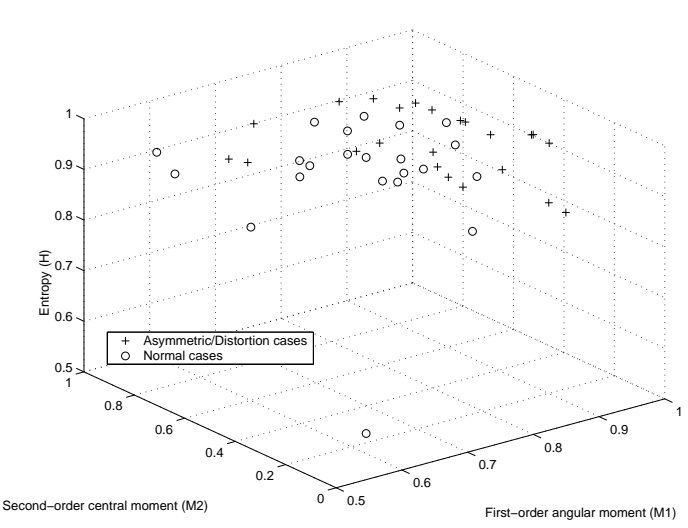

(d)

Figura 8.13: Distribuições das combinações entre os atributos $\left(M_{1}, M_{2}\right.$, e $\left.H\right)$ extraídos dos diagramas de rosa para o processamento de 40 casos. 
Tabela 8.1. O melhor resultado do processo de classificação, usando apenas um dos atributos, foi alcançado através do momento angular de primeira ordem $\left(M_{1}\right)$, com valores de sensibilidade, especificidade e taxa média de acerto iguais a $77.3 \%$, $71.4 \%$ e $74.4 \%$, respectivamente.

Usando dois atributos, o melhor resultado foi obtido através da combinação do momento angular de primeira ordem $\left(M_{1}\right)$ e da medida de entropia $(H)$, indicando que $80 \%$ dos casos de densidades assimétricas e distorções do parênquima mamário, e $65 \%$ dos casos normais foram corretamente classificados. A taxa média de acerto na classificação nesse caso foi de $72.5 \%$.

A taxa média de acertos na classificação de $80 \%$ para casos de assimetria pode ser considerada como um bom resultado visto o pequeno número de atributos usados na classificação das imagens. Entretanto, a taxa de $65 \%$ para os casos normais é relativamente baixa.

O atributo entropia $(H)$, que é uma medida de uniformidade da distribuição do diagrama de rosa, quando usado em conjunto com o momento angular de primeira ordem $\left(M_{1}\right)$ aumenta a taxa de acertos na classe assimétrica, no entanto diminui a taxa de acertos na classe normal. Acreditamos que esse fato possa ser explicado pela própria assimetria natural apresentada por alguns casos rotulados como normais, presentes na base de dados utilizada neste trabalho.

Usando os três atributos $\left(M_{1}, M_{2}\right.$, e $\left.H\right)$, a taxa de sensibilidade alcançada foi a maior, $81.8 \%$. Entretanto, a especificidade correspondente de $52.4 \%$ significa que quase metade dos casos normais foram incorretamente classificados.

O momento angular de primeira ordem $\left(M_{1}\right)$, mostrou-se eficiente na classificação das imagens, apresentando taxas satisfatórias em ambas as classes. Entretanto, os atributos caracterizando dispersão $\left(M_{2}\right.$ e $\left.H\right)$ não apresentaram bom desempenho, especialmente no reconhecimento de casos normais.

Devido ao comportamento global dessa abordagem, o atributo $M_{1}$ provou ser efetivo na caracterização da quantidade de informações direcionais na orientação média entre os mamogramas esquerdo e direito. Em casos normais, quase sempre 
a orientação média está em concordância com o segmento de reta perpendicular ao músculo peitoral e passando pelo mamilo. Para casos assimétricos, espera-se que as distribuições das estruturas direcionais, em relação a orientação média, sejam diferentes entre os mamogramas esquerdo e direito.

Tabela 8.1: Resultados médios para a classificação dos casos normais e assimétricos através do classificador Bayesiano linear, usando os atributos $M_{1}, M_{2}$, e $H$ em todas as possíveis combinações.

\begin{tabular}{l|c|c|c} 
Atributos & Sensibilidade & Especificidade & Média de acerto \\
\hline$M_{1}$ & $77.3 \%$ & $71.4 \%$ & $74.4 \%$ \\
\hline$M_{2}$ & $59.1 \%$ & $23.8 \%$ & $41.9 \%$ \\
\hline$H$ & $63.6 \%$ & $28.6 \%$ & $46.5 \%$ \\
\hline$M_{1}, M_{2}$ & $72.3 \%$ & $66.7 \%$ & $72.1 \%$ \\
\hline$M_{1}, H$ & $80.0 \%$ & $65.0 \%$ & $72.5 \%$ \\
\hline$M_{2}, H$ & $68.2 \%$ & $28.6 \%$ & $48.8 \%$ \\
\hline$M_{1}, M_{2}, H$ & $81.8 \%$ & $52.4 \%$ & $67.4 \%$ \\
\hline
\end{tabular}

\subsection{2 $\quad 2^{\mathrm{a}}$ Etapa}

Nesta segunda etapa, um total de 88 imagens foram analisadas (22 casos normais, 14 casos de assimetria, e 8 casos de distorção de arquitetura).

Atributos de forma e densidade, extraídos dos discos fibro-glandulares dos mamogramas esquerdo e direito, foram incluídos na classificação. Os diagramas de rosa calculados para cada imagem foram alinhados antes da subtração entre eles e dois novos atributos foram extraídos: a orientação dominante dos diagramas de rosa $\left(\theta_{R}\right)$ e a variância circular $\left(s_{\theta}^{2}\right)$. Todos os valores dos atributos foram normalizados para ter média zero e desvio padrão igual a unidade.

Além da combinação exaustiva usada para testar os 5 atributos direcionais e os 11 atributos extraídos dos discos fibro-glandulares, a transformada KL foi utilizada para tentar reduzir a dimensionalidade dos grupos formados tanto por estes 11 quanto por todos os 16 atributos originais, eliminando possíveis redundâncias entre eles. Neste caso, apenas os $n$ primeiros autovetores, com autovalores contribuindo com mais de $2 \%$ da variância total dos dados, foram mantidos na matriz de transformação linear. 


\subsubsection{Análise direcional}

Como pode ser observado na primeira avaliação do método de detecção de assimetrias baseada em informações direcionais, os atributos medindo a dispersão dos diagramas de rosa não foram eficazes como se esperava. Portanto, nesta segunda etapa de avaliação, os diagramas de rosa foram alinhados antes da subtração, como sugerido em [FERRARI et al. (2001), Seção "Discussion and Conclusion"]. Esse procedimento foi realizado para ajustar a direção média dos diagramas em relação a orientação natural do fluxo de elementos direcionais (ductos e tecidos conjuntivos) que normalmente convergem para o mamilo. Também, dois novos atributos foram extraídos dos diagramas: a orientação dominante dos diagramas de rosa e a variância circular.

Para efeito de comparação com os resultados apresentados na Tabela 8.1, os novos resultados da classificação envolvendo apenas os atributos $M_{1}, M_{2}$ e $H$, extraídos dos diagramas de rosa após o alinhamento, são apresentados na Tabela 8.2 .

Tabela 8.2: Resultados médios para a classificação dos casos normais e assimétricos através do classificador Bayesiano linear, usando os atributos $M_{1}, M_{2}$, e $H$ em todas as possíveis combinações.

\begin{tabular}{l|c|c|c} 
Atributos & Sensibilidade & Especificidade & Média de acerto \\
\hline$M_{1}$ & $10.0 \%$ & $68.18 \%$ & $33.33 \%$ \\
\hline$M_{2}$ & $56.52 \%$ & $40.91 \%$ & $48.89 \%$ \\
\hline$H$ & $69.57 \%$ & $90.91 \%$ & $80.00 \%$ \\
\hline$M_{1}, M_{2}$ & $47.83 \%$ & $68.18 \%$ & $57.78 \%$ \\
\hline$M_{1}, H$ & $65.22 \%$ & $86.36 \%$ & $75.56 \%$ \\
\hline$M_{2}, H$ & $73.91 \%$ & $86.36 \%$ & $80.00 \%$ \\
\hline$M_{1}, M_{2}, H$ & $69.57 \%$ & $86.36 \%$ & $77.78 \%$ \\
\hline
\end{tabular}

Nessa nova situação, os atributos $M_{2}$ e $H$, que medem a dispersão dos diagramas de rosa, foram mais eficazes na discriminação entre as classes assimétricas e normais, contribuindo para o aumento da taxa média de acertos da classificação, de $74.4 \%$ (na Tabela 8.1) para $80.0 \%$ (na Tabela 8.2). Diferentemente da primeira avaliação, nesta nova situação, o atributo $M_{1}$ mostrou-se ineficaz na classificação dos casos malignos ( sensibilidade $=10.0 \%$ ). 
Os melhores resultados da classificação (em termos da taxa média de acerto) utilizando todas as possíveis combinações entre os 5 atributos direcionais, através dos classificadores de Bayes linear e quadrático, são apresentados nas Tabelas 8.3 e 8.4 .

Tabela 8.3: Melhores resultados para a classificação dos casos normais e assimétricos através do classificador Bayesiano linear, analisando todas as possíveis combinações dos atributos $\theta_{R}, s_{\theta}^{2}, M_{1}, M_{2}$, e $H$.

\begin{tabular}{l|c|c|c} 
Atributos & Sensibilidade & Especificidade & Média de acerto \\
\hline$H$ & $69.57 \%$ & $90.91 \%$ & $80.00 \%$ \\
\hline$s_{\theta}^{2}, H$ & $73.91 \%$ & $86.36 \%$ & $80.00 \%$ \\
\hline$\theta_{R}, M_{1}, H$ & $73.91 \%$ & $86.36 \%$ & $80.00 \%$ \\
\hline$\theta_{R}, s_{\theta}^{2}, M_{1}, M_{2}$ & $73.91 \%$ & $86.36 \%$ & $80.00 \%$ \\
\hline$\theta_{R}, s_{\theta}^{2}, M_{1}, M_{2}, H$ & $78.26 \%$ & $77.27 \%$ & $77.78 \%$ \\
\hline
\end{tabular}

A melhor taxa média de acertos obtida para o classificador de Bayes linear foi de $80.0 \%$, usando apenas o atributo entropia $(H)$, e o atributo entropia juntamente com a variância circular $\left(s_{\theta}^{2}\right)$. Os atributos momento angular de primeira ordem $\left(M_{1}\right)$ e momento angular de segunda ordem $\left(M_{2}\right)$ não apresentaram nenhuma influência significativa na classificação. A combinação entre $H$ e $M_{2}$ na última linha da tabela, fez a taxa média de acertos diminuir de $80 \%$ para $77.78 \%$. Em contraste, a taxa de sensibilidade aumento de $73.91 \%$ para $78.26 \%$.

Tabela 8.4: Melhores resultados médios para a classificação dos casos normais e assimétricos através do classificador Bayesiano quadrático, analisando todas as possíveis combinações dos atributos $\theta_{R}, s_{\theta}^{2}, M_{1}, M_{2}$, e $H$.

\begin{tabular}{l|c|c|c} 
Atributos & Sensibilidade & Especificidade & Média de acerto \\
\hline$H$ & $65.22 \%$ & $90.91 \%$ & $77.78 \%$ \\
\hline$\theta_{R}, s_{\theta}^{2}$ & $73.91 \%$ & $81.82 \%$ & $77.78 \%$ \\
\hline$\theta_{R}, M_{2}, H$ & $78.26 \%$ & $86.36 \%$ & $82.22 \%$ \\
\hline$\theta_{R}, M_{1}, M_{2}, H$ & $82.61 \%$ & $86.36 \%$ & $84.44 \%$ \\
\hline$\theta_{R}, s_{\theta}^{2}, M_{1}, M_{2}, H$ & $86.96 \%$ & $77.27 \%$ & $82.22 \%$ \\
\hline
\end{tabular}

A melhor taxa média de acertos para o classificador de Bayes quadrático foi de $84.44 \%$, usando os atributos orientação dominante $\left(\theta_{R}\right)$, momento angular de primeira ordem $\left(M_{1}\right)$, momento angular de segunda ordem $\left(M_{2}\right)$ e entropia $(H)$. Neste caso, as taxas de sensibilidade e especificidade foram de $82.61 \%$ e $86.36 \%$, 
respectivamente. A maiores taxas de sensibilidade e especificidade obtidas foram $86.96 \%$ e $90.91 \%$, respectivamente.

\subsubsection{Análise com base no modelo de densidades}

As Figuras 8.14(a)-(b) e (c)-(d) ilustram dois pares de imagens usados para a discussão dos resultados obtidos do procedimento de análise de forma e densidade aplicado aos discos fibro-glandulares. O par de imagens mdb003 e mdb004 é classificado na base de dados Mini-MIAS como um caso normal, e o par mdb117 e mdb118 como um caso de densidade assimétrica.

As Figuras 8.15(a)-(b) e (c)-(d) ilustram, respectivamente, as imagens de $K$ níveis, obtidas a partir do modelo de densidades proposto, e os respectivos discos fibro-glandulares das imagens mdb003 e mdb004 ilustradas nas Figuras 8.14(a) e (b). Embora não estejam alinhados, os discos fibro-glandulares são bastante semelhantes em relação a suas formas e densidades, como pode ser observado visualmente e também por análise dos valores dos atributos indicados na Tabela 8.5 .

Tabela 8.5: Valores dos atributos de forma e densidade extraídos do caso normal; par de imagens mdb003 e mdb004.

\begin{tabular}{c|c|c|c} 
Atributo & Image esquerda & Imagem direita & Diferença absoluta \\
\hline$\phi_{1}$ & 9.4220 & 9.4787 & 0.0567 \\
\hline$\phi_{2}$ & 18.4793 & 18.5086 & 0.0293 \\
\hline$\phi_{3}$ & 20.2602 & 21.0420 & 0.7818 \\
\hline$\phi_{4}$ & 19.3752 & 20.0875 & 0.7123 \\
\hline$\phi_{5}$ & 38.8692 & 39.9413 & 1.0721 \\
\hline$\phi_{6}$ & 28.0245 & 28.0863 & 0.0618 \\
\hline$\phi_{7}$ & 39.1694 & 40.6496 & 1.4802 \\
\hline Excentricidade & 1.7012 & 1.47 & 0.2312 \\
\hline Alongamento & 0.4317 & 0.3557 & 0.0760 \\
\hline Área (no pixels) & 31356 & 34340 & 2984 \\
\hline Densidade média & 205 & 201 & 4
\end{tabular}

Os descritores de $\mathrm{Hu}\left(\phi_{1}-\phi_{7}\right)$ apresentaram valores bastante similares entre as imagens esquerda e direita, mesmo estando os discos fibro-glandulares em posições espaciais diferentes. Neste trabalho, os atributos foram normalizados para 


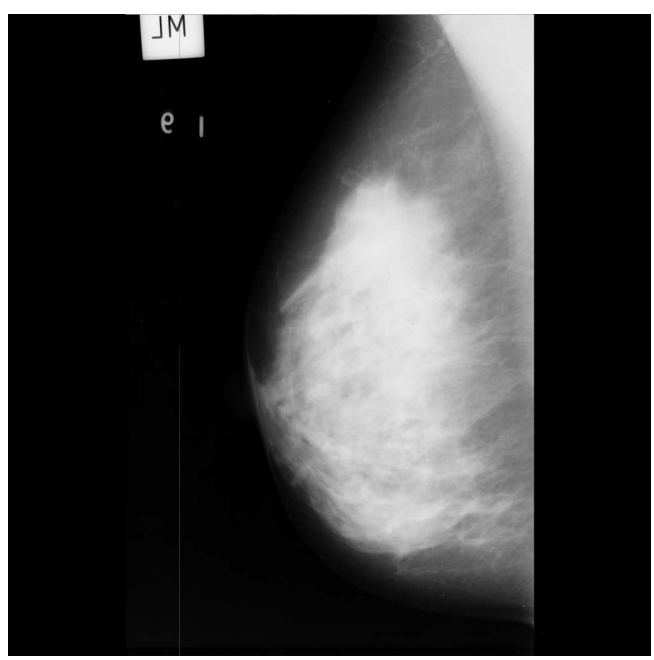

(a)

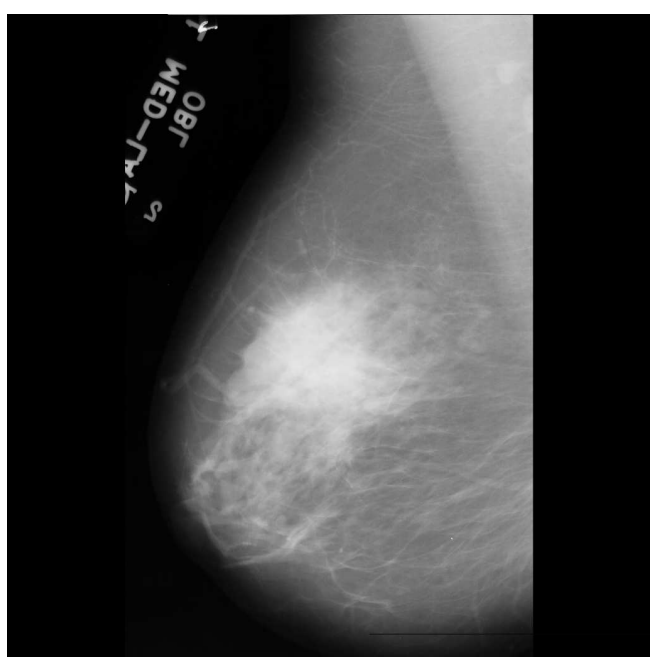

(c)

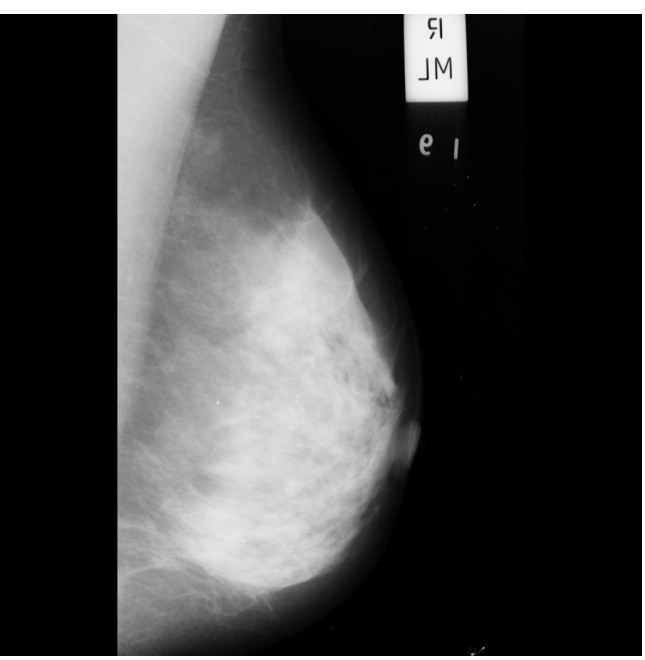

(b)

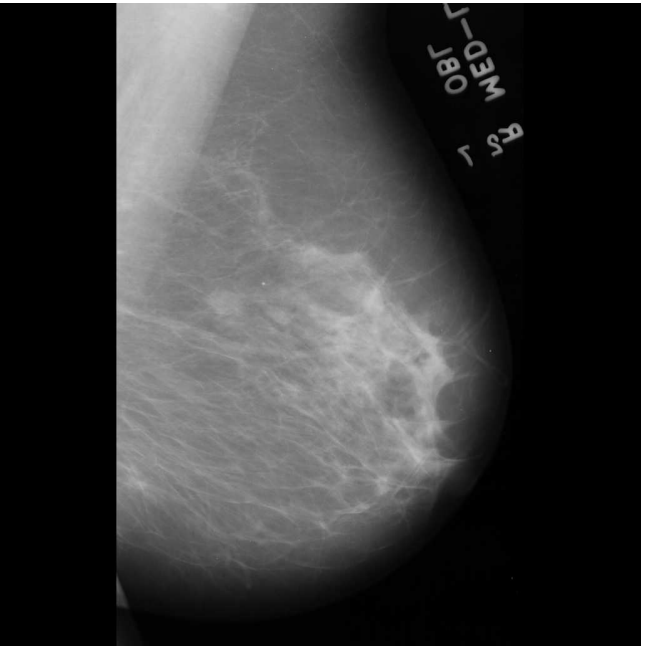

(d)

Figura 8.14: (a)-(b) Imagens mdb003 e mdb004 classificadas como um caso normal. (c)-(d) Imagens mdb081 e mdb082 classificadas como contendo uma densidade assimétrica. 


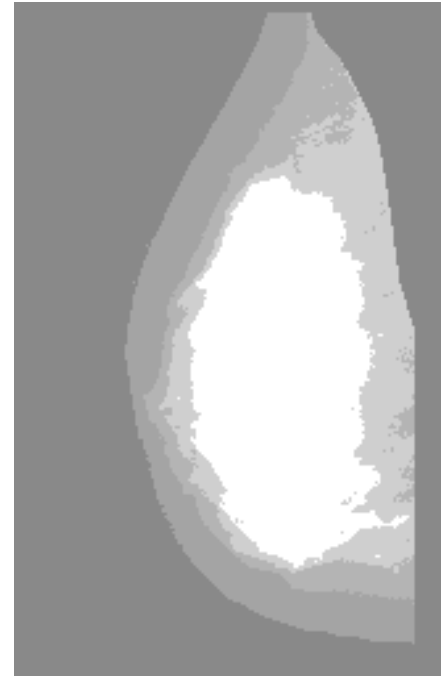

(a)

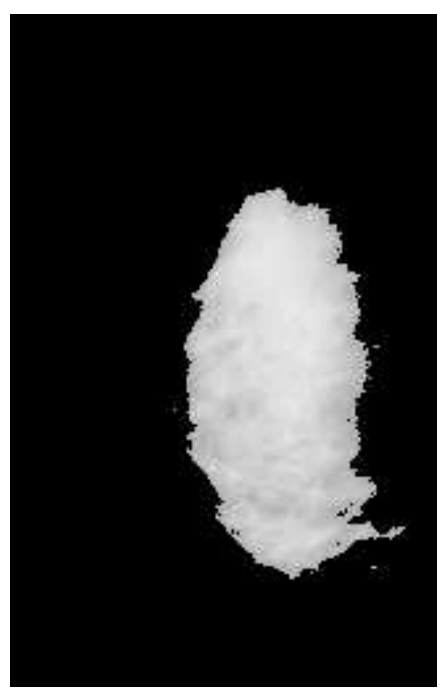

(c)

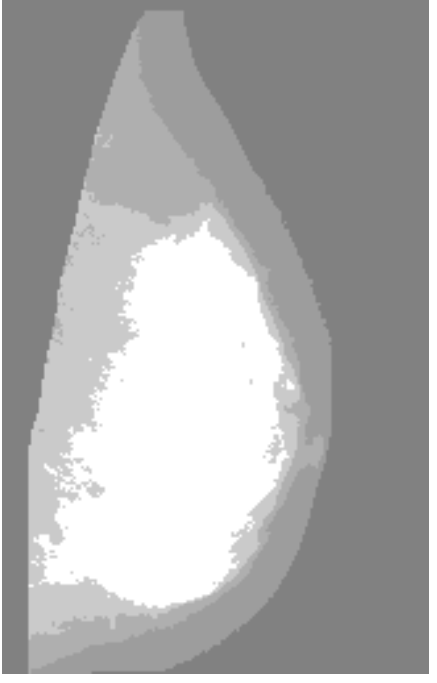

(b)

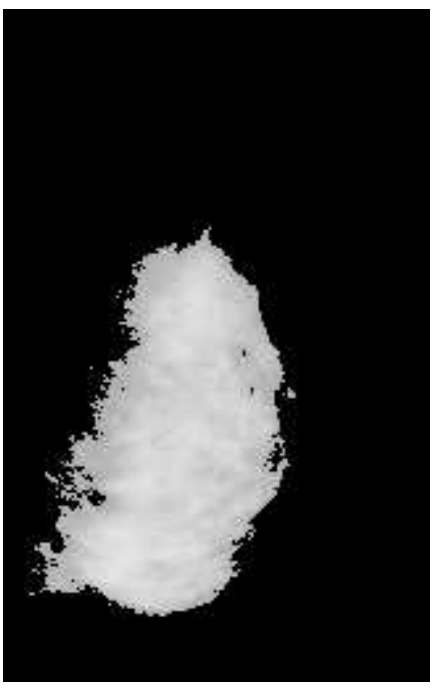

(d)

Figura 8.15: Resultados da segmentação dos discos fibro-glandulares das imagens mdb003 e mdb004 (caso normal) indicadas na Figura 8.14(a)-(b). (a)-(b) Imagens $K$-níveis resultantes do método de segmentação do disco fibro-glandular. (c)-(d) Discos fibro-glandulares segmentados. 
serem invariantes à rotação e translação. A normalização em relação à escala não foi realizada pois o tamanho dos discos glandulares é uma informação importante neste caso.

As imagens $K$-níveis e os respectivos discos fibro-glandulares das imagens mdb081 e mdb082, ilustradas na Figura 8.14(c)-(d), são apresentadas na Figura 8.16. Diferente do caso normal mostrado anteriormente, para esse caso assimétrico os discos fibro-glandulares possuem não apenas diferenças consideráveis em suas formas, mas também na densidade entre eles. A Tabela 8.6 apresenta os valores dos atributos extraídos dos discos fibro-glandulares. Neste caso, os descritores de forma apresentaram valores bastante diferentes entre as imagens esquerda e direita. A diferença absoluta da densidade média também foi bastante grande quando comparada ao caso normal, e a diferença entre as áreas dos discos fibro-glandulares também foi significativa.

Tabela 8.6: Valores dos atributos de forma e densidade extraídos do caso assimétrico; par de imagens mdb081 e mdb082.

\begin{tabular}{c|c|c|c} 
Atributo & Image esquerda & Imagem direita & Diferença absoluta \\
\hline$\phi_{1}$ & 8.7674 & 9.2681 & 0.5007 \\
\hline$\phi_{2}$ & 16.4410 & 17.3901 & 0.9491 \\
\hline$\phi_{3}$ & 19.4434 & 21.0502 & 1.6069 \\
\hline$\phi_{4}$ & 19.1716 & 20.7196 & 1.5480 \\
\hline$\phi_{5}$ & 38.4439 & 41.5748 & 3.1309 \\
\hline$\phi_{6}$ & 27.2621 & 29.2909 & 2.0288 \\
\hline$\phi_{7}$ & 37.9097 & 41.4765 & 3.5668 \\
\hline Excentricidade & 1.1648 & 1.1984 & 0.0336 \\
\hline Alongamento & 0.0806 & 0.0714 & 0.0092 \\
\hline Área (no pixels) & 16436 & 26320 & 9884 \\
\hline Densidade média & 191.982 & 150.914 & 41.068 \\
\hline
\end{tabular}

Um total de 11 atributos foram extraídos dos discos fibro-glandulares e usados nesta análise. Tanto a análise exaustiva quanto a análise de componentes principais foram utilizadas para determinar os melhores resultados da classificação dos mamogramas. 


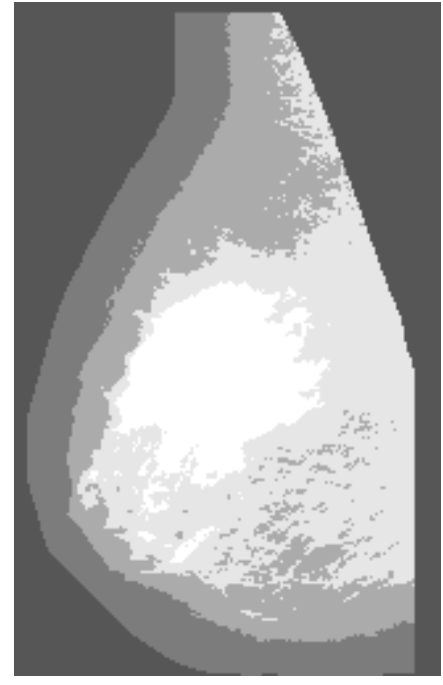

(a)

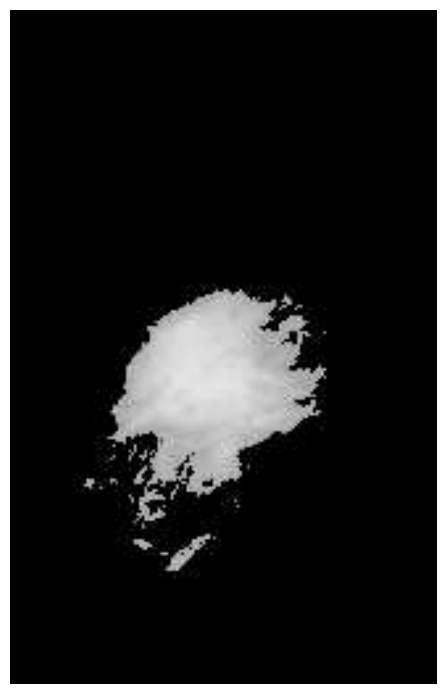

(c)

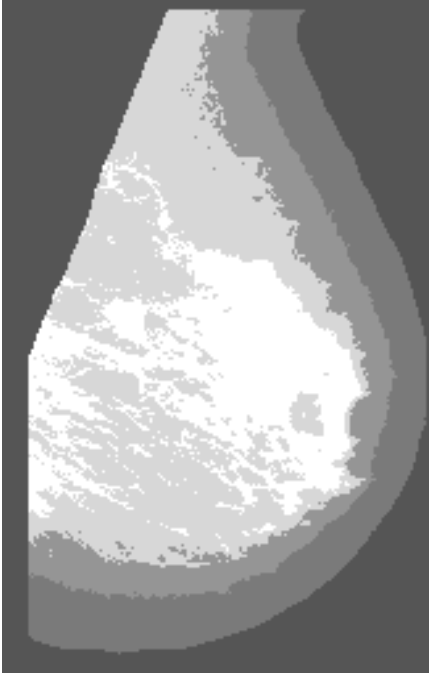

(b)

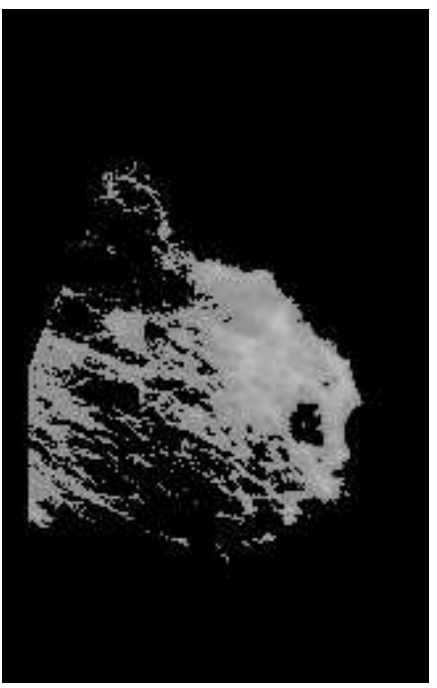

(d)

Figura 8.16: Resultados da segmentação dos discos fibro-glandulares das imagens mdb081 e mdb082 (caso assimétrico) indicadas na Figura 8.14(c)-(d). (a)-(b) Imagens $K$-níveis resultantes do método de segmentação do disco fibro-glandular. (c)-(d) Discos fibro-glandulares segmentados. 
As Tabelas 8.7 e 8.8 apresentam, respectivamente, os melhores resultados para a análise combinatória dos 11 atributos utilizando os classificadores de Bayes linear e quadrático.

Tabela 8.7: Melhores resultados médios da classificação dos casos normais e assimétricos através do classificador Bayesiano linear, analisando todas as possíveis combinações dos atributos de forma, área e densidade.

\begin{tabular}{l|c|c|c} 
Atributos & Sensibilidade & Especificidade & Média de acerto \\
\hline$\phi_{1}$ & $56.52 \%$ & $86.36 \%$ & $71.11 \%$ \\
\hline$\phi_{1}, \phi_{4}$ & $60.87 \%$ & $86.36 \%$ & $73.33 \%$ \\
\hline$\phi_{1}, D A, D D$ & $65.22 \%$ & $90.91 \%$ & $77.78 \%$ \\
\hline$\phi_{1}, \phi_{3}, D A, D D$ & $60.87 \%$ & $95.45 \%$ & $77.78 \%$ \\
\hline$\phi_{1}, A l, D A, D D$ & $65.22 \%$ & $90.91 \%$ & $77.78 \%$ \\
\hline$\phi_{1}, \phi_{2}, \phi_{4}, D A, D D$ & $60.87 \%$ & $90.91 \%$ & $75.56 \%$ \\
\hline$\phi_{1}, \phi_{2}, \phi_{4}, \phi_{7}, D A, D D$ & $65.22 \%$ & $86.36 \%$ & $75.56 \%$ \\
\hline$\phi_{1}, \phi_{2}, \phi_{4}, \phi_{7}, A l, D A, D D$ & $56.52 \%$ & $86.36 \%$ & $71.11 \%$ \\
\hline$\phi_{1}, \phi_{3}-\phi_{5}, \phi_{7}, A l, D A, D D$ & $60.87 \%$ & $77.27 \%$ & $68.89 \%$ \\
\hline$\phi_{1}, \phi_{2}, \phi_{4}-\phi_{7}, A l, E . D A, D D$ & $60.87 \%$ & $59.09 \%$ & $60.00 \%$ \\
\hline$\phi_{1}-\phi_{7}, A l, E . D A, D D$ & \multicolumn{2}{l}{$56.52 \%$} & $51.11 \%$ \\
\hline$D A$ é a diferença entre áreas dos discos fibro-glandulares. \\
\hline$D D$ é a diferença entre densidades dos discos fibro-glandulares. \\
\hline Al é a medida de alongamento, e $E$ indica a excentricidade. \\
\hline
\end{tabular}

Tabela 8.8: Melhores resultados médios da classificação dos casos normais e assimétricos através do classificador Bayesiano quadrático, analisando todas as possíveis combinações dos atributos de forma, área e densidade.

\begin{tabular}{l|c|c|c} 
Atributos & Sensibilidade & Especificidade & Média de acerto \\
\hline$\phi_{1}$ & $47.83 \%$ & $86.36 \%$ & $66.67 \%$ \\
\hline$\phi_{7}, D D$ & $52.17 \%$ & $90.91 \%$ & $71.11 \%$ \\
\hline$\phi_{7}, E, D D$ & $60.87 \%$ & $86.36 \%$ & $73.33 \%$ \\
\hline$\phi_{1}, \phi_{4}, \phi_{7}, D A$ & $65.22 \%$ & $81.82 \%$ & $73.33 \%$ \\
\hline$\phi_{1}, \phi_{2}, \phi_{7}, D A, D D$ & $65.22 \%$ & $90.91 \%$ & $77.78 \%$ \\
\hline$\phi_{1}, \phi_{2}, \phi_{4}, \phi_{7}, D A, D D$ & $69.57 \%$ & $90.91 \%$ & $80.00 \%$ \\
\hline$\phi_{1}, \phi_{2}, \phi_{4}, \phi_{5}, \phi_{7}, D A, D D$ & $73.91 \%$ & $86.36 \%$ & $80.00 \%$ \\
\hline$\phi_{1}, \phi_{2}, \phi_{4}, \phi_{5}, \phi_{7}, A l, D A, D D$ & $78.26 \%$ & $81.82 \%$ & $80.00 \%$ \\
\hline$\phi_{1}-\phi_{7}, D A, D D$ & $78.26 \%$ & $72.73 \%$ & $75.56 \%$ \\
\hline$\phi_{1}-\phi_{7}, A l, D A, D D$ & $78.26 \%$ & $54.55 \%$ & $66.67 \%$ \\
\hline$\phi_{1}-\phi_{7}, A l, E, D A, D D$ & $78.26 \%$ & $45.45 \%$ & $62.22 \%$ \\
\hline$D A$ é a diferença entre áreas dos discos fibro-glandulares. \\
\hline$D D$ é a diferença entre densidades dos discos fibro-glandulares. \\
\hline$A l$ é a medida de alongamento, e $E$ indica a excentricidade. \\
\hline
\end{tabular}

Embora a combinação exaustiva entre os vetores de atributos num espaço de alta dimensionalidade não seja a maneira mais apropriada para a determinação do melhor conjunto de atributos a ser usado pelo classificador, neste trabalho, os resultados foram calculados e apresentados nas Tabelas 8.7 e 8.8, para efeito 
de comparação com os resultados obtidos a partir dos componentes principais descritos a seguir.

O melhor resultado utilizando o classificador linear foi de $77.78 \%$, para um total de 3,4 e 5 atributos. As maiores taxas de sensibilidade e especificidade obtidas foram de $65.22 \%$ e $95.45 \%$, respectivamente.

O classificador quadrático apresentou melhor desempenho que o classificador linear com uma taxa média de acertos de $80 \%$. As máximas taxas de sensibilidade e especificidade foram de $78.26 \%$ e $90.91 \%$, respectivamente.

A análise dos 11 atributos extraídos dos discos fibro-glandulares foi também realizada usando os componentes principais calculados através da transformada KL. Embora essa técnica não necessariamente garanta a melhor taxa de acertos na classificação [WEBB (1999)], a análise combinatória desses atributos, aplicada anteriormente, envolve um custo computacional muito alto. Além desse fato o número crescente da dimensão do espaço original de atributos quase sempre implica em problemas de mal-condicionamento das matrizes de covariâncias.

Através da transformada KL, um total de 7 componentes principais, correspondendo a $97.54 \%$ da variância total dos dados, foram selecionados para representar o novo sub-espaço de atributos. Os autovalores juntamente com suas contribuições relativas na variância total dos dados são apresentados na Tabela 8.9 .

Tabela 8.9: Relação de autovalores e as respectivas contribuições na formação da matriz de transformação linear da transformada KL.

\begin{tabular}{c|c|c} 
& Autovalores & Contribuição na variância total \\
\hline 1 & 6.7589 & $61.45 \%$ \\
\hline 2 & 1.0780 & $9.80 \%$ \\
\hline 3 & 1.0497 & $9.54 \%$ \\
\hline 4 & 0.6519 & $5.93 \%$ \\
\hline 5 & 0.4949 & $4.50 \%$ \\
\hline 6 & 0.4283 & $3.89 \%$ \\
\hline 7 & 0.2670 & $2.43 \%$ \\
\hline \multicolumn{2}{|c|}{ TOTAL } & $\mathbf{9 7 . 5 4 \%}$ \\
\hline
\end{tabular}


Após a aplicação da transformada KL, os classificadores de Bayes linear e quadrático foram utilizados para determinar a melhor combinação entre os componentes principais. A taxa média de acertos na classificação foi usada como critécio de seleção dos componentes principais.

As Tabelas 8.10 e 8.11 apresentam os melhores resultados da classificação dos 44 casos, obtidos através dos classificadores linear e quadrático, respectivamente. Os números indicados na primeira coluna dessas tabelas representam os componentes principais utilizados na classificação.

Tabela 8.10: Melhores resultados médios para a classificação dos casos normais e assimétricos através do classificador Bayesiano linear, analisando todos os 7 componentes principais.

\begin{tabular}{l|c|c|c} 
Comp. principais & Sensibilidade & Especificidade & Média de acerto \\
\hline 4 & $52.17 \%$ & $86.36 \%$ & $68.89 \%$ \\
\hline 15 & $56.52 \%$ & $86.36 \%$ & $71.11 \%$ \\
\hline 125 & $56.52 \%$ & $86.36 \%$ & $71.11 \%$ \\
\hline 1456 & $65.22 \%$ & $72.27 \%$ & $71.11 \%$ \\
\hline 12356 & $56.52 \%$ & $72.73 \%$ & $64.44 \%$ \\
\hline 123456 & $56.52 \%$ & $63.64 \%$ & $60.00 \%$ \\
\hline 1234567 & $47.83 \%$ & $59.09 \%$ & $53.33 \%$ \\
\hline
\end{tabular}

Para o classificador linear, um dos melhores resultados em termos da taxa média de acertos foi de $71.11 \%$, com $65.22 \%$ de sensibilidade e $72.27 \%$ de especificidade, obtido através dos componentes principais 1, 4, 5 e 6 . As maiores taxas de sensibilidade e especificidade foram de $65.22 \%$ e $72.73 \%$, respectivamente.

Tabela 8.11: Melhores resultados médios para a classificação dos casos normais e assimétricos através do classificador Bayesiano quadrático, analisando todos os 7 componentes principais.

\begin{tabular}{l|c|c|c} 
Comp. principais & Sensibilidade & Especificidade & Média de acerto \\
\hline 5 & $39.13 \%$ & $86.36 \%$ & $62.22 \%$ \\
\hline 13 & $60.87 \%$ & $77.27 \%$ & $68.89 \%$ \\
\hline 125 & $52.17 \%$ & $86.36 \%$ & $68.89 \%$ \\
\hline 1247 & $60.87 \%$ & $72.73 \%$ & $66.67 \%$ \\
\hline 13567 & $52.17 \%$ & $81.82 \%$ & $66.67 \%$ \\
\hline 134567 & $56.52 \%$ & $72.73 \%$ & $64.44 \%$ \\
\hline 1234567 & $52.17 \%$ & $59.09 \%$ & $55.56 \%$ \\
\hline
\end{tabular}

Os dois melhores resultados obtidos para o classificador quadrático (taxa 
média de $68.89 \%$ ) foram obtidos para taxas de sensibilidade e especificidade iguais a $60.87 \%$ e $77.27 \%$, e $52.17 \%$ e $86.36 \%$. Neste último exemplo, quase metade dos casos assimétricos foram incorretamente classificados (52.17\%). A melhor taxa de sensibilidade obtida foi de $60.87 \%$, e a melhor taxa de especificidade foi de $86.36 \%$. O primeiro componente principal aparece em praticamente todas as combinações, indicando que ele foi eficaz na discriminação das duas classes.

A Figura 8.17 apresenta os gráficos de distribuição dos três primeiros componentes principais (1, 2 e 3 ) e dos três melhores componentes (1, 2 e 5), selecionados pelo classificador linear.

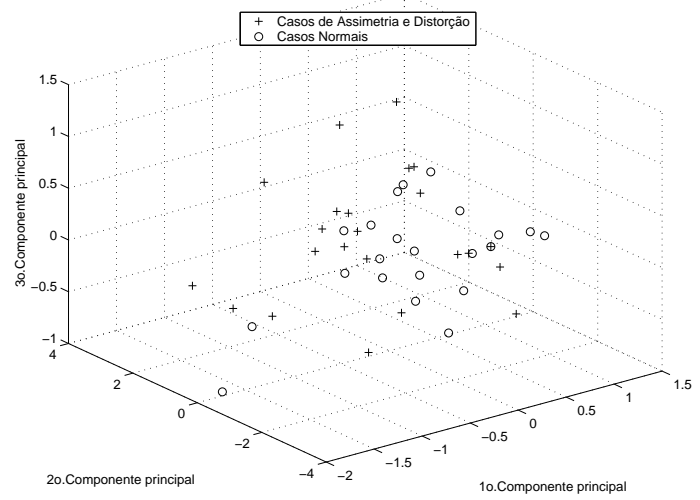

(a)

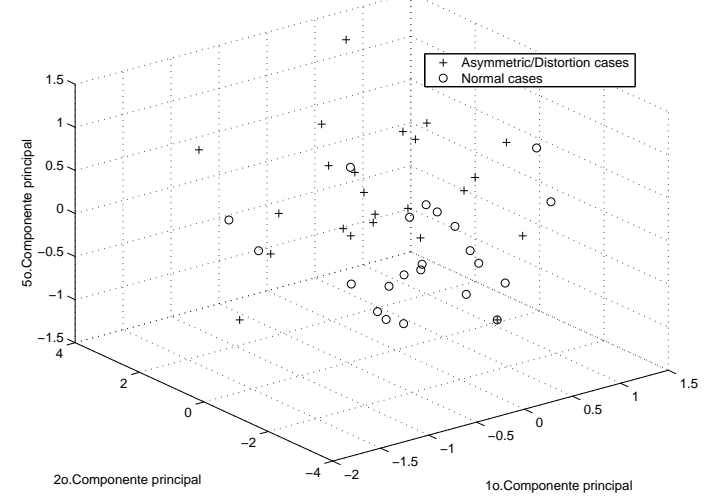

(b)

Figura 8.17: (a) Distribuição dos dados para os três primeiros componentes principais. (b) Distribuição dos dados para os três melhores componentes principais selecionados pelo classificador linear de Bayes.

\subsubsection{Análise combinada}

A análise combinada envolveu os 5 atributos extraídos dos diagramas de rosa e os 11 extraídos dos discos fibro-glandulares. Também nesse caso, a análise de componentes principais foi usada na tentativa de reduzir a dimensionalidade do espaço original dos dados. Um total de 8 componentes principais foram selecionados com base nos autovalores com contribuição maior que $2 \%$ da variância total dos dados, conforme relacionados na Tabela 8.12.

Os melhores resultados para os classificadores linear e quadrático são apre- 
Tabela 8.12: Relação de autovalores e as respectivas contribuições na formação da matriz de transformação linear da transformada KL.

\begin{tabular}{c|c|c} 
& Autovalores & Contribuição na variância total \\
\hline 1 & 6.8575 & $42.86 \%$ \\
\hline 2 & 2.6884 & $16.80 \%$ \\
\hline 3 & 1.4663 & $9.16 \%$ \\
\hline 4 & 1.1511 & $7.19 \%$ \\
\hline 5 & 0.9919 & $6.20 \%$ \\
\hline 6 & 0.7576 & $4.74 \%$ \\
\hline 7 & 0.6718 & $4.20 \%$ \\
\hline 8 & 0.4561 & $2.85 \%$ \\
\hline \multicolumn{2}{|c|}{ TOTAL } & $\mathbf{9 4 . 0 0 \%}$ \\
\hline
\end{tabular}

sentados nas Tabelas 8.13 e 8.14, respectivamente.

Tabela 8.13: Melhores resultados da classificação dos casos normais e assimétricos usando 8 componentes principais e o classificador linear Bayesiano.

\begin{tabular}{l|c|c|c} 
Comp. principais & Sensibilidade & Especificidade & Média de acerto \\
\hline 6 & $56.52 \%$ & $95.45 \%$ & $75.56 \%$ \\
\hline 25 & $78.26 \%$ & $77.27 \%$ & $77.78 \%$ \\
\hline 258 & $78.26 \%$ & $86.36 \%$ & $82.22 \%$ \\
\hline 1258 & $73.91 \%$ & $81.82 \%$ & $77.78 \%$ \\
\hline 12456 & $69.57 \%$ & $77.27 \%$ & $73.33 \%$ \\
\hline 124568 & $60.87 \%$ & $72.73 \%$ & $66.67 \%$ \\
\hline 1245678 & $56.52 \%$ & $68.18 \%$ & $62.22 \%$ \\
\hline 12345678 & $43.48 \%$ & $50.00 \%$ & $46.67 \%$ \\
\hline
\end{tabular}

O melhor resultado médio usando o classificador linear de Bayes foi de 82.22\%, com taxas de sensibilidade e especificidade de $78.26 \%$ e $86.36 \%$, respectivamente. Neste caso, apenas os componentes principais 2,5 e 8 foram utilizados. As maiores taxas de sensibilidade e especificidade foram de $78.26 \%$ e $95.45 \%$, respectivamente. Essas taxas são muito boas levando-se em consideração que apenas 3 componentes principais $(2,5$ e 8$)$ foram usados na classificação.

Para o classificador quadrático, a melhor taxa média de acertos na classificação foi de $82.22 \%$, usando apenas 3 componentes principais; o segundo, o sexto, e o oitavo componentes. Para este caso, as taxas de sensibilidade e especificidade alcançadas foram de $73.91 \%$ e $90.91 \%$, respectivamente. A melhor taxa de sensibilidade obtida com a classificador quadrático foi de $78.26 \%$, enquanto que a melhor taxa de especificidade foi de $95.45 \%$. 
Tabela 8.14: Melhores resultados para a classificação dos casos normais e assimétricos usando 8 componentes principais e o classificador quadrático Bayesiano.

\begin{tabular}{l|c|c|c} 
Comp. principais & Sensibilidade & Especificidade & Média de acerto \\
\hline 6 & $65.22 \%$ & $95.45 \%$ & $80.00 \%$ \\
\hline 68 & $78.26 \%$ & $81.82 \%$ & $80.00 \%$ \\
\hline 268 & $73.91 \%$ & $90.91 \%$ & $82.22 \%$ \\
\hline 1567 & $78.26 \%$ & $81.82 \%$ & $80.00 \%$ \\
\hline 12567 & $73.91 \%$ & $81.82 \%$ & $77.78 \%$ \\
\hline 135678 & $73.91 \%$ & $77.27 \%$ & $75.56 \%$ \\
\hline 1234568 & $73.91 \%$ & $63.64 \%$ & $68.89 \%$ \\
\hline 12345678 & $65.22 \%$ & $50.00 \%$ & $57.78 \%$ \\
\hline
\end{tabular}

Analisando ambas as Tabelas 8.13 e 8.14, observa-se que as taxas médias de acerto diminuem a medida que mais componentes principais são utilizados, e que os componentes 2, 5, 6 e 8 foram os mais eficazes. O sexto componente foi o mais efetivo na discriminação entre as classes normal e assimétrica em ambos os casos; tanto para o classificador linear quanto para o quadrático.

A Figura 8.18 ilustra os gráficos de distribuição dos três primeiros componentes principais (1, 2 e 3 ) e dos três melhores componentes (2, 5 e 8$)$, selecionados pelo classificador linear.

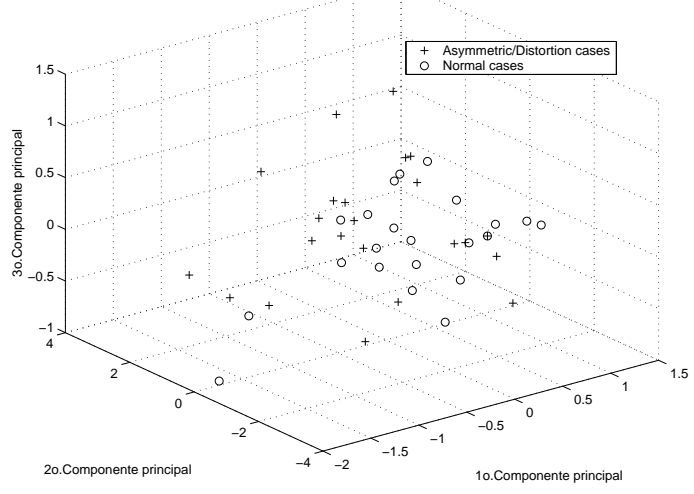

(a)

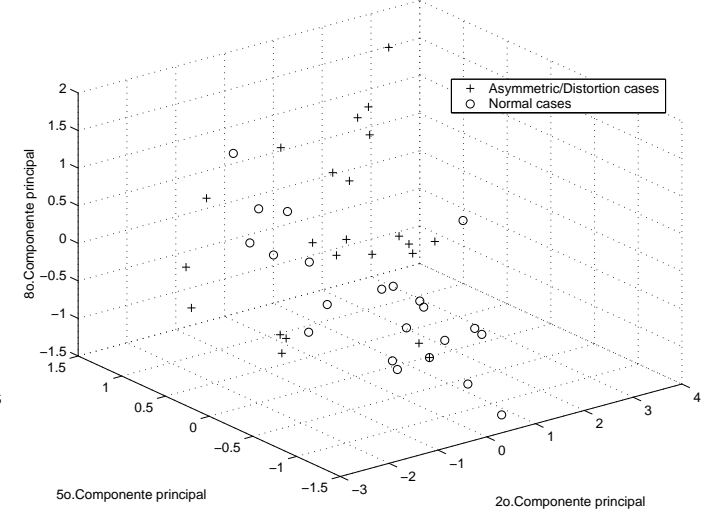

(b)

Figura 8.18: (a) Distribuição dos dados para os três primeiros componentes principais. (b) Distribuição dos dados para os três melhores componentes principais selecionados pelo classificador linear de Bayes. 


\subsubsection{Conclusões parciais}

Analisando as médias de acerto relacionadas nas Tabelas 8.10, 8.11, 8.13 e 8.14, pode-se constatar que os melhores resultados foram obtidos utilizando 3 ou 4 componentes principais, e que a partir desses valores há uma degradação no desempenho do classificador.

O sexto componente principal mostrou-se bastante efetivo na caracterização da classe normal (especificidade média de 95.45\%). Além disso, de maneira geral, as melhores taxas de acerto na classificação, referem-se à especificidade. Esse fato, eventualmente poderá ser utilizado para a caracterização de um padrão de normalidade em mamografia.

A seleção dos componentes principais com base num critério de mínimo erro, ou máxima taxa de acertos, é fundamental para o método de classificação, como pode ser observado pela análise dos gráficos de distribuição das Figuras 8.18 e 8.18. No entanto, erroneamente, muitos trabalhos na literatura não levam esse fato em consideração.

Após a correção da orientação dos diagramas de rosa, os atributos $M_{2}$ e $H$, que medem a dispersão e desorganização dos discos fibro-glandulares, se mostraram bastante eficazes para a caracterização de distorções assimétricas.

Os resultados da análise de assimetrias baseada na diferença topológica dos discos fibro-glandulares foram inferiores aos obtidos pelo método de análise direcional. Acreditamos que esse resultado esteja relacionado à sutileza das densidades assimétricas apresentadas pelas imagens da base de dados utilizada.

Devido ao caráter global dessa análise e pelo fato de que apenas projeções MLO foram utilizadas na análise, uma taxa média de acerto de $84.44 \%$ é bastante satisfatória se compararmos com os resultados apresentados na literatura [MILLER \& ASTLEY (1993) - 74.0\%, LAU \& BISCHOF (1991) - 80.0\%], e considerando o pequeno número de atributos utilizados.

Acreditamos que resultados superiores a $90 \%$ possam ser obtidos utilizando-se projeções CC e a investigação localizada de distorções de parênquima e nódulos 
assimétricos. 


\section{Capítulo 9}

\section{Conclusões Finais}

\subsection{Conclusões}

A técnica para a identificação da borda da mama através do modelo de contorno ativo proposto, foi capaz de segmentar com sucesso a maioria das imagens analisadas da base de dados Mini-MIAS.

A limitação imposta pela representação do músculo peitoral por uma linha reta foi eliminada pelo novo método usando filtros de Gabor e a técnica "edgeflow". O novo método foi aplicado com sucesso na maioria das imagens da base de dados Mini-MIAS, inclusive naquelas onde o contorno do músculo peitoral apresenta-se diferente de uma linha reta.

O modelo de densidades da mama proposto neste trabalho foi utilizado para a segmentação do disco fibro-glandular e análise de assimetrias entre mamogramas com sucesso. Alguns problemas ocorreram em relação à segmentação dos discos fibro-glandulares devido a ineficácia da função custo utilizada na seleção do melhor modelo a ser utilizado para a representação das classes de tecidos dos mamogramas. Uma possível solução para esse problema seria a determinação de uma nova função custo, em substituição à técnica MDL, ou a utilização de técnicas de "clustering" para a determinação mais eficiente do número de classes de densidades presentes no mamograma. O uso da técnica DAEM tornou o 
método de estimação do modelo bastante robusto em relação a inicialização dos parâmetros do modelo.

Os métodos de segmentação das bordas da mama e do músculo peitoral foram avaliados de maneira quantitativa através de um protocolo estabelecido por radiologistas. Os resultados do método de segmentação do disco fibro-glandular foram avaliados de forma subjetiva pelos radiologistas através da comparação visual entre as imagens originais e segmentadas. Esse procedimento foi utilizado devido à dificuldade na demarcação exata dessa região, visto que em algumas imagens o músculo peitoral aparece misturado à porções de tecidos fibro-glandulares no mamograma.

A deteç̧ão automática de assimetrias entre os mamogramas esquerdo e direito de uma mesma paciente foi executada com base em dois tipos diferentes de informações: informações direcionais, obtidas usando Gabor wavelets e diagramas de rosa, e informações topológicas, obtidas dos discos fibro-glandulares segmentados. Os atributos direcionais foram mais eficazes que os topológicos na classificação das imagens assimétricas e normais. O fato das informações extraídas dos discos fibro-glandulares não terem sido tão eficazes pode estar relacionado com a sutileza das densidades assimétricas presentes nas imagens da base de dados utilizada. Neste sentido, as informações direcionais, embora meçam apenas distorções globais do parênquima mamário, foram mais sensíveis a tais sutilezas.

Visto o alto custo computacional envolvido no procedimento de análise dos componentes direcionais nos mamogramas (aplicação de $K \times S$ FFTs e $K \times$ $S$ IFFTs por imagem), o uso de processamento paralelo ou de um "hardware" dedicado é altamente indicado.

Os resultados apresentados pelos métodos de detecção de assimetrias são relevantes, visto o caráter global da análise realizada e pelo fato de que apenas projeções médio-laterais foram usadas neste trabalho. Em comparação aos principais trabalhos apresentados na literatura para a análise de assimetrias [MILLER \& ASTLEY (1993), LAU \& BISCHOF (1991)], a abordagem proposta nesta tese 
apresentou um melhor desempenho.

\subsection{Sumário de contribuições}

Essa pesquisa contribuiu para o desenvolvimento de:

1. novas técnicas para a segmentação automática de mamogramas. A proposta de "segmentação anatômica" de mamogramas com base nas técnicas de contornos ativos, Gabor wavelets e no modelo de densidades de tecidos, estimado através da técnica DAEM, é original e foi usada neste trabalho para a análise de assimetrias entre mamogramas. As técnicas propostas mostraram-se bastante robustas quando aplicadas à base de dados MiniMIAS.

2. uma nova abordagem para a análise de assimetrias entre mamogramas esquerdo e direito de uma mesma paciente. A aplicação da transformada Gabor wavelets e os atributos extraídos de diagramas de distribuição angular (diagramas de rosa), usados neste trabalho para a análise do fluxo de tecidos fibro-glandulares, permitiu a classificação de mamogramas em normais e assimétricos.

\subsection{Publicações relacionadas a essa tese}

Ano 2000

1. Rangayyan, R.M. Ferrari, R.J. Desautels, J.E.L. Frère, A.F.; Directional analysis of images with Gabor wavelets, XIII Brazilian Symposium on Computer Graphics and Image Processing, 170-177, Gramado, RS, Brazil, October, 2000.

2. Ferrari, R.J. Rangayyan, R.M. Desautels, J.E.L. Frère, A.F.; Segmentation of mammograms: identification of the skin - air boundary, pectoral muscle, 
and fibro-glandular disc, Proceedings of the 5th International Workshop on Digital Mammography, Yaffe, M.J. editor, 573-579, Toronto, ON, Canada, June, 2000.

3. Ferrari, R.J. Rangayyan, R.M. Desautels, J.E.L. Frère, A.F.; Segmentação de mamogramas: identificação da borda da mama, músculo peitoral e disco glandular, XVII Congresso Brasileiro de Engenharia Biomédica (in Portuguese), 1255-1261, Florianópolis, SC, Brazil, Setembro, 2000.

4. Ferrari, R.J. Rangayyan, R.M. Desautels, J.E.L. Frère, A.F. Borges, R.A.; Automatic identification of the skin - air boundary, pectoral muscle, and fibro-glandular disc in mammograms, IEEE Transactions on Medical Imaging, submitted, 2000.

Ano 2001

1. Ferrari, R.J. Rangayyan, R.M. Desaultels, J.E.L. Frère, A.F.; Analysis of asymmetry in mammograms via directional filtering with Gabor wavelets, IEEE Transactions on Medical Imaging, 20(9), 953-964, September, 2001.

\subsection{Propostas para trabalhos futuros}

1. Como sugerido nos seguintes trabalhos [FERRARI et al. (2000), FERRARI et al. (2000b), FERRARI et al. (2001b)], a abordagem proposta para a segmentação anatômica dos mamogramas traz de imediato uma série de aplicações em mamografia, das quais podemos citar: compressão de dados (através da limitação da área útil da mama), quantificação e classificação de padrões de tecidos e densidades mamárias e suas associações com o risco do câncer de mama.

2. Inclusão da técnica minmax [LAI (1994)] para o ajuste local dos parâmetros de energia do modelo de contorno ativo, permitindo maior robustez da técnica no uso de diferentes bases de dados. 
3. Estudo de outras funções de custo, em substituição ou para ser combinada à técnica MDL usada para selecionar o melhor modelo da mistura de densidades.

4. Análise localizada de distorções do parênquima mamário através de mapas de gradientes, tais como "EdgeFlow", "Gradient Vector Flow", etc..

5. Extensão do método de análise de assimetrias através do uso combinado de projeções médio-laterais e crânio-caudais e também de projeções de uma mesma mama durante diferentes períodos de tempo.

6. Comparação dos resultados através do uso de técnicas de classificação nãosupervisionadas e não-paramétricas. 


\section{Apêndice A}

\section{Representação de componentes}

\section{direcionais em imagens através}

\section{de Gabor wavelets}

\section{A.1 Estudos neurofisiológicos e o processo de decomposição das imagens}

O processo de filtragem multi-canal para a análise de componentes direcionais permite explorar diferenças em termos de tamanho e orientação dos diferentes elementos visuais de uma imagem [JAIN \& FARROKHNIA (1991)]. Essa abordagem é motivada na teoria formulada por CAMPBELL \& ROBSON (1968) para o processamento visual de informações em estágios primários do sistema visual humano. Nessa teoria, os autores demonstraram que o sistema visual decompõe a imagem formada na retina em um conjunto de sub-imagens, cada uma contendo uma variação de intensidade restrita a uma dada faixa de freqüências e orientações. Esse mecanismo de decomposição, denominado "decomposição em canais", pode ser interpretado como um conjunto de filtros passa-banda.

O uso de filtros de Gabor para a caracterização de canais em imagens baseiase em estudos na área de neurofisiologia. Nesses estudos, foi determinado que 
filtros de Gabor 2-D conseguem modelar com uma boa correspondência os perfis de campos receptivos de células primárias do córtex visual de mamíferos [MARCELJA (1980), De Valois et al. (1982), DAUGMAN (1985)]. O termo "perfil de um campo receptivo" pode ser entendido na terminologia de sinais e sistemas como a resposta impulsiva da célula.

\section{A.2 Breve introdução à teoria de Wavelets}

De maneira similar a teoria de filtragem multi-canal, na teoria de wavelets um sinal é representado por um grupo de funções base que amostram os espaços tempo-freqüência ou espaço-freqüência, no caso de imagens, fornecendo uma representação local da freqüência com uma resolução ajustada a cada escala, da seguinte forma

$$
f(t)=\sum_{i} c_{i} \psi_{i}(t)
$$

onde $\psi_{i}(t)$ são as funções base e $c_{i}$ são os coeficientes que constituem a representação da função $f(t)$ naquela base. A idéia principal da transformada Wavelet é que as funções base sejam obtidas através da translação e dilatação de uma única wavelet [NAVARRO et al. (1996)], conhecida como wavelet-mãe.

No caso contínuo 1-D, a transformada em wavelets da função $f(t)$ é definida pela equação

$$
W\left(s, t_{0}\right)=\frac{1}{\sqrt{|s|}} \int_{-\infty}^{+\infty} f(t) \psi *\left(\frac{t-t_{0}}{s}\right) d t=<f, \psi_{s, t_{0}}>
$$

onde $\psi *$ indica o conjugado complexo de $\psi$ e a função $\psi_{s, t_{0}}$ é a expressão geral de um função base ou wavelet, sendo definida como

$$
\psi_{s, t_{0}}=\frac{1}{\sqrt{s}} \psi\left(\frac{t-t_{0}}{s}\right), \quad s, t_{0} \in \Re, s \neq 0
$$


onde os coeficientes $s$ e $t_{0}$ representam, respectivamente, informações de escala e tempo, [GOMES et al. (1997)].

Através de translações e dilatações de uma wavelet-mãe é possível obter uma família inteira de funções auto-similares. No entanto, para que uma função $\psi$ possa ser utilizada como wavelet-mãe, ela deve satisfazer a condição de admissibilidade de energia finita [MALLAT (1989)], ou seja

$$
C_{\psi}=2 \pi \int_{-\infty}^{+\infty} \frac{|\Psi(u)|^{2}}{|u|} d u<\infty
$$

onde $\Psi(u)$ é a transformada de Fourier de $\psi$.

A partir da condição de admissibilidade, representada pela Equação A.4, podese concluir que:

1. Se $\Psi(u)$ é contínua, então $\lim _{u \rightarrow 0} \Psi(u)=0$, ou seja, $\int_{-\infty}^{+\infty} \psi(t) d t=0$.

2. Visto que $\Psi(u) \in \mathrm{L}^{2}(\Re)$, e juntamente com o ítem 1, conclui-se que geometricamente o gráfico da função $\psi$ deve oscilar de forma a cancelar áreas positivas e negativas para que o valor da integral do ítem 1 seja zero.

3. Se $\Psi(u)$ decai rapidamente quando $u \rightarrow 0$ e $u \rightarrow \infty$, então $\Psi(u)$ assume valores muito pequenos fora de uma determinada banda de freqüências. Logo, conclui-se que $\Psi(u)$ deve ser uma função passa-banda com resposta ao nível d.c. igual a zero.

A transformada Wavelet pode ser entendida como uma forma de decomposição de um sinal (1-D ou 2-D) em um conjunto de canais de freqüência de mesma largura de banda numa escala logarítmica [NAVARRO et al. (1996)]. A formulação da transformada Wavelet para o caso 2-D (representação de imagens) é apresentada em [ANTOINE et al. (1993)]. 


\section{A.3 Função de Gabor como wavelet-mãe}

Uma função de Gabor bidimensional (2-D) é uma função Gaussiana (função envelope) modulada por uma senóide complexa (função moduladora). No domínio espacial (domínio da imagem), ela é especificada pela freqüência da senóide $W$ e pelos valores de desvios padrão $\sigma_{x}$ e $\sigma_{y}$ da função Gaussiana como

$$
\psi(x, y)=\frac{1}{2 \pi \sigma_{x} \sigma_{y}} \exp \left[-\frac{1}{2}\left(\frac{x^{2}}{\sigma_{x}^{2}}+\frac{y^{2}}{\sigma_{y}^{2}}\right)+2 \pi j W x\right]
$$

Com base em estudos neurofisiológicos [MARCELJA (1980), JONES \& PALMER (1987)] e na teoria de wavelets [MALLAT (1989), DAUBECHIES (1990)], a função de Gabor, normalizada de forma apropriada, pode ser usada como uma wavelet-mãe para gerar uma família de wavelets direcionais não-ortogonais.

Entretanto, como discutido por JAIN \& FARROKHNIA (1991), embora a função de Gabor possa satisfazer a condição de admissibilidade de energia finita [MALLAT (1989)], através da remoção de seu nível DC, ela não resulta numa base ortogonal. Isso significa que a transformada Wavelet usando tal função como base apresentará redundâncias em sua representação. Muitos trabalhos têm sido propostos na literatura para superar esse problema; através do uso de métodos iterativos [DAUGMAN (1988)] e "frames" duais ou funções bi-ortogonais [DAUBECHIES (1990), LEE (1996)]. Uma formalização matemática bastante detalhada das Gabor wavelets bidimensionais é apresentada em [LEE (1996)].

Desconsiderando a não-ortogonalidade apresentada pelas Gabor wavelets, a função de Gabor é a única função a atingir o limite teórico ótimo de resolução (princípio da incerteza, GOMES et al. (1997)) comum a ambos os espaços: o da imagem e o da freqüência [NAVARRO et al. (1996)]. 


\section{A.4 Representação Gabor wavelets usada neste trabalho}

A decomposição das imagens em canais de freqüência foi realizada neste trabalho através da representação Gabor wavelets proposta por MANJUNATH \& MA (1996). Nesta representação, as funções de Gabor auto-similares (wavelets) são obtidas por dilatação e rotação da função $\psi(x, y)$ através da seguinte função geradora

$$
\begin{aligned}
& \psi_{m, n}(x, y)=a^{-m} \psi\left(x^{\prime}, y^{\prime}\right), \quad a>1, \quad m, n=\text { integers, } \\
& x^{\prime}=a^{-m}\left[\left(x-x_{0}\right) \cos \theta+\left(y-y_{0}\right) \sin \theta\right], \\
& y^{\prime}=a^{-m}\left[-\left(x-x_{0}\right) \sin \theta+\left(y-y_{0}\right) \cos \theta\right]
\end{aligned}
$$

onde $\left(x_{0}, y_{0}\right)$ é o centro do filtro definido no domínio espacial, $\theta=n \pi / K, K$ é o número total de orientações desejadas, e $m$ e $n$ indicam a escala e a orientação, respectivamente. O fator de escala $a^{-m}$ é usado para assegurar que a energia seja independente de $m$. Alguns exemplos de wavelets de Gabor projetadas no domínio espacial e usadas neste trabalho são apresentadas na Figura A.1.

A parte real (função cosseno real-simétrica) da Equação da A.5 pode ser reescrita no domínio da freqüência como

$\Psi(u, v)=\frac{1}{2 \pi \sigma_{u} \sigma_{v}}\left\{\exp \left[-\frac{1}{2}\left(\frac{(u-W)^{2}}{\sigma_{u}^{2}}+\frac{v^{2}}{\sigma_{v}^{2}}\right)\right]+\exp \left[-\frac{1}{2}\left(\frac{(u+W)^{2}}{\sigma_{u}^{2}}+\frac{v^{2}}{\sigma_{v}^{2}}\right)\right]\right\}$

onde $\sigma_{u}=\frac{1}{2 \pi \sigma_{x}}$ e $\sigma_{v}=\frac{1}{2 \pi \sigma_{y}}$. A estratégia usada por MANJUNATH \& MA (1996) no projeto dos filtros assegura que os suportes de magnitude das respostas dos filtros (forma elíptica) no espectro de freqüências se toquem uns aos outros quando a magnitude da resposta do filtro decai à metade do seu valor máximo, como mostrado na Figura A.2. Através desse procedimento, assegura-se que os filtros capturarão o máximo de informação com a mínima redundância.

Vários métodos propostos na literatura para a representação multiresolução de imagens usam a componente imaginária dos filtros de Gabor [BOVIK et al. 


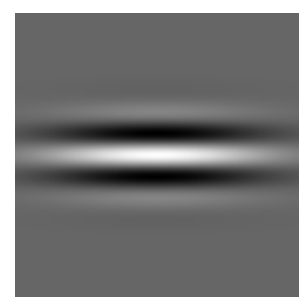

(a)

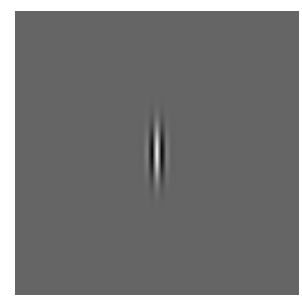

(c)

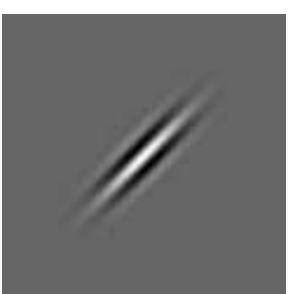

(b)

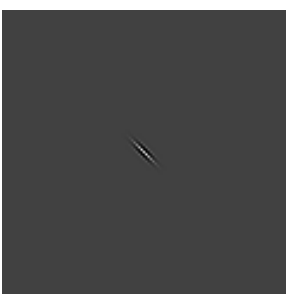

(d)

Figura A.1: Exemplos de Gabor wavelets projetadas no domínio espacial com quatro orientações $\left(\theta=0^{\circ}, 45^{\circ}, 90^{\circ}\right.$, e $\left.135^{\circ}\right)$ e quatro escalas $\left(\sigma_{x}=11,5,2,1\right.$ e $\sigma_{y}=32,16,8,4$ pixels) diferentes. O tamanho de cada matriz imagem é de $121 \times 121$ pixels.

(1990)] ou pares de filtros com relacionamento em quadratura [TURNER (1986)]. A representação Gabor wavelets utilizada neste trabalho usa apenas a parte real das funções de Gabor e com orientação apenas entre 0 e $180^{\circ}$.

O uso somente da parte real da função de Gabor nessa representação tem por base dois modelos apresentados na literatura sobre os mecanismos primários da visão [RENTSCHLER et al. (1988), MALIK \& PERONA (1990)]. Além disso, utilizando apenas a parte real da função de Gabor implica em menor tempo para o processamento de uma imagem.

A justificativa em se utilizar filtros orientados apenas entre 0 e $180^{\circ}$ está no fato de que os filtros de Gabor são usados para extrair características relevantes de imagens reais, e portanto com resposta em freqüência Hermitiana [JÄHNE (1997)], ou seja, o valor da transformada de Fourier em qualquer ponto $\left(f_{x}, f_{y}\right)$ do espectro é o conjugado complexo desse ponto refletido em ambos os eixos $\left(H\left(f_{x}, f_{y}\right)=H^{*}\left(-f_{x},-f_{y}\right)\right.$, onde $H$ e $H^{*}$ indicam, respectivamente, a transformada de Fourier e o seu conjugado complexo). 
De forma a assegurar que os filtros de Gabor se tornem uma família admissível de Gabor wavelets, como descrito na Seção A.2, o ganho DC de cada filtro foi ajustado para zero $\Psi(0,0)=0$, assegurando que eles não respondam à regiões com intensidade constante.

A representação proposta por MANJUNATH \& MA (1996), de acordo com a estratégia apresentada anteriormente, resulta nas seguintes fórmulas para o cálculo dos parâmetros $\sigma_{u}$ e $\sigma_{v}$ dos filtros de Gabor:

$$
\begin{gathered}
a=\left(\frac{U_{h}}{U_{l}}\right)^{\frac{1}{S-1}} \\
\sigma_{u}=\frac{(a-1) U_{h}}{(a+1) \sqrt{2 \ln 2}}, \\
\sigma_{v}=\frac{\tan \left(\frac{\pi}{2 K}\right)\left[U_{h}-\left(\frac{\sigma_{u}^{2}}{U_{h}}\right) 2 \ln 2\right]}{\sqrt{2 \ln 2-\frac{(2 \ln 2)^{2} \sigma_{u}^{2}}{U_{h}^{2}}}}
\end{gathered}
$$

onde $U_{l}$ e $U_{h}$ indicam, respectivamente, os limites inferior e superior dos centros de freqüência de interesse. Os parâmetros $K$ e $S$ representam, respectivamente, o número de orientações e o número de escalas usadas no processo de decomposição da imagem. A freqüência $W$ da senóide é ajustada igual ao limite superior $U_{h}$, e $m=0,1, \ldots, S-1$.

Em muitos trabalhos apresentados na literatura, a escolha do número de escalas e orientações, usados no processo de decomposição das imagens através das Gabor wavelets, tem sido baseada em estudos e modelos da área de neurofisiologia sobre sistemas visuais de mamíferos [De Valois et al. (1982), DAUGMAN (1985)]. Tais modelos indicam que as larguras de banda de freqüência de células simples e complexas do sistema visual de mamíferos se encontra na faixa de 0.5 a 2.5 oitavas, agrupando-se em torno de 1.2 e 1.5 oitavas. Eles também sugerem que as larguras de banda angulares são ligeiramente menores do que $30^{\circ}$ [DAUGMAN (1985), JONES \& PALMER (1987)]. 
Exemplos de espectros de freqüências gerados a partir de um banco de filtros de Gabor são ilustrados na Figura A.2.

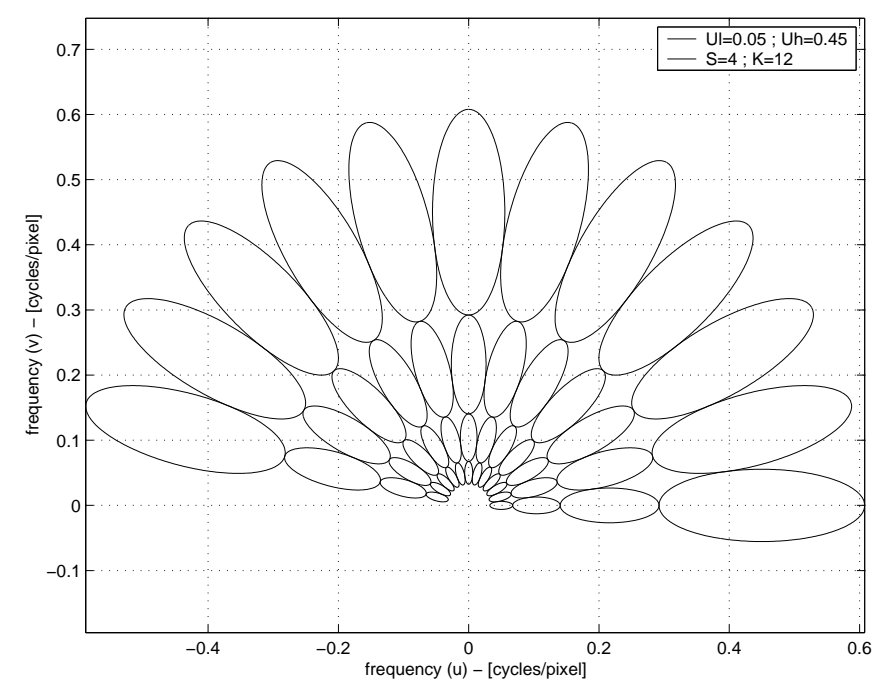

(a)

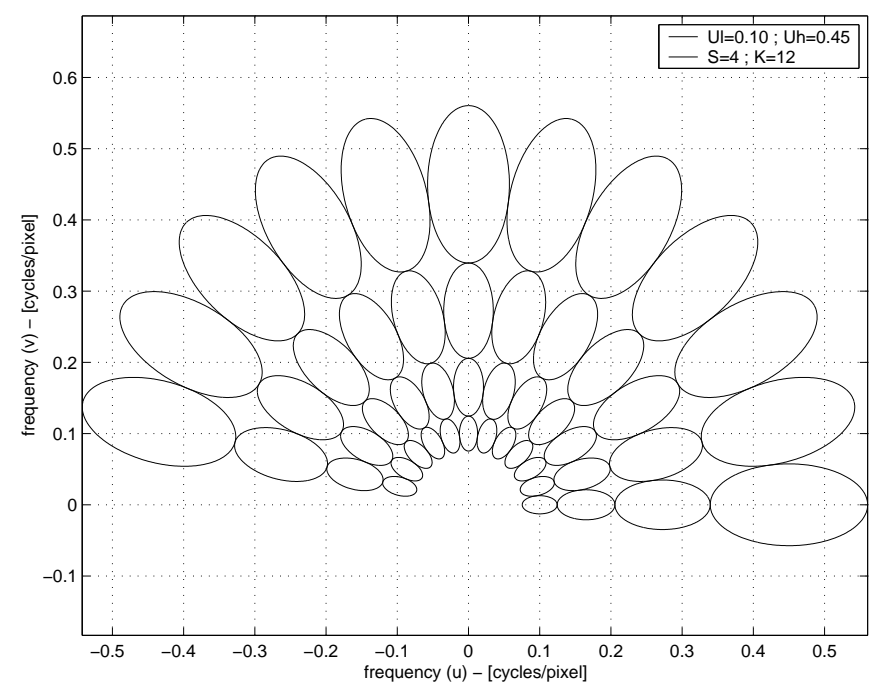

(b) 


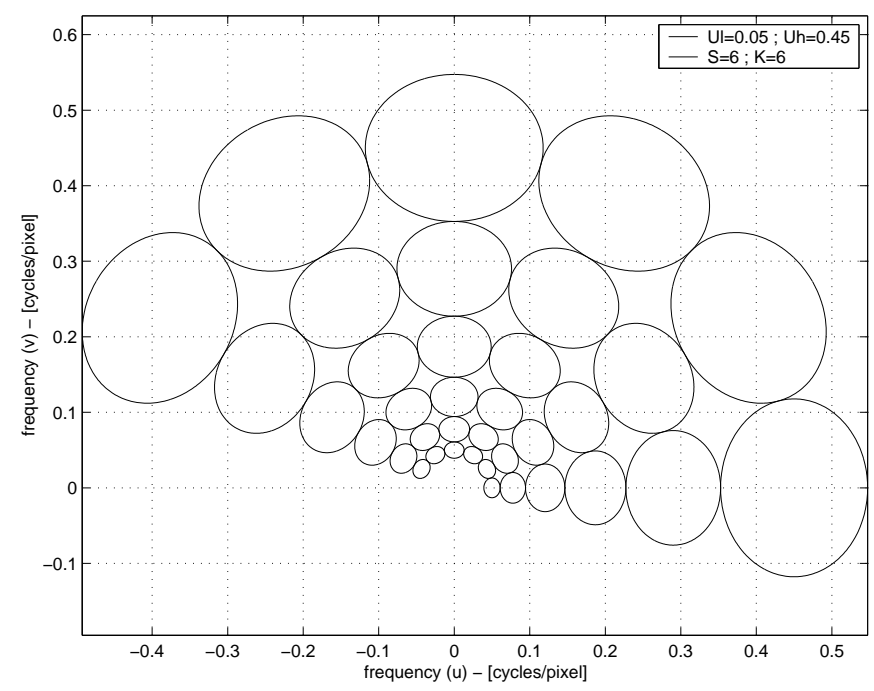

(c)

Figura A.2: Exemplos de filtros de Gabor projetados no domínio da freqüência. Cada elipse representa uma faixa de resposta de um filtro específico com magnitude ao quadrado variando de 0.5 a 1.0. Os gráficos (a), (b) e (c) ilustram três maneiras diferentes de amostrar o espectro de freqüências através da alteração dos parâmetros $U_{l}, U_{h}, S$ e $K$ da representação de Gabor. Os gráficos (a) e (b) representam, respectivamente, os bancos de filtros usados na análise de mamogramas e da imagem de teste usada para ilustrar o método proposto.

Devido ao fato das Gabor wavelets não formarem uma base ortogonal, não é possível realizar o cálculo dos coeficientes da transformada Wavelet mediante uma simples projeção da imagem no espaço das wavelets. Entretanto, a localização ótima em ambos os espaços (o da imagem e o da freqüência) e a ortogonalidade de um conjunto de funções são propriedades que não podem ser satisfeitas simultaneamente [NAVARRO et al. (1996)].

Com base no que foi exposto no parágrafo anterior, nesse trabalho as análises foram realizadas usando a magnitude das respostas dos filtros, calculadas como

$$
a_{m, n}=\left|f * \psi_{m, n}^{\mathrm{par}}(x, y)\right|
$$

onde $\psi_{m, n}^{\mathrm{par}}(x, y)$ indica apenas a parte real simétrica do filtro de Gabor, e o símbolo * representa o operador convolução. 
A Figura A.3 mostra uma imagem de $256 \times 256$ pixels, e 8-bits de resolução de uma textura natural [WEBER (1977)]. Essa imagem será usada para descrever e ilustrar o método proposto para a análise de componentes direcionais.

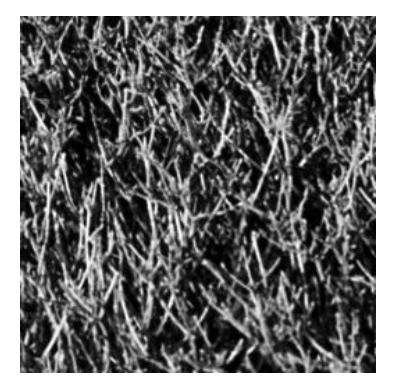

(a)

Figura A.3: Imagem de uma textura natural da base de dados WEBER (1977).

\section{A.5 Redução de redundâncias através da apli- cação da transformada de Karhunen-Loève}

A transformada KL foi usada para selecionar os componentes principais das imagens filtradas, preservando apenas os elementos direcionais mais relevantes entre as escalas. Esta transformação pode ser entendida como uma compressão dos dados, através da eliminação das redundâncias entre as imagens filtradas [GONZALEZ \& WOODS (1992), página 106].

Para a aplicação da transformada KL, as imagens filtradas a partir do banco de filtros de Gabor foram organizadas de acordo com a Figura A.4 a fim de permitir a formação de um vetor $\bar{x}$ de dimensão $S$ para cada posição relativa $(x, y)$ nas imagens ( $S$ representa o número de escalas). Os vetores $\bar{x}$ foram usados para o cálculo do vetor de médias $\bar{\mu}$ e da matriz de covariância $\bar{C}$ de acordo com as equações

$$
\bar{\mu}=\frac{1}{M} \sum_{k=1}^{M} \bar{x}_{k}
$$


e

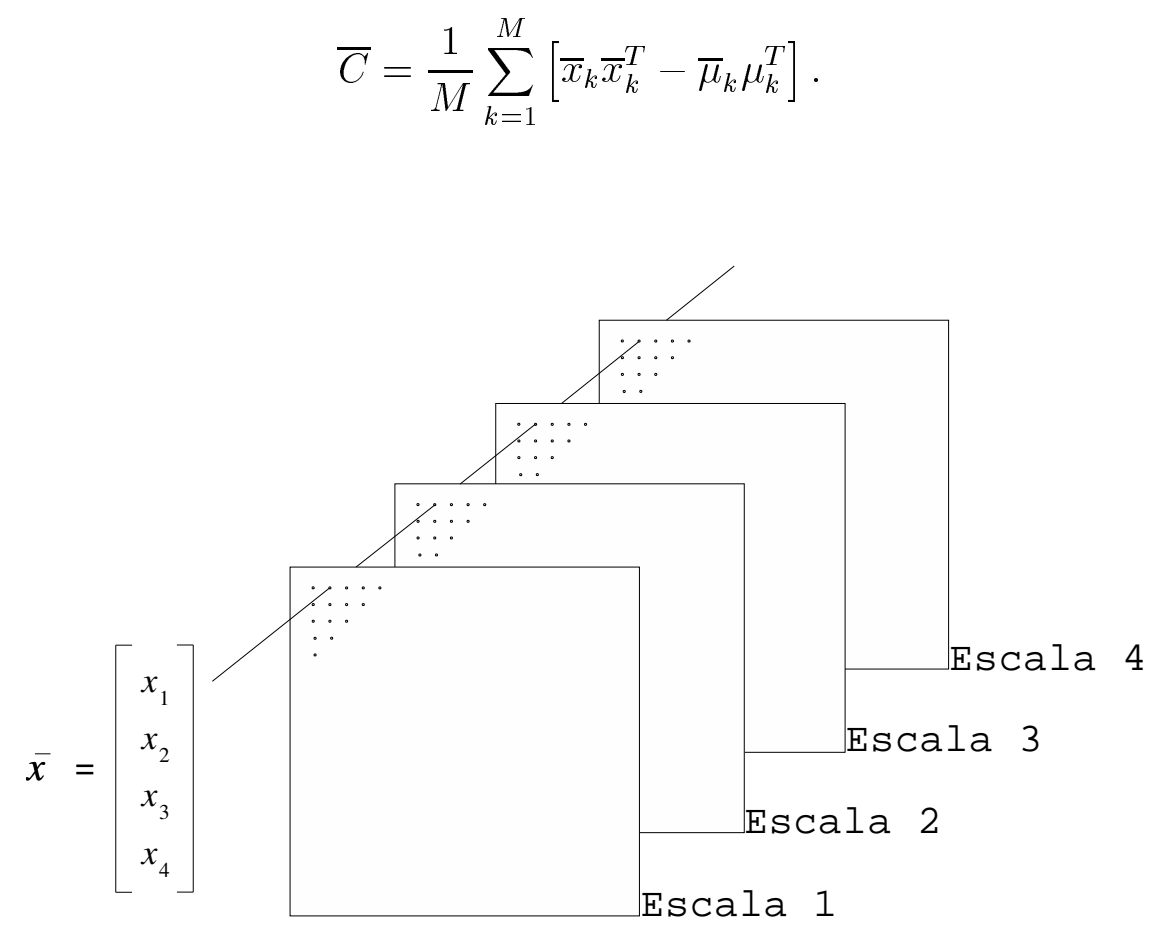

(a)

Figura A.4: Exemplo de um vetor $\bar{x}$ formado a partir de pixels correspondentes entre diferentes escalas, de uma mesma orientação.

A seguir, os autovalores e autovetores da matriz de covariância foram calculados e ordenados (ordem decrescente) na matriz $\bar{A}$ de maneira que a primeira linha de $\bar{A}$ é o autovetor correspondente ao maior autovalor e a última linha é o autovetor correspondente ao menor autovalor. Os primeiros $N$ autovetores correspondendo a 95\% da variância total, calculada a partir dos autovalores, foram selecionados e usados para o cálculo dos componentes principais em cada orientação analisada como $\bar{y}=\bar{A}(\bar{x}-\bar{\mu})$.

A transformada KL é ótima no sentido que ela minimiza o erro médio quadrático entre os vetores $\bar{x}$ e a aproximação resultante $\bar{y}$ [GONZALEZ \& WOODS (1992)].

O resultado da aplicação da transformada KL para todas as orientações, conforme descrito acima, é um conjunto de $K$ imagens contendo as informações mais 
relevantes em cada orientação, onde $K$ é o número de orientações analisadas.

A Figura A.5 ilustra os componentes principais para o orientação de $90^{\circ}$ obtidos para a imagem teste da Figura A.3 de acordo com o procedimento descrito anteriormente. Os autovalores da matriz $\bar{A}$ indicados na legenda da Figura A.5 foram usados para selecionar os componentes representando as informações direcionais mais relevantes. Neste exemplo, apenas os três componentes principais com autovalores somando $99.11 \%$ (> 95\%) da variância total foram usados para compor o componente final a $90^{\circ}$.

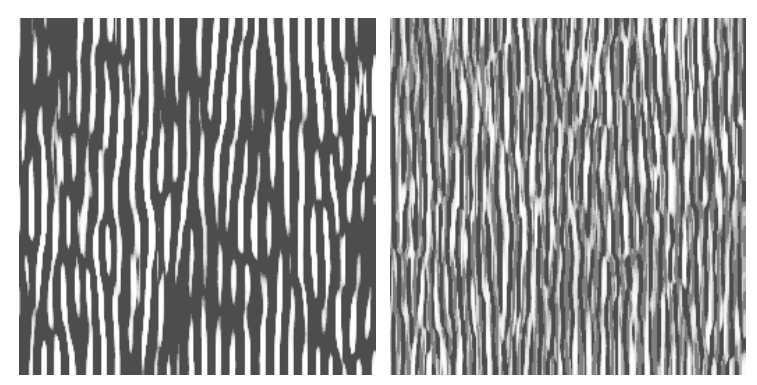

(a)

(b)

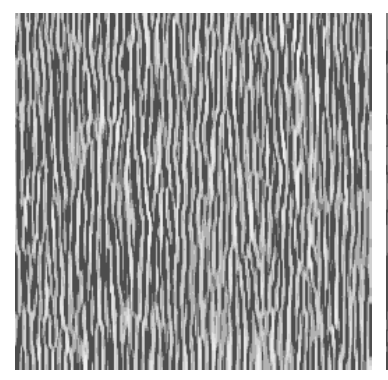

(c)

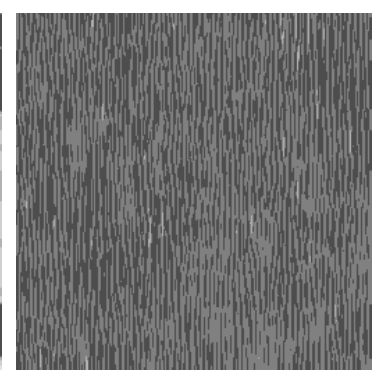

(d)

Figura A.5: As imagens (a)-(d) indicam, respectivamente, os primeiro, segundo, terceiro e quarto componentes, resultantes da aplicação da transformada KL aplicada às respostas dos filtros com orientação de $90^{\circ}$ para a imagem mostrada na Figura A.3. Os autovalores dos quatro componentes indicados acima são: $\lambda_{1}=85.840935, \lambda_{2}=36.408596, \lambda_{3}=11.485662$ e $\lambda_{4}=1.204247$. O contraste das imagens foram igualmente corrigidos para melhor visualização. 


\section{A.6 Eliminação de espúrios através da técnica de limiarização de Otsu}

Visto que as Gabor wavelets não formam uma base ortogonal, elas não permitem uma condição perfeita para a reconstrução das imagens filtradas. Esse fato resulta numa quantidade pequena de energia fora da banda de freqüência de análise, gerando artefatos na imagem filtrada. Embora, o objetivo desse trabalho não é a reconstrução da imagem original, a eliminação de pequenos efeitos de espalhamento espectral pode evitar que os componentes direcionais usados na análise não se tornem polarizados. Para reduzir esse problema, as $K$ imagens resultantes da transformada KL foram limiarizadas através da técnica de Otsu [OTSU (1979)].

O método de limiarização de Otsu é uma técnica não paramétrica que permite o cálculo rápido, automático e de maneira simples (derivado a partir de momentos de primeira ordem dos níveis de cinza) de um valor ótimo de limiar, através da maximização da seguinte medida de separatibilidade entre classes:

$$
\eta(k)=\frac{\sigma_{B}^{2}(k)}{\sigma_{T}^{2}},
$$

onde $\sigma_{B}^{2}(k)$ é a variância entre classes com o limiar sendo $k$ e $\sigma_{T}^{2}$ é a variância total do histograma da imagem. Na Equação A.12, Otsu considera o histograma da imagem, normalizado para área unitária, como uma distribuição de probabilidades. Apenas duas classes são consideradas: o fundo da imagem $\left(C_{0}\right)$ representado pelos pixels com nível de cinza de 0 a $k$, e os objetos $\left(C_{1}\right)$ representado pelos pixels com nível de cinza de $k+1$ até 255 . O valor do limiar é então definido como o limiar ótimo $k^{*}$, no sentido da análise discriminante, que maximiza a seguinte equação:

$$
\sigma_{B}^{2}\left(k^{*}\right)=\left\{\max _{0 \leq k \leq 255} \eta(k)\right\}=\left\{\max _{0 \leq k \leq 255} \sigma_{B}^{2}(k)\right\} .
$$


O valor de $\sigma_{T}^{2}$ não é considerado na equação acima por ser independente do limiar $k$.

A limitação do método de Otsu aparece quando a função densidade de probabilidade, considerada aqui como o histograma normalizado da imagem, se distancia da distribuição bimodal. Neste caso, o valor do limiar calculado é geralmente maior do que o limiar ideal (limiar esperado intuitivamente). Neste trabalho, no entanto, o método de Otsu mostrou-se suficiente para a remoção dos efeitos de sobreposição espectral.

\section{A.7 Soma vetorial das imagens filtradas}

As imagens de fase e magnitude, descrevendo as informações direcionais mais relevantes da imagem original são compostas através da soma vetorial [JÄHNE (1997), página 379] das $K$ imagens resultantes do procedimento descrito anteriormente, como ilustra a Figura A.6.

Neste procedimento, cada vetor (relativo a cada posição $(x, y)$ das imagens filtradas) é representado pela magnitude da imagem filtrada e pela orientação dos filtros de Gabor usados para gerá-la. As imagens de magnitude e fase obtidas para a imagem da Figura A.3 são apresentadas na Figura A.7.

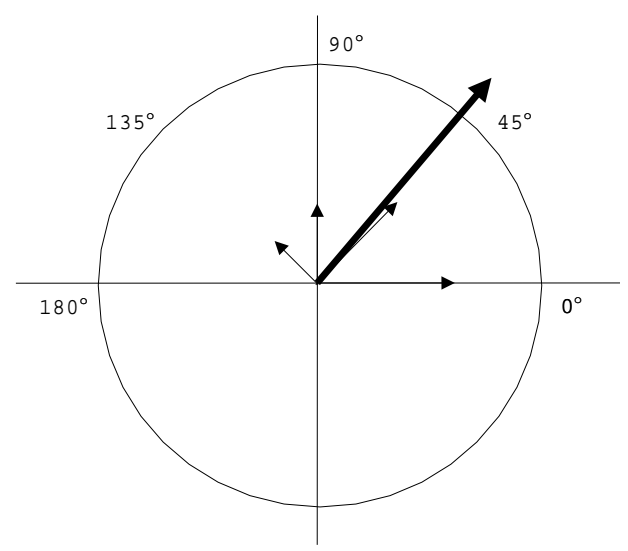

Figura A.6: Exemplo da soma vetorial empregada neste trabalho para compor as imagens de magnitude e fase. Por simplicidade, apenas quatro componentes direcionais são ilustrados na figura. 


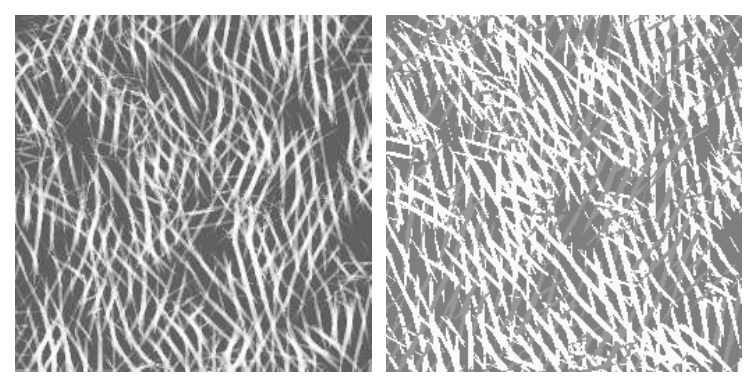

(a)

(b)

Figura A.7: Imagens de magnitude e fase da imagem de teste da Figura A.3. As imagens foram equalizadas para melhor visualização. 


\section{Apêndice B}

\section{Os algoritmos EM e DAEM}

\section{B.1 Estimativa por máxima-verossimilhança a partir de dados incompletos}

Suponha que $Z$ é um grupo de dados gerados a partir de um processo aleatório e consiste de "dados observáveis", $X=\left\{x_{1}, x_{2}, \ldots, x_{M}\right\}$, e "dados não-observáveis", $Y=\left\{y_{1}, y_{2}, \ldots, y_{M}\right\}$, de forma que $Z=(X, Y)=\left\{\left(x_{j}, y_{j}\right)\right.$, com $j=$ $1, \ldots, M\}$. Neste tipo de formulação, os grupos $Z$ e $X$ são chamados, respectivamente, de dados "completos" e "incompletos".

Em problemas de treinamento não-supervisionado, como por exemplo no caso da estimação da função densidade de probabilidade (f.d.p.) de uma mistura finita de gaussianas, $y_{j}$ é representado por um valor inteiro $\left(y_{j}=i, \quad i \in\{1,2, \ldots, K\}\right.$, onde $K$ é o número de componentes da mistura) indicando o núcleo gaussiano do qual o dado observado $x_{j}$ se origina.

Assumindo que a densidade de probabilidade conjunta de $X$ e $Y$ é parametricamente representada por $f\left(x_{j}, y_{j} \mid \Theta\right)$, onde $\Theta$ é o vetor de parâmetros da densidade a ser estimada (a dimensionalidade de $\Theta$ é finita e fixa), e que os dados são amostras identicamente e independentemente distribuídas (i.i.d.), então a distribuição acima pode ser escrita como: 


$$
f(x, y \mid \Theta)=\prod_{j=1}^{M} f\left(x_{j}, y_{j} \mid \Theta\right) .
$$

O estimador de máxima-verossimilhança de $\Theta$ é o valor de $\Theta$ que maximiza o logarítmo da função de verossimilhança dos "dados observáveis" definida por $L(\Theta \mid x) \stackrel{\text { def }}{=} \ln f(x \mid \Theta)$, ou de forma equivalente, ele corresponde a solução da seguinte equação de probabilidade

$$
\frac{\partial L(\Theta \mid x)}{\partial \Theta}=0
$$

Entretanto, visto que em muitas aplicações a Equação B.2 se torna não-linear, e portanto de difícil solução, algoritmos iterativos devem ser aplicados. Um dos algoritmos mais utilizados em problemas práticos, por ser computacionalmente simples e eficiente, é o algoritmo EM proposto por DEMPSTER et al. (1977).

\section{B.2 Algoritmo EM}

Como mencionado anteriormente, o algoritmo EM é um método iterativo utilizado para aproximar o estimador de máxima-verossimilhança em problemas onde o cálculo direto (através de técnicas numéricas) do estimador é muito difícil, ou quando os dados observáveis são incompletos.

Para a determinação do algoritmo EM, considere o problema de estimação do vetor de parâmetros $\Theta$ usando o estimador de máxima-verossimilhança, dado um grupo de variáveis observáveis $x_{j}$ para as quais a densidade de probabilidade é bem definida. Assume-se também que a maximização da f.d.p. $f(x \mid \Theta)$ é difícil de ser realizada, mas que, a partir de informações adicionais $y_{j}$, a maximização da probabilidade dos dados completos $f(x, y \mid \Theta)$ é relativamente fácil de se calcular. No entanto, os dados completos nem sempre estão disponíveis.

A idéia principal do algoritmo EM é então utilizar a relação entre as probabilidades condicionais e conjuntas expressa na forma logaritmica por 


$$
\ln f(x \mid \Theta)=\ln f(y, x \mid \Theta)-\ln f(y \mid x, \Theta)
$$

e o fato que $f(x \mid \Theta)$ é, na realidade, uma identidade, ou seja, $f(x \mid \Theta)$ se mantém inalterada para qualquer valor $y$ inserido no lado direito da equação.

Supondo, por exemplo, que $y$ seja gerado pela distribuição de probabilidade $f\left(y \mid x, \Theta^{k}\right)$, onde $\Theta^{k}$ é um valor qualquer escolhido para $\Theta$. Então, calculando-se o valor da esperança da Equação B.3 em relação a $y \mid x, \Theta^{k}$ (o espaço dos dados completos), tem-se:

- do lado esquerdo

$$
\int \ln f(x \mid \Theta) f\left(y \mid x, \Theta^{k}\right) \mathrm{d} y=\ln f(x \mid \Theta) \int f\left(y \mid x, \Theta^{k}\right) \mathrm{d} y=\ln f(x \mid \Theta)
$$

- e do lado direito

$$
\int \ln f(y, x \mid \Theta) f\left(y \mid x, \Theta^{k}\right) \mathrm{d} y-\int \ln f(y \mid x, \Theta) f\left(y \mid x, \Theta^{k}\right) \mathrm{d} y
$$

De maneira simplificada, as Equações B.4 e B.5 podem ser reescritas como:

$$
\ln f(x \mid \Theta)=Q\left(\Theta, \Theta^{k}\right)-H\left(\Theta, \Theta^{k}\right)
$$

onde

$$
\begin{aligned}
Q\left(\Theta, \Theta^{k}\right) & =\int \ln f(y, x \mid \Theta) f\left(y \mid x, \Theta^{k}\right) \mathrm{d} y=E[\ln f(y, x \mid \Theta)], \quad \text { e } \\
H\left(\Theta, \Theta^{k}\right) & =\int \ln f(y \mid x, \Theta) f\left(y \mid x, \Theta^{k}\right) \mathrm{d} y .
\end{aligned}
$$

O objetivo do algoritmo EM é encontrar um $\Theta^{k+1}$ tal que $\ln f\left(x \mid \Theta^{k+1}\right) \geq$ $\ln f\left(x \mid \Theta^{k}\right)$, ou seja, que o logaritmo da função de verossimilhança aumente a 
cada iteração. Nesta situação, substituindo-se a Equação B.6 na desigualdade acima e rearranjando os termos, tem-se:

$$
\begin{gathered}
Q\left(\Theta^{k+1}, \Theta^{k}\right)-Q\left(\Theta^{k}, \Theta^{k}\right) \\
-H\left(\Theta^{k+1}, \Theta^{k}\right)+H\left(\Theta^{k}, \Theta^{k}\right) \geq 0 .
\end{gathered}
$$

Uma propriedade importante a respeito da equação $H$, a qual pode ser provada pela desigualdade de Jensen [HARDY et al. (1952) apud TAGARE (1998)], é que quando $H\left(\Theta, \Theta^{k}\right)$ é interpretada como uma função de $\Theta$ (para um valor fixo de $\left.\Theta^{k}\right)$, então ela tem seu máximo em $\Theta=\Theta^{k}$. Logo, para qualquer $\Theta^{k+1}$, tem-se que

$$
H\left(\Theta^{k+1}, \Theta^{k}\right) \leq H\left(\Theta^{k}, \Theta^{k}\right),
$$

e conseqüentemente

$$
Q\left(\Theta^{k+1}, \Theta^{k}\right)-Q\left(\Theta^{k}, \Theta^{k}\right) \geq 0
$$

Portanto, a desigualdade $\ln f\left(x \mid \Theta^{k+1}\right) \geq \ln f\left(x \mid \Theta^{k}\right)$, pode ser garantida mediante a escolha de um valor

$$
\Theta^{k+1}=\arg \max _{\Theta} Q\left(\Theta, \Theta^{k}\right) .
$$

Dessa forma, a cada iteração do algoritmo EM a probabilidade condicional da estimativa aumenta até que a estimativa converja para um máximo local do logaritmo da função de verossimilhança $(\ln f(x \mid \Theta))$.

Com base nas Equações B.7 e B.13, o método iterativo EM pode ser sumarizado como indicado no algoritmo 2. 


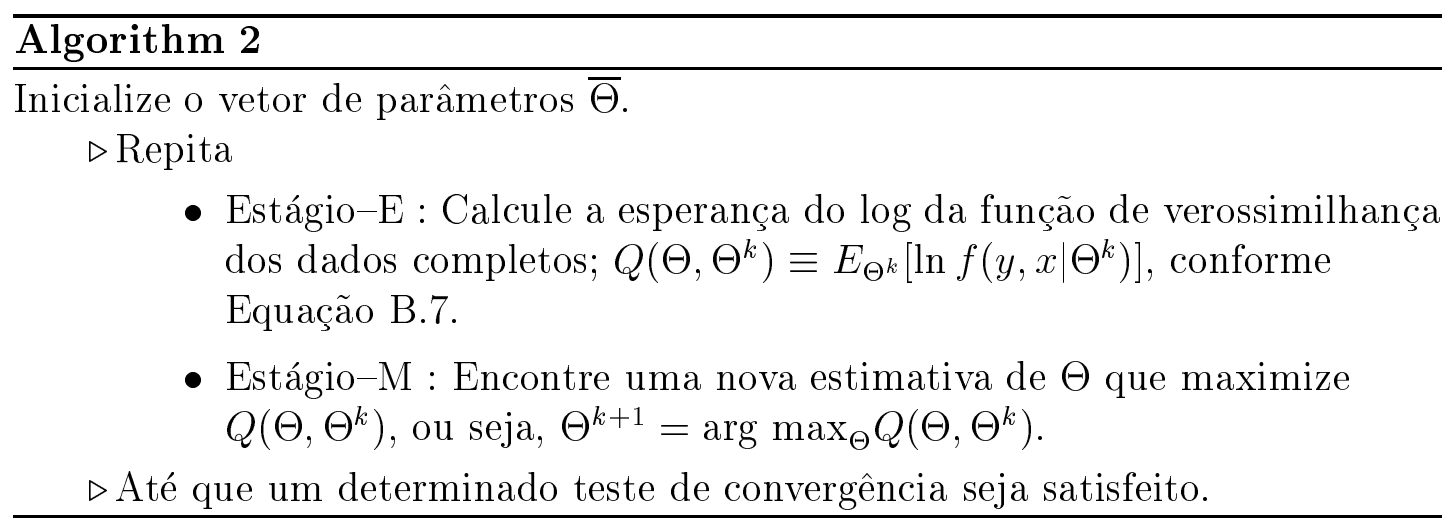

\section{B.3 Algoritmo DAEM baseado na f.d.p. a pos- teriori parametrizada}

A f.d.p. a posteriori $f(y \mid x, \Theta)$ exerce uma função importante na etapa "M" (maximização) do algorimto EM, como pode ser observado nas Equações B.7 e B.8. No entanto, nos estágios iniciais do processo de iteração ela não é confiável devido ao valor aleatório usado na inicialização dos seus parâmetros. Com base neste fato, o método DAEM proposto por UEDA \& NAKANO (1998), introduz uma nova f.d.p. a posteriori $p(y \mid x, \Theta)$ em substituição à função $f(y \mid x, \Theta)$ original.

Visto não haver nenhum conhecimento a priori a respeito de $p(y \mid x, \Theta)$, UEDA \& NAKANO (1998) utilizaram o princípio da máxima entropia para especificá-la. Tal princípio afirma que quando apenas informações parciais estiverem disponíveis sobre determinados resultados, devemos escolher as probabilidades de forma a maximizar a incerteza sobre a informação perdida, ou de outra forma, se existirem $n$ resultados possíveis, então, na ausência de informações adicionais, eles devem ser considerados eventos com a mesma probabilidade de ocorrência [UFFINK (1995)].

Neste caso, UEDA \& NAKANO (1998) supuseram que quando um dado $x$ é observado, o "micro" estado, isto é $p(y \mid x, \Theta)$, é ainda desconhecido; no entanto a "macro" informação, que é a esperança do logarítmo da função de verossimilhança dos dados completos, é constante, ou seja, 


$$
E[\ln f(y, x \mid \Theta)]=c t e
$$

Então, a função $p$ pode ser obtida como a distribuição de probabilidade que maximiza a entropia

$$
S=-\int[\ln p(y \mid x, \Theta)] p(y \mid x, \Theta) \mathrm{d} y
$$

sob a restrição da Equação B.14 e $\int p(y \mid x, \Theta) \mathrm{d} y=1$. O princípio da máxima entropia pode ser interpretado como um método para projeto de um modelo estatístico onde um peso é igualmente associado" a cada "micro" estado desde que a "macro" informação seja satisfeita [UEDA \& NAKANO (1998)].

Esse problema de maximização pode ser resolvido através do método de multiplicadores de Lagrange [BISHOP (1995), Apêndice C], com a função objetiva formulada da seguinte forma:

$$
J[p] \stackrel{\text { def }}{=} S+\beta(E[\ln f(y, x \mid \Theta)]-c t e)+\lambda\left(\int p(y \mid x, \Theta) \mathrm{d} y-1\right)
$$

sendo que $\beta$ e $\lambda$ são os multiplicadores de Lagrange.

Calculando a derivada parcial de $J$ em relação à $p$, que é indicada por

$$
\partial J=\int[-1-\ln p(y \mid x, \Theta)+\beta \ln f(x, y \mid \Theta)+\lambda] \partial p \mathrm{~d} y
$$

e fazendo $\partial J=0$, o termo [·] na equação acima deve ser igual a zero, e portanto,

$$
p(y \mid x, \Theta)=\exp [\beta \ln f(x, y \mid \Theta)+\lambda-1]
$$

A partir da Equação B.18 e visto que $\int p(y \mid x, \Theta) \mathrm{d} y=1$, então tem-se a

\footnotetext{
${ }^{1}$ No caso do modelo de misturas de Gaussianas, o termo "peso igualmente associado" significa que um dado $x_{j}$ é associado com igual probabilidade a cada um dos componentes da mistura.
} 
seguinte distribuição de Gibbs [ROSE et al. (1990), ROSE (1998)]:

$$
p(y \mid x, \Theta)=\frac{1}{Z} \exp \{-\beta(-E[\ln f(y, x \mid \Theta)])\},
$$

onde

$$
Z=\int \exp \{-\beta(-E[\ln f(y, x \mid \Theta)])\} \mathrm{d} y=\int f(x, y \mid \Theta)^{\beta} \mathrm{d} y
$$

Fazendo uma analogia com processos "Annealing” [ROSE (1998)], observa-se que $1 / \beta$ corresponde a temperatura. Substituindo a Equação B.20 na Equação B.19 obtem-se a nova probabilidade a posteriori parametrizada por $\beta$,

$$
p(y \mid x, \Theta)=\frac{f(x, y \mid \Theta)^{\beta}}{\int f(x, y \mid \Theta)^{\beta} \mathrm{d} y} .
$$

Analisando a Equação B.21 para diferentes valores de $\beta$, observa-se dois casos especiais; o primeiro é quando $\beta=0$ o que faz de $p(y \mid x, \Theta)$ uma distribuição uniforme. O segundo caso é para $\beta=1$, onde $p$ reduz-se a f.d.p. a posterior original dada pela Equação B.1. Portanto, para o intervalo $0<\beta \leq 1$, um aumento de $\beta$ significa uma mudança na forma de $p$ de uniforme até f.d.p. a posteriori original, $f$.

O algoritmo DAEM, descrito a seguir - algoritmo 3, pode ser visto como um método iterativo de minimização de $U_{\beta}$ em cada temperatura $(1 / \beta)$. Uma importante distinção entre o método "Simulated Annealing" (SA) e o método DAEM, é que neste último, o processo de otimização (realizado nos estágios E e M do algoritmo 3) é realizado de forma determinística através do incremento do valor de $\beta$. 


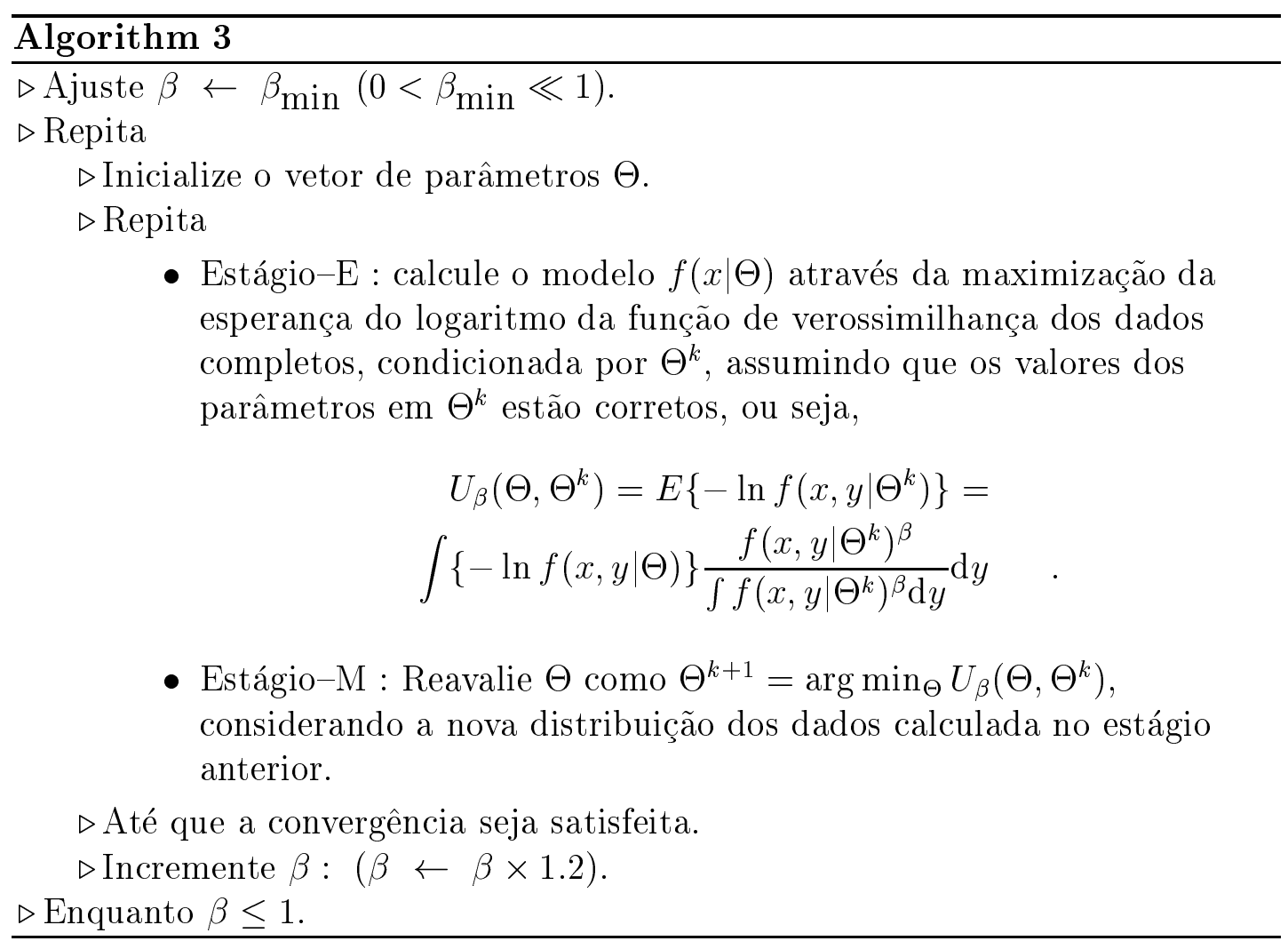

\section{B.4 Estimativa da densidade da mistura de gaus- sianas através dos algoritmos EM e DAEM}

No modelo da mistura de gaussianas, a distribuição dos "dados incompletos" $\left(x_{j}, j=\{1 \ldots M\}\right)$ é formulada como

$$
f(x \mid \bar{\Theta})=\sum_{i=1}^{K} W_{i} N\left(x \mid \theta_{i}\right)
$$

onde os valores de $x$ representam os valores dos níveis de cinza da imagem, $W_{i}$ são os parâmetros normalizados da mistura $\left(\sum_{i=1}^{K} W_{i}=1\right.$ e $\left.0 \leq W_{i} \leq 1\right)$, e $N\left(x \mid \theta_{i}\right)$ é a função densidade de probabilidade gaussiana parametrizada por $\theta_{i}=\left[\mu_{i}, \Sigma_{i}\right]$ (i.e., o valor da média e da matriz de covariância do núcleo gaussiano $i$ ). O vetor $\Theta$ representa a coleção de parâmetros do modelo da mistura $\left(W_{1}, \ldots, W_{K}, \theta_{1}, \ldots, \theta_{K}\right)$,

e $K$ é o número de núcleos gaussianos. Cada núcleo gaussiano é representado por

$$
N\left(x \mid \theta_{i}\right)=(2 \pi)^{-d / 2}\left|\Sigma_{i}\right|^{1 / 2} \exp \left[-\frac{1}{2}\left(x-\mu_{i}\right)^{T} \Sigma_{i}^{-1}\left(x-\mu_{i}\right)\right]
$$


Usando a formulação de "dados observáveis e não-observáveis", descrito na seção B.1, para a densidade da mistura de gaussianas definida acima, tem-se que os dados observáveis ou incompletos são representados pelos valores $x_{j}$, e os dados não-observáveis por rótulos $y_{j} \in\{1,2, \ldots, K\}$ indicando o núcleo gaussiano do qual o dado observado $x_{j}$ se origina.

Neste contexto, a partir de um grupo de eventos $x_{j}$, os parâmetros do modelo da mistura podem ser determinados através do método de estimação por máximaverossimilhança usando o algoritmo EM.

Em primeiro lugar, calcula-se o estágio "E” (a esperança dos dados completos) como:

$$
\begin{aligned}
Q\left(\Theta, \Theta^{k}\right)= & \int \ln f(y, x \mid \Theta) f\left(y \mid x, \Theta^{k}\right) \mathrm{d} y \\
= & \int[\ln f(x \mid y, \Theta)+\ln f(y \mid \Theta)] f\left(y \mid x, \Theta^{k}\right) \mathrm{d} y \\
= & \int\left[\ln \prod_{j=1}^{M} N\left(x_{j} \mid \mu_{y_{j}}, \Sigma_{y_{j}}\right)+\ln W_{y_{j}}\right] f\left(y \mid x, \Theta^{k}\right) \mathrm{d} y \\
= & \int\left\{\sum_{j=1}^{M}\left[-\frac{1}{2} \ln \Sigma_{y_{j}}-\frac{1}{2}\left(x_{j}-\mu_{y_{j}}\right)^{2} / \Sigma_{y_{j}}\right]+\right. \\
& \left.\sum_{j=1}^{M} \ln W_{y_{j}}+k\right\} f\left(y \mid x, \Theta^{k}\right) \mathrm{d} y
\end{aligned}
$$

onde a terceira equação segue da definição da mistura de gaussianas. Visto que as amostras são independentes e usando a regra de Bayes, então $f\left(y \mid x, \Theta^{k}\right)$ pode ser simplificada como:

$$
\begin{aligned}
f\left(y \mid x, \Theta^{k}\right) & \propto f\left(x \mid y, \Theta^{k}\right) f\left(y \mid \Theta^{k}\right) \\
& \propto \prod_{j=1}^{M} f\left(x_{j} \mid y_{j}, \Theta^{k}\right) f\left(y_{j} \mid \Theta^{k}\right) \\
& \propto \prod_{j=1}^{M} f\left(y_{j} \mid x_{j}, \Theta\right)
\end{aligned}
$$


onde a segunda equação segue da independencia entre os dados, e a última equação usa a regra de Bayes na forma inversa. A probabilidade condicional dos dados não-observáveis então é dada por

$$
\begin{aligned}
f\left(y_{j}=i \mid x_{j}, \Theta^{k}\right) & =\frac{f\left(x_{j} \mid y_{j}=i, \Theta^{k}\right) f\left(y_{j}=i \mid \Theta^{k}\right)}{\sum_{m=1}^{K} f\left(x_{j} \mid y_{j}=m, \Theta^{k}\right) f\left(y_{j}=i \mid \Theta^{k}\right)} \\
& =\frac{N\left(y_{j} ; \mu_{i}^{0}, \Sigma_{i}^{0}\right) W_{i}^{0}}{\sum_{m=1}^{K} N\left(y_{j} ; \mu_{m}^{0}, \Sigma_{m}^{0}\right) W_{m}^{0}} \\
& \equiv \widehat{P}_{j}^{i} .
\end{aligned}
$$

Com a notação acima, o estágio "E" do algoritmo EM pode ser calculado como:

$$
\begin{aligned}
Q\left(\Theta, \Theta^{k}\right)= & \int\left\{\sum_{j=1}^{M}\left[-\frac{1}{2} \ln \Sigma_{y_{j}}-\frac{1}{2}\left(x_{j}-\mu_{y_{j}}\right)^{2} / \Sigma_{y_{j}}\right]+\right. \\
& \left.\sum_{j=1}^{M} \ln W_{y_{j}}+k\right\} f\left(y \mid x, \Theta^{k}\right) \mathrm{d} x \\
= & \sum_{i=1}^{K} \sum_{j=1}^{M}\left\{\left[-\frac{1}{2} \ln \Sigma_{i}-\frac{1}{2}\left(x_{j}-\mu_{i}\right)^{2}\right]+\ln W_{i}+k\right\} \widehat{P}_{j}^{i} .
\end{aligned}
$$

Para obter uma estimativa atualizada dos parâmetros da mistura $W_{i}$ maximizase a expressão acima, sujeito a seguinte restrição $\sum_{i=1}^{K} W_{i}=1$. As partes dependentes de $W_{i}$ na Equação B.34 podem ser separadas e adicionadas à restrição de igualdade com um operador de Lagrange $\lambda$. Dessa forma, a função objetiva para o operador de Lagrange é definida como:

$$
L\left(W_{i}\right)=\sum_{i=1}^{K} \sum_{j=1}^{M} \hat{P}_{j}^{i} \ln W_{i}-\lambda \sum_{i=1}^{K} W_{i} .
$$

Diferenciando $L\left(W_{i}\right)$ em relação a $W_{i}$ e igualando a zero tem-se: 


$$
\widehat{W}_{i}=\sum_{j=1}^{M} \widehat{P}_{j}^{i} / \lambda=\frac{\sum_{j=1}^{M} \widehat{P}_{j}^{i}}{\sum_{i=1}^{K} \sum_{j=1}^{M} \hat{P}_{j}^{i}}=\frac{\sum_{j=1}^{M} \widehat{P}_{j}^{i}}{M} .
$$

De maneira similar, diferenciando $Q\left(\Theta, \Theta^{k}\right)$ em relação a $\mu_{i}$ e a $\Sigma_{i}$, e igualando a seguir o resultado a zero, tem-se, respectivamente:

$$
\widehat{\mu}_{i}=\frac{\sum_{j=1}^{M} x_{j} \widehat{P}_{j}^{i}}{\sum_{j=1}^{M} \widehat{P}_{j}^{i}}
$$

e

$$
\widehat{\Sigma}_{i}=\frac{\sum_{j=1}^{M}\left(x_{j}-\widehat{\mu}_{i}\right)^{2} \widehat{P}_{j}^{i}}{\sum_{j=1}^{M} \widehat{P}_{j}^{i}} .
$$

As equações acima podem ser facilmente reescritas para o método DAEM através da substituição da Equação B.31 pela Equação B.21. 


\section{Bibliografia}

AMINI (1990) Amini, A. A.; Weymouth, T. E.; Jain, R. C. Using dynamic programming for solving variational problems in vision. IEEE Transactions on Pattern Analysis and Machine Intelligence, 12(9):855-867, 1990.

ANTOINE (1993) Antoine, J.; Carrete, P.; Murenzi, R.; Piette, B. Image analysis with two-dimensional continuous wavelet transform. Signal Processing, 31:241$272,1993$.

AYLWARD (1998) Aylward, S. R.; Hemminger, B. H.; Pisano, E. D. Mixture modeling for digital mammogram display and analysis. In Karssemeijer, N.; Thijssen, M.; Hendriks, J.; van Erning, L., editors, Proceedings of the 4th International Workshop on Digital Mammography, pages 305-312, Nijmegen, The Netherlands, 1998.

BANKMAN (2000) Bankman, I. N., editor. Handbook of Medical Imaging Processing and Analysis. Academic Press, London, UK, 2000.

BASSETT (1987) Bassett, L. W.; Gold, R. H. Breast Cancer Detection: Mammography and Other Methods in Breast Imaging. Grune \& Stratton, Orlando, Florida, second edition, 1987.

BICK (1996) Bick, U.; Giger, M. L.; Schmidt, R. A.; Nishikawa, R. M.; Doi, K. Density correction of peripheral breast tissue on digital mammograms. RadioGraphics, 16(6):1403-1411, 1996.

BICK (1995) Bick, U.; Giger, M. L.; Schmidt, R. A.; Nishikawa, R. M.; Wolverton, 
D. E.; Doi, K. Automated segmentation of digitized mammograms. Academic Radiology, 2(1):1-9, 1995.

BIRD (1992) Bird, R. E.; Wallace, T. W.; Yankaskas, B. C. Analisys of cancers missed at screening mammography. Radiology, 184:613-617, 1992.

BISHOP (1995) Bishop, C. M. Neural Networks for Pattern Recognition. Claredon Press, Oxford, UK, 1995.

BISOGNI (2000) Bisogni, G.; Bottigli, U.; Ceccopieri, A.; Delogu, P.; Fantacci, M. E.; Marchi, A.; Marzulli, V. M.; Oliva, P.; Palmiero, R.; Reggiani, M.; Stefanini, A.; Tangaro, S.; Venier, O. The CALMA mammographs database: image collection and CAD tools for spiculated lesions detection and texture classification. In Yaffe, M. J., editor, Proceedings of the 5th International Workshop on Digital Mammography, pages 302-307, Toronto, ON, Canada, 2000.

BOOKSTEIN (1989) Bookstein, F. L. Principal warps: thin-plate splines and the decomposition of deformations. IEEE Transactions on Pattern Analysis and Machine Intelligence, 11(6):567-585, 1989.

BOVIK (1990) Bovik, A. C.; Clark, M.; Geisler, W. S. Multichannel texture analysis using localized spatial filters. IEEE Transactions on Pattern Analysis and Machine Intelligence, 12(1):55-73, 1990.

BOWYER (1996) Bowyer, K.; Kopans, D.; Kegelmeyer Jr., W. P.; Moore, R.; Sallam, M.; Chang, K.; Woods, K. The digital database for screening mammography. In Doi, K.; Giger, M. L.; Nishikawa, R. M.; Schmidt, R. A., editors, Proceedings of the 3rd International Workshop on Digital Mammography, pages 431-434, Chicago, IL - USA, 1996.

BYNG (1994) Byng, J. W.; Boyd, N. F.; Fishell, E.; Jong, R. A.; Yaffe, M. J. The quantitative analysis of mammographic densities. Physics in Medicine and Biology, 39:1629-1638, 1994. 
BYNG (1996) Byng, J. W.; Boyd, N. F.; Fishell, E.; Jong, R. A.; Yaffe, M. J. Automated analysis of mammographic densities. Physics in Medicine and Biology, 41:909-923, 1996.

BYNG (1997) Byng, J. W.; Critten, J. P.; Yaffe, M. J. Thickness-equalization processing for mammographic images. Radiology, 203(2):564-568, 1997.

CAMPBELL (1968) Campbell, F. W.; Robson, J. G. Application of Fourier analysis to the visibility of gratings. Journal of Physiology, 197:551-566, 1968.

CARDEnOSA (1997) Cardenosa, G. Breast Imaging Companion. Lippincott-Raven, Philadelphia, NY, 1997.

CARSON (1999) Carson, C.; Thomas, M.; Belongie, S.; Hellerstein, J. M.; Malik, J. Blobworld: A system for region-based image indexing and retrieval. In Huijsmans, D. P.; Smeulders, A. W. M., editors, Proceedings of the 3rd International Conference on Visual Information and Information Systems, pages 509-516, Amsterdam, The Netherlands, 1999.

CAULKIN (1998) Caulkin, S.; Astley, S.; Asquith, J.; Boggis, C. Sites of occurrence of malignancies in mammograms. In Karssemeijer, N.; Thijssen, M.; Hendriks, J.; van Erning, L., editors, Proceedings of the 4th International Workshop on Digital Mammography, pages 279-282, Nijmegen, The Netherlands, 1998.

CHANDRASEKHAR (1997) Chandrasekhar, R.; Attikiouzel, Y. A simple method for automatically locating the nipple on mammograms. IEEE Transactions on Medical Imaging, 16(5):483-494, 1997.

COHEN (1993) Cohen, L. D.; Cohen, I. Finite-element methods for active contour models and ballons for 2-D and 3-D images. IEEE Transactions on Pattern Analysis and Machine Intelligence, 15(11):1131-1147, 1993.

DANCE (1996) Dance, D. R. Physical principles of breast imaging. In Doi, K.; Giger, M. L.; Nishikawa, R. M.; Schmidt, R. A., editors, Proceedings of the 3rd International Workshop on Digital Mammography, pages 427-430, Chicago, IL USA, 1996. 
DAUBECHIES (1990) Daubechies, I. The wavelet transform, time-frequency localization and signal analysis. IEEE Transactions on Information Theory, 36(5):9611004, 1990.

DAUGMAN (1985) Daugman, J. G. Uncertainty relation for resolution in space, spatial frequency, and orientation optimized by two-dimensional visual cortical filters. Journal of the Optical Society of America, 2(7):1160-1169, 1985.

DAUGMAN (1988) Daugman, J. G. Complete discrete 2-D Gabor transforms by neural networks for image analysis and compression. IEEE Transactions on Acoustics, Speech, and Signal Processing, 36(7):1169-1179, 1988.

De Valois (1982) De Valois, R. L.; Albrecht, D. G.; Thorell, L. G. Spatial frequency selectivity of cells in macaque visual cortex. Vision Research, 22:545-559, 1982.

DEMPSTER (1977) Dempster, A. P.; Laird, N. M.; Rubin, D. B. Maximum likelihood from incomplete data via the EM algorithm. Journal of the Royal Statistical Society, B 39(1):1-38, 1977.

DOI (1996) Doi, K.; Giger, M. L.; Nishikawa, R. M.; Schmidt, R. A., editors. Proceedings of the 3rd International Workshop on Digital Mammography, Chicago, IL - USA, 1996.

DOI (1999) Doi, K.; MacMahon, H.; Katsuragawa, S.; Nishikawa, R. M.; Jiang, Y. Computer-aided diagnosis in radiology: potential and pitfalls. European Journal of Radiology, 31:97-109, 1999.

DUDA (1973) Duda, R. O.; Hart, P. E. Pattern Classification and Scene Analysis. Wiley, New York, NY, 1973.

FERRARI (2001) Ferrari, R. J.; Rangayyan, R. M.; Desaultels, J. E. L.; Frère, A. F. Analysis of asymmetry in mammograms via directional filtering with Gabor wavelets. IEEE Transactions on Medical Imaging, 20(9):953-964, 2001.

FERRARI (2000) Ferrari, R. J.; Rangayyan, R. M.; Desautels, J. E. L.; Frère, A. F. Segmentação de mamogramas: identificação da borda da mama, músculo peitoral 
e disco glandular. In XVII Congresso Brasileiro de Engenharia Biomédica (in Portuguese), pages 1255-1261, Florianópolis, SC, Brazil, 2000.

FERRARI (2000b) Ferrari, R. J.; Rangayyan, R. M.; Desautels, J. E. L.; Frère, A. F. Segmentation of mammograms: identification of the skin - air boundary, pectoral muscle, and fibro-glandular disc. In Yaffe, M. J., editor, Proceedings of the 5th International Workshop on Digital Mammography, pages 573-579, Toronto, ON, Canada, 2000.

FERRARI (2001b) Ferrari, R. J.; Rangayyan, R. M.; Desautels, J. E. L.; Frère, A. F.; Borges, R. A. Automatic identification of the skin - air boundary, pectoral muscle, and fibro-glandular disc in mammograms. IEEE Transactions on Medical Imaging, page submitted, 2001.

GAUDETTE (1997) Gaudette, L. A.; Gao, R. N.; Wysockei, M.; Nault, F. Update on breast cancer mortality, 1995. Health Reports, 9(1):31-34, 1997.

GIGER (1996) Giger, M. L. Current issues in CAD for mammography. In Doi, K.; Giger, M. L.; Nishikawa, R. M.; Schmidt, R. A., editors, Proceedings of the 3rd International Workshop on Digital Mammography, pages 53-59, Chicago, IL USA, 1996.

GOMES (1997) Gomes, J.; Velho, L.; Goldenstein, S. Wavelets: Teoria, software e aplicações. 21o Colóquio Brasileiro de Matemática. Instituto de Matemática Pura e Aplicada (IMPA), Rio de Janeiro, RJ. Brasil, 1997.

GONZALEZ (1992) Gonzalez, R. C.; Woods, R. E. Digital Image Processing. Addison-Wesley, Reading, MA, 1992.

HARDY (1952) Hardy, G.; Littlewood, J. E.; Polya, G. Inequaities. Cambridge University Press, second edition, 1952.

HARLEY (1993) Harley, J. A.; Fajardo, L. L.; Inis, C. A. Previous mammograms in patients with impalpable breast carcinoma: Retrospective vs blinded interpretation. American Journal of Roentgenology, 161:1167-1172, 1993. 
HOFFBECK (1996) Hoffbeck, J. P.; Landgrebe, D. A. Covariance matrix estimation and classification with limited training data. IEEE Transactions on Pattern Analysis and Machine Intelligence, 18(7):763-767, 1996.

HOMER (1997) Homer, M. J. Mammographic Interpretation: A Practical Approach. McGraw-Hill, Boston, MA, 1997.

HU (1962) Hu, M. K. Visual pattern recognition by moment invariants. IRE Transactions on Information Theory, IT-8:28-32, 1962.

HUO (2000) Huo, Z.; Giger, M. L.; Zhong, W.; Olopade, O. I. Analysis of relative contributions of mammographic features and age to breast cancer risk prediction. In Yaffe, M. J., editor, Proceedings of the 5th International Workshop on Digital Mammography, pages 732-736, Toronto, ON, Canada, 2000.

JÄHNE (1997) Jähne, B. Digital Image Processing. Springer, San Diego, CA, 4th edition, 1997.

JAIN (1991) Jain, A. K.; Farrokhnia, F. Unsupervised texture segmentation using Gabor filters. Pattern Recognition, 24(12):1167-1186, 1991.

JONES (1987) Jones, P.; Palmer, L. A. An evaluation of the two-dimensional Gabor filter model of simple receptive fields in cat striate cortex. Journal of Neurophysiology, 58(6):1233-1258, 1987.

KARSSEMEIJER (1998) Karssemeijer, N. Automated classification of parenchymal patterns in mammograms. Physics in Medicine and Biology, 43(2):365-378, 1998.

KARSSEMEIJER (1996) Karssemeijer, N.; te Brake, G. Detection of stellate distortions in mammograms. IEEE Transactions on Medical Imaging, 15(5):611-619, 1996.

KARSSEMEIJER (1998b) Karssemeijer, N.; te Brake, G. M. Combining single view features and asymmetry for detection of mass lesions. In Karssemeijer, N.; Thijssen, M.; Hendriks, J.; van Erning, L., editors, Proceedings of the 4th International Workshop on Digital Mammography, pages 95-102, Nijmegen, The Netherlands, 1998. 
KARSSEMEIJER (1998c) Karssemeijer, N.; Thijssen, M.; Hendriks, J.; van Erning, L., editors. Proceedings of the 4 th International Workshop on Digital Mammography, Nijmegen, The Netherlands. Kluwer Academic Publishers, 1998.

KOK-WILES (1998) Kok-Wiles, S. L.; Brady, M.; Highnam, R. Comparing mammogram pairs for the detection of lesions. In Karssemeijer, N.; Thijssen, M.; Hendriks, J.; van Erning, L., editors, Proceedings of the 4th International Workshop on Digital Mammography, Nijmegen, The Netherlands, 1998.

KOPANS (1991) Kopans, D. B. Discriminating analysis uncovers breast lesions. Diagnostic Imaging, pages 94-101, 1991.

KOPANS (1992) Kopans, D. B. Positive predictive value of mammography. American Journal of Radiology, 158:521-526, 1992.

KULKARNI (1994) Kulkarni, A. D. Artificial Neural Networks for Image Understanding. Van Nostrand Reinhold, New York, NY, USA, 1994.

LAI (1994) Lai, K. F. Deformable contours: modeling, extraction, detection and classification. Tese de Doutoramento, Department of Electrical Engineering, University of Wisconsin-Madison, Madison, WI, USA, 1994.

LAU (1991) Lau, T. K.; Bischof, W. F. Automated detection of breast tumors using the asymmetry approach. Computers and Biomedical Research, 24:273-295, 1991.

LEE (1996) Lee, T. S. Image representation using 2-D Gabor wavelets. IEEE Transactions on Pattern Analysis and Machine Intelligence, 18(10):959-971, 1996.

LLOYD (1982) Lloyd, S. Least squares quantization in PCM. IEEE Transactions on Information Theory, 28:129-137, 1982.

LOBREGT (1995) Lobregt, S.; Viergever, M. A. A discrete dynamic contour model. IEEE Transactions on Medical Imaging, 14(1):12-24, 1995.

LOU (2000) Lou, S. L.; Lin, H. D.; Lin, K. P.; Hoogstrate, D. Automatic breast region extraction from digital mammograms for PACS and telemammography applications. Computerized Medical Imaging and Graphics, 24:205-220, 2000. 
MA (2000) Ma, W. Y.; Manjunath, B. S. EdgeFlow: A technique for boundary detection and image segmentation. IEEE Transactions on Image Processing, 9(8):1375-1388, 2000.

MACKIEWICH (1995) Mackiewich, B. Intracranial boundary detection and radio frequency correction in magnetic resonance images. Tese de Mestrado, School of Computing Science - Simon Fraser University, Burnaby, BC, Canada, 1995.

MALIK (1990) Malik, J.; Perona, P. Preattentive texture discrimination with early vision mechanisms. Journal of the Optical Society of America A, 7(2):923-932, 1990.

MALLAT (1989) Mallat, S. A theory for multiresolution signal decomposition: The wavelet representation. IEEE Transactions on Pattern Analysis and Machine Intelligence, 11(7):674-693, 1989.

MANJUNATH (1996) Manjunath, B. S.; Ma, W. Y. Texture features for browsing and retrieval of image data. IEEE Transactions on Pattern Analysis and Machine Intelligence, 18(8):837-842, 1996.

MARCELJA (1980) Marcelja, S. Mathematical description of the response of simple cortical cells. Journal of the Optical Society of America, 70(11):1297-1300, 1980.

MARDIA (1972) Mardia, K. V. Statistics of Directional Data. Academic Press, New York, 1972.

MARTI (2000) Marti, R.; Zwiggelaar, R.; Rubin, C. Comparing image correspondence in mammograms. In Yaffe, M. J., editor, Proceedings of the 5th International Workshop on Digital Mammography, pages 295-301, Toronto, ON, Canada, 2000.

MASCIO (1996) Mascio, L. N.; Frankel, S. D.; Hernandez, J. M.; Logan, C. M. Building the LLNL/UCSF Digital Mammogram Library with image groundtruth. In Doi, K.; Giger, M. L.; Nishikawa, R. M.; Schmidt, R. A., editors, Proceedings of the 3rd International Workshop on Digital Mammography, pages 427-430, Chicago, IL - USA, 1996. 
MATSUBARA (2000) Matsubara, T.; Yamazaki, D.; Fujita, H.; Hara, T.; Iwase, T.; Endo, T. An automated classification method for mammograms based on evaluation of fibroglandular breast tissue density. In Yaffe, M. J., editor, Proceedings of the 5th International Workshop on Digital Mammography, pages 737-741, Toronto, ON, Canada, 2000.

MATTEO (2001) Matteo, F.; Johnson, S. G. FFTW - The Fastest Fourier Transform in the West. http://www.fftw.org, 2001.

MATTIS (1997) Mattis, P.; Kimball, S. GIMP - GNU Image Manipulation Program version 1.1.17. http://www.gimp.org - GNU General Public License - GPL, 1997.

MCKENNA (1994) Mckenna, R. J. The abnormal mammogram radiographic findings, diagnostic options, pathology, and stage of cancer diagnosis. Cancer, 74(Suppl. 1):244-255, 1994.

MÉnDEZ (1996) Méndez, A. J.; Tahoces, P. G.; Lado, M. J.; Souto, M.; Correa, J. L.; Vidal, J. J. Automatic detection of breast border and nipple in digital mammograms. Computer Methods and Programs in Biomedicine, 49:253-262, 1996.

MILLER (1993) Miller, P.; Astley, S. Automated detection of mammographic asymmetry using anatomical features. International Journal of Pattern Recognition and Artificial Intelligence, 7(6):1461-1476, 1993.

MOBERG (2001) Moberg, K.; Bjurstam, N.; Wilczek, B.; Rostgard, L.; Egge, E.; Muren, C. Computed assisted detection of interval breast cancers. European Journal of Radiology, 39:104-110, 2001.

NAVARRO (1996) Navarro, R.; Tabernero, A.; Cristóbal, G. Image representation with Gabor wavelets and its applications. In Hawkes, P. W., editor, Advances in Imaging and Electron Physics, volume 97, chapter 1, pages 2-84. Academic Press, San Diego, CA, USA, 1996.

NISHIKAWA (2000) Nishikawa, R. M.; Giger, M. L.; Vyborny, C. J.; Bick, U.; Doi, K.; Schmidt, R. A. Prospective computer analysis of cancer missed on scree- 
ning mammography. In Yaffe, M. J., editor, Proceedings of the 5th International Workshop on Digital Mammography, pages 493-498, Toronto, ON, Canada, 2000.

NISHIKAWA (1996) Nishikawa, R. M.; Johnston, R. E.; Wolverton, D. E.; Schmidt, R. A.; Pisano, E. D.; Hemminger, B. M.; Moody, J. A common database of mammograms for research in digital mammography. In Doi, K.; Giger, M. L.; Nishikawa, R. M.; Schmidt, R. A., editors, Proceedings of the 3rd International Workshop on Digital Mammography, pages 435-438, Chicago, IL - USA, 1996.

NISHIKAWA (1996b) Nishikawa, R. M.; Schmidt, R. A.; Papaioannou, J.; Osnis, R.; Haldemann Heusler, R. A.; Giger, M. L.; Wolverton, D. E.; Comstock, C. E.; Doi, K. Performance of a prototype clinical "intelligent" mammography workstation. In Doi, K.; Giger, M. L.; Nishikawa, R. M.; Schmidt, R. A., editors, Proceedings of the 3rd International Workshop on Digital Mammography, pages 93-96, Chicago, IL - USA, 1996.

OJALA (2001) Ojala, T.; Näppi, J.; Nevalainen, O. Accurate segmentation of the breast region from digitized mammograms. Computerized Medical Imaging and Graphics, 25:47-59, 2001.

OTSU (1979) Otsu, N. A threshold selection method from gray-level histograms. IEEE Transactions on Systems, Man, and Cybernetics, SMC-9(1):62-66, 1979.

PRECHELT (1994) Prechelt, L. PROBEN1 - A set of neural network benchmark problems and benchmarking rules. Technical Report 21/94, Fakultät für Informatik - Univesität Karlsruhe, Germany, 1994.

RANGAYYAN (2000) Rangayyan, R. M.; Ferrari, R. J.; Desautels, J. E. L.; Frère, A. F. Directional analysis of images with Gabor wavelets. In XIII Brazilian Symposium on Computer Graphics and Image Processing, pages 170-177, Gramado, RS, Brazil. IEEE Computer Press, 2000.

RENTSCHLER (1988) Rentschler, I.; Hubner, M.; Caelli, T. On the discrimination of compound Gabor signals and texture. Vision Research, 28:279-291, 1988. 
RISSANEN (1978) Rissanen, J. Modeling by shortest data description. Automatica, 14:465-471, 1978.

ROSE (1998) Rose, K. Deterministic annealing for clustering, compression, classification, regression, and related optimization problems. In Proceedings of the IEEE, volume 86, pages 2210-2239, 1998.

ROSE (1990) Rose, K.; Gurewitz, E.; Fox, G. C. Statistical mechanics and phase transitions in clustering. Physical Review Letters, 65(8):945-948, 1990.

RUTTER (2001) Rutter, C. M.; Mandelson, M. T.; Laya, M. B.; Taplin, S. Changes in breast density associated with initiation, discontinuation, and continuing use of hormone replacement therapy. Journal of the American Medical Association, 285(2):171-176, 2001.

SALLAM (1994) Sallam, M. Y.; Bowyer, K. Registering time sequences of mammograms using a two-dimensional image unwarping technique. In Gale, A. G.; Astley, S. M.; Dance, D. R.; Cairns, A. Y., editors, Proceedings of the 2nd International Workshop on Digital Mammography, volume 1069 of Excerpta Medica International Congress Series, pages 121-130, York, England, 1994.

SALLAM (1996) Sallam, M. Y.; Bowyer, K. Detecting abnormal densities in mammograms by comparison to previous screenings. In Doi, K.; Giger, M. L.; Nishikawa, R. M.; Schmidt, R. A., editors, Proceedings of the 3rd International Workshop on Digital Mammography, pages 417-420, Chicago, IL - USA, 1996.

SCHMIDT (1998) Schmidt, R. A.; Newstead, G. M.; Linver, M. N.; Eklund, G. W.; Metz, C. E.; Winkler, M. A.; Nishikawa, R. M. Mammographic screening: sensitivity of general radiologists. In Karssemeijer, N.; Thijssen, M.; Hendriks, J.; van Erning, L., editors, Proceedings of the 4th International Workshop on Digital Mammography, pages 383-388, Nijmegen, The Netherlands, 1998.

SCHNEIDER (2000) Schneider, M. A. Better detection: improving our chances. In Yaffe, M. J., editor, Proceedings of the 5th International Workshop on Digital Mammography, pages 3-6, Toronto, ON, Canada, 2000. 
SEMMLOW (1980) Semmlow, J. L.; Shadagopappam, A.; Ackerman, L. V.; Hand, W.; Alcorn, F. S. A fully automated system for screening xeromammograms. Computers and Biomedical Research, 13:350-362, 1980.

SHTERN (1992) Shtern, F. Digital mammography and related technologies: A perspective from the national cancer institute. Radiology, 183:629-630, 1992.

SIVARAMAKRISHNA (2001) Sivaramakrishna, R.; Obuchowski, N. A.; Chilcote, W. A.; Powell, K. A. Automatic segmentation of mammographic density. Academic Radiology, 8(3):250-256, 2001.

SKEA (1993) Skea, D.; Barrodale, I.; Kuwahara, R.; Poeckert, R. A control point matching algorithm. Pattern Recognition, 26(2):269-276, 1993.

SUCKLING (1994) Suckling, J.; Parker, J.; Dance, D. R.; Astley, S.; Hutt, I.; Boggis, C. R. M.; Ricketts, I.; Stamatakis, E.; Cerneaz, N.; Kok, S. L.; Taylor, P.; Betal, D.; Savage, J. The Mammographic Image Analysis Society digital mammogram database. In Gale, A. G.; Astley, S. M.; Dance, D. R.; Cairns, A. Y., editors, Proceedings of the 2nd International Workshop on Digital Mammography, volume 1069 of Excerpta Medica International Congress Series, pages 375-378, York, England, 1994.

TAGARE (1998) Tagare, H. D. A gentle introduction to the EM algorithm - Part I: Theory. Technical report, Departments of Diagnostic Radiology and Electrical Engineering - Yale School of Medicine, http://noodle.med.yale.edu, 1998.

TAHOCES (1995) Tahoces, P. G.; Correa, J.; Souto, M.; Gómez, L.; Vidal, J. J. Computer-assisted diagnosis: the classification of mammographic breast parenchymal patterns. Physics in Medicine and Biology, 40:103-117, 1995.

te Brake (1996) te Brake, G.; Karssemeijer, N. Detection of stellate breast abnormalities. In Doi, K.; Giger, M. L.; Nishikawa, R. M.; Schmidt, R. A., editors, Proceedings of the 3rd International Workshop on Digital Mammography, pages 341-346, Chicago, IL - USA, 1996. 
TUCKER (1993) Tucker, A. K. Textbook of mammography. Churchill Livingstone, New York, NW, 1993.

TURNER (1986) Turner, M. R. Texture discrimination by Gabor functions. Biological Cybernetics, 55:71-82, 1986.

UEDA (1998) Ueda, N.; Nakano, R. Deterministic annealing EM algorithm. Neural Networks, 11:271-282, 1998.

UFFINK (1995) Uffink, J. The constraint rule of the maximum entropy principle. Technical report, Department of History and Foundations of Mathematics ans Science - University of Utrecht, Utrecht, The Netherlands, 1995.

VUJOVIC (1996) Vujovic, N.; Bakic, P.; Brzakovic, D. Detection of potentially cancerous signs by mammogram followup. In Doi, K.; Giger, M. L.; Nishikawa, R. M.; Schmidt, R. A., editors, Proceedings of the 3rd International Workshop on Digital Mammography, pages 421-424, Chicago, IL - USA, 1996.

VUJOVIC (1997) Vujovic, N.; Brzakovic, D. Establishing the correspondence between control points in pairs of mammographic images. IEEE Transactions on Image Processing, 6(10):1388-1399, 1997.

VYBORNY (1994) Vyborny, C. J. Can computers help radiologists read mammograms. Radiology, 191:315-317, 1994.

WEBB (1999) Webb, A. Statistical Pattern Recognition. Oxford University Press Inc., New York, NY, USA, 1999.

WEBER (1977) Weber, A., editor. The USC-SIPI Image Database. http://sipi.usc.edu/services/database/Database.html, Signal and Image Processing Institute - University of Southern California, Los Angeles, CA, 1977.

WILLIAMS (1992) Williams, D. J.; Shah, M. A fast algorithm for active contours and curvature estimation. Computer Vision, Graphics, and Image Processing: Image Understanding, 55(1):14-26, 1992. 
WOLFE (1976) Wolfe, J. N. Breast parenchymal patterns and their changes with age. Radiology, 121:545-552, 1976.

WOLFE (1976b) Wolfe, J. N. Risk for breast cancer development determined by mammographic parenchymal pattern. Cancer, 37:2486-2492, 1976.

WOO (2000) Woo, J. H.; Cho, B. H.; Kim, S. I.; Park, D. S.; Moon, W. K.; Ro, Y. M. Evaluation of the architecture similarity between left and right breast. In Yaffe, M. J., editor, Proceedings of the 5th International Workshop on Digital Mammography, pages 402-407, Toronto, ON, Canada, 2000.

XU (1998) Xu, C.; Prince, J. L. Snakes, shapes, and gradient vector flow. IEEE Transactions on Image Processing, 7(3):359-369, 1998.

YAFFE (2000) Yaffe, M. J., editor. Proceedings of the 5th International Workshop on Digital Mammography, Toronto, ON, Canada, 2000.

YIN (1991) Yin, F. F.; Giger, M. L.; Doi, K.; Metz, C. E.; Vyborny, C. J.; Schmidt, R. A. Computerized detection of masses in digital mammograms: Analysis of bilateral subtraction images. Medical Physics, 18(5):955-963, 1991.

YIN (1994) Yin, F. F.; Giger, M. L.; Doi, K.; Metz, C. E.; Vyborny, C. J.; Schmidt, R. A. Computerized detection of masses in digital mammograms: Investigation of feature-analysis techniques. Journal of Digital Imaging, 7(1):18-26, 1994.

YIN (1994b) Yin, F. F.; Giger, M. L.; Doi, K.; Vyborny, C. J.; Schmidt, R. A. Computerized detection of masses in digital mammograms: Automated alignment of breast images and its effect on bilateral-subtraction technique. Medical Physics, 21(3):445-452, 1994.

YIN (1993) Yin, F. F.; Giger, M. L.; Vyborny, C. J.; Doi, K.; Schmidt, R. A. Comparison of bilateral-subtraction and simgle-image processing techniques in the computerized detection of mammographic masses. Investigative Radiology, 28(6):473481, 1993. 
ZHOU (2001) Zhou, C.; Chan, H. P.; Petrick, N.; Helvie, M. A.; Goodsitt, M. M.; Sahiner, B.; Hadjiiski, L. M. Computerized image analysis: estimation of breast density on mammograms. Medical Physics, 28(6):1056-1069, 2001.

ZOURAS (1996) Zouras, W. K.; Giger, M. L.; Lu, P.; Wolverton, D. E.; Vyborny, C. J.; Doi, K. Investigation of a temporal subtraction scheme for computerized detection of breast masses in mammograms. In Doi, K.; Giger, M. L.; Nishikawa, R. M.; Schmidt, R. A., editors, Proceedings of the 3rd International Workshop on Digital Mammography, pages 411-415, Chicago, IL - USA, 1996. 